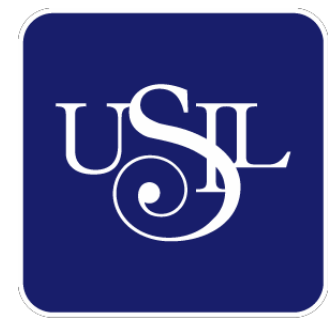

UNIVERSIDAD

SAN IGNACIO

DE LOYOLA

ESCUELA DE POSTGRADO

Maestría en Ciencias Empresariales

\title{
PLAN DE NEGOCIO PARA LA CREACIÓN DE UN CENTRO DE DIVERSIÓN - BAR CERO ALCOHOL - EN EL DISTRITO DE BARRANCO
}

Trabajo de Investigación para optar el grado de Maestro en Ciencias Empresariales con Mención en Gestión de Pequeñas y Medianas Empresas

\section{JAIME ALBERTO AMPUERO GONZALES \\ MANUEL LLATANCE MANTARI}

Asesor:

Flor Rios Rivero

Lima - Perú

2019 
"PLAN DE NEGOCIO PARA LA CREACION DE UN CENTRO DE DIVERSION - BAR CERO ALCOHOL - EN EL DISTRITO DE BARRANCO" 


\section{Dedicatoria}

A mis padres Luis Alberto y Yolanda por darme la vida, a mi esposa Marty por su paciencia y amor, a mi hijo David por ser motor y motivo para seguir superándome, a toda mi familia por el apoyo de siempre.

Jaime Ampuero

A Nuestro Padre Celestial por la vida y la salud, a mi padres Esteban e Ines por su sacrificio y dedicación, a mi esposa Paola por ser la compañera ideal de esta vida, a mis hijos Andrée y Valentina por inspirarme cada día.

Manuel Llatance 


\section{Agradecimientos}

Agradecemos a nuestra asesora, la maestra Flor Ríos Rivero, por volcar su experiencia profesional en nuestra investigación. Asimismo, le agradecemos por su paciencia, apoyo y acompañamiento en todo este proceso, sin los cuales no terminaríamos esta maestría con la satisfacción ni con la calidad que este trabajo merece.

Jaime Ampuero y Manuel Llatance 


\section{Resumen Ejecutivo}

El presente documento busca desarrollar un Plan de Negocio que está basado en un bar donde se expenda cocteles sin contenido de alcohol, ofrecidos en un espacio atractivo, de diversión y de mucha interacción sana como alternativa diferente; un lugar para pasar un buen rato de conversación y sin los efectos nocivos propios del consumo de alcohol tales como accidentes de tránsito, vandalismo, violencia familiar, problemas sociales, etc.

Se ha observado que el emprendimiento plasmado no tiene competidores directos y más aún en la zona donde se ha analizado como punto localización optimo, en el distrito de Barranco, es que el estudio de mercado ha sido considerado como factible en base a las investigaciones cuantitativas y cualitativas; esto teniendo como base el resultado del análisis de los factores externos pertenecientes al macroentorno en la que todos (económico, social cultural, tecnológico, y político) influyen de manera positiva y coadyuvan para el desarrollo del presente plan expresado en la proyección de ventas. Adicionalmente, la amenaza latente de entrada de competidores potenciales, ha exigido diseñar estrategias de marketing que tengan como principal objetivo el posicionamiento de la marca, así como formas de identificar y hacer llegar la propuesta de valor al segmento de mercado respectivo.

Por otro lado, los estudios de ingeniera realizados exigen que para cumplir con las exigencias identificadas por los usuarios según el estudio de mercado, se ha considerado activos que cumplan las normas de calidad y las condiciones para dar al cliente los productos que esperan así como el servicio que satisfaga las expectativas ofrecidas por los diferentes canales de comunicación según estrategia de marketing planteada.

Asimismo, siendo una de los principales factores críticos de éxito el capital humano, es que se ha diseñado una visión, misión, estrategias que al ser cumplida fielmente garantiza el buen servicio a brindar de parte de los diferentes colaboradores internos y externos, con el objetivo de una satisfacción total de los clientes y un buen posicionamiento en la mente del consumidor permitiendo dar sostenibilidad a la empresa, todo lo anterior planteado en el capítulo de Aspectos Organizacionales.

Finalmente, recogiendo la información vertida en base a las investigaciones realizadas, y valorizando los requerimientos que se determinaron en el flujo económico - financiero, llegamos a que la inversión en activos y capital de trabajo asciende a S/. 296,457 (de los cuales se financiará el $40 \%$ y $60 \%$ será con aportes propios), el mismo que será recuperado en un periodo de 1.8 años dentro de un horizonte de evaluación de 5 años, y generando un VANE S/. 
562,319 y un VANF de S/ 592,450 con una TIRE de $75 \%$ y un TIRF de $100 \%$ en base a un COK de $18.25 \%$ y una WACC de $17.4 \%$; por consiguiente el proyecto demuestra indicadores bastante atractivos para cualquier inversionista interesado en un actividad empresarial diferente con base de innovación. 


\section{Tabla de Contenidos}

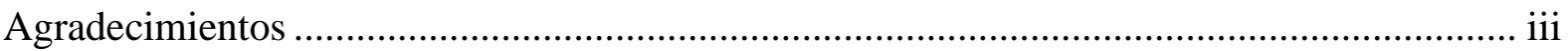

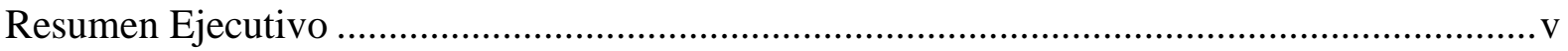

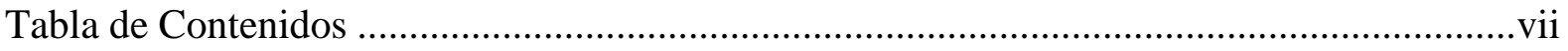

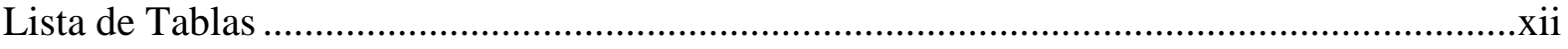

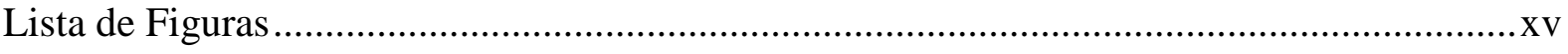

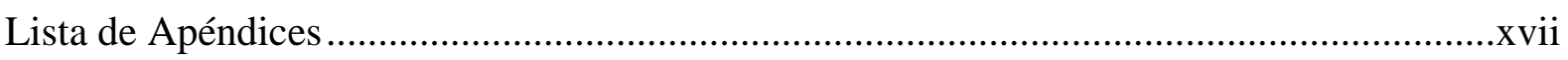

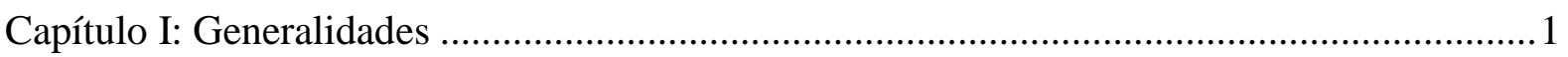

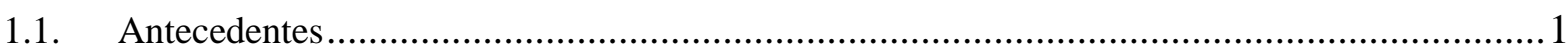

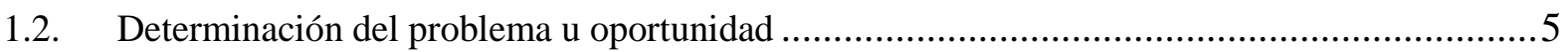

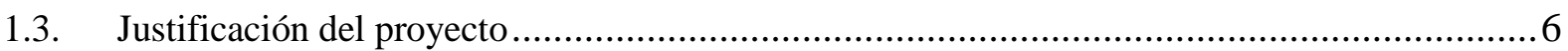

1.4. Objetivo generales y específicos del proyecto …........................................................

1.5. Alcances y limitaciones de la investigación .................................................................

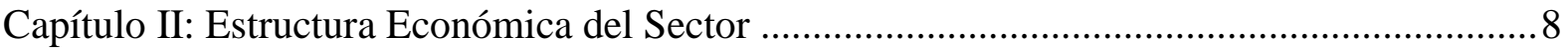

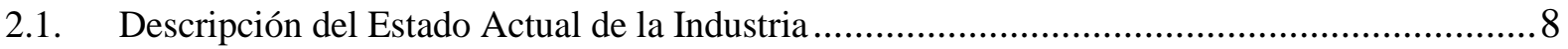

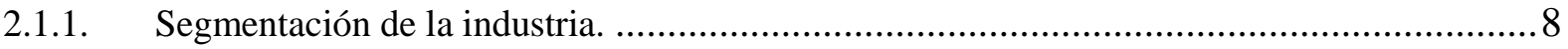

2.1.2. Empresas que la conforman (ubicación, volumen de ventas, empleados, etc.).................... 9

2.2. Tendencias de la industria (crecimiento, inversiones) …............................................. 17

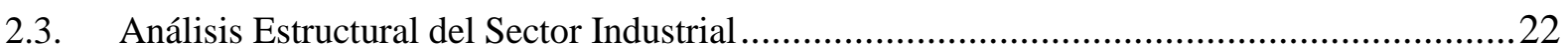

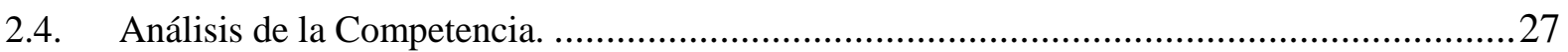

2.4.1. Empresas que ofrecen el mismo producto o servicio .....................................................2

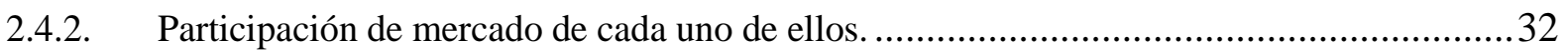

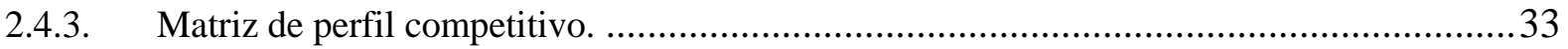

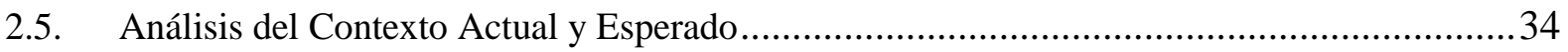

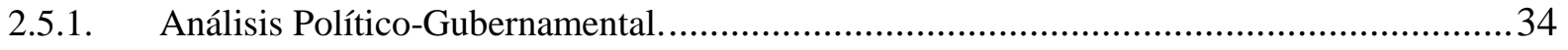

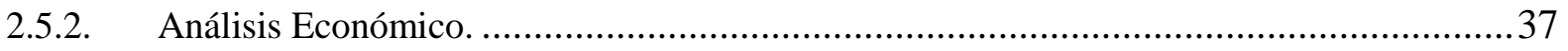

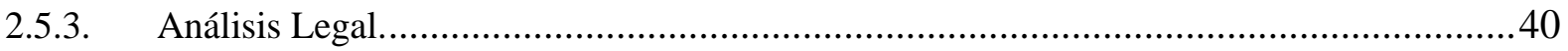




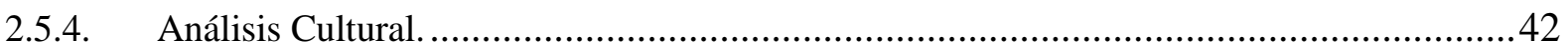

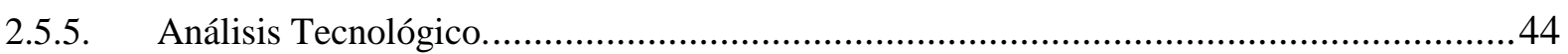

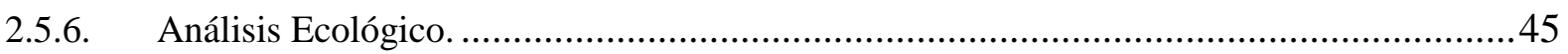

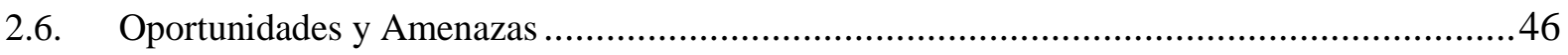

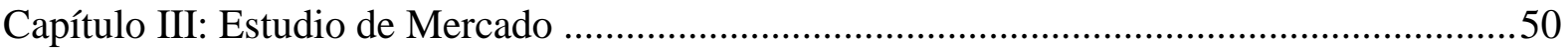

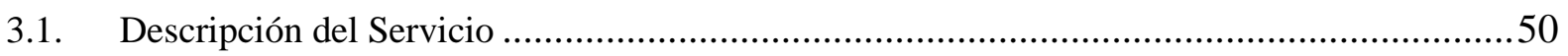

3.2. Selección del Segmento de Mercado ........................................................................ 51

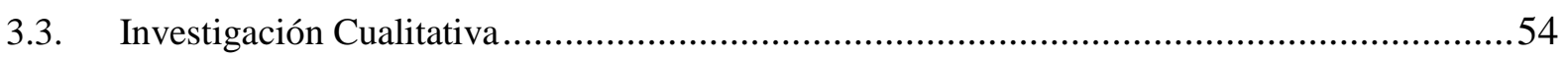

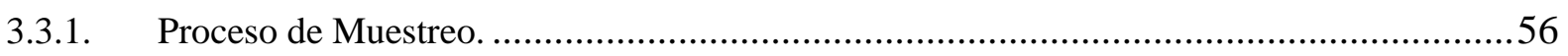

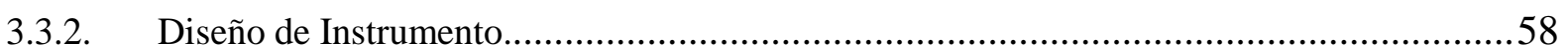

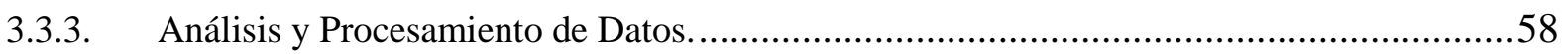

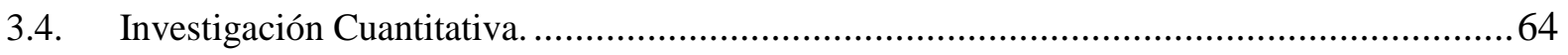

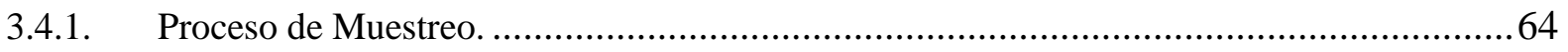

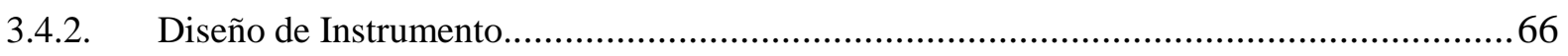

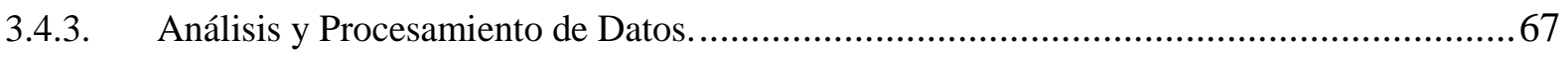

3.5. Conclusiones y recomendaciones del Estudio Cualitativo y Cuantitativo. ............................ 75

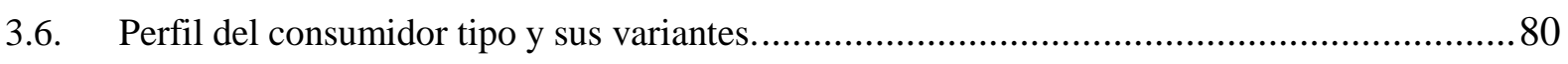

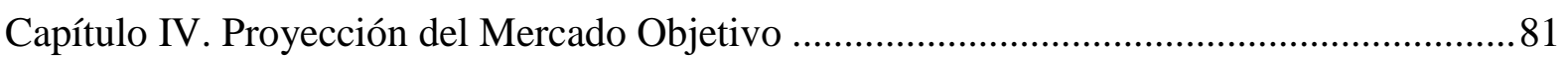

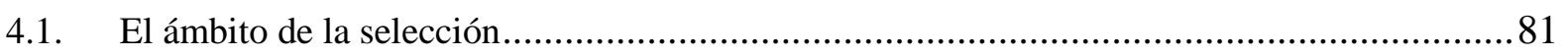

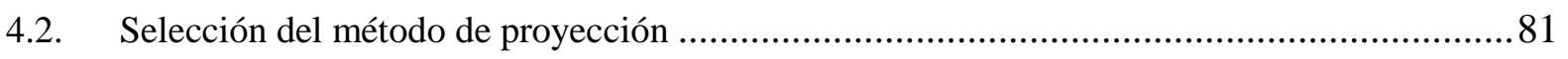

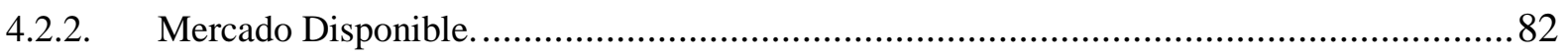

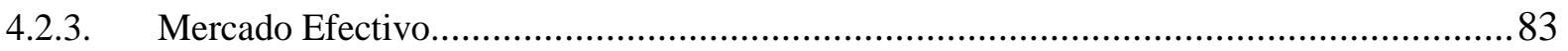

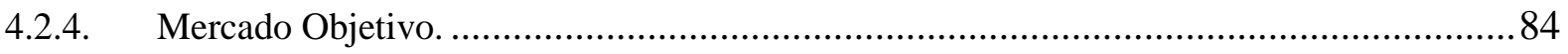

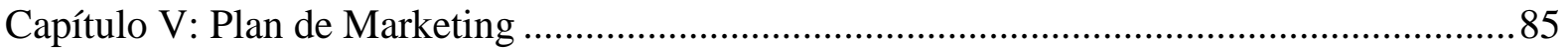

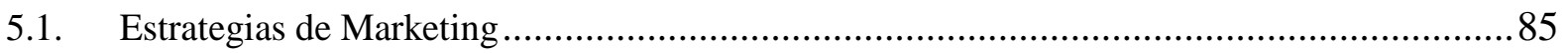

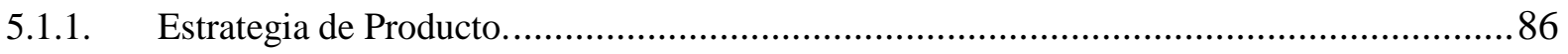

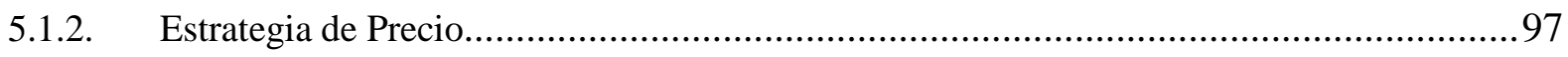




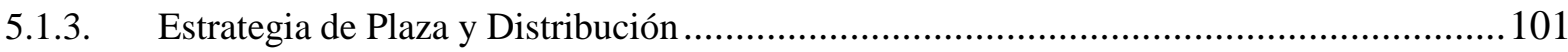

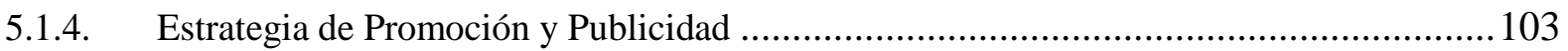

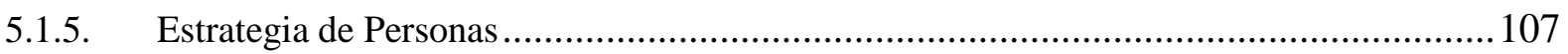

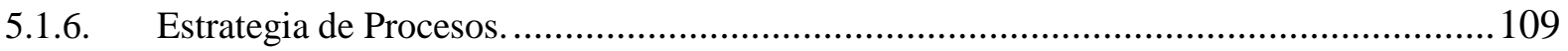

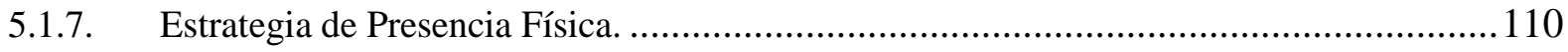

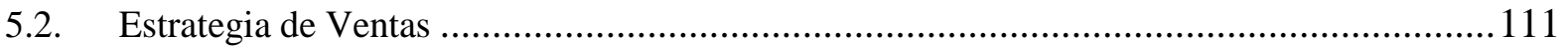

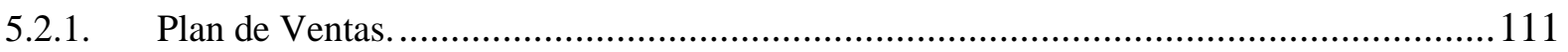

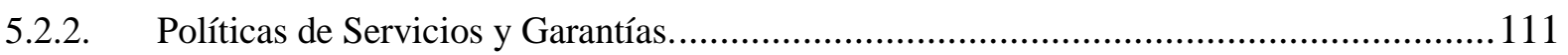

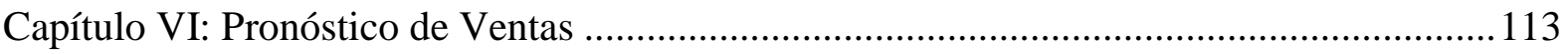

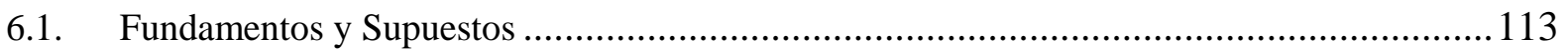

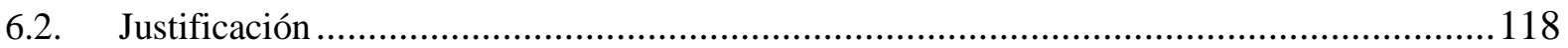

6.3. Análisis de los Riesgos y aspectos críticos que impactan en el negocio............................. 119

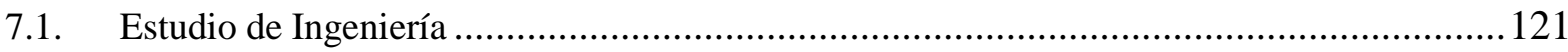

7.1.1. Modelamiento y Selección de Procesos Productivos.................................................... 121

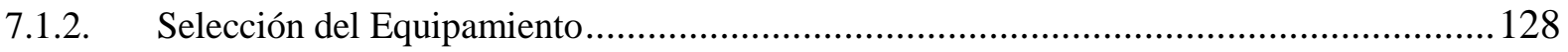

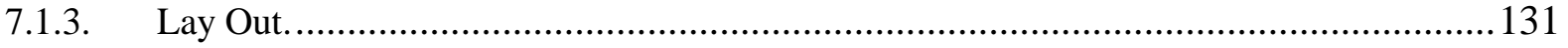

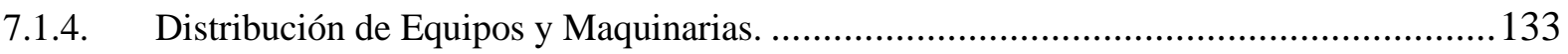

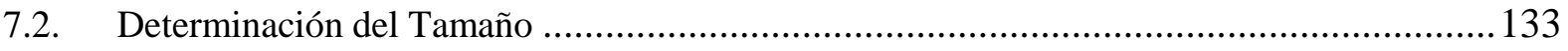

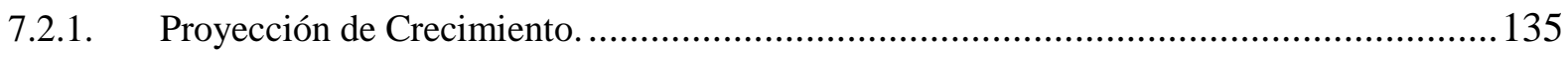

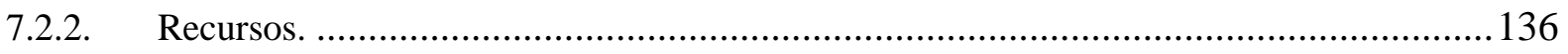

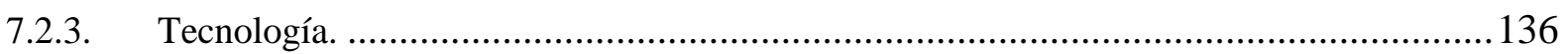

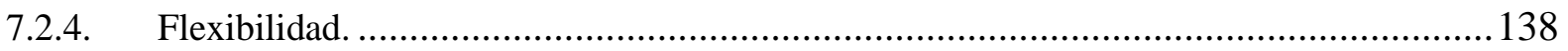

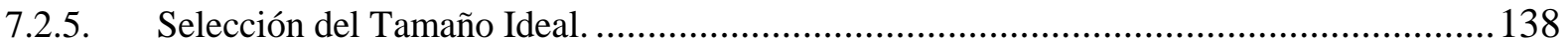

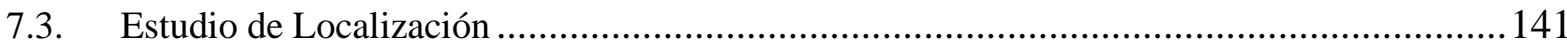

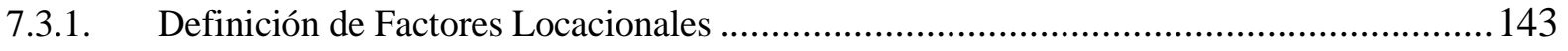

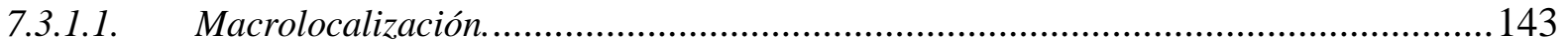

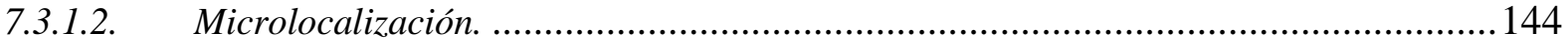


7.3.2. Consideraciones Legales.

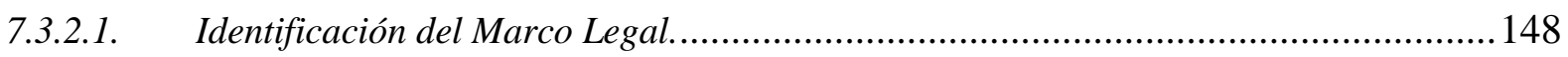

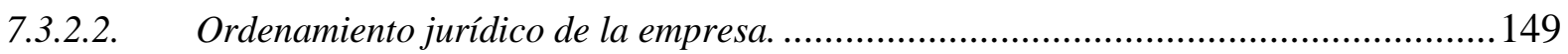

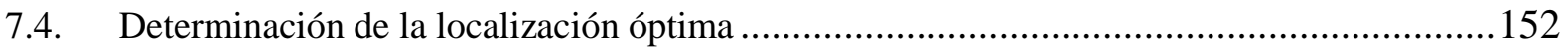

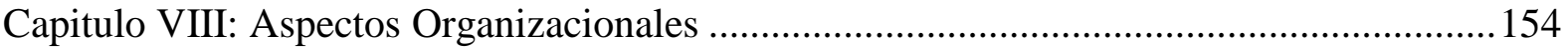

8.1. Caracterización de la cultura organizacional deseada ................................................. 154

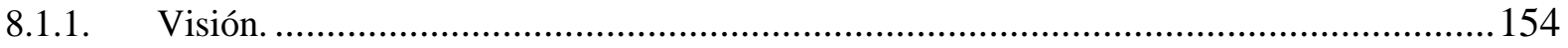

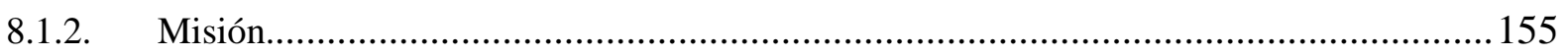

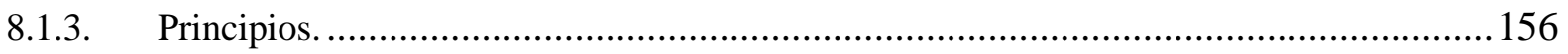

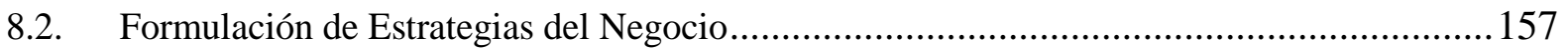

8.3. Determinación de las Ventajas Competitivas Críticas ...................................................... 158

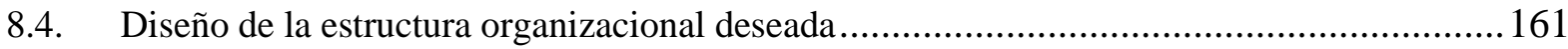

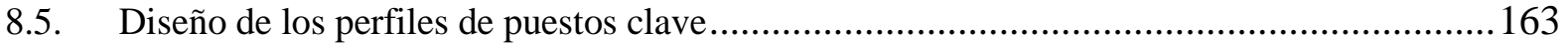

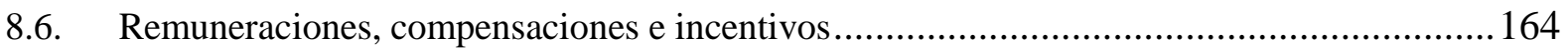

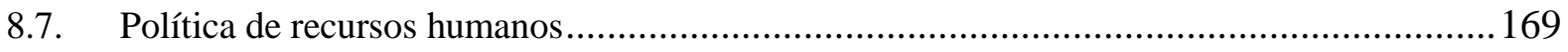

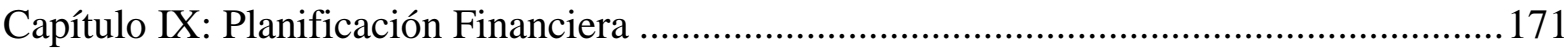

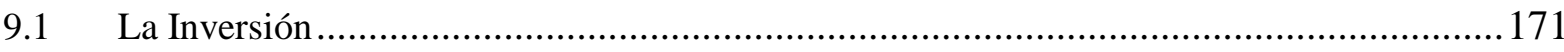

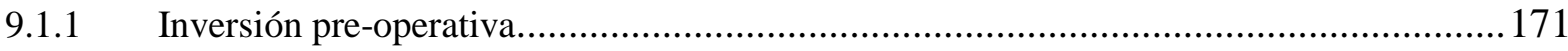

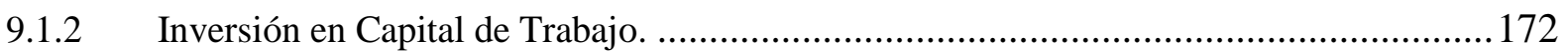

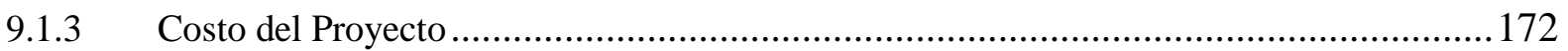

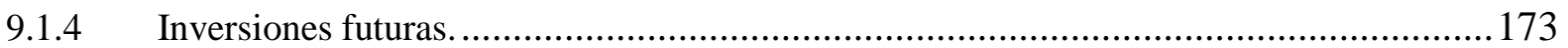

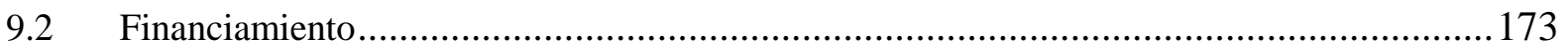

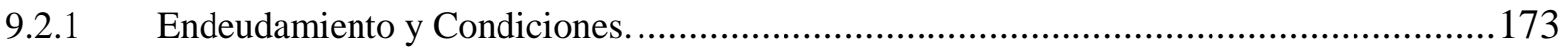

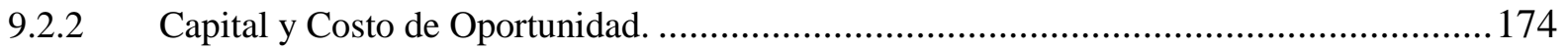

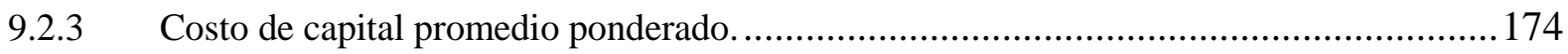

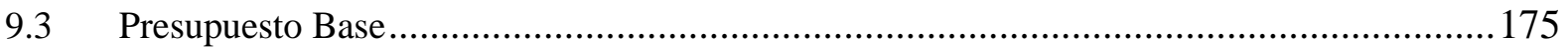

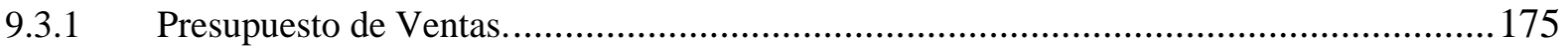




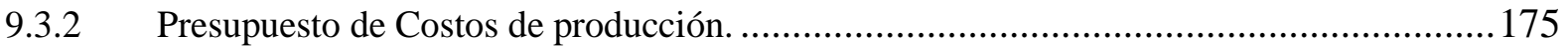

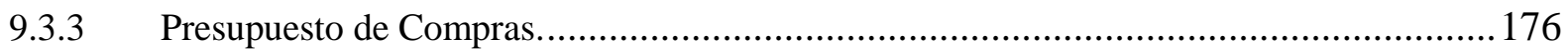

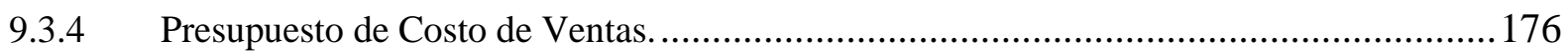

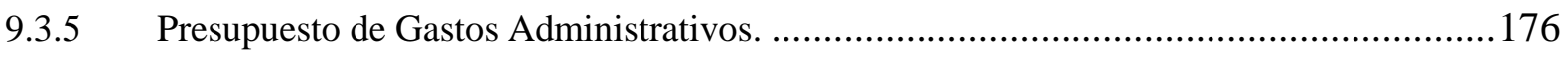

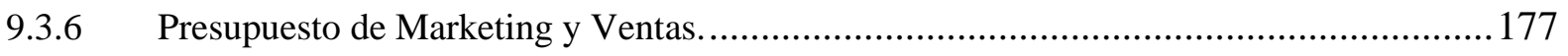

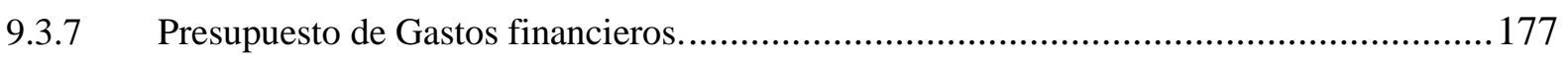

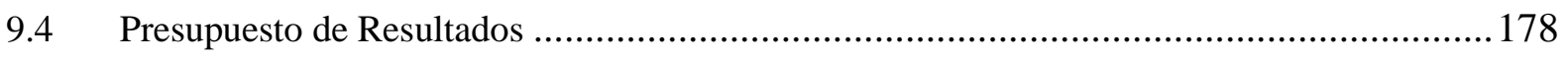

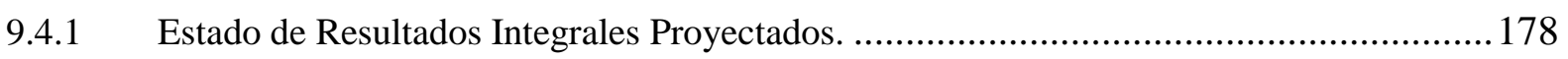

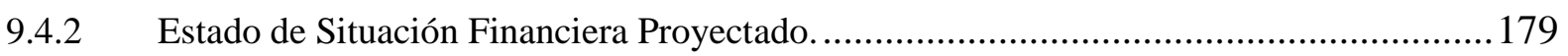

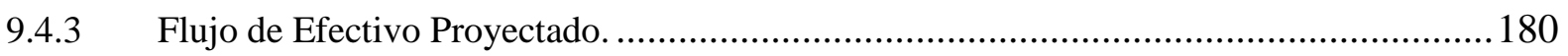

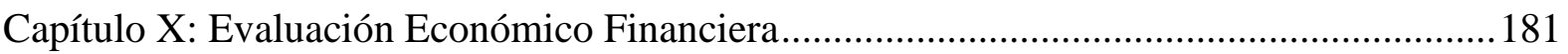

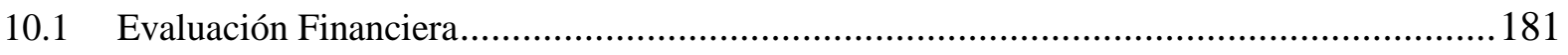

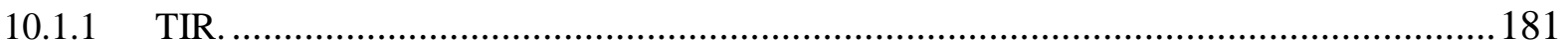

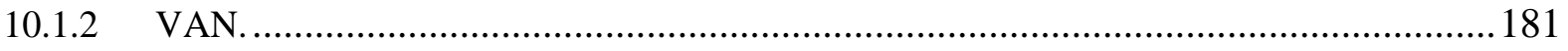

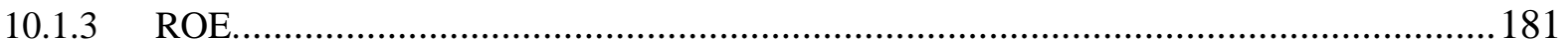

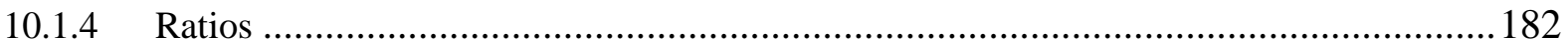

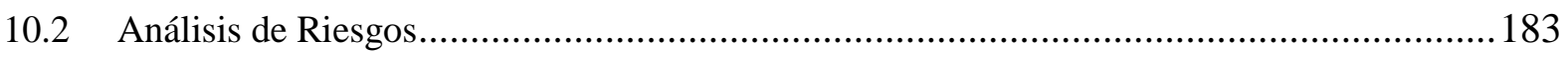

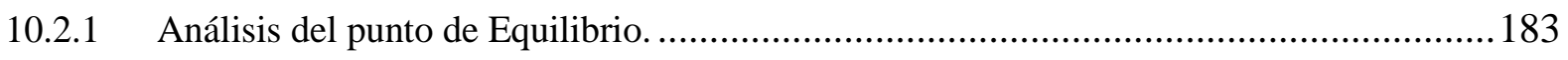

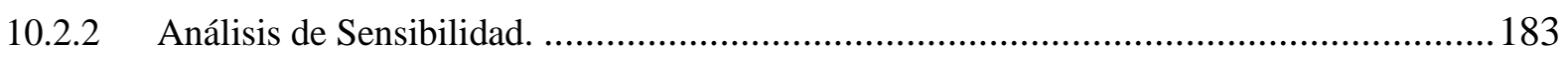

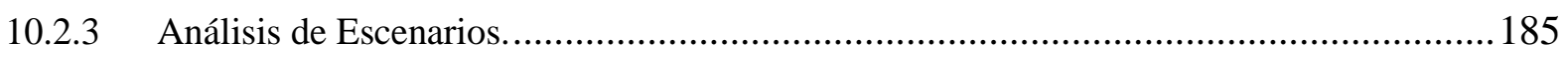

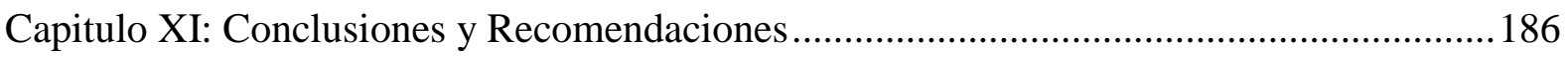

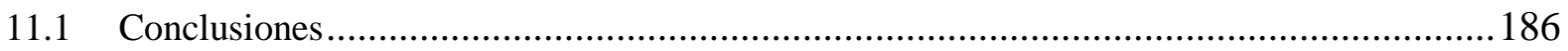

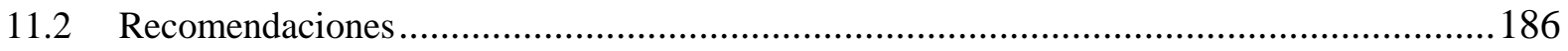

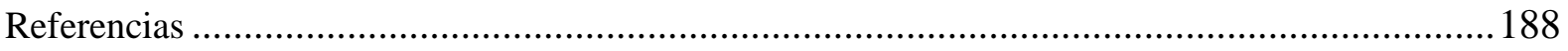

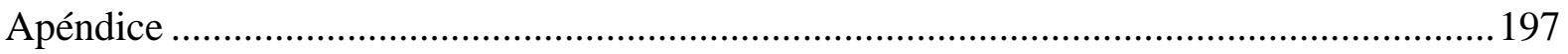




\section{Lista de Tablas}

Tabla 1 Perú: Stock y Variación Neta de Empresas por Trimestre, 2015-2017 ...................... 17

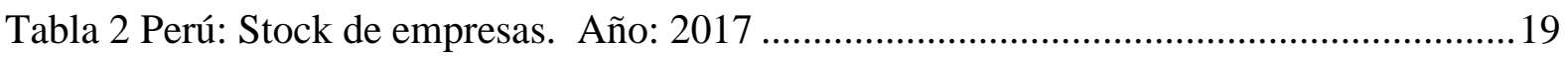

Tabla 3 Perú: Número de Altas y Bajas (Empresas)............................................................ 19

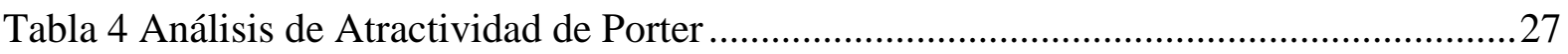

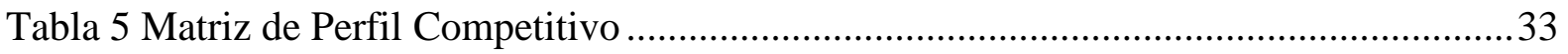

Tabla 6 Evolución del Índice Mensual de Producción Nacional 2017 / 2016 (Año Base 2007)

Tabla 7 Matriz de Influencia de Factores Externos (a) .......................................................... 48

Tabla 8 Matriz de Influencia de Factores Externos (b)......................................................... 49

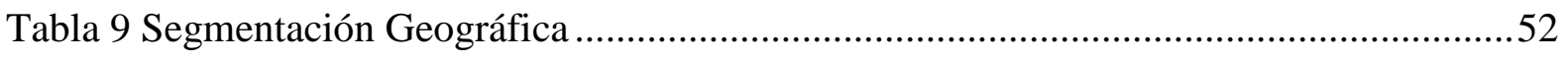

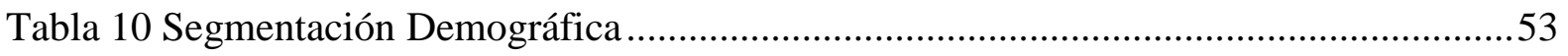

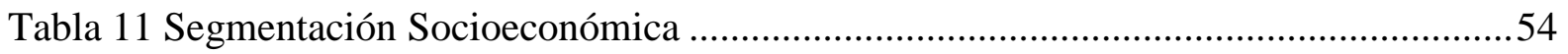

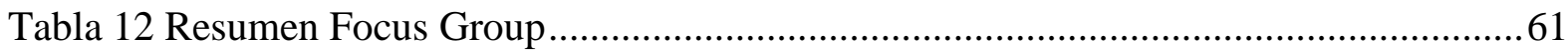

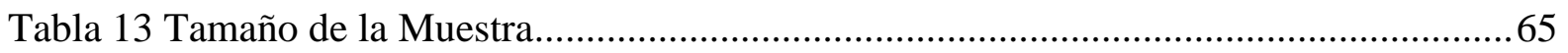

Tabla 14 Ficha Técnica de la Investigación Cuantitativa ................................................... 67

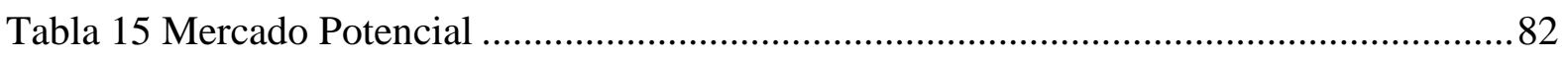

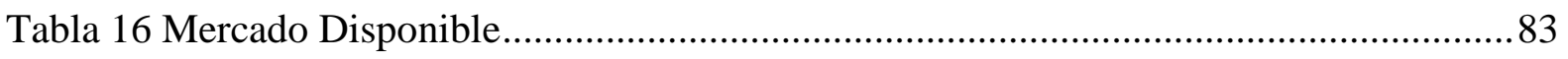

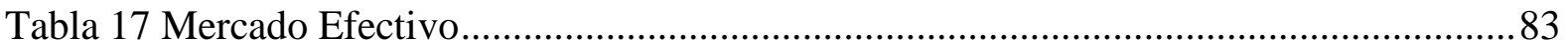

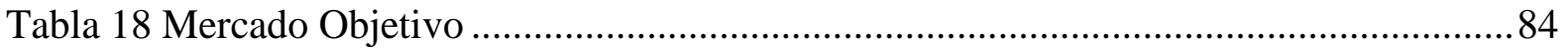

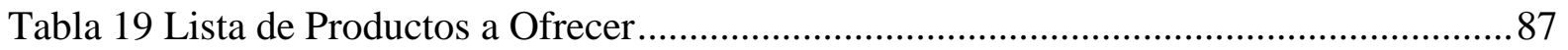

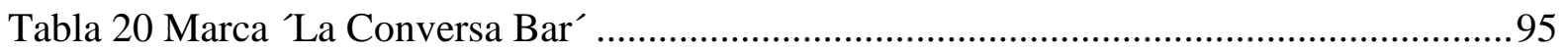

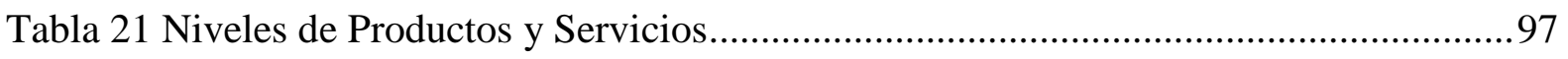

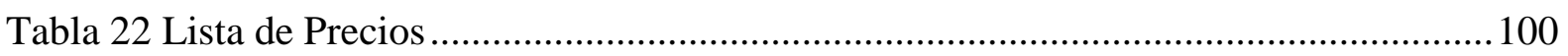

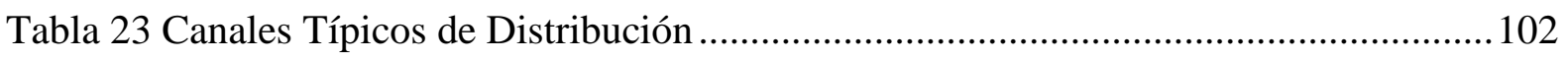

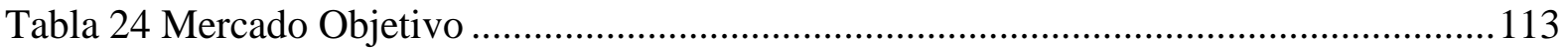

Tabla 25 Frecuenca de Compra Mercado Efectivo............................................................... 114

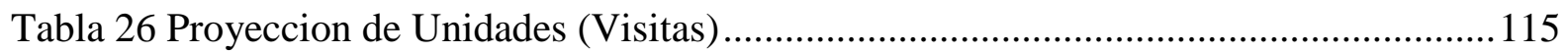

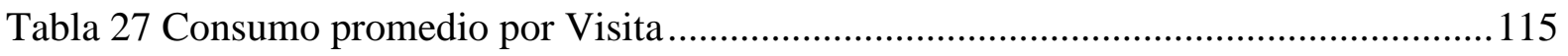

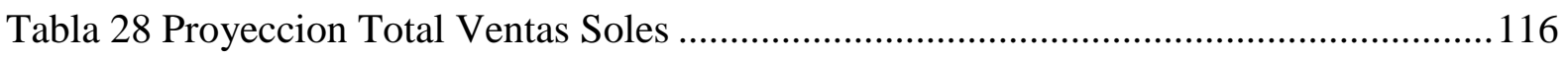

Tabla 29 Mezcla Consumo Promedio Bares........................................................................... 116

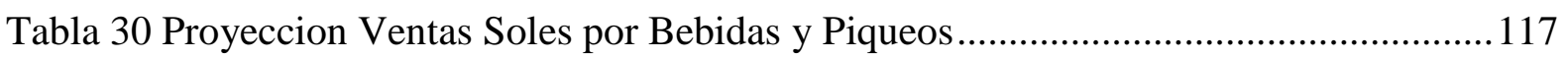

Tabla 31 Precio a Pagar por Unidad Mercado Efectivo ...................................................... 117

Tabla 32 Proyeccion Ventas Unidades por Bebidas y Piqueo ............................................ 118 


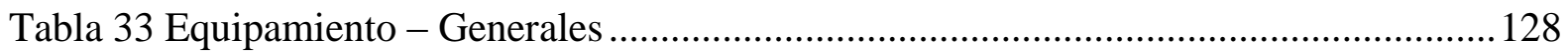

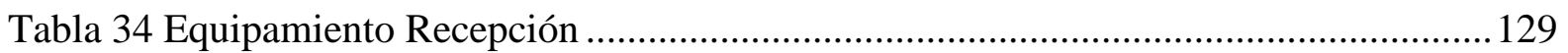

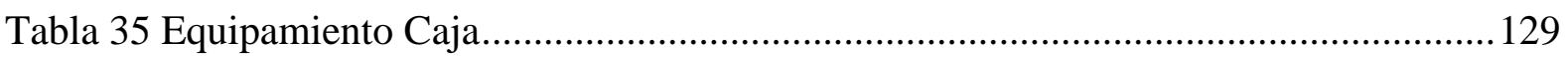

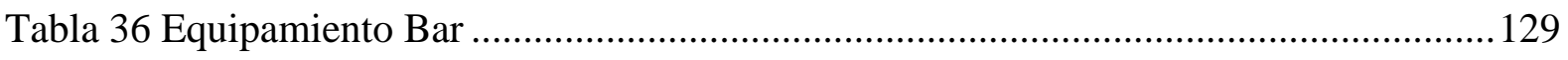

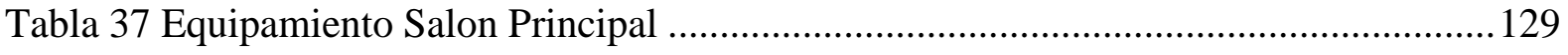

Tabla 38 Equipamiento Baño Administración Vestuario ………………………………….... 130

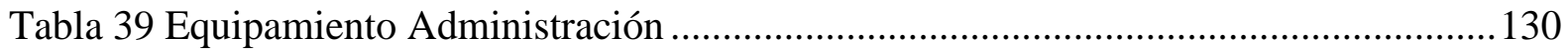

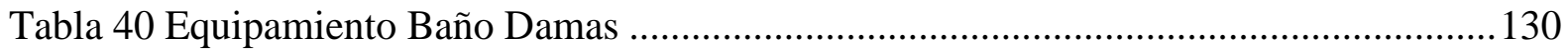

Tabla 41 Equipamiento Baño Caballeros ......................................................................... 130

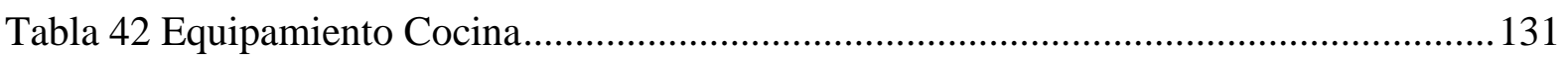

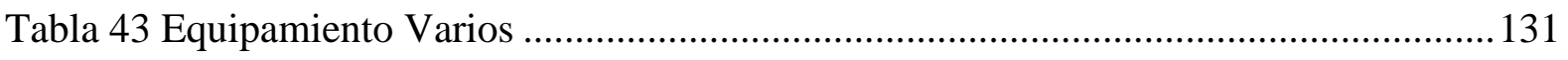

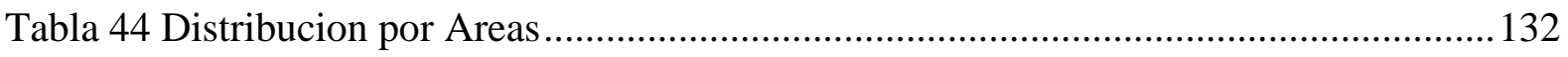

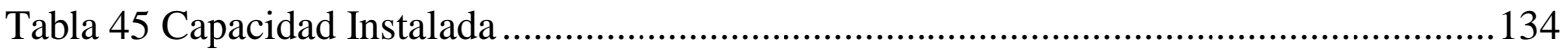

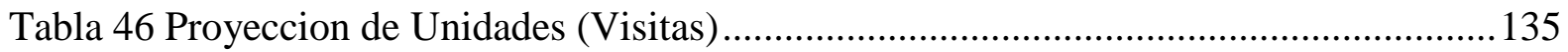

Tabla 47 Calificación de Factores Macrolocalización............................................................... 143

Tabla 48 Método Cualitativo por Puntos Macrolocalización ................................................... 144

Tabla 49 Calificación de Factores Microlocalización ............................................................. 147

Tabla 50 Método Cualitativo por Puntos Microlocalización...................................................147

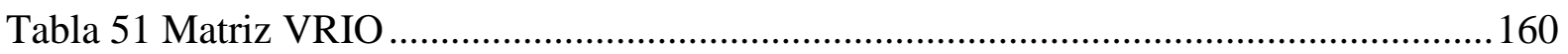

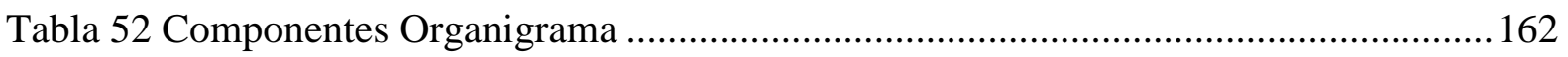

Tabla 53 Competencias identificadas para la Organización ..................................................... 165

Tabla 54 Perfiles de los Puestos de Trabajo (1/3).................................................................. 166

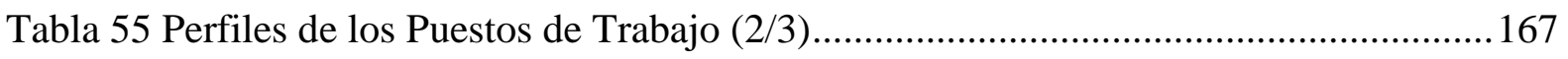

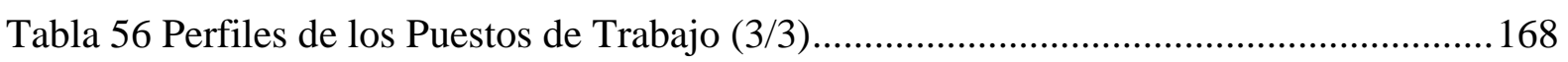

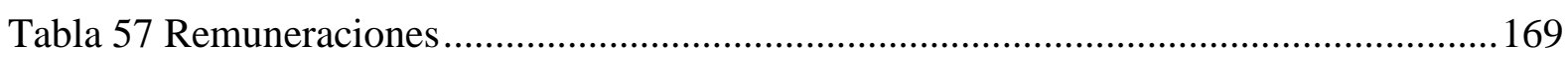

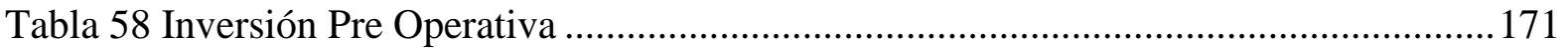

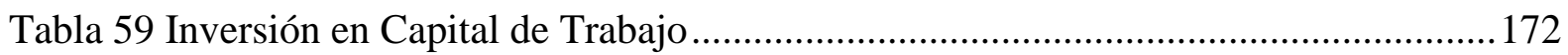

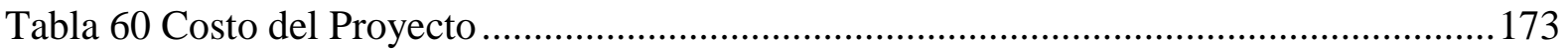

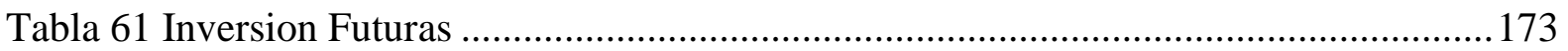

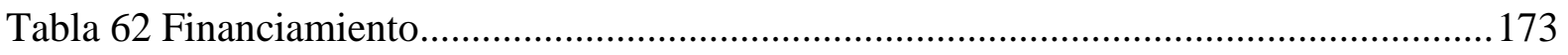

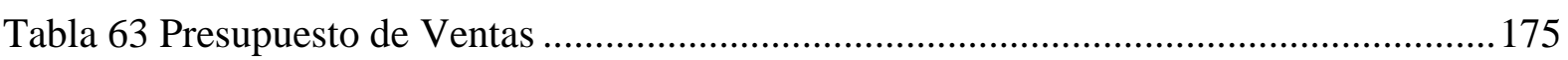

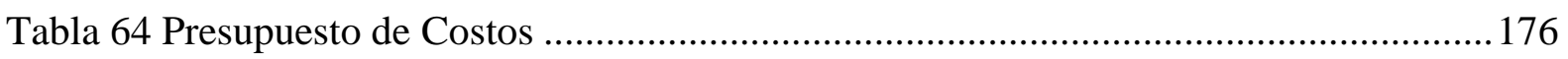

Tabla 65 Presupuesto de Gastos Administrativos.................................................................. 176

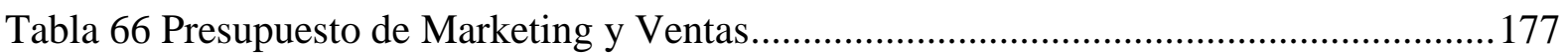




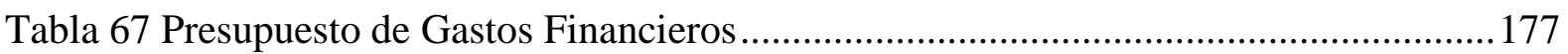

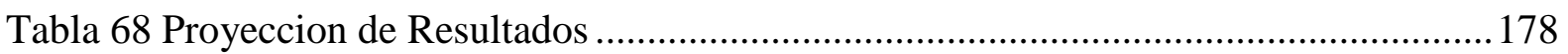

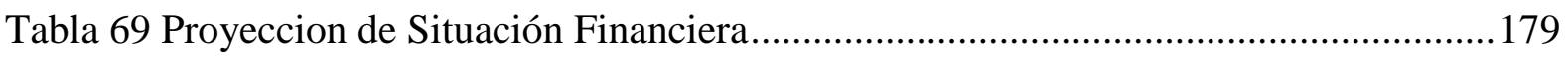

Tabla 70 Proyección Flujo de Efectivo.......................................................................... 180

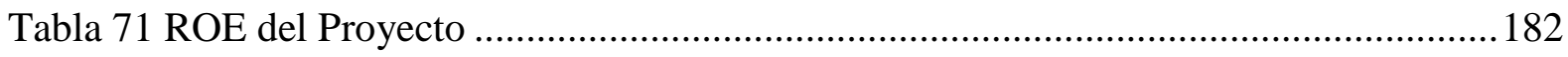

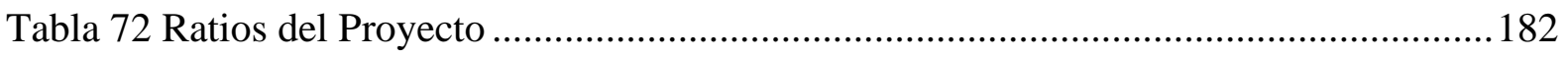

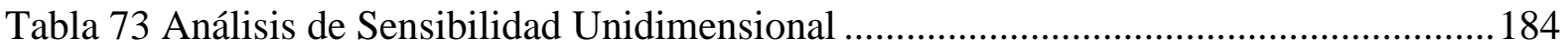

Tabla 74 Análisis de Sensibilidad Bidimensionla .................................................................. 184

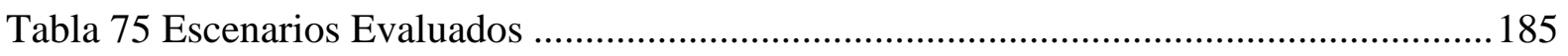

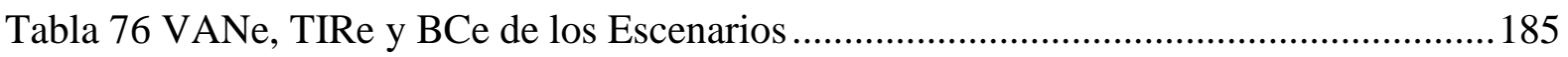




\section{Lista de Figuras}

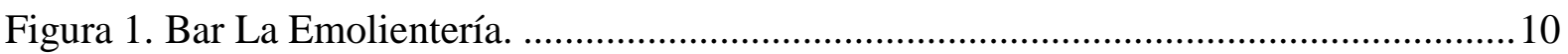

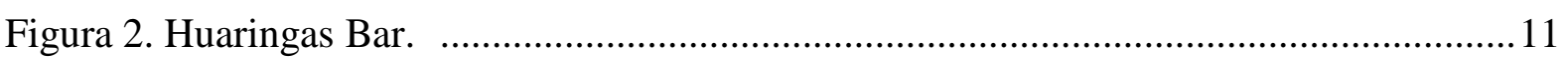

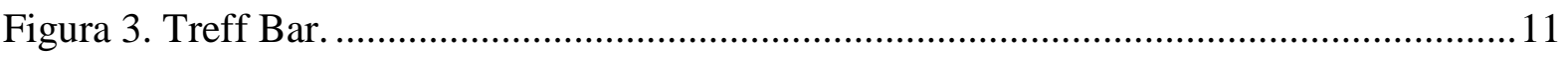

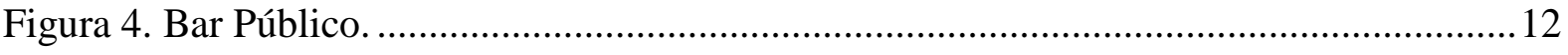

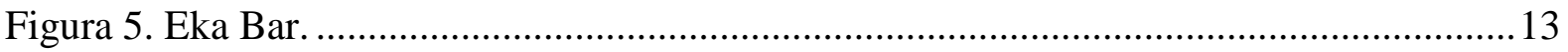

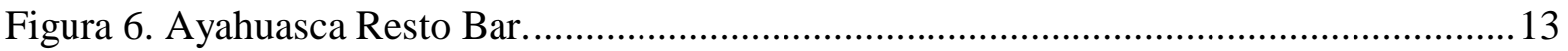

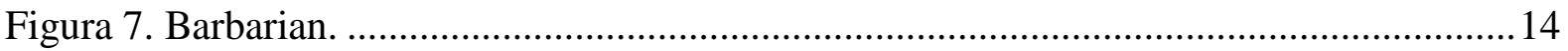

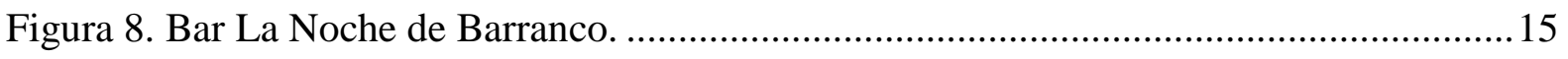

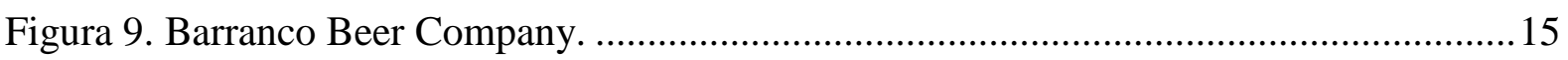

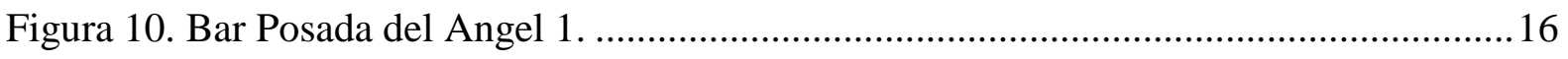

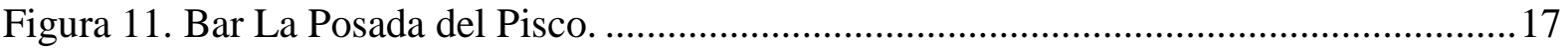

Figura 12. Perú Stock de empresas por Trimestre. ............................................................ 18

Figura 13. Empresas a nivel nacional / Empresas Lima Metropolitana 2017. .......................20

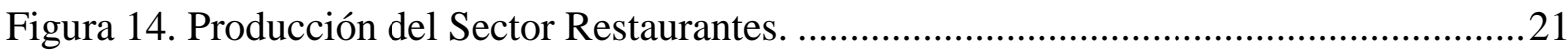

Figura 15. Las Cinco Fuerzas de Porter.............................................................................2 22

Figura 16. Las Cinco Fuerzas de Porter para el Sector de Servicios y Bebidas. .....................26

Figura 17. Ingresos Tributarios del Gobierno Central 2011-2018 ….....................................35

Figura 18. Causas que originan Accidentes de Tránsito.......................................................... 36

Figura 19. Accidentes de Tránsito causados por comportamiento humano. .............................37

Figura 20. Evolución de la Producción Nacional 2013-2018..................................................38

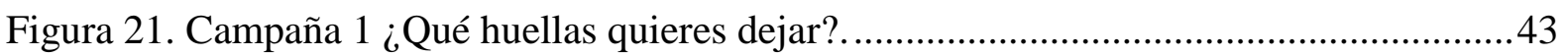

Figura 22. Campaña 2 ¿Qué huellas quieres dejar?............................................................ 43

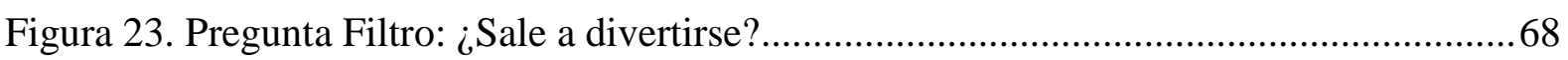

Figura 24. Tipos de Establecimientos de diversión o de entretenimiento que asiste...............68

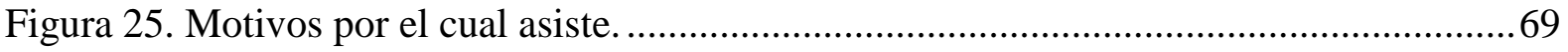

Figura 26. Frecuencia de asistencia a los establecimientos................................................69

Figura 27. Criterios de distinción y de preferencia para la asistencia a los establecimientos. 70

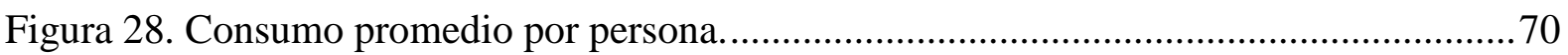

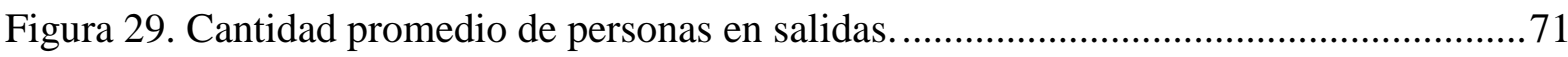

Figura 30. Motivos para el consumo de bebidas alcohólicas.............................................. 71

Figura 31. Aspectos más valorados en un Bar sin Alcohol. .................................................. 72

Figura 32. Alternativas de nombres para el nuevo concepto de Bar. .................................... 72

Figura 33. Rango de precio a pagar por un coctel sin alcohol............................................. 73 
Figura 34. Factores relevantes para la ubicación de una propuesta del Bar sin alcohol en Barranco.

Figura 35. Procesos de importancia en este tipo de bar....................................................... 74

Figura 36. Factores relevantes en la atención del personal................................................. 74

Figura 37. Medios preferentes para ser contactado. ............................................................ 75

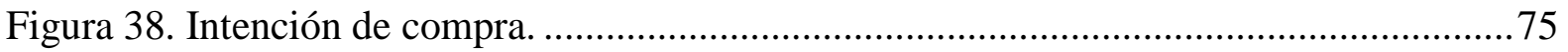

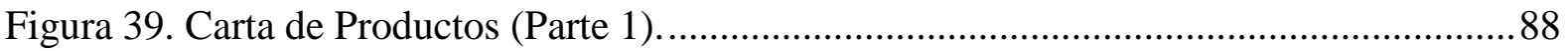

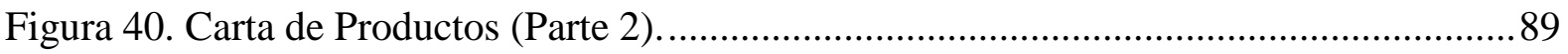

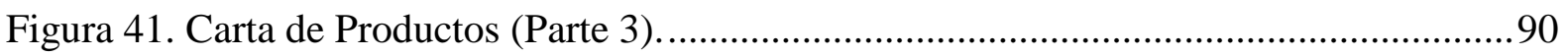

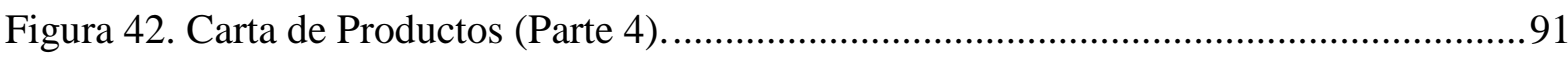

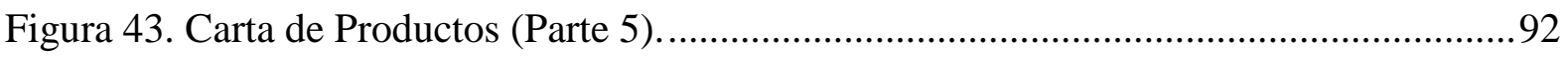

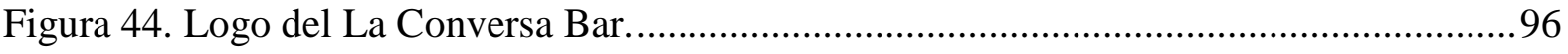

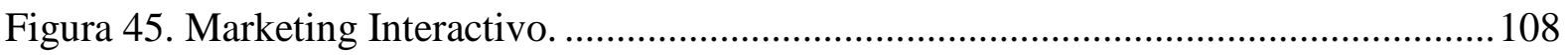

Figura 46. Proceso de Preparación de Bebidas...................................................................... 122

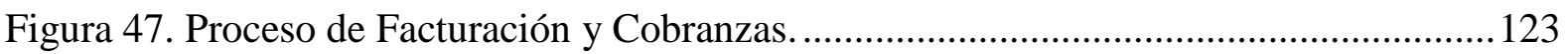

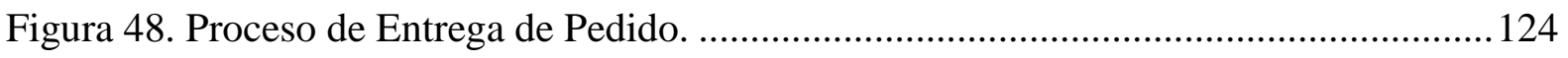

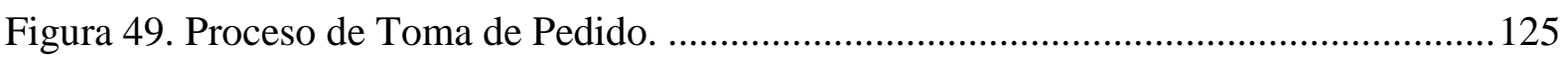

Figura 50. Proceso de Preparación de Piqueos. .................................................................... 126

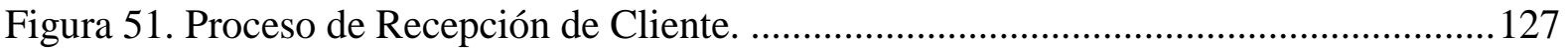

Figura 52. Plano de Distribución La Conversa Bar................................................................ 132

Figura 53. Diseño Gráfico de la parte interior del local en 3D (1) .................................... 139

Figura 54. Diseño Gráfico de la parte interior del local en 3D (2)....................................... 139

Figura 55. Diseño Gráfico de la parte interior del local en 3D (3) ...................................... 140

Figura 56. Diseño Gráfico de la parte interior del local en 3D (4) ...................................... 140

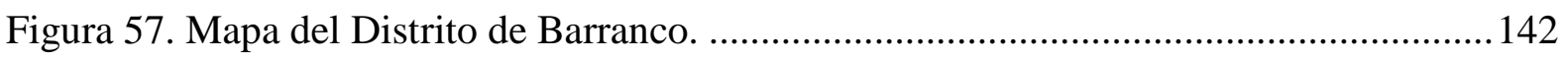

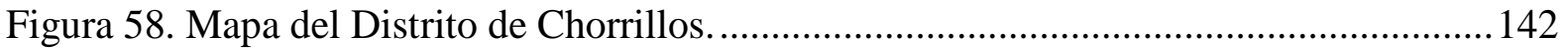

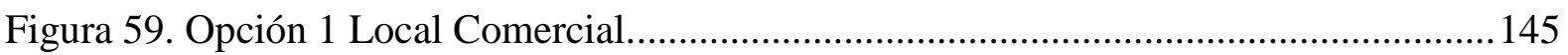

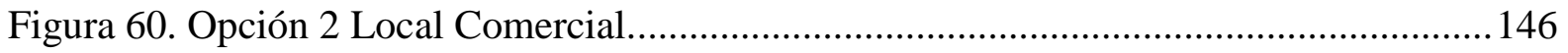

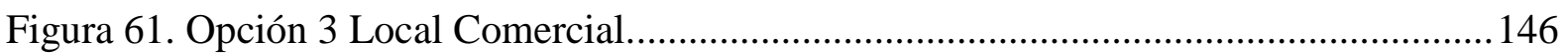

Figura 62. Proceso de Autorización de Licencia de Funcionamiento. .................................. 152

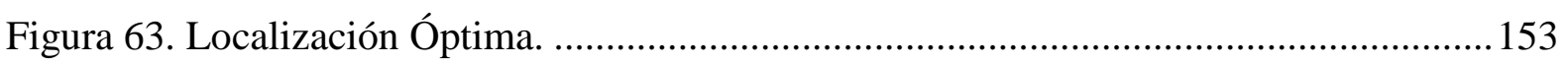

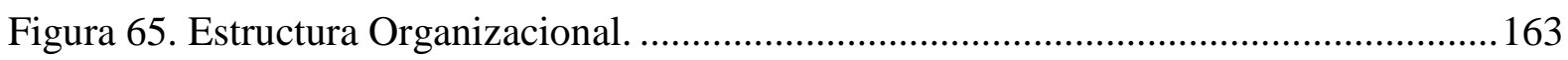




\section{Lista de Apéndices}

Apéndice

Apéndice 1: Ficha de Reclutamiento 197

Apéndice 2: Guía de Indagación o Guía de preguntas para el Focus Group 201

Apéndice 3: Guía para la Entrevista en Profundidad 204

Apéndice 4: Cuestionario 206

Apéndice 5: Focus Groups 207

Focus Numero 1 "La Conversa Bar" 207

Focus Número 2 "La Conversa Bar" 214

Apéndice 6: Entrevistas a expertos

Entrevista Experto 1. Gerente General Cervecería y Bar Barbarian "Ignacio Schwalb Pomareda"

Entrevista Experto 2 Gerente General Bar Ayahuasca "Alexander Von Ehren". 237

Entrevista Experto 3 Socio Fundador Bar Victoria "Giancarlo Gomero" 246

Apéndice 7: Calificación de Factores de éxito. 229

Apéndice 8: Calificación cruzada de Expertos 229 


\section{Introducción}

El presente Plan de Negocios ha sido diseñado para evaluar la factibilidad de la propuesta de emprendimiento que este propone, el cual consiste en brindar un espacio de diversión para aquellos que no desean consumir bebidas alcohólicas, pero que sí desean estar en un ambiente socialmente acogedor y donde se consuma bebidas que no lleven este ingrediente, contribuyendo así a la generación de una propuesta disruptiva como alternativa de diversión sana y sin los efectos negativos propios de la ingesta de las bebidas alcohólicas, los cuales están directa y negativamente relacionados con consecuencias tales como los accidentes de tránsito -con resultados fatales-, violencia familiar, vandalismo, entre otros.

Por ello, dicha factibilidad se desarrolla en los 11 capítulos de los que consta este documento, los cuales se describen a continuación:

1. El capítulo I, detalla los antecedentes, identifica el problema a atender y determina la justificación del por qué se realizará este negocio. Se plantean objetivos alcanzables dentro de un horizonte de evaluación y de la demarcación de los alcances de la investigación.

2. El capítulo II, es de suma importancia conocer el Macro Entorno y los Factores Externos que pueden afectar de manera positiva o negativa el desempeño de la actividad empresarial a desarrollar. Es por ello, que en este capítulo describe el estado actual del sector, el comportamiento de las empresas que actualmente están en el mercado, así como la participación en el mercado de ellas mismas.

3. El capítulo III, explica y analiza la demanda, a través del perfil del consumidor, su comportamiento, y las tendencias que influyen en su actuar; así como también analiza la oferta, a través de las fuerzas que influyen en el micro entorno como son los competidores actuales y/o potenciales, los productos sustitutos, y los productos complementarios. Además, se diseña el plan de marketing para finalmente poder estimar los ingresos o ventas que el proyecto generará dentro de su horizonte de evaluación.

4. El capítulo IV, define en primer lugar al Mercado Potencial, al Mercado Disponible, al Mercado Efectivo y finalmente el Mercado Objetivo a partir de los resultados obtenidos en el estudio de Mercado. Adicionalmente se proyectará dicho mercado para todo el horizonte de evaluación del proyecto. 
5. El capítulo V, plantea la estrategia general, así como las diferentes estrategias de marketing (Marketing Mix) que se aplicará para ofrecer y hacer llegar la propuesta de valor de la mejor manera al respectivo mercado.

6. El capítulo VI, con la información de capítulos anteriores, proyecta las ventas en base a supuestos que influirán en el comportamiento de las mismas dentro del horizonte de evaluación del proyecto

7. El capítulo VII, con las ventas proyectadas establece los requerimientos técnicos así como los estudios de ingeniería que se dispondrá para un buen desenvolvimiento de las actividades de abastecimiento, producción, y comercialización del servicio.

8. El capítulo VIII, establece la Visión, Misión, Principios; así como el tipo de estructura que tendrá y regirá para el capital humano que la conformará, definiendo para ellos sus respectivas responsabilidades y actividades a realizar cada uno.

9. El capítulo IX, encuentra la posibilidad de valorizar la inversión a realizar en Activos Fijos, Activos Intangibles, y Gastos Pre-Operativos en que se incurrirá, así como establecer los diferentes costos operativos que serán establecidos en los diferentes presupuestos y estados financieros.

10. El capítulo X, define la viabilidad económica financiera del proyecto, a través de los diferentes indicadores financieros sometidos a diferentes estados, análisis de riesgo y simulaciones.

11. El capítulo XI, describe las conclusiones a las que se ha llegado, así como se brinda las recomendaciones respectivas para la sostenibilidad y viabilidad del negocio.

12. Finalmente, se encuentran los apéndices y referencias que complementan información sostenida en los capítulos anteriores. 


\section{Capítulo I: Generalidades}

En este capítulo se detalla la justificación para la realización de este negocio, la cual toma como base los antecedentes encontrados y la identificación de la solución al problema planteado. Por ello, en este estudio se han establecido objetivos alcanzables en un horizonte de evaluación dentro de la demarcación de los alcances de la investigación.

\subsection{Antecedentes}

Todas las personas y especialmente los jóvenes tienen la necesidad de divertirse, compartir momentos agradables con familiares, amigos, compañeros de trabajo, de estudios o de cualquier otro círculo social, cultural, religioso, etc., en el cual se desarrolla. No obstante, culturalmente hablando, el término diversión es considerado perjudicial o negativo, precisamente porque un compartir entre amigos, por lo general, incluye el consumo de bebidas alcohólicas, especialmente en centros de diversión dedicados al expendio de estos productos, comúnmente llamados bares.

Según la Real Academia de la Lengua Española (RAE, 2014), la definición de 'Bar' derivada del idioma ingles bar, cuya traducción al español es 'barra' y es definida de la siguiente forma: "Local en que se despachan bebidas que suelen tomarse de pie, ante el mostrador".

Por lo anterior, es correcto usar la denominación bar para un centro de diversión cero alcoholes, puesto que la definición no incluye necesariamente el expendio de bebidas que contengan alcohol, como ha sido generalizado. Los bares han existido desde tiempos memorables, cumpliendo un rol en la sociedad como dar descanso, refresco y diversión momentánea para los viajeros.

\subsubsection{Historia de los bares.}

La historia se remonta a los denominados "thermopolias" de origen romano donde se vendían todo tipo de bebidas y comidas que se ofrecían dentro de un establecimiento. Por otro lado, existían los llamados "cauponae" donde el consumidor adquiría al paso los productos que vendía el lugar. Posteriormente, en Inglaterra aparece un lugar novedoso que recibía el nombre de "pub" que proviene de los sectores obreros de una determinada población. (El Bartender, 2011).

En Perú, los bares tienen su origen en el emblemático Cordano propiedad de emigrantes italianos que inició sus operaciones en el año 1905. En 1915, el Queirolo inauguró su local con gran aceptación, ofreciendo al público una diversidad de bebidas alcohólicas, sobre todo a base de pisco peruano que actualmente tiene un reconocimiento mundial. Estos 
dos bares guardan mucha historia y son paradas obligadas no solo de residentes peruanos, sino también de extranjeros que buscan deleitarse con las bebidas nacionales. Tanto en el mundo entero como en el Perú existen diversos tipos de bares, desde los más básicos y clásicos hasta los más modernos y sofisticados. (La República, 2004)

\subsubsection{Tipos de bares.}

Según García (Original Music.es, 2012) los bares se pueden clasificar de la siguiente manera:

- Bares de tapas, bar típico español donde se sirven tapas acompañadas de bebidas.

- Bar de Vinos, bar de origen anglosajón en los se sirven vinos en copas.

- Bar Tradicional, pequeños locales suelen tener una barra larga y ofrecer servicio en mesa.

- Bar Terraza, especiales para tomar algo al aire libre con atención desde fuera del local.

- Pub, "Public Houses" están centrados en el ocio nocturno donde la música es protagonista para amenizar el ambiente.

- Bar Ingles, establecimientos comerciales con ambientes tranquilos y agradables con servicio generalmente en barra.

- Bar Irlandés, locales decorados con acabados en madera, suelen especializar en cervezas y tener música melódica.

- Bar Cervecería, locales especializados en cervezas de todas partes del mundo y cervezas artesanales.

- Bar Piscina, típico de zonas tropicales y suelen estar integrados dentro de un hotel, cerca o dentro de la piscina.

- Lobby Bar o Bar de Hotel, ubicados dentro del vestíbulo de un hotel, acogedores para refrescarse, leer o relajarse.

- Bar Café, especializados en servir desayunos y meriendas, de ambiente agradable y música suave para hablar y relajarse.

- Taberna, locales de origen popular donde se sirven comidas y bebidas, suelen tener estilo rústico.

- Cantina, locales frecuentados por hombres mayoritariamente donde sirven bebidas alcohólicas y aperitivos como botanas.

- Bar de Cócteles, bares especializados en coctelería, variedad de bebidas con alcohol y sin alcohol preparados al momento. 
- Bar Restaurante, estos locales suelen un salón comedor y poner énfasis en el ambiente del comensal.

- Bar Karaoke, estos locales cuentan con karaoke donde los clientes pueden elegir y cantar canciones.

- Bares temáticos, ambientados con una temática en concreto, ambientes que transportan al cliente a un espacio diferente.

- Lounge Bar, bares donde la música principalmente Jazz y la estética predominan para poder conversar tranquilos.

El consumidor habitual de los bares, en general, ha evolucionado con el tiempo desde ser un bebedor empedernido hasta uno más moderado y consciente sobre su salud e imagen personal.

\subsubsection{Tendencias de consumo.}

La influencia de las redes sociales y su impacto por la exposición del comportamiento de los usuarios han llevado a los jóvenes a beber mucho menos que sus padres y en la mayoría de los casos, por "vergüenza social", son abstemios totales. "Si en el pasado la presión social llevaba a millones de adolescentes sin personalidad a beber alcohol para no quedar mal ante su grupo de amigos, hoy sucede todo lo contrario". (15 Minutos, 2017).

La investigación de la consultora Canvas (2016), realizada con jóvenes entre los 21 y 35 años, procedentes de Gran Bretaña, Estados Unidos, Países Bajos, México y Brasil, determinó que el $75 \%$ de los encuestados reduce deliberadamente su consumo. De todos ellos el 59\% lo hace para evitar "perder el control".

En Inglaterra, la Oficina Nacional de Estadísticas señaló que: Los chicos entre 16 y 24 años son completamente abstemios (15 Minutos, 2017).

Esta tendencia ha traído consigo diversos intentos para tratar de satisfacerla.

\subsubsection{Experiencias en otros países.}

La Universidad Lovaina de Bélgica brindó apoyo para la apertura de un bar para estudiantes, donde solo se sirven bebidas sin alcohol o con muy baja graduación, como cócteles y cervezas. En este lugar se realizan eventos temáticos cada día, como concursos, fiestas de música, noches de monólogos. (EFE, 2016)

En países como Argentina, están promoviendo la realización de eventos donde los jóvenes pueden reunirse sin necesidad de consumir bebidas alcohólicas, su programa denominado "divertite sin alcohol" viene generando mayor interés en la población. Estos eventos tienen buena acogida por parte de los jóvenes y sus padres (Divertite Sin Alcohol, 2018). 
En México desde el año 2004 el concepto de bares sin alcohol, también conocido como "dry bar" surgió con aceptación en un mercado que buscaba la posibilidad de divertirse en lugares tan iguales que aquellos donde se expenden bebidas con alcohol. Uno de los lugares emblemáticos fue el entonces llamado "BARSIN", lugar donde se expendía bebidas sin una gota de alcohol (Alto Nivel, 2013).

En México incentivan que los bares ofrezcan a sus clientes bebidas que no contengan alcohol con el fin que las personas tomen conciencia de que se puede divertir sanamente. Entre los lugares que están ofreciendo este tipo de productos son: Bar Don Quijote y Mr. Jacks (Televisa News, 2018) .

El Perú no ha sido ajeno a promover campañas de consumo responsable de bebidas alcohólicas, cuyo exceso es responsable de muchos accidentes de tránsito; los excesos de varias generaciones de deportistas privaron al Perú de una clasificación mundialista.

\subsubsection{Consumo responsable en Perú.}

En Perú en el año 2009, los Ministerios de Transportes y del Interior, ante la creciente ola de accidentes de tránsito ocasionados por la ingesta de alcohol, realizaron una campaña para prevenir accidentes de tránsito denominada el "Amigo Elegido", el cual consiste en que un grupo de amigos al ingresar al local de diversión, elegirá a uno de ellos para que en esa ocasión no ingiera alcohol, de esta manera, el “Amigo Elegido" será el responsable de manejar el vehículo en el cual se trasladará el grupo que asista a una discoteca, bar o lugar donde se consuma licor (La República, 2009).

Esta campaña fue el inicio de un cambio en la cultura de diversión y responsabilidad al volante, creándose actividades comerciales conexas, como servicios de "chofer de reemplazo" y muchos bares incluyeron en su carta el concepto de tragos vírgenes y bebidas sin alcohol. En el 2017, el Perú gozó de la clasificación al mundial de futbol después de 36 años y en 2018 concreta su participación. Sin lugar a dudas uno de los motivos de los malos resultados en procesos anteriores fue la indisciplina del jugador peruano, el cual lejos de trabajar como un profesional se escapaba de las concentraciones para divertirse sin medir las consecuencias, envueltos en escándalos por el desenfreno y excesivo consumo de alcohol.

En general existen personas asignadas recurrentemente por el grupo de amigos a no consumir bebidas alcohólicas por tener que manejar y llevarlos a casa; además se identifica personas abstemias y quienes siendo consumidores habituales en algún momento desean divertirse sin necesidad de consumir alcohol, tales como estudiantes previos a una evaluación, deportistas que desean mantener la concentración previa a un evento, personas 
que guardan dietas saludables, personas con tratamiento médico, mujeres en periodo de gestación, etc.

Barranco es un distrito en Lima donde se puede encontrar una gran diversidad de oferta de bares de diferentes tipos.

\subsubsection{Barranco distrito bohemio.}

El Distrito de Barranco es el más pequeño de los 43 distritos de Lima, ciudad capital del Perú. Ocupa una superficie de 3,33 km2 y fue creado el 26 de Octubre de 1874 llamándose originalmente San José de Surco con su capital La Ermita de Barranco. Su primer alcalde fue el General Pedro Bustamante. Actualmente Barranco cuenta con una población de 33,903 habitantes (2007).

Barranco es considerado como el distrito cultural de Lima entre sus antiguas calles alberga galerías de arte, centros culturales, escuelas de danza y teatro, talleres artísticos, cinematógrafos, museos además de 15 colegios privados, 8 colegios nacionales, 6 institutos de educación especializada, 2 campus universitarios, y muchos talleres en diferentes áreas educativas y artísticas.

En Lima hay muchos lugares que valen la pena conocer pero Barranco es el lugar que no puede dejar de conocer porque está lleno del glamour de una época que solo se puede imaginar a través de sus calles, plazas y casonas. Barranco es un poema al amor, es el testigo de inigualable noches de bohemia y es el rincón de Lima, más pequeño pero el más grande en tradición y nobleza. (Lima Find, 2016).

En Barranco, distrito objeto de estudio se encuentran, entre otros, los siguientes bares:

- Ayahuasca. Dirección: Av. San Martin 130

- Barbarian. Dirección: Av. Pedro de Osma 144 - Interior 102

- Barranco Beer Company. Dirección: Av. Almte. Miguel Grau 308

- Bar Medicinal. Dirección: Av. Nicolás de Piérola 285

- Juanito de Barranco. Dirección: Av. Almte. Miguel Grau 270

- El Acantilado. Dirección: Ermita 102

- Picas. Dirección: Av. San Martin 340

- Sibaris Cocina Libre. Dirección: Jirón, 28 De Julio 206B

- Sofá Café Barranco. Dirección: Av. San Martin N480, Interior 105

- Trapiche Bar Ecological. Dirección: Av. Almte. Miguel Grau

\subsection{Determinación del problema u oportunidad}

La información disponible permite identificar lo siguiente: 
- La falta de centros de diversión donde los jóvenes puedan divertirse sin necesidad de consumir bebidas alcohólicas en un ambiente donde tampoco se consuman este tipo de bebidas, además seguro, con buena música y una carta de consumos adicionales (piqueos) para pasar un momento agradable y divertido.

- Desmitificar el concepto de "Bar", el cual está comúnmente relacionado con el consumo de alcohol.

- Introducir un nuevo tipo de bar, el cual será considerado como bar cero alcohol, donde no se expenda bebidas alcohólicas.

- La tendencia mundial de los jóvenes a reducir el consumo e incluso dejar de consumir bebidas alcohólicas es una oportunidad para desarrollar la presente investigación.

- La experiencia exitosa en la implementación de este concepto de negocios en otros países como Argentina, Bélgica y México, representan una oportunidad para replicarlo en Perú.

- En Perú la efectiva campaña social el "amigo elegido" brinda soporte para la viable implementación de la presente propuesta.

- Existe demanda de ofertas gastronómicas y especialmente de bebidas saludables, público joven, estudiantes, deportistas y en general quienes desean cuidar su salud.

- Aprovechar la afluencia de público que genera el distrito de Barranco para brindar una alternativa diferente a los bares actuales.

\subsection{Justificación del proyecto}

La realización de este plan de negocios es importante porque brindará un espacio de diversión para aquellos que no desean consumir bebidas alcohólicas y/o estar en un ambiente donde se consuma este tipo de bebidas. También será una alternativa de diversión sana, sin los efectos negativos propios de la ingesta de alcohol, la cual está directamente relacionada con los accidentes de tránsito con consecuencias fatales, violencia familiar, vandalismo y otros males de la sociedad.

Generación de puestos de trabajo, especialmente para jóvenes estudiantes, los cuales deben ser reconocidos en sus labores para así mantener un buen clima laboral que impacte en un buen servicio al cliente.

Plasmar conocimientos adquiridos en la Maestría de Ciencias Empresariales con especialización en PYMES y demás formación académica por parte de los autores de la propuesta, sumado a la experiencia profesional de más de 20 años en diferentes sectores de servicios como consumo masivo, retail, finanzas, asesorías y consultorías. 


\subsection{Objetivo generales y específicos del proyecto}

\subsubsection{Objetivo General}

Desarrollar un Plan de Negocios para la creación de un Bar cero Alcohol en Lima Metropolitana, con ubicación física en el distrito de Barranco en 2018.

\subsubsection{Objetivos Específicos}

- Analizar la estructura económica del sector de bares y restaurantes.

- Realizar el estudio de mercado para determinar el perfil del cliente y la aceptación de la propuesta.

- Realizar el pronóstico de ventas en base a la información del estudio de mercado.

- Formular los aspectos organizacionales de la propuesta.

- Formular la ingeniería del proyecto necesaria para la implementación.

- Formular el plan de marketing para la promoción de la propuesta.

- Realizar la planificación financiera para el periodo de evaluación.

- Determinar la viabilidad económica financiera de la propuesta.

\subsection{Alcances y limitaciones de la investigación}

La realización de este plan de negocios se centra en jóvenes residentes en los distritos de Lima Metropolitana. Si bien se propone la ubicación en el distrito de Barranco, jóvenes de todo Lima se trasladan hacia los locales de su preferencia, siendo los distritos que concentran las mayores cantidades de bares Miraflores y Barranco principalmente, existen otros puntos de concentración de bares en los conos de la capital los cuales no están comprendidos en este estudio. El plan de negocios será desarrollado durante el 2018 y para todo efecto considera como fecha de inicio de operaciones el 2019. Una limitante a considerar es la poca disposición o interés de los jóvenes y adultos para colaborar con la realización del estudio.

Otra limitante importante es la falta de información histórica del sector, de los competidores, específicamente de bares, la información no es pública como en otros sectores, por lo tanto se recurre a expertos e información de negocios similares como puntos de referencia. 


\section{Capítulo II: Estructura Económica del Sector}

Es de suma importancia conocer el macro entorno y los factores externos que pueden afectar de manera positiva o negativa el desempeño de la actividad empresarial a desarrollar. Es por ello, que en este capítulo se describirá el estado actual del sector, el comportamiento de las empresas que actualmente están en el mercado, así como de su participación en el mercado de las mismas.

\subsection{Descripción del Estado Actual de la Industria}

Antes de formular un plan de negocio o un plan estratégico, es fundamental que el emprendedor o empresario defina claramente en qué industria está, es decir, cuál es el marco de referencia que se empleará para analizar la empresa y su potencial de crecimiento y desarrollo. Cuando se analiza una industria se hace referencia a un grupo de compañías que ofrecen los mismos productos o servicios, o que siendo muy similares, satisfacen las mismas necesidades y compiten por los mismos compradores o por un segmento nuevo (Weinberger, 2009).

Una de las formas de uso que toma la acepción de Industria es un conjunto de empresas que elaboran productos y/o brindan servicios similares en un mismo sector de un país o en alguna parte del mismo (Franco, 2013). De allí la importancia de analizar el estado actual de la industria de restaurantes y servicios de bebidas en su conjunto y poder observar cómo se encuentra clasificado y segmentado, conocer las principales empresas que la conforman, los factores del macro y micro entorno que influyen, principalmente, en la actividad de servicios de bebidas.

\subsubsection{Segmentación de la industria.}

De acuerdo a la teoría económica, cuando se refiere a la segmentación de la industria el término conlleva a bloque de empresas que producen bienes o servicios homogéneos o idénticos considerados bienes sustitutos así sean diferentes. Sin embargo, en la práctica es muy diferente definir los límites internos de una industria, optándose por definiciones dentro de las actividades de la industria como en el caso de estudio que se separa restaurantes, bares, cafés, lounges, entre otros. Una definición adecuada al problema concreto que se quiera resolver (Cuartas \& Escobar, 2006).

La industria objeto de estudio corresponde a actividades de servicio de comidas y bebidas, y específicamente a Actividades de Servicio de Bebidas según la Clasificación Industrial Internacional Uniforme (CIIU), cuyo alcance abarca a todas las actividades económicas, a las que se refieren tradicionalmente a las actividades productivas, es decir, aquellas que producen bienes y servicios. 
En el Perú, el Instituto Nacional de Estadística e Informática (INEI, 2008) ha establecido oficialmente la adopción de la nueva revisión de la Clasificación Industrial Internacional Uniforme de todas las actividades económicas (CIIU Revisión 4). Siendo las empresas objeto de estudio las clasificadas en la División 56 denominada actividades de Servicio de Comidas y Bebidas y que se encuentran integradas por:

5610 Actividades de restaurantes y de servicio móvil de comidas.

5621 Suministro de comidas por encargo.

5629 Otras actividades de servicio de comidas.

5630 Actividades de servicio de bebidas.

Asimismo, según Reglamento de Restaurantes Ministerio de Comercio Exterior y Turismo (MINCETUR, 2004), modificado con DS 009-2017 MINCETUR, y según lo explicado en capitulo anterior, se puede indicar que la diferencia que existe entre Restaurante y Bar es la siguiente: (a) el primero es un establecimiento que expende comidas y bebidas al público preparadas en el mismo local y (b) el segundo es un recinto o parte del restaurante que contiene una barra o mostrador donde se expende bebidas de todo tipo. Por lo tanto, según MINCETUR, en la Actividad de Servicio de Bebidas están comprendidos los:

- Bares

- Restaurantes

- Cafeterías,

- Discotecas,

- Pubs

Finalmente, una de las asociaciones más importantes del sector en estudio AHORA Perú, asociación sin fines de lucro, solo clasifica a sus socios en: Hoteles, Restaurantes, y Afines (Ahora-Perú, 2018).

\subsubsection{Empresas que la conforman (ubicación, volumen de ventas, empleados, etc.).}

Las empresas que principalmente conforman la actividad de Restaurantes y Servicio de Bebidas ascienden a 2006 unidades de negocios y que se encuentran en los distritos de Miraflores y Barranco distribuidos en 547 y 1458 empresas respectivamente, según información recabada de las oficinas de MINCETUR.

Entre las empresas que se dedican exclusivamente al servicio de bebidas son las siguientes: 
- La Emolientería

Alcance: Este lugar es una propuesta de bar $100 \%$ peruano, acondicionado con elementos oriundos del país, así como plasma el arte alternativo urbano (ver Figura 1).

Servicios Adicionales: música fusión y una variada carta de tragos, todos inspirados en una de las bebidas más conocidas del país, el emoliente.

Razón Social: Grupo Wira S.A.C

No. RUC: 20544753577

Localización: Diagonal 598, Miraflores

Horario: Lun a Jue 12m a 01am / Vie y Sab 12m a 2.30am / Dom 05.30am a 01am

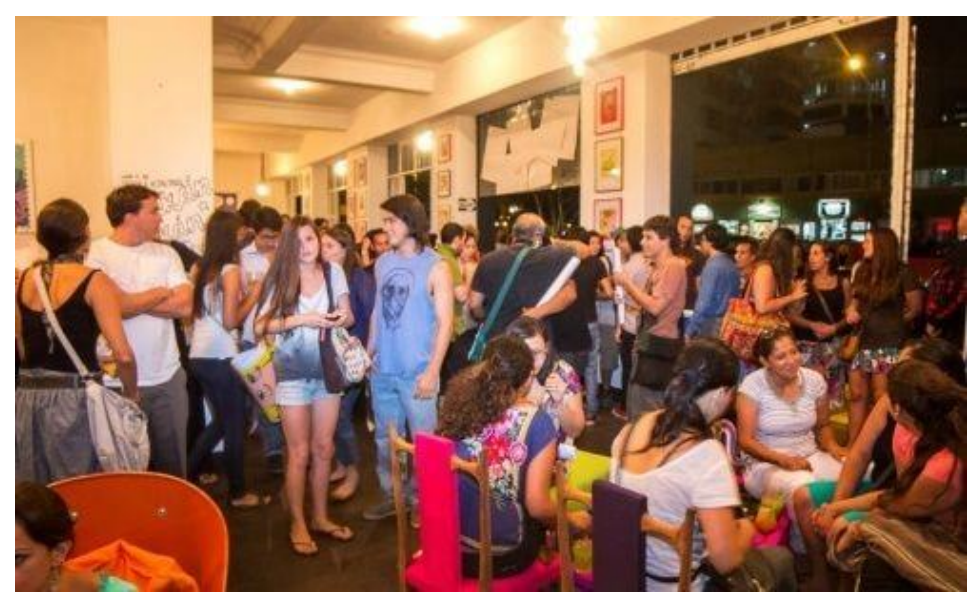

Figura 1. Bar La Emolientería. Tomado de Diario El Comercio "Sigue la ruta de Bares en Lima", 17.02.2018, Recuperado de https://elcomercio.pe/vamos/planes-sigue-ruta-bareslima-noticia-497798

- Huaringas Bar

Alcance: Este concurrido bar se caracteriza por sus cómodos sillones y sus piscos sours de diversos sabores y de diferentes frutas exóticas, cuenta con varios ambientes (ver Figura 2). Servicios Adicionales: con una muy buena atención también brinda música Jazz electrónica y también música en vivo

Razón Social: Huaringas S.A.C

No. RUC: 20508410906

Localización: Bolognesi 460, Miraflores

Horario: Lun a Jue 07pm a 01am / Vie y Sab desde 07 pm a 2.30am 


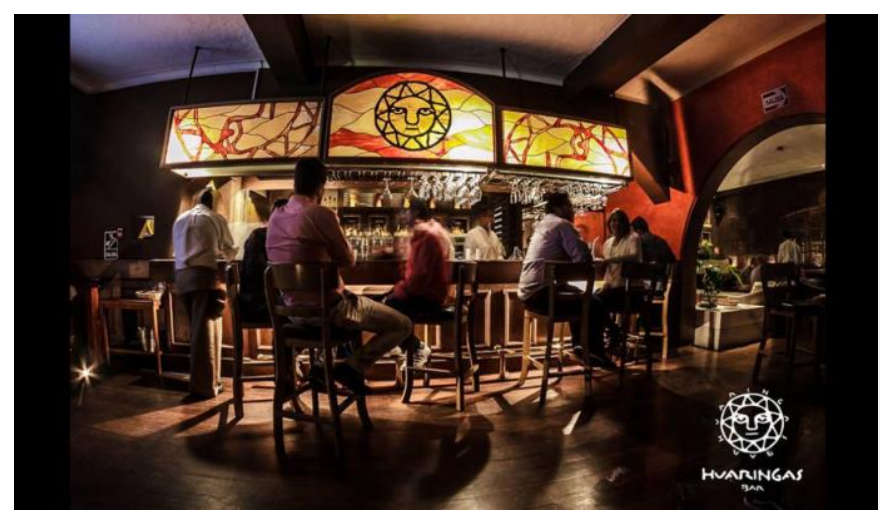

Figura 2. Huaringas Bar. Tomado de Diario El Comercio "Sigue la ruta de Bares en Lima", 17.02.2018, Recuperado de https://elcomercio.pe/vamos/planes-sigue-ruta-bares-limanoticia-497798

- Treff:

Alcance: Es uno de los bares más confortables en el distrito de Miraflores. Es uno de los bares más pintorescos de la zona. Venden múltiples jarras de cerveza y dentro de sus especialidades cuenta con la sangría multisabor (ver Figura 3).

Servicios Adicionales: Es un lugar propicio para el disfrute de amistades, de la música, de piqueos alemanes y atención esmerada.

Razón Social: TREFF S.C.R.L.

No. RUC: 29140519457

Localización: Av. Benavides 571, Miraflores.

Horario: Lun a Jue 07pm a 01am / Vie y Sab desde 07 pm a 3.00am

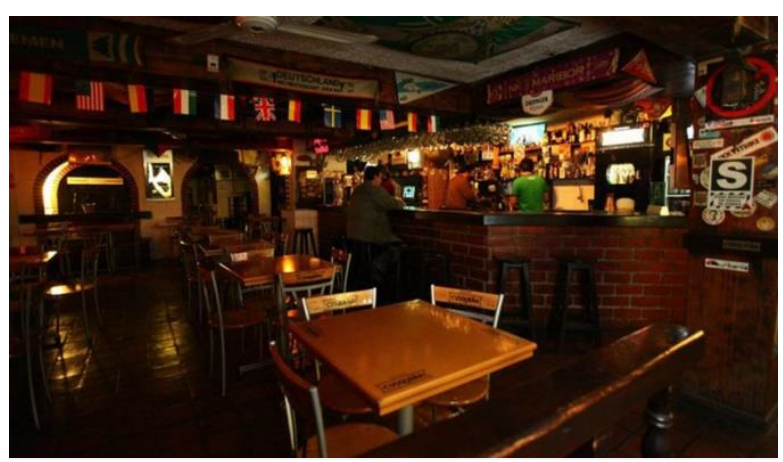

Figura 3. Treff Bar. Tomado de Diario El Comercio: 10 de los Mejores Bares para el After Office. 15.09.2016. https://elcomercio.pe/vamos/peru/10-mejores-bares-miraflores-afteroffice -278600 ?foto $=6$ 
- Bar Público

Alcance: Este bar de estilo bohemio proporciona una gran variedad de tragos y música en un ambiente lleno de diversión y buena vibra., caracterizándose por el económico de sus precios. Servicios Adicionales: Una de sus mejores opciones son los piqueos, principalmente la salchipapa; así como también busca diferenciarse a través de sus precios (ver Figura 4). Razón Social: BAR PUBLICO S.A.C

No. RUC: 20523283902

Localización: Calle Esperanza 335, Miraflores

Horario: Lun a Jue 07pm a 01am / Vie y Sab desde 07 pm a 3.00am

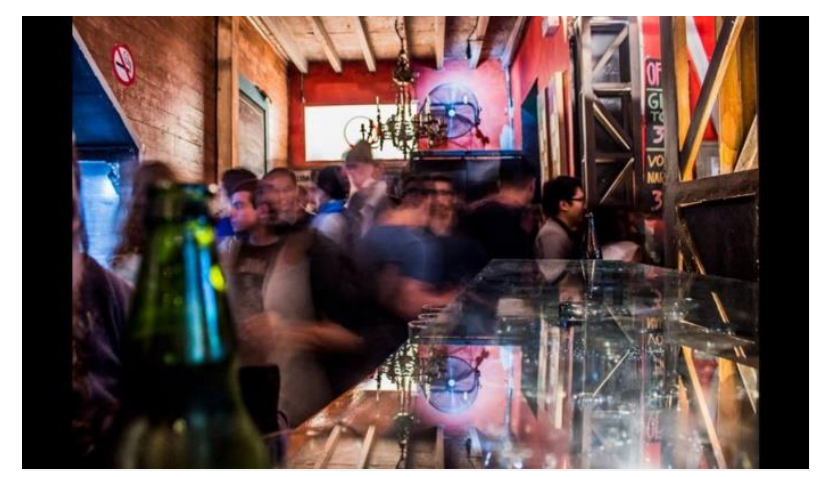

Figura 4. Bar Público. Tomado de Diario El Comercio: 10 de los Mejores Bares para el After Office. 15.09.2016. https://elcomercio.pe/vamos/peru/10-mejores-bares-miraflores-afteroffice- 278600 ?foto $=6$

- Eka Bar

Alcance: Cuenta con presentaciones acústicas. Es un bar con una ambientación especialmente para grupos de amigos que deseen conversar tomando tragos.

Servicios Adicionales: Mantiene una propuesta arquitectónica fundamentada en el art nouveau, art deco y gaudi (ver Figura 5).

Razón Social: INVERSIONES PRO DIVERSION SAC

No. RUC: 20504389457

Localización: Calle Esperanza 375, Miraflores

Horario: Lun a Jue 07pm a 01am / Vie y Sab desde 07 pm a 3.00am 


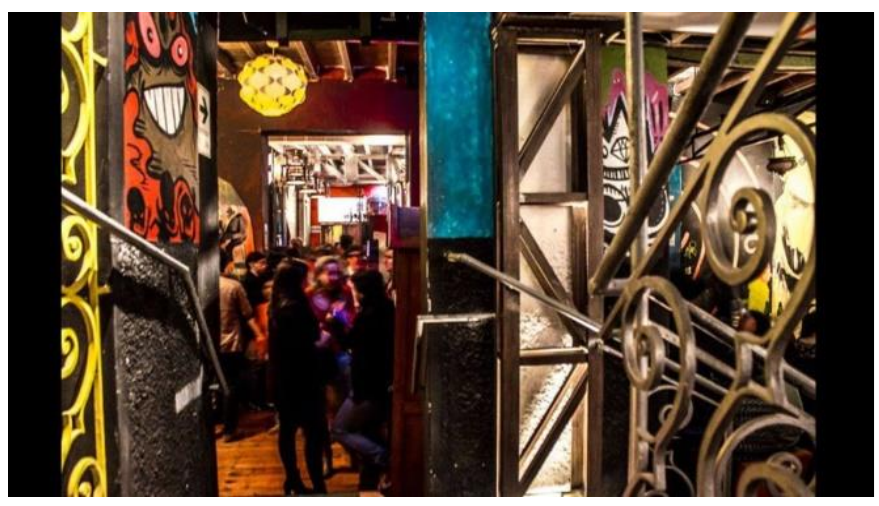

Figura 5. Eka Bar. Tomado de Diario El Comercio: 10 de los Mejores Bares para el After Office. 15.09.2016. https://elcomercio.pe/vamos/peru/10-mejores-bares-miraflores-afteroffice- 278600 ?foto $=6$

- Ayahuasca Resto Bar

Alcance: Considerado uno de los mejores bares de Barranco, tiene una gran variedad de tragos en especial los piscos (de diversas frutas). El local es una casona antigua remodelada en donde la arquitectura, decoración e iluminación que se puede apreciar es muy buena. Servicios Adicionales: Además de los tragos puedes pedir comida como picarones, anticuchos, brochetas, etc (ver Figura 6).

Razón Social: RESTAURANTEUR S.A.C.

No. RUC: 20511918546

Localización: Prolongación San Martín 130 Barranco

Horario: Lun a Jue 08pm a 01am / Vie y Sab desde 08 pm a 3.00am

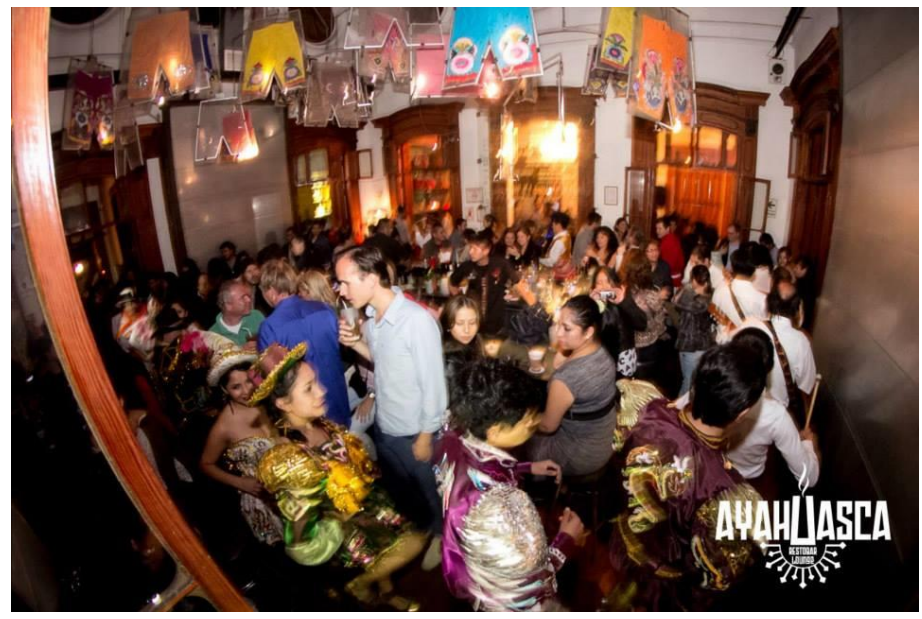

Figura 6. Ayahuasca Resto Bar. Recuperado de: https://diversionenlima.com/ayahuascarestobar-barranco/

- Barbarian 
Alcance: Es uno de los bares más populares y reconocidos por la producción propia de su cerveza artesanal con variedad de sabores, así como también, cuenta con piqueos de lo más contundente. Su fortaleza es que cuenta con una planta donde produce más de 13000 litros de cerveza artesanal al mes (ver Figura 7).

Servicios Adicionales: También vende cervezas artesanales de otras marcas que no son propias.

\section{Razón Social: J. Y R. BARBARIAN S.A.C}

No. RUC: 20544879244

Localización: Pedro de Osma 144, Barranco

Horario: Lun a Jue 07pm a 01am / Vie y Sab desde 07 pm a 2.30am

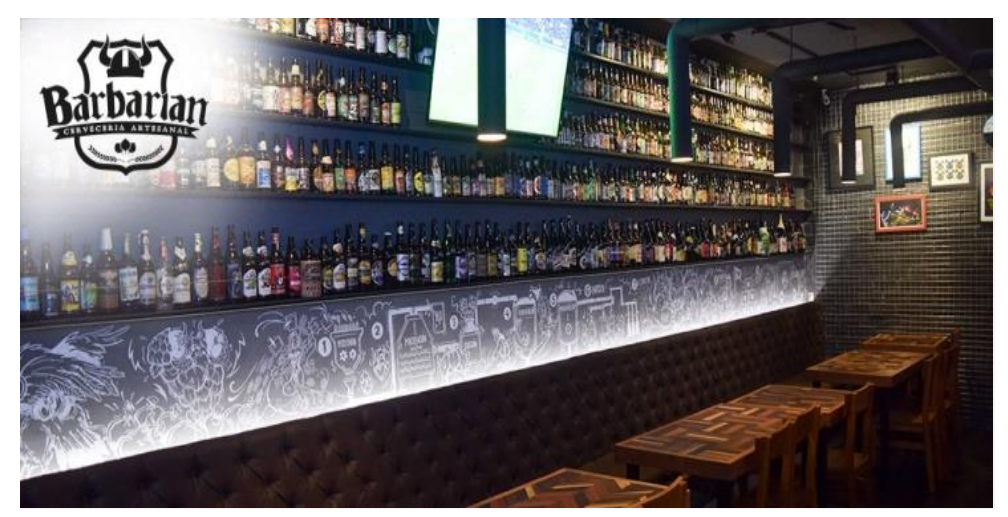

Figura 7. Barbarian. Tomado de TripAdvisor: "Muro con más de 400 botellas de todo el mundo". Recuperado de: https://www.tripadvisor.com.pe/LocationPhotoDirectLinkg294316-d12562793-i275149571-BarBarian_Barranco-Lima_Lima_Region.html

- Bar "La Noche de Barranco"

Alcance: Hace más de 20 años se abren las puertas de esta antigua casona por primera vez con el espíritu de ofrecer un espacio para la conversación, música y tragos (ver Figura 8).

Servicios Adicionales: ofrece conciertos todos los días, principalmente de bandas nacionales Razón Social: LA NOCHE DE BARRANCO EIRL

No. RUC: 20510113170

Localización: Sánchez Carrión 199, Barranco

Horario: Lun a Jue 07pm a 03am / Vie y Sab desde 07 pm a 2.30am 


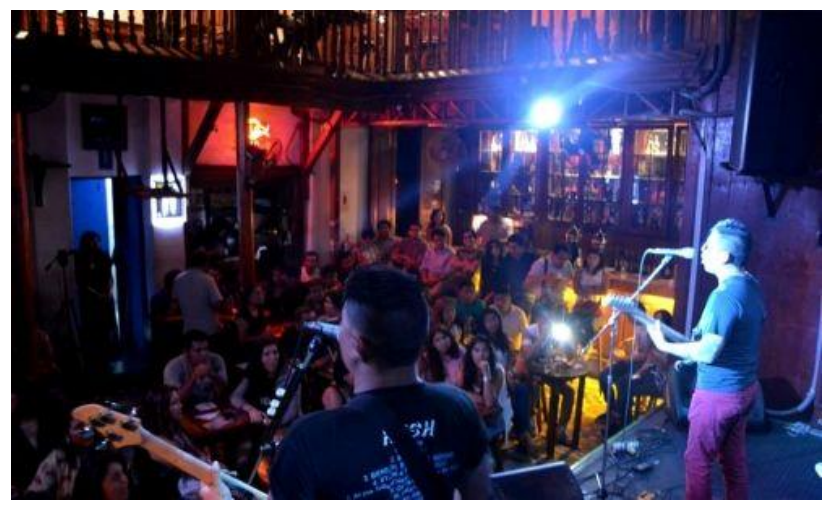

Figura 8. Bar La Noche de Barranco. Tomado de Diario El Comercio "Sigue la ruta de Bares en Lima", 17.02.2018, Recuperado de https://elcomercio.pe/vamos/planes-sigue-ruta-bareslima-noticia-497798

- Barranco Beer Company

Alcance: Es una cervecería-bar, donde se sirve la cerveza del tanque al vaso chopp, sin filtrar.

Ofrece dos tipos de cervezas: la 50/Fifty Lager, dorada, ligera y refrescante; y la Bulls Ale, roja e intensa en sabor y olor (ver Figura 9).

Servicios Adicionales: También preparan choptails (cocteles a base de cerveza), acompañados de piqueos

Razón Social: BARRANCO BEER COMPANY S.A.C

No. RUC: 20552874651

Localización: Av. Almirante Grau Nro. 308 Barranco

Horario: Lun a Jue $12 \mathrm{~m}$ a $01 \mathrm{am}$ / Vie y Sab desde $12 \mathrm{~m}$ a 3.00am

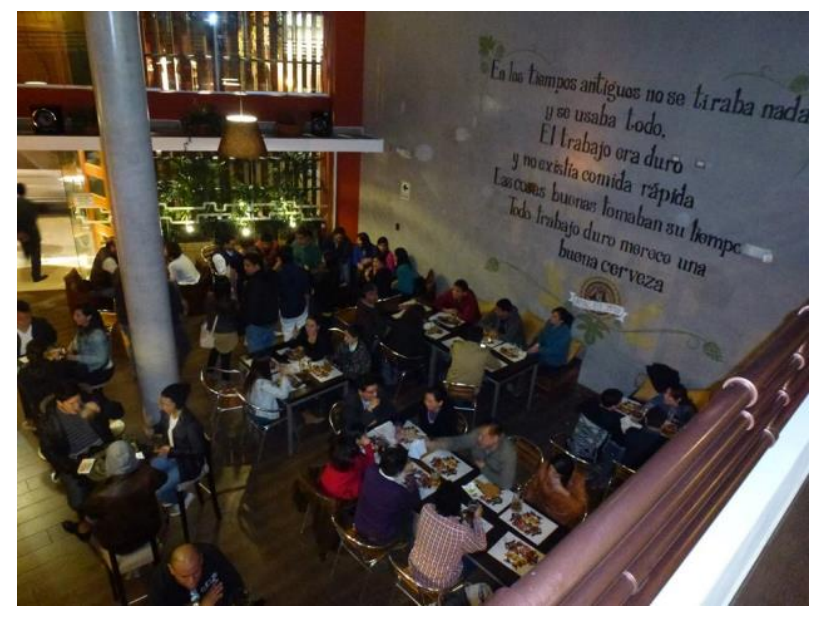

Figura 9. Barranco Beer Company. Tomado de Emarket.pe: Restaurantes y Bares. Recuperado de: https://emarket.pe/restaurantes/barranco-beercompany/e/fotos/?id=0000007703 
- Bar "Posada del Ángel I"

Alcance: Espacio rústico y pintoresco con cálidas luces y full confort, decorado con antigüedades y vitrales Música en vivo ideal para conversar y relajarse (ver Figura 10). Servicios Adicionales: Se cuenta con una variada carta de piqueos y cócteles nacionales e internacionales. Atención personalizada con mozos capacitados en los productos que ofrece. Razón Social: POSADA DEL ANGEL I II III S.A.C

No. RUC: 20513558652

Localización: Prolong. San Martin Nro. 157

Horario: Lun a Jue 07pm a 01am / Vie y Sab desde 07 pm a 2.30am

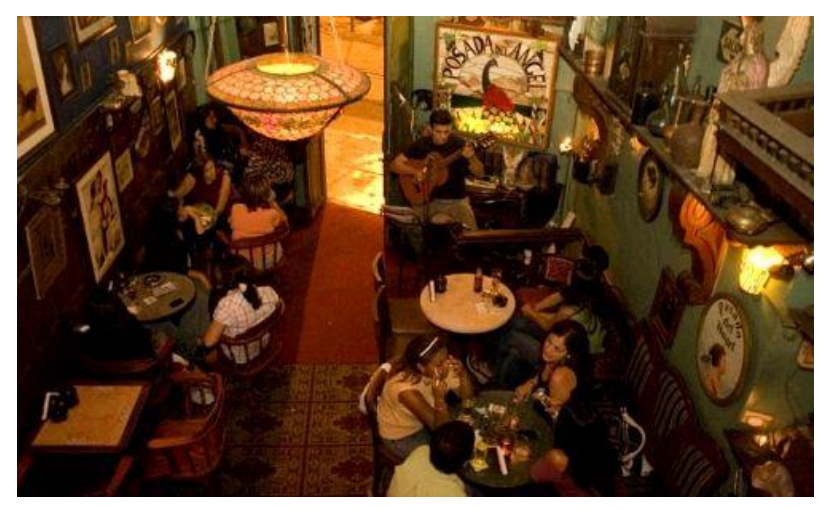

Figura 10. Bar Posada del Angel 1. Tomado de Diario El Comercio: 5 de los mejores bares para una cita romántica. 18.08.2016. Recuperado de:

http://archivo.elcomercio.pe/vamos/peru/5-mejores-bares-tener-cita-romantica-lima-noticia$1924903 / 7$

- Bar La Posada del Pisco

Alcance: Es un Bar de Tapas y Restaurante. La Posada del Pisco está ubicado en el distrito bohemio y cultural de Barranco, y ofrece variadas opciones, cuenta con ambientes diversos ambientados como casa para darle un sentido acogedor (ver Figura 11).

Servicios Adicionales: La carta de bebidas relacionadas principalmente con el pisco se puede combinar con piqueos, pastas y también las pizzas de estilo español que preparan de manera artesanal. La música es variada pero siempre con un elevado volumen.

Razón Social: La Posada del Pisco Tradición Peruana E.I.R.L

No. RUC: 20552848145

Localización: Av. Pedro de Osma 214 | Barranco

Horario: Lun a Jue 07pm a 01am / Vie y Sab desde 07 pm a 2.30am 


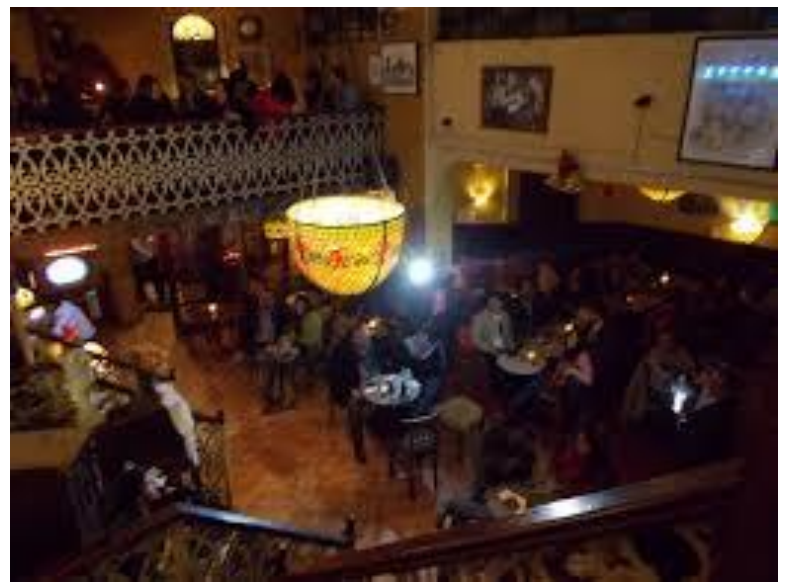

Figura 11. Bar La Posada del Pisco. Tomado de Diario El Comercio "Sigue la ruta de Bares en Lima", 17.02.2018, Recuperado de https:/elcomercio.pe/vamos/planes-sigue-ruta-bareslima-noticia-497798

\subsection{Tendencias de la industria (crecimiento, inversiones)}

Según INEI (2017), en el Perú el número de empresas que se han creado y se encuentran activas en el año 2017 asciende a 2 303,662 unidades, habiendo crecido en 8.4\% respecto a finales del 2016, lo que representa aproximadamente la creación de 283892 nuevas empresas durante el año 2017 (ver Tabla 1 y Figura 12).

Tabla 1

Perú: Stock y Variación Neta de Empresas por Trimestre, 2015-2017

\begin{tabular}{|c|c|c|c|c|c|c|c|c|c|c|c|c|}
\hline \multirow{2}{*}{ Concepto } & \multicolumn{4}{|c|}{2015} & \multicolumn{4}{|c|}{2016} & \multicolumn{4}{|c|}{2017} \\
\hline & I Trim & II Trim & III Trim & IV Trim & I Trim & II Trim & III Trim & IV Trim & I Trim & II Trim & III Trim & IV Trim \\
\hline Stock al inicio del período & $1,883,531$ & $1,942,600$ & $1,972,725$ & $2,011,755$ & $2,042,992$ & $2,084,725$ & $2,085,499$ & $2,108,295$ & $2,124,280$ & $2,177,500$ & $2,216,081$ & $2,258,741$ \\
\hline Altas & 55,081 & 68,116 & 65,473 & 62,581 & 63,658 & 63,940 & 70,390 & 64,849 & 68,746 & 67,976 & 78,754 & 68,416 \\
\hline Bajas & $-32,722$ & $-39,845$ & $-44,571$ & $-45,393$ & $-47,097$ & $-47,391$ & $-46,740$ & $-49,588$ & $-26,590$ & $-39,322$ & $-47,506$ & $-34,718$ \\
\hline Otros Ingresos y salidas & 36,710 & 1,854 & 18,128 & 14,049 & 25,172 & $-15,775$ & -854 & 724 & 11,064 & 9,927 & 11,412 & 11,223 \\
\hline Variacion neta & 22,359 & 28,271 & 20,902 & 17,188 & 16,561 & 16,549 & 23,650 & 15,261 & 42,156 & 28,654 & 31,248 & 33,698 \\
\hline Stock al final del periodo & $1,942,600$ & $1,972,725$ & $2,011,755$ & $2,042,992$ & $2,084,725$ & $2,085,499$ & $2,108,295$ & $2,124,280$ & $2,177,500$ & $2,216,081$ & $2,258,741$ & $2,303,662$ \\
\hline
\end{tabular}

Nota. Tomado de Directorio Central de Empresas y Establecimientos (p. 56), por el Instituto Nacional de Estadística e Informática, 2018, Lima Perú. Copyright 2018 por el INEI. 


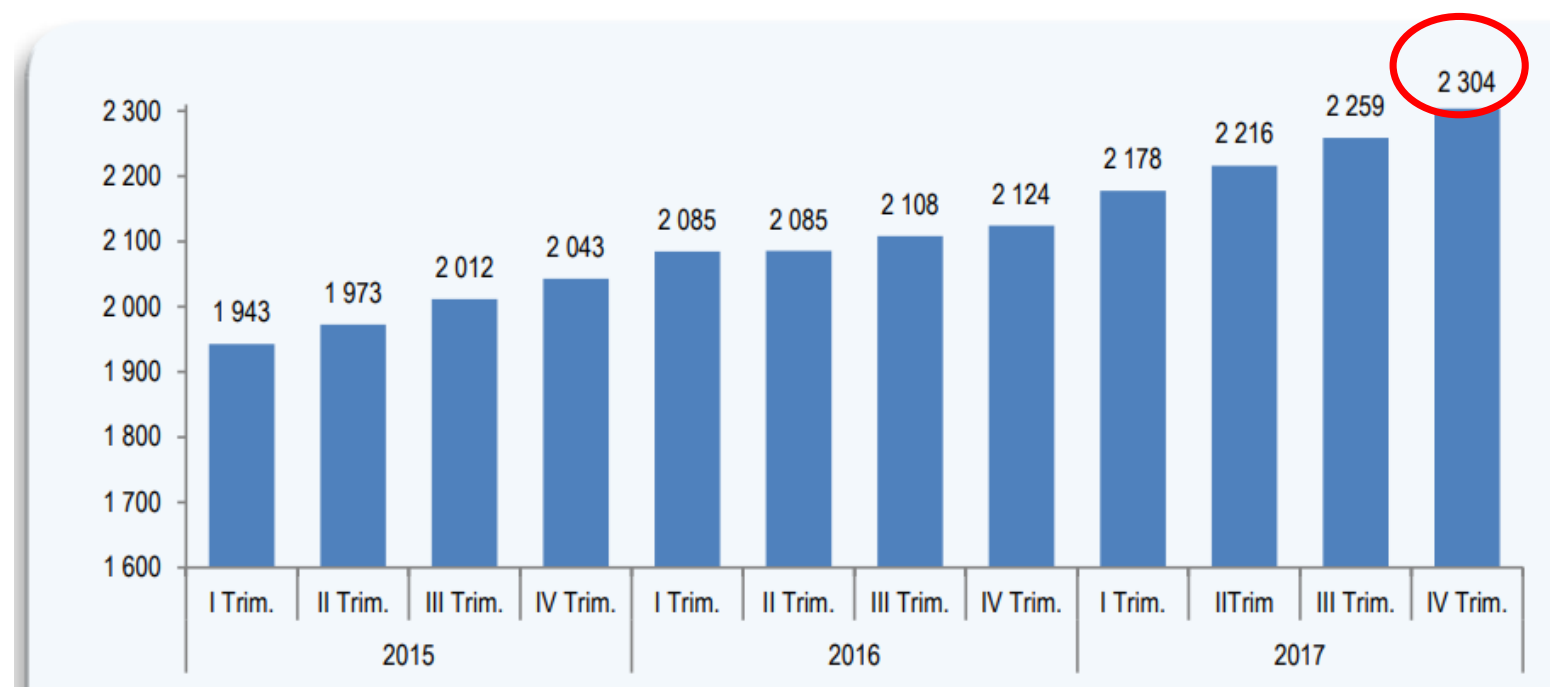

Figura 12. Perú Stock de empresas por Trimestre. Tomado de "Directorio Central de Empresas y Establecimientos" por el Instituto Nacional de Estadística e Informática, 2018, Lima Perú. Copyrigtht 2018 por el INEI.

Representando al sector en estudio, la actividad de servicios de bebidas y comidas, la cantidad de 179,387 unidades de negocio lo que significa aproximadamente el $8 \%$ del total de empresas existentes en Perú (ver Tabla 2).

Asimismo, se ha podido observar que en el año 2017 se crearon 26442 empresas relacionadas a la actividad de servicio de comidas y bebidas; así como se dieron de baja la suma de 7777 empresas, representando un 29\% de grado de siniestralidad empresarial en este sector, manteniéndose ese promedio desde años anteriores (Ver Tabla 3).

No obstante, entre las actividades económicas de mayor crecimiento respecto a la creación de empresas, es la de Servicio de Comidas y Bebidas la que ocupa un tercer lugar con un promedio de crecimiento del $9.9 \%$ en al año 2017, siendo la de Comercio al por Mayor y Menor $38.1 \%$ y la de Otros Servicios $14.4 \%$ (actividades inmobiliarias, administración pública, enseñanza, salud, salones de belleza, actividades artísticas, de entretenimiento y otras actividades de servicios personales) la que ocupa el primer y segundo lugar respectivamente

Por lo general, la concentración de empresas que se crean cada año se encuentran geográficamente ubicadas en el provincia de Lima representando un $44.0 \%$ del total a nivel nacional, lo que indica de cada 100 empresas son 44 que se originan en la provincia de Lima, siguiéndole en orden de importancia Arequipa (6.1\%), La Libertad (5.7\%) y Piura (4.3\%). Por lo tanto, de 179387 empresas (restaurantes y bares) que existen a nivel nacional la cantidad de 78930 han sido creadas en la Provincia de Lima (ver Figura 13). 
Tabla 2

Perú: Stock de empresas. Año: 2017

\begin{tabular}{lr}
\hline \multicolumn{1}{c}{ Actividad económica } & Stock \\
\hline Agricultura, ganaderia, silvicultura y pesca & 38,877 \\
Explotacion de minas y canteras & 18,895 \\
Industrias manufactureras & 183,327 \\
Construccion & 63,428 \\
Venta y reparación de vehículos & 63,591 \\
Comercio al por mayor & 208,866 \\
Comercio al por menor & 766,207 \\
Transporte y almacenamiento & 120,517 \\
Actividades de alojamiento & 24,266 \\
Actividades de servicio de comidas y bebidas & 179,387 \\
Informacion y comunicaciones & 54,408 \\
Servicios prestados a empresas & 237,484 \\
Salones de belleza & 32,554 \\
Otros servicios & 311,855 \\
\hline
\end{tabular}

Nota. Tomado de Directorio Central de Empresas y Establecimientos (p. 89), por el Instituto Nacional de Estadística e Informática, 2018, Lima Perú. Copyrigtht 2018 por el INEI.

Tabla 3

Perú: Número de Altas y Bajas (Empresas)

\begin{tabular}{|c|c|c|c|}
\hline Año 2017 & Altas & Bajas & $\%$ \\
\hline Trim 1 & 6,465 & 1,637 & $25.32 \%$ \\
\hline Trim 2 & 6,441 & 2,043 & $31.72 \%$ \\
\hline Trim 3 & 7,336 & 2,291 & $31.23 \%$ \\
\hline Trim 4 & 6,2 & 1,806 & $29.13 \%$ \\
\hline Total & 26,442 & 7,777 & $29.41 \%$ \\
\hline
\end{tabular}

Nota. Tomado de Directorio Central de Empresas y Establecimientos (p. 94), por el Instituto Nacional de Estadística e Informática, 2018, Lima Perú. Copyrigtht 2018 por el INEI. 


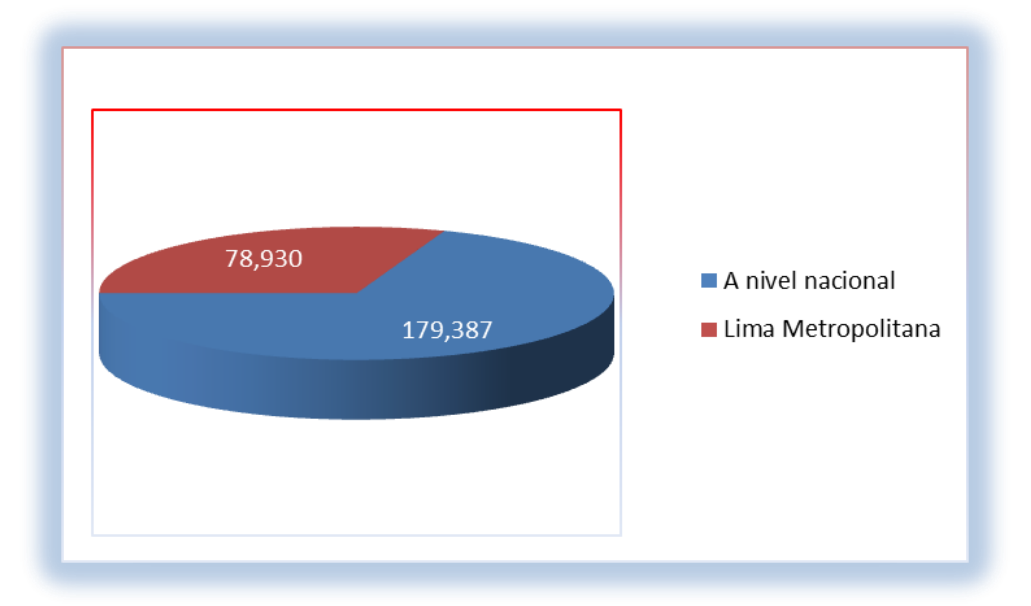

Figura 13. Empresas a nivel nacional / Empresas Lima Metropolitana 2017. Tomado de "Directorio Central de Empresas y Establecimientos" por el Instituto Nacional de Estadística e Informática. 2017.

Sumado a lo anterior, la composición de organización jurídica de las empresas de la Actividad de Comidas y Bebidas, el $66.1 \%$ pertenece a Personas Naturales, el 16.1\% como Sociedades Anónimas, 11.0\% como Empresa Individual de Responsabilidad Ltda., y el 6.8\% distribuido en Asociaciones y Otros.

Finalmente, el promedio mensual respecto a generación de empresas que se ha venido dando en el periodo 2016 y 2017, la actividad de Servicio de Comida y Bebida ocupa el 4to lugar con 2067 empresas por mes a nivel nacional, correspondiendo a Lima Metropolitana la cantidad de 770 empresas en promedio, y exclusivamente para el distrito de Barranco la cantidad de 49 empresas adicionales dedicadas a la actividad Servicio de Comida y Bebidas al mes.

Así como también se informó que la actividad de Restaurantes y Servicio de Bebidas tuvo un crecimiento de $1.18 \%$ en el año del 2017, respaldado por el incremento de establecimientos dedicados a la actividad: pollerías, comidas rápidas, restaurantes, café, y bares, manteniendo un crecimiento sostenido en el tiempo, siendo este reforzado especialmente por el Servicio de Bebidas con un crecimiento del 1.32\% (INEI,2018).

Para el mes de enero del año 2018, (INEI, 2018), la actividad de Restaurante y Servicio de Bebidas continuó su crecimiento a una tasa de 2.10\% (Ver Figura 14); no obstante, el Servicio de Bebidas tuvo un negativo crecimiento de $-0.74 \%$ debido a una baja en el consumo en los establecimientos de juguerías, cafés, y bares, a pesar de haberse registrado mayor actividad en remodelación y arreglos de locales así como un aumento de promociones. En visita con expertos, nos comentaron, y coincide con la afirmación anterior, que las 
actividades son estacionales y sus bajas se reflejan justamente en el mes de enero y agosto, luego de un alta en los meses de diciembre y julio, respectivamente.

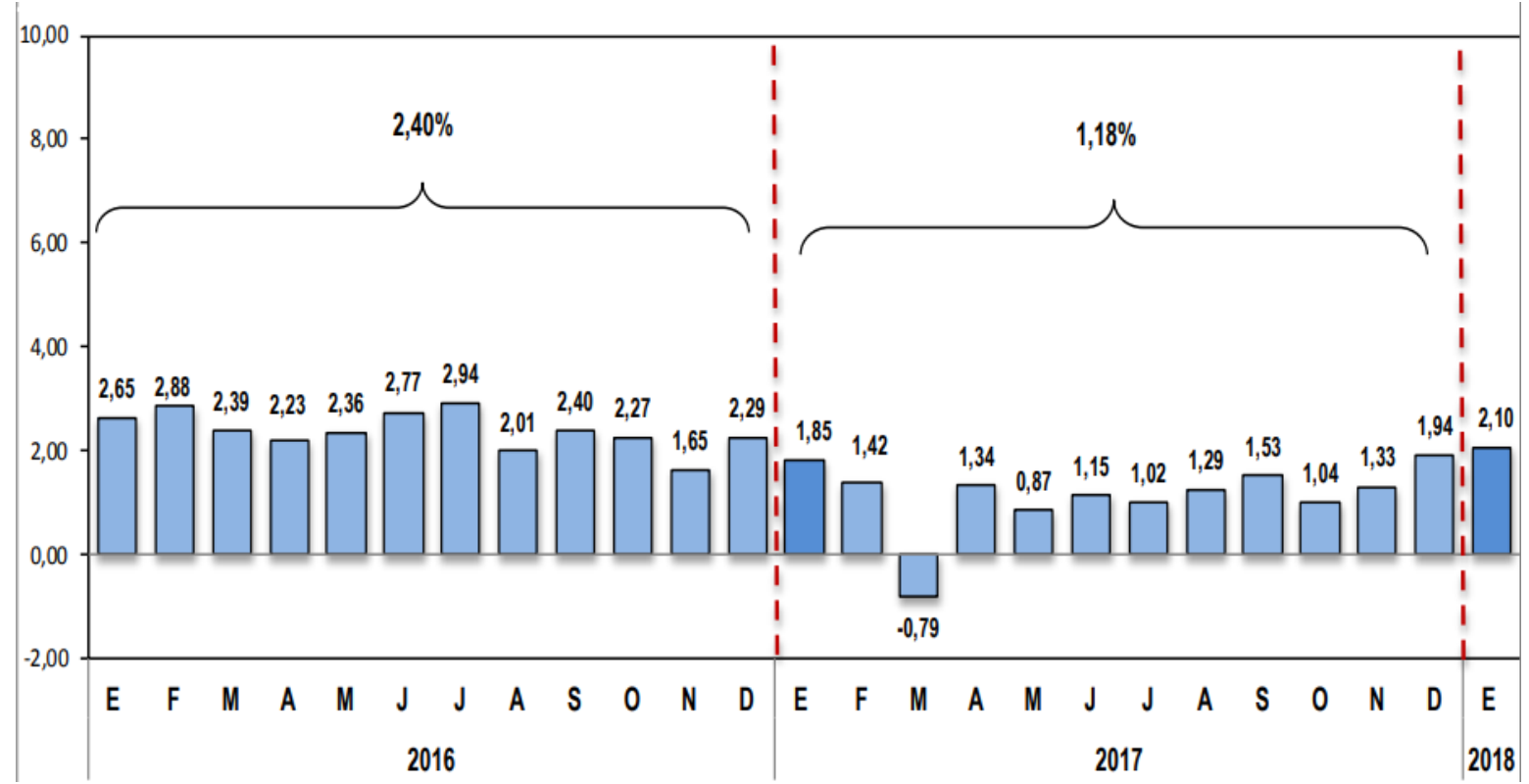

Figura 14. Producción del Sector Restaurantes. Tomado de "Encuesta Mensual de Restaurantes” por el Instituto Nacional de Estadística e Informática-INEI. 2018.

Según Cámara de Comercio de Lima (CCL, 2017) y a través del presidente del Subcomité de Gastronomía, Nicolai Stakeeff, indicaba en ese entonces que muchas personas y empresas en el país apuestan por el negocio de comidas y bebidas, a pesar que del total de establecimientos abiertos en un mes, casi un 50\% cierra antes de los 90 días, ello por una falta de capacitación y conocimiento de lo que significa el rubro. Estas cifras no han cambiado y se mantienen hasta la actualidad tal como se ha demostrado en párrafos anteriores.

Asimismo, la tendencia de la actividad de servicio de bebidas, especialmente los bares, según Diaz (2015), reside en la aplicación de la Coctelería Conceptual, técnicas que se viene aplicando en bares de primer nivel, y consta de encontrar procesos que hace que la creación de cada producto tenga identidad, basado en la combinación de sabores y aromas con el añadido de conocer la historia y cultura de los ingredientes que acompaña a cada coctel preparado, haciendo que todo lo anterior se convierta en una nueva propuesta para el que visita los establecimientos respectivos.

Finalmente, según El Comercio (2013) las tendencias que provienen del extranjero y aterrizan en los bares peruanos están relacionadas a la técnicas de tener su propia producción de hielos con formas, sabores, y aromas para la creación de sus productos cocteleros; personalizar los cocteles de acuerdo a las exigencias de cada cliente; una mayor interacción 
entre el bartender y el consumidor; utilizar ingredientes extremos como fresa y canela, naranja y pimienta; o aplicar técnicas de coctelería molecular (nitrógeno, brulee, carbonatación, espuma, gelificación).

\subsection{Análisis Estructural del Sector Industrial}

Para explicar el análisis estructural del Sector Industrial en estudio, se debe de conocer las fuerzas que influyen en su competitividad así como las causas que la provocan, como Porter (2009) lo establece, y en base a ello dar un diagnóstico que permita diseñar la estrategia correspondiente de como poder enfrentar de manera anticipada a la competencia (Ver Figura 15). Esta comprensión estructural de la industria también es fundamental para tener una visión de lo atractivo que puede ser y permita lograr un posicionamiento efectivo, así como tomar las acciones en beneficio de la propia empresa acompañada de aspectos cruciales para emprender un negocio sostenible.

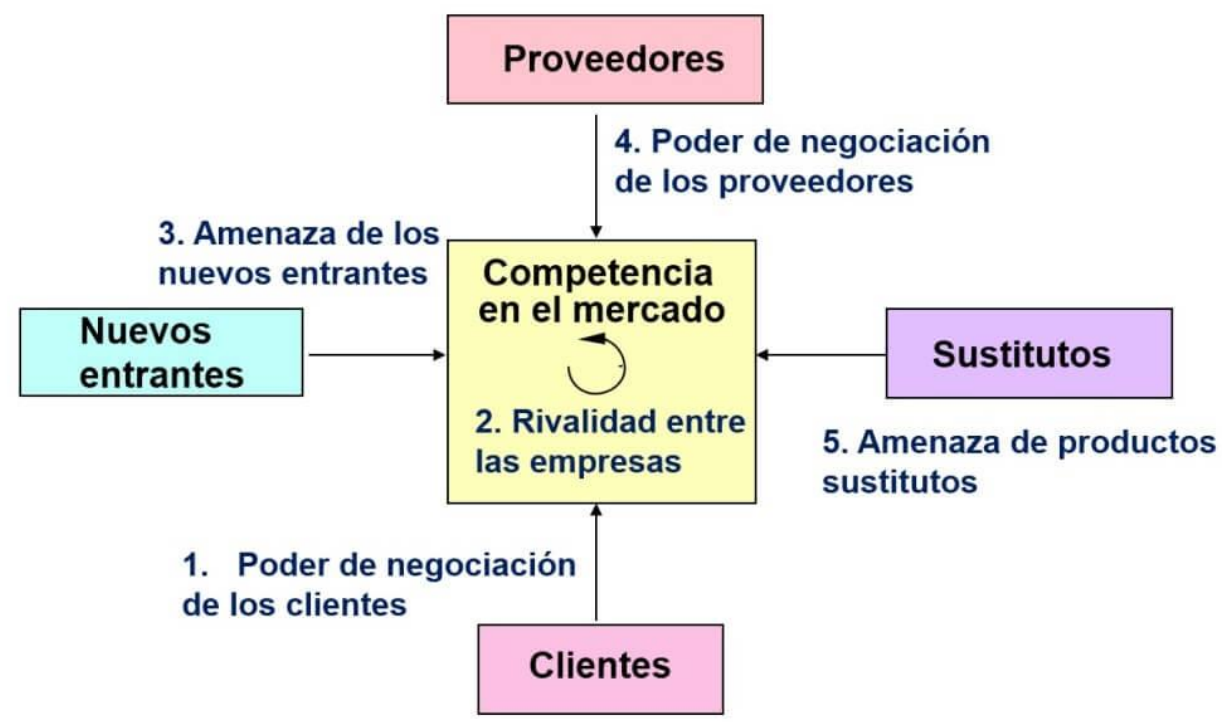

Figura 15. Las Cinco Fuerzas de Porter. Tomado de Las 5 Fuerzas de Porter - Clave para el Éxito de la Empresa. Santiago por Riquelme Leiva, Matias (2015, Junio)., Chile. Recuperado de http://www.5fuerzasdeporter.com/

1. Rivalidad entre competidores existentes

Esta fuerza mide la intensidad de la rivalidad entre los competidores que ya se encuentran en el mercado por la lucha constante de mejorar su posicionamiento frente a diferentes tácticas empleadas.

Por lo tanto, existe alta rivalidad entre competidores cuando:

a. Existen muchos competidores y todos tienen similares productos o servicios. 
b. El mercado crece muy despacio lo que dificulta aumentar el market share.

c. Las empresas mantienes costos fijos elevados lo que hace que tengan que cumplir con mínimos de ventas

d. Las empresas tienen servicios similares y difíciles de ser diferenciados

En la actividad de Servicio de Bebidas se considera competidores a aquellas empresas que se encuentran actualmente en el mercado y son una alternativa más de decisión para el disfrute de los productos y servicios similares que se ofrecerá, se puede indicar que el grado de rivalidad es elevado lo que hace que los beneficios sean mínimos en relación a la inversión, como consecuencia del grado de réplica y poca diferenciación observada, elevando el nivel de riesgo de los participantes empresarios. Además, el tener costos fijos elevados por el alto precio de alquiler que tiene que asumir cada establecimiento en zonas como Barranco y Miraflores, obliga a tener que cumplir con cuotas de ventas mínimas, haciendo más aguerrido la competencia entre ellas.

2. Amenaza de servicios sustitutos

Entendiendo como servicio sustituto a aquel servicio que se ofrece con diferentes características, sin embargo, satisfacen la misma necesidad. Entonces, se dice que existe amenaza de este tipo cuando:

Los servicios sustitutivos limitan el potencial de rendimiento expresado en rentabilidad de un sector al colocar un límite superior en la colocación de precios

Para el comprador, el coste de pasarse a un servicio sustituto es muy bajo

Por lo tanto, el grado de amenaza es alto (lo que hace poco atractivo al sector) cuando no existen barreras de entrada, y el grado de amenaza es bajo cuando tenemos un bajo costo de cambio de proveedor del servicio que también satisface la misma necesidad.

Para el proyecto se identifica qué los posibles servicios en estudio se encuentra en:

- Cafés, como por ejemplo, Café Cultural

- Peñas, como por ejemplo, La Candelaria

- Discoteca, como por ejemplo, Barranco Bar

- Restaurantes Convencionales, como por ejemplo, Rústica

- Lugares de Socialización, como por ejemplo, Club Lima

- Lounge, como por ejemplo, Hotel Miraflores Park

Entre los que destaca por su grado de importancia son los cafés temáticos y pueden ser considerados como sustitutos de grado Medio

3. Poder de negociación de los compradores 
Cuando los clientes tienen poder se encuentran en la posibilidad de exigir mayores beneficios, precios menores, o mayores exigencias de calidad haciendo que haya mayor competencia entre los actores del sector en estudio. Esto se ve más pronunciado con compradores que tienen una elasticidad precio elevada, lo que hace que se les vea más fortalecido y con mayor poder de negociación.

Entonces, el comprador tiene poder de negociación cuando:

a. Existen poco compradores o tienen capacidad de tomar una exclusiva parte del servicio

b. El servicio que toma el cliente tiene especificaciones que es relevante e influye en el nivel de ingresos para la empresa.

c. El costo de cambio de proveedor tiene un costo muy bajo.

d. La misma calidad del servicio es exigida a menores precios.

En el presente caso de estudio, se observa que el poder de negociación de los clientes es moderado lo que hace medianamente atractivo al sector en este aspecto, esto debido a los bajos costos de cambio y la calidad en el servicio exigida siempre a menores precios. Los clientes del sector Alimentos y Bebidas tiene como características, la poca posibilidad de agruparse los clientes y presionar en relación a los precios; así como tampoco se encuentra con consumidores importantes que sean referentes frente a otros consumidores. Sin embargo, el panorama cambia cuando las ventas institucionales toman representación haciendo que exista poder de negociación por el cliente relacionado con las especificaciones del pedido.

4. Poder de negociación de los proveedores

Por lo general el poder de negociación de los proveedores frente a las empresas es casi nula, dado que el poder lo tienen las empresas debido a la capacidad de pagar precios mayores e influir en la calidad o imponer condiciones en ventaja para ellos, de tal manera que ocasione una disminución del excedente del proveedor y le permita mayores indicadores de rentabilidad a la empresa

Por lo tanto, de acuerdo con (Weinberger, 2009) se puede decir que existe poder de negociación de los proveedores cuando:

a. Debido a altas barreras de entrada existen pocos proveedores

b. Cuando nos existe bienes sustitutos que brinden la misma satisfacción o tengan las mismas especificaciones

c. Cuando la empresa, en particular, no es un actor importante para el proveedor.

d. Cuando el proveedor sabe de su importancia en el desarrollo cotidiano de la empresa. 
e. Cuando la calidad del servicio o condiciones adicionales son difíciles de ser reemplazadas.

En el caso de estudio el poder de negociación que tienen los proveedores es bajo, especialmente los proveedores de insumos que se encuentra en los mercados tradicionales lo que hace atractivo al sector, sin embargo, esta condición de bar grado cero alcohol (para el proyecto en estudio) obliga a la precaución de tener proveedores de frutas con abastecimiento continuo a pesar de la estacionalidad de las materias primas. Como, por ejemplo: fresa, lúcuma, granadilla, granada, etc.

Por el contrario, con una cartera de proveedores cada vez más grande se puede disminuir esta leve dependencia. Lo mismo con el personal técnico de mantenimiento de los equipos que se necesiten, para mantener una producción continua.

5. Amenaza de competidores potenciales

La amenaza de competidores potenciales está influenciada directamente con las barreras de ingreso que existen y permiten un tráfico de altas de empresas relacionadas al sector en estudio, así como también, marca una frontera frente a la posibilidad de generación de rentabilidad frente a altas amenazas.

Entonces se puede afirmar que existe amenaza de competidores potenciales cuando:

a. Las empresas que se encuentran operando no manejan altas economías de escala

b. No es muy difícil la creación del servicio y tenga la oportunidad de ser diferenciado

c. Cuando la posibilidad de inversión es viable debido a la proporción o a la posibilidad de acceder a créditos.

d. Si el cliente No tiene que incurrir en costos adicionales para consumir el servicio.

Es de grado Medio por las barreras de entrada legales de permisos y licencias, principalmente, que se presentan para ingresar al mercado, así como de la factibilidad de requerimiento de capital para materializar el proyecto, y los costos independientes de la escala. Todo lo anterior explica, que no existe una amenaza continua de nuevos competidores pero si una atención permanente a la situación que se puede presentar por actores para tomarse una cuota del mercado.

A continuación, en las siguientes figura y tabla (Ver Figura 16 y Tabla 4), se muestra en consolidado las ponderaciones aplicadas a cada uno de los factores de las fuerzas que influyen en el sector. 


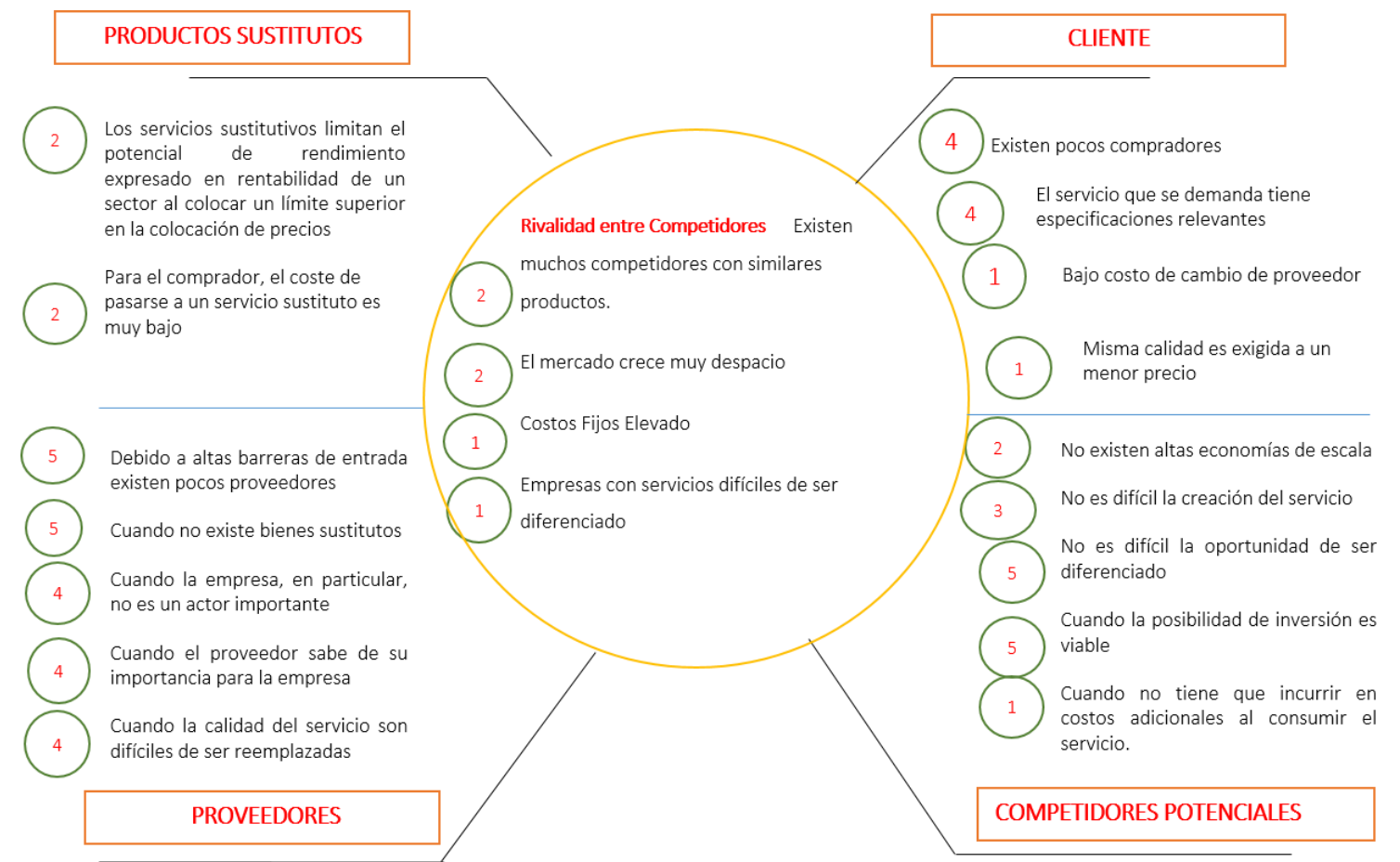

Figura 16. Las Cinco Fuerzas de Porter para el Sector de Servicios y Bebidas. Tomado de Villajuana, Carlos. Gestión estratégica integral. Lima, Perú: Ed. Villajuana Consultores SAC. 2003. 
Tabla 4

Análisis de Atractividad de Porter

\begin{tabular}{|c|c|c|c|c|c|c|}
\hline \multicolumn{7}{|c|}{ ANALISIS DE ATRACTIVIDAD } \\
\hline \multirow{3}{*}{ FACTORES COMPETITIVOS } & \multicolumn{5}{|c|}{ ATRACTIVIDAD } & \multirow{3}{*}{ CONCEPTO } \\
\hline & $\begin{array}{l}\text { muy } \\
\text { bajo }\end{array}$ & bajo & medio & alto & $\begin{array}{c}\text { muy } \\
\text { alto }\end{array}$ & \\
\hline & 1 & 2 & 3 & 4 & 5 & \\
\hline Rivalidad entre competidores & $\mathbf{x}$ & & & & & $\begin{array}{l}\text { El grado de rivalidad hace poco } \\
\text { atractivo al sector. Muchas } \\
\text { empresas con similares } \\
\text { propuestas }\end{array}$ \\
\hline Amenaza de productos sustitutos & & $\mathbf{x}$ & & & & $\begin{array}{l}\text { Manteniendo la misma } \\
\text { propuesta no es difícil el } \\
\text { ingreso de productos sustitutos }\end{array}$ \\
\hline $\begin{array}{l}\text { Poder de negociación de los } \\
\text { compradores }\end{array}$ & & & $\mathbf{x}$ & & & $\begin{array}{l}\text { Bajos costos de cambio y } \\
\text { exigencia de calidad en } \\
\text { servicio a menores precios, } \\
\text { coadyuvan al poder de decisión }\end{array}$ \\
\hline $\begin{array}{l}\text { Poder de negociación de los } \\
\text { proveedores }\end{array}$ & & & & & $\mathbf{x}$ & $\begin{array}{l}\text { Excesiva cantidad de } \\
\text { proveedores disminuye } \\
\text { completamente el poder de } \\
\text { negociación de los mismos }\end{array}$ \\
\hline $\begin{array}{l}\text { Amenaza de entrada de nuevas } \\
\text { empresas }\end{array}$ & & & $\mathbf{x}$ & & & $\begin{array}{l}\text { Barreras legales y de } \\
\text { requerimiento de capital, } \\
\text { atenúa la amenaza de nuevos } \\
\text { competidores }\end{array}$ \\
\hline
\end{tabular}

EVALUACION GENERAL

X

Nota. Adaptado de Gestión estratégica integral por C. Villajuana (2003) Ed. Villajuana Consultores SAC.

\subsection{Análisis de la Competencia.}

La competencia está compuesta por actores claves que determinan el hasta ahora buen desempeño de la actividad de servicio de bebidas, no obstante, su bajo nivel de asociatividad o de conglomeración hace que tengan bajo poder de negociación frente a potenciales competidores que tientan ingresar al mercado; originando un mayor número de actores y locales que no permitirán perder participación en el mercado (Schwalb, 2018).

\subsubsection{Empresas que ofrecen el mismo producto o servicio.}

Entre las empresas que ofrecen el mismo servicio tenemos aquellas que aunque no están dentro del mismo distrito pero son consideradas como competidores directos por la propuesta similar que ofrecen y podrían afectar de manera relevante el comportamiento del proyecto.

En visitas de observación se pudo identificar las siguientes características: 


\section{Bravo Bar}

- Dirección: Av. Conquistadores 1005 - Miraflores

- Pisos: 1

- Aforo: 100 personas

- Mesas: $50 \%$ ocupadas

- Bartenders: 02

- Música: moderna para escuchar

- Atención: Buena. Saludo cortés y de inmediato facilitan la carta. Atención rápida. Muestran proatividad

- Decoración: Moderna, iluminación tenue

- Productos: Tragos con alcohol, piqueos. Bebidas decoradas con fruta.

- Asistente (Género Masculino): 40\%

- Asistente (Género Femenino): 60\%

- Edad: $25-40$

- Estado: Acompañados

- Procedencia aparente: Peruanos

- Tiempo de permanencia aprox.: 2 horas

- Segmento aparente: NSE A y B

- Promedio por Mesa (personas): 04 a 06 personas

- Tiempo de espera (promedio): 10 a 15 minutos

Entre Copas

- Dirección: Av. Bolognesi 506 Miraflores.

- Pisos: 2

- Aforo: 100 personas

- Mesas: $60 \%$ ocupadas

- Bartenders: 02

- Show: No

- Musica: moderna para escuchar

- Atención: Atención rápida. Bastante empáticos. Muestran proactividad

- Decoración: Moderna

- Productos: Tragos con alcohol, piqueos

- Asistente (Género Masculino): 35\% 
- Asistente (Género Femenino): 65\%

- Edad: 25-45

- Estado: Acompañados

- Procedencia aparente: Peruanos

- Tiempo de permanencia aprox.: 2 horas

- Segmento aparente: NSE A y B+

- Promedio por Mesa (personas): 04 a 06

- Tiempo de espera (promedio): 10 a 15 minutos

Picas

- Dirección: Bajada de Baños 340. Barranco

- Pisos: 02

- Mozos: 08

- Anfitriona: $\mathrm{Si}$

- Barras: 02

- Aforo: 200 personas

- Mesas: $70 \%$ ocupadas

- Rotación de Mesa: 02

- Bartenders: 02

- Show: No

- Música: moderna para escuchar

- Atención: Cordial. Aunque cuando llega el pedido a la mesa no recuerda los productos a que persona corresponde.

- Decoración: Bastante moderna

- Productos: Tragos con alcohol, piqueos, tragos vírgenes, platos fuertes.

- Asistente (Género Masculino): 60\%

- Asistente (Género Femenino): $40 \%$

- Edad: $30-60$

- Estado: Acompañados

- Procedencia aparente: Peruanos

- Tiempo de permanencia aprox.: 2 horas

- Segmento aparente: NSE B+

- Promedio por Mesa (personas): 04 a 06 
- Tiempo de espera (promedio): 10 minutos

Tayta

- Dirección: Av Grau 266. Barranco

- Pisos: 01

- Mozos: 08

- Anfitriona: $\mathrm{Si}$

- Barras: 01

- Aforo: 50 personas

- Mesas: $100 \%$ ocupadas

- Rotación de Mesa: 02

- Bartenders: 02

- Show: Si

- Música: moderna

- Atención: Trato amable y empático. Se apoya en la tecnología (Tablet) para una mejor atención

- Decoración: Moderno

- Productos: Tragos con alcohol, piqueos. Tiene una carta con diseño bastante original. Bebidas con nombres temáticos.

- Asistente (Género Masculino): 70\%

- Asistente (Género Femenino): 30\%

- Edad: $30-50$

- Estado: Acompañados en grupo

- Procedencia aparente: Peruanos y Turistas

- Segmento aparente: NSE B+

- Promedio por Mesa (personas): 04 a 06

- Tiempo de espera (promedio): 07 a 10 minutos

Ayahuasca

- Dirección: Prolongación San Martín 130. Barranco

- Pisos: 02

- Mozos: 10

- Anfitriona: $\mathrm{Si}$

- Barras: 01 
- Aforo: 500 personas

- Mesas: $90 \%$ ocupadas

- Bartenders: 02

- Show:

- Música: moderna para bailar y escuchar

- Atención: Saludo al ingresar. Atención rápida. Recuerdan el pedido por persona.

- Decoración: Novo - Andina

- Productos: Tragos con alcohol, piqueos. Bebidas con nombres temáticos.

- Asistente (Género Masculino): 50\%

- Asistente (Género Femenino): 50\%

- Edad: $25-50$

- Estado: Acompañados en grupo mayor o igual de 4. Aprox.

- Procedencia aparente: Turistas y Peruanos

- Segmento aparente: NSE A y B+

- Promedio por Mesa (personas): 04 a 06

- Tiempo de espera (promedio): 10 a 15 minutos

\section{Bares Exclusivos}

Existe una categoría de bares, que no son la competencia directa por lo exclusivo de sus servicios y porque muestran propuestas de valor diferentes así como se dirigen a segmentos que no son parte del público objetivo. Sin embargo, es importante señalarlos como potenciales o indirectos en un mediano plazo, entre los que figura (Diario El Comercio, Dic 2017):

\section{El Carnaval de Aarón Díaz}

Abocado netamente a lo que se denomina la "coctelería conceptual" tomando la materia prima e insumos de diferente partes del país. Se encuentra en el distrito de San Isidro, y cuenta con un local acondicionadamente moderno, así como los menajes ha sido elaborados por Marcelo Wong, Albel Martin, y Carlos Runcie. Se diferencia por poseer un sistema de tratamiento del agua del bar hace que esta sea procesada y quede propicia para la preparación los cócteles. Elabora hielo con diseños de forma y gusto de sus piezas.

\section{Bitter Cocktail Club}

Es un bar que para ingresar se tiene que dar contraseña que se publica en redes y 
camba constantemente y debido a llo funciona a puertas cerradas. Su colección de amargos (tragos bitter) es otra de las características del lugar.

3. El Bar de Osso: de la mesa a la barra

Si bien es cierto que es más que restaurante que bar, pero su peso como bar ha tomado tanta relevancia que han mezclado sus especialidades tanto así que existen cocteles que llevan carbón activado o cavar de carbón dándole un sabor ahumado al bebida que hace que tenga un color muy especial. A ello se suma una barra artesana sostenible donde los insumos se utilizan al máximo.

Por lo tanto, dentro de las características principales y en común que cuentan los bares observados entre los días jueves y sábado, y entre las 9pm y 1am, aproximadamente, son las siguientes:

- Horario de atención oscila entre las 7pm y 1am los día jueves, y éntrelas 6pm y 3am los días viernes y sábados, y de 6pm a 11 pm los demás días de la semana.

- A determinada hora la buena conversación es interrumpida por una música estridente

- Existe marcada afluencia, pero no existe diferenciación socioeconómica aparentemente.

- $\quad$ La edad promedio es de 25 a 50 años

- Las bebidas preferidas, observadas, son Pisco Sour y tragos peruanos con insumos peruanos.

- Los piqueos se piden por unidad por cada 3 personas, aprox. Varían según local. Los preferidos son las bolitas de yucas y anticuchitos.

- El servicio brindado no es homogéneo, y actúan de manera reactiva a los clientes (al llamado).

- Tienen productos diversificados.

- No todos presentan en su carta tragos sin alcohol (vírgenes).

\subsubsection{Participación de mercado de cada uno de ellos.}

Esta información no se encuentra como disponible. Sin embargo, en base al trabajo de campo y, especialmente, en las entrevistas realizadas a expertos, se ha identificado que el mercado de ofertantes situados en el distrito de Barranco es liderado principalmente por cuatro empresas dedicadas al servicio de bebidas, como se señala en orden de importancia a continuación:

1. Barbarian Bar

(Barranco) 
2. Ayahuasca

(Barranco)

3. Barranco Beer Company

4. La Posada del Pisco.
(Barranco)

(Barranco)

\subsubsection{Matriz de perfil competitivo.}

Según F. David (2008), los factores críticos de éxito que comprende la matriz de perfil competitivo incluye cuestiones tanto externas como internas, teniendo resultados que se refieren a fortalezas y debilidades, como se presenta a continuación:

$\begin{array}{lll}\text { Fortaleza principal } & = & 4 \\ \text { Fortaleza menor } & = & 3 \\ \text { Debilidad menor } & = & 2 \\ \text { Debilidad principal } & = & 1\end{array}$

Esta matriz (ver Tabla 5), también muestra el comportamiento de los más cercanos competidores frente a determinados criterios considerados como factores de éxito entre los que destacan: tener un concepto, promoción, precios competitivos, servicio al cliente, ubicación, marketing digital; y que, en base a la entrevista y la calificación de los factores de éxito más importantes realizado por los expertos se ha determinado el peso de cada factor en diferente intensidad, de las empresas determinadas como competidoras (Ver Apéndice 6 y 7). Para luego, proceder a una calificación cruzada entre los mismos expertos y obtener el competidor mayor ponderado (ver Apéndice 8).

Tabla 5

Matriz del Perfil Competitivo

\begin{tabular}{|c|c|c|c|c|c|c|c|}
\hline \multirow{4}{*}{ Factores De Éxito } & \multirow{4}{*}{ Peso } & \multicolumn{6}{|c|}{ Barranco } \\
\hline & & \multicolumn{2}{|c|}{ Ayahuasca } & \multicolumn{2}{|c|}{ Beer Company } & \multicolumn{2}{|c|}{ Barbarian } \\
\hline & & & PESO & & PESO & & PESO \\
\hline & & CAL. & POND & CAL. & POND & CAL. & POND \\
\hline Tener un concepto & 0.30 & 4 & 1.20 & 3 & 0.90 & 4 & 1.20 \\
\hline Servicio al cliente & 0.25 & 2 & 0.50 & 1 & 0.25 & 2 & 0.50 \\
\hline Precio Competitivo & 0.20 & 1 & 0.20 & 4 & 0.80 & 4 & 0.80 \\
\hline Promoción & 0.10 & 3 & 0.30 & 1 & 0.10 & 4 & 0.40 \\
\hline Ubicación & 0.10 & 4 & 0.40 & 2 & 0.20 & 3 & 0.30 \\
\hline Marketing Digital & 0.05 & 3 & 0.15 & 1 & 0.05 & 4 & 0.20 \\
\hline TOTAL & 1.00 & & 2.75 & & 2.30 & & 3.40 \\
\hline
\end{tabular}

Nota: Tomado de Conceptos de Administración Estratégica, por F.R. David, 2008, México.

En la tabla anterior se observa que la empresa competidora Barbarian es la que ha resaltado con el puntaje más alto, esto debido al fuerte posicionamiento presentado 
ocasionado por el producto artesanal propio que expende con el mismo nombre, frente a Barranco Beer Company que registró un puntaje menor frente a los mismo criterios especialmente en términos de promoción y marketing digital.

\subsection{Análisis del Contexto Actual y Esperado}

Para la realización del presente proyecto es necesario el análisis de las variables que se encuentran en el macro entorno y pueden influir de manera positiva, para lo cual habría que aprovecharlas; o de manera negativa, a las que habría que esquivarla con el fin de que no afecte ni altere el buen desempeño de la actividad empresarial a emprender.

La metodología empleada para revisar el entorno general es también conocida como el Análisis PEST que consiste en examinar el impacto de aquellos factores externos que están fuera del control de la empresa, pero que pueden afectar a su desarrollo futuro. (Martínez \& Milla, 2012).

\subsubsection{Análisis Político-Gubernamental.}

Los procesos políticos y la legislación influencian las regulaciones del entorno a las que los sectores deben someterse. Las legislaciones gubernamentales pueden beneficiar o perjudicar de forma evidente los intereses de una compañía. (Martínez \& Milla, 2012).

Actualmente el gobierno del Perú, tiene como política de estado incrementar la productividad a través de los actores de ecosistema empresarial y facilitar la interrelación entre ellos y habiéndole dado la responsabilidad a diferentes unidades ejecutoras pertenecientes al Ministerio de Producción, siendo uno de las principales el Programa Nacional de Innovación para la Competitividad y Productividad (Innóvate Perú).

De la misma forma en el Centro Nacional de Planeamiento Estratégico (CEPLAN, 2016), en su agenda al 2030 tienen estipulado para este sector fortalecer las actividades empresariales productivas a través de la innovación y la tecnología, y en la que se verá reflejado con las siguientes responsabilidades y objetivos:

- Empresas con tecnología productiva mejorada y estándares de calidad implementados.

- Formalización de empresas que facilite el ingreso al sistema financiero, sobre todo a las PYMES.

- Organización mejora la atención al usuario a través de la simplificación y automatización administrativa.

- Orientar a la actividad empresarial hacia el aseguramiento continuo de la calidad y el servicio al cliente. 
En ese sentido el gobierno peruano apoya el crecimiento efectivo de las empresas que se viene desarrollando en el ecosistema y confía en que para planear el futuro solo se puede lograr con una buena capacitación de los emprendedores peruanos, así como dotándolos de una serie de oferta de desarrollo empresarial, según Carlos Carrillo Mora, Vice-ministro de Mype e Industria del Ministerio de Producción (Diario La República, 2015, julio).

Por otro lado, desde la Superintendencia de Administración Tributaria (SUNAT), se proyecta para el año 2021 que el 60\% (hoy apenas es el 30\%) de las empresas de la economía peruana sea formal y tribute ante el organismo recaudador a través de incentivos tributarios; siendo una de ellas la reducción progresiva del IGV, así como simplificar el Régimen Único Simplificado RUS y el Régimen Especial de Renta RER, especialmente que favorezca la pequeña y mediana empresa. Actualmente, el IGV en el Perú es del $18 \%$ y es más elevado que el promedio de América Latina que es del 15,2\% y es la cuarta más alta en América Latina y el Caribe (ALC).

En materia tributaria, en febrero de 2018 como se observa en Figura 17, los ingresos del Gobierno Central ascendieron a S/. 7091 millones, cifra que representó un aumento real de $9,8 \%$, reflejando un ascenso de S/. 709 millones con relación al mismo mes del año anterior. Este buen resultado se explica por el resultado neto de los mayores pagos registrados tanto en tributos internos $(9,3 \%)$, como en tributos aduaneros $(7,1 \%)$ (SUNAT, 2018)

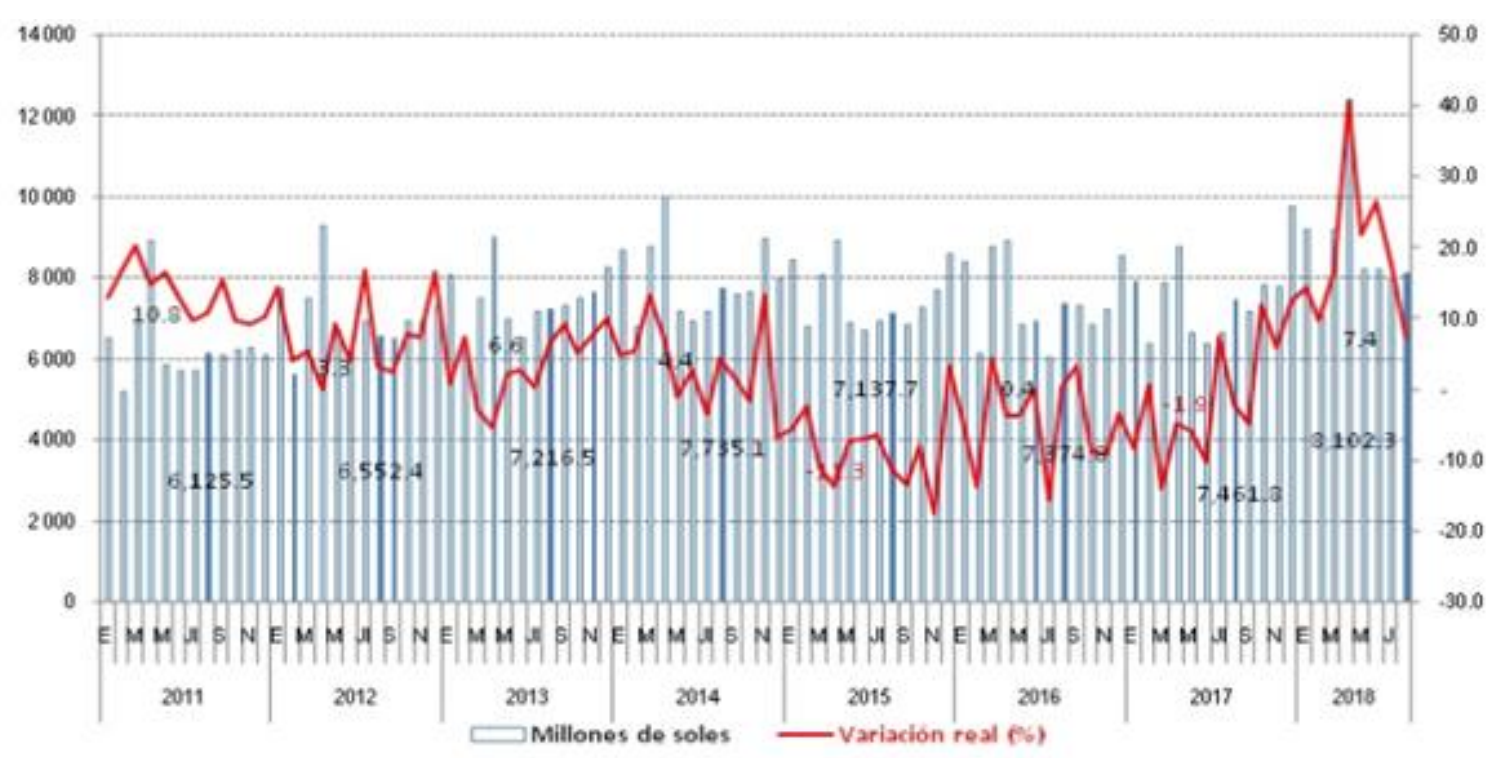

Figura 17. Ingresos Tributarios del Gobierno Central 2011-2018. Tomado de Estadísticas y Estudios por Superintendencia de Administración Tributaría - SUNAT. (2018). Recuperado de: http://www.sunat.gob.pe/estadisticasestudios/

Finalmente, y muy relacionado al concepto del proyecto en estudio, tenemos la política de seguridad vial, la misma que se detalla en el Plan Estratégico de Seguridad Vial 
2017 -2021, y en la cual se estructuran las dimensiones temáticas y de trabajo de este aspecto, concibiendo al tránsito como un sistema altamente complejo. Por ello, en coordinación con la Policía Nacional del Perú sugiere continuar con los operativos realizados de "Conductor Seguro" a través del control de velocidad y del consumo de alcohol en los conductores (Alcoholemia: Examen o prueba para detectar consumo o presencia de alcohol en la sangre de una persona. Además, considera programas de formación y educación vial con la tasa de siniestros y de accidentes de tránsito; y conforme datos proporcionados por la Policía Nacional la primera causa de accidentes de tránsito es el conducir imprudentemente en excesiva velocidad y en estado de ebriedad.

Se tiene como meta disminuir en $30 \%$ el número de siniestros de tránsito y el número de fallecidos cuya causa sea atribuida al consumo de alcohol en la conducción, al final del año 2021. El conducir estado de ebriedad está sancionado en la normativa de tránsito, sin embargo, los usuarios de las vías no acatan dicho mandato. Siendo el objetivo de las campañas la concienciación de que los usuarios tomen conciencia del riesgo al que se exponen y varíen su conducta y actitud acatando las normas de tránsito y puedan evitar ser parte de las estadísticas de accidentes de tránsito (ver Figuras 18 y 19).

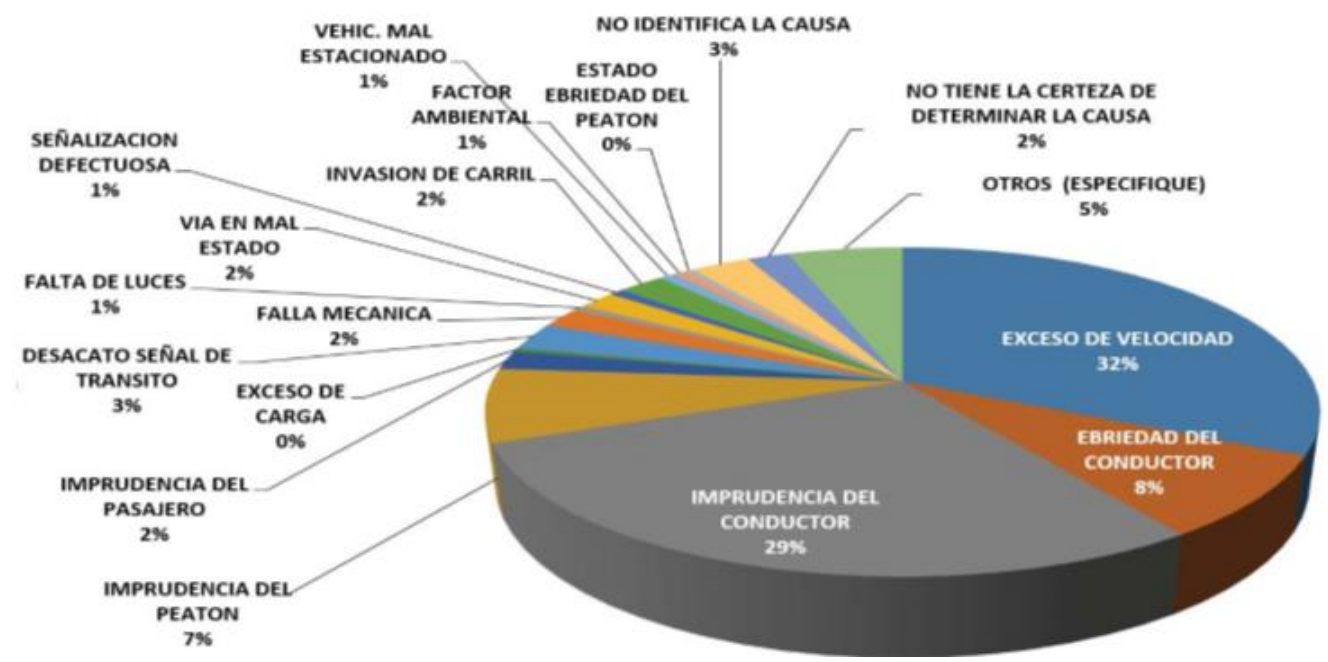

Figura 18. Causas que originan Accidentes de Tránsito. Tomado de Consejo Nacional de Seguridad Vial por Ministerio de Transportes y Comunicaciones (2017, Setiembre). 


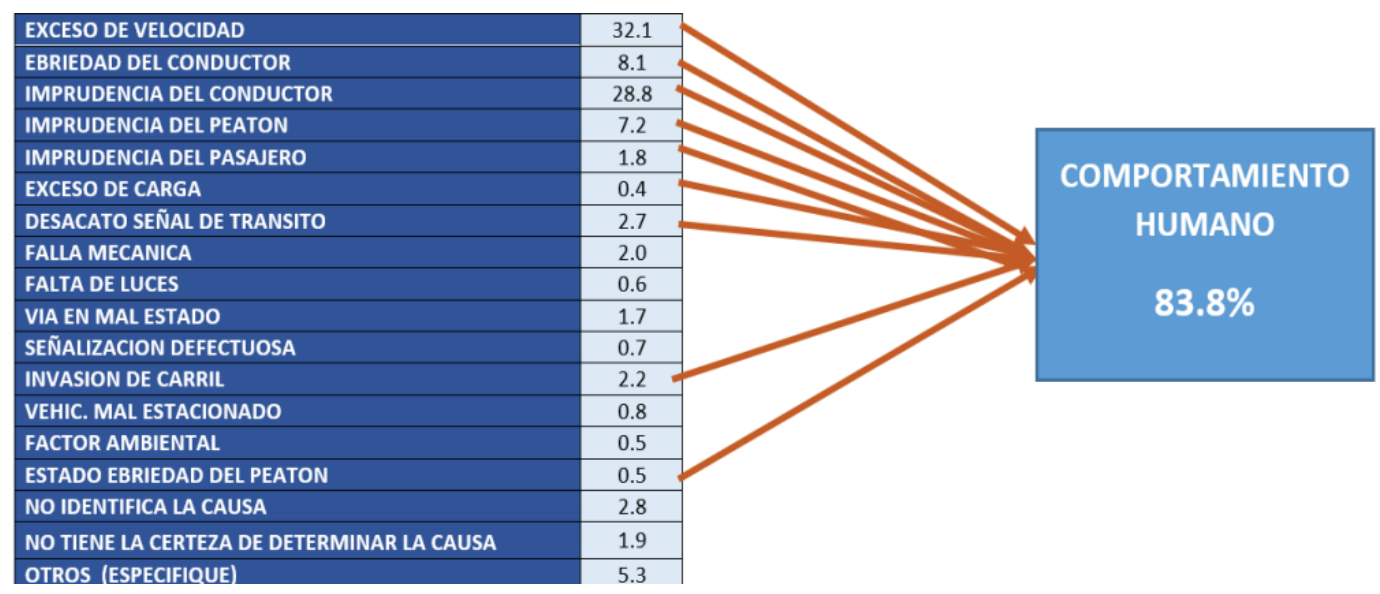

Figura 19. Accidentes de Tránsito causados por comportamiento humano. Tomado de Consejo Nacional de Seguridad Vial por Ministerio de Transportes y Comunicaciones. (2017, Setiembre).

En conclusión, se espera a través de las políticas públicas expresadas tratar de disminuir los accidentes de tránsito fatales y no fatales causados por el consumo de alcohol (Ministerio de Transportes y Comunicaciones, 2017).

\subsubsection{Análisis Económico.}

La evolución de determinados indicadores macroeconómicos puede tener influencia sobre la evolución del sector en el que opera la sociedad. Cada sociedad deberá escoger aquellos indicadores económicos cuya evolución ha tenido o puede tener una influencia importante en su entorno y, por lo tanto, en su futuro. Existen multitud de factores económicos influyentes en el entorno de una sociedad, pero no todos tienen un impacto relevante sobre la actividad del sector, por lo tanto, la sociedad deberá escoger (Martínez \& Milla, 2012)

Según INEI (2018), la producción nacional en enero de 2018 creció 2,81\%, registrando 102 meses de crecimiento continuo, debido igualmente al crecimiento de la mayoría de los sectores productivos, principalmente, construcción, transporte, telecomunicaciones, y comercio; y correspondiendo a la actividad de Restaurantes y Bebidas el crecimiento de $1.30 \%$ para el periodo en mención (ver Figura 20). 


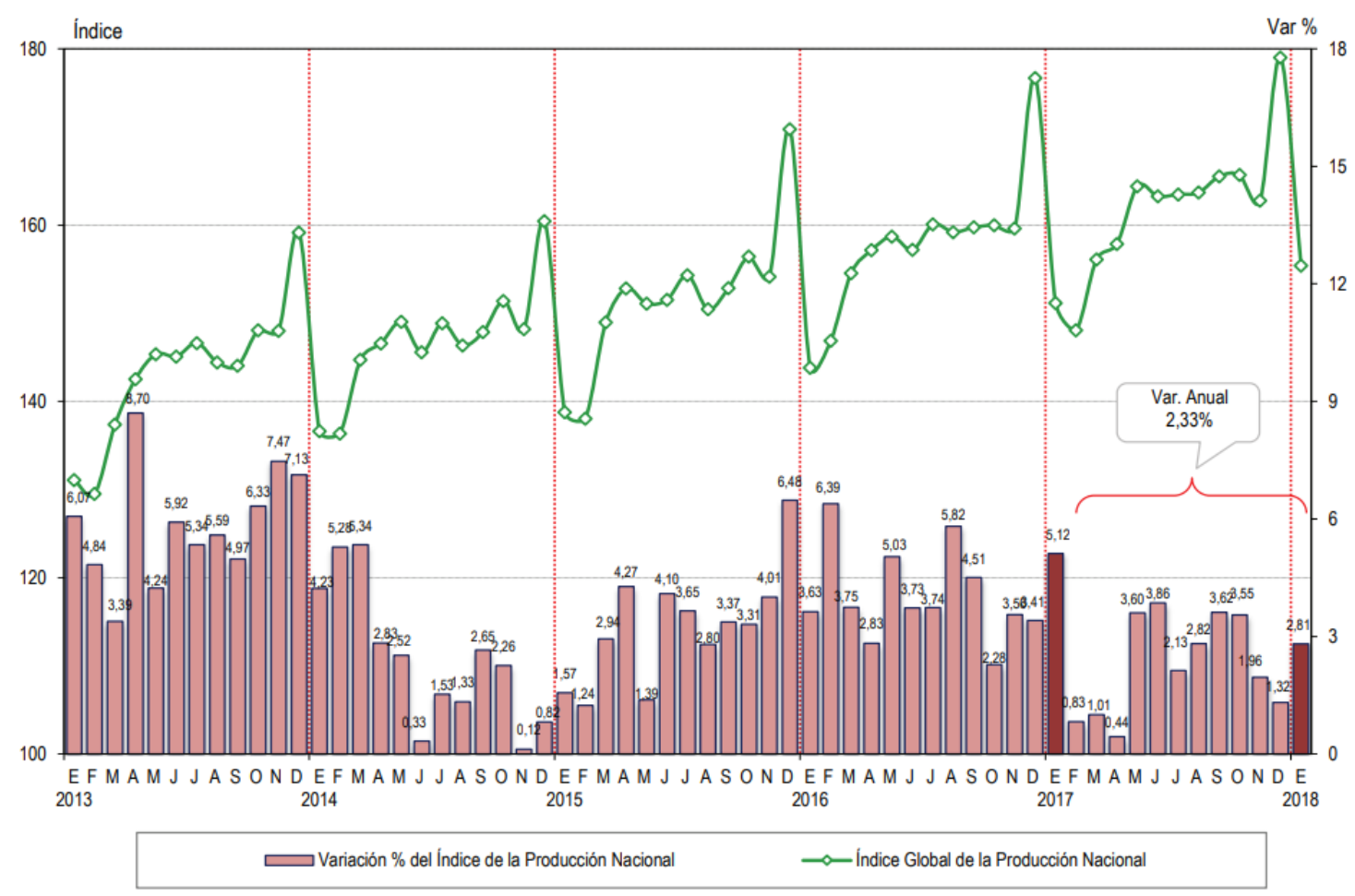

Figura 20. Evolución de la Producción Nacional 2013-2018. Tomado de Evolución del Índice Mensual de la Producción Nacional por Instituto Nacional de Estadística e Informática. (2018).

Según, el Banco Central de Reserva del Perú, la esperanza de crecimiento del PBI ha disminuido en $0.05 \%$ para el año 2018 , lo que se refleja de un $4 \%$ a $3.5 \%$, teniendo como reto para las autoridades recuperar la inversión y la confianza. Asimismo, el Instituto Peruano de Economía, lo anterior es debido a la ausencia de cambios estructurales en los últimos cinco años. Por otro lado, el BBVA Research apunta que el crecimiento será muy por debajo del $3.5 \%$, siempre relacionado con la disminución de inversiones de mediano plazo, traduciéndose con una menos acumulación de capital físico, factor clave la productividad del país.

El nuevo gobierno asumido por el presidente Vizcarra, ha expresado la posibilidad de que el Perú tenga la oportunidad de crecer un 5\% para el año 2021, lo que significa incrementar en 1.5 puntos porcentuales cada año, frente al último cálculo del BCR como se indica en párrafos anteriores, y para ello indica hacer esfuerzos que debe de hacer las entidades del estado en no descuidar el rol de guiar el mercado, a los agentes económicos, y reducir la incertidumbre.

Según INEI (2017) en el año 2017, el Producto Bruto Interno (PBI) de Perú aumentó 1.32\% en diciembre del 2017 y acumuló 101 meses continuos de avance, con lo que el año 
2017 cerró con un crecimiento de $2.50 \%$, impulsada por los sectores Primario (3.06\%) y Servicios (2.74\%), y sumó 19 años de crecer en forma consecutiva. Correspondiendo para ese mismo año un aumento de $1.24 \%$ al sector de Alojamiento y Restaurantes (ver Tabla 6).

Tabla 6

Evolución del Índice Mensual de Producción Nacional 2017 / 2016 (Año Base 2007)

\begin{tabular}{|c|c|c|c|}
\hline \multirow{3}{*}{ Sector } & \multirow{3}{*}{ Ponderación 1/ } & \multirow{2}{*}{\multicolumn{2}{|c|}{$\begin{array}{c}\text { Variación Porcentual } \\
2017 / 2016\end{array}$}} \\
\hline & & & \\
\hline & & Diciembre & Enero-Diciembre \\
\hline Economia Total & 100,00 & 1,32 & 2,50 \\
\hline DI-Otros Impuestos a los Productos & 8,29 & $-1,29$ & 4,15 \\
\hline Total Industrias (Producción) & 91,71 & 1,53 & 2,36 \\
\hline Agropecuario & 5,97 & 11,47 & 2,62 \\
\hline Pesca & 0,74 & $-66,87$ & 4,67 \\
\hline Mineria e Hidrocarburos & 14,36 & 5,55 & 3,19 \\
\hline Manufactura & 16,52 & $-12,50$ & $-0,27$ \\
\hline Electricidad, Gas y Agua & 1,72 & $-0,63$ & 1,14 \\
\hline Construcción & 5,10 & 6,62 & 2,20 \\
\hline Comercio & 10,18 & 1,93 & 1,03 \\
\hline Transporte, Almacenamiento, Correo y Mensajeria & 4,97 & 4,01 & 2,92 \\
\hline Alojamiento y Restaurantes & 2,86 & 2,21 & 1,24 \\
\hline Telecomunicaciones y Otros Servicios de Informaciön & 2,66 & 6,35 & 8,02 \\
\hline Financiero y Seguros & 3,22 & 4,73 & 1,24 \\
\hline Servicios Prestados a Empresas & 4,24 & 2,01 & 1,01 \\
\hline Administración Pública, Defensa y otros & 4,29 & 4,02 & 4,13 \\
\hline Otros Servicios 2 & 14,89 & 3,69 & 3,68 \\
\hline
\end{tabular}

Nota: Tomado de Evolución del Índice Mensual de la Producción Nacional por Instituto Nacional de Estadística e Informática, 2018.

Según INEI (2018), la inflación registró un descenso a 1.25\% siendo la más baja en siete años. La inflación se acercó al límite inferior del rango meta que maneja el Banco Central de Reserva (BCR), que es entre 1\% y 3\%. Es, además, el resultado más bajo de inflación observado en los últimos siete años. En mayo del 2010, el alza de precios fue 1,04\%. Este resultado se explica, pues, entre febrero del 2017 y enero de este año, la rama de alimentos y bebidas ha mostrado precios $0,22 \%$ superiores al mismo período del año previo

Por lo tanto, según BCR (2018), para el año 2018 no se esperan mayores presiones inflacionarias debido a que el crecimiento se ubicaría debajo de su potencial calculado, a la baja probabilidad de incrementos fuertes del tipo de cambio y a que no hay indicios de 
eventos climáticos adversos. En este escenario, se proyecta que la inflación caiga por debajo de $1 \%$ en el primer trimestre y, posteriormente, se acerque a alrededor de $2 \%$ a fines de año.

Para el próximo año 2019, según BBVA Research (2018), las proyecciones son favorables, impulsado por el contexto económico internacional, los precios de los metales y las inversiones públicas en infraestructura por los daños ocasionados por El Niño Costero, así como los relacionados con los Juegos Panamericanos 2019 y la Línea 2 del Metro de Lima. Estos factores serán el motor dinamizador de la activación económica.

En resumen, los porcentajes proyectados para el Perú, se encuentran entre los más elevados de la región. Chile, Colombia, Brasil y Estados Unidos muestran un incremento significativo para su PBI para el año 2018 el presente año; por otro lado, tanto México como Canadá, son los países del continente que se proyecta reducirán su porcentaje de PBI para el mismo año.

Por el lado del tipo de cambio, las condiciones indican no tener mayores preocupaciones en las proyecciones para el 2018 y 2019 oscilando entre $3.24 \%$ y $3.34 \%$ de fluctuación para los periodos en mención. (Durand, 2018)

\subsubsection{Análisis Legal.}

Para el análisis legal, se considera factores que están constituidos por una serie de regulaciones emanadas de los gobiernos municipales, regionales y central, así como de organismos reguladores como Osiptel, Osinergmin, Indecopi, entre otros, e instituciones como la Sunat, el Poder Judicial, etc. Las normas legales, reglamentaciones, etc. impactan en las en el comportamiento de las organizaciones (Conexión Esan, 2016).

Desde el año 2004 existe el Reglamento de Restaurantes elaborado por MINCETUR y aprobado con Decreto Supremos No. 025-200, el mismo que diferencia como restaurante a establecimiento que expende comidas y bebidas al público, preparadas en el mismo local, y a bares como recintos caracterizado por contar con una barra o mostrador, destinado al servicio de bebidas de diversa índole y otros. Entre los requisitos exigidos a estos tipos de establecimientos es contar con la Licencia Municipal de Funcionamiento y cumplir con las demás disposiciones municipales correspondientes. Además, según articulo $26^{\circ}$ del presente reglamento se indica que la calidad en la preparación de comidas (piqueos) y bebidas deberá utilizar alimentos o ingredientes idóneos y en buen estado de conservación, sujetándose estrictamente a las normas que emitan los organismos competentes. y cuando algún ingrediente se desee cambiar se deberá contar con la aprobación previa del cliente. (Mincetur, 2004) 
Por otro lado, aprueban para la Municipalidad de Barranco la Ordenanza 387 que tiene como finalidad dar el marco jurídico normativo que regule los aspectos técnicos y normativos concernientes al otorgamiento de licencias de funcionamiento para locales de servicio y comerciales. Cabe señalar que la ordenanza, a los locales conocidos como bares los identifica como centros nocturnos, siendo definidos estos como centro de reuniones acústicamente aislados con música en vivo o en discos $\mathrm{CD}$ digital y que cuentan con servicio de bar sin vista la calle.

El Congreso de la República a través de la ley 28015 Promoción y Formalización de la Micro y Pequeña Empresa, implementa instrumentos de utilidad para el fin que se busca, darle viabilidad a la formación de MYPES, y el el 02 de Julio del 2013, el Congreso de la República promulgó la Ley No 30056 "Ley que modifica diversas leyes para facilitar la inversión, impulsar el desarrollo productivo y el crecimiento empresarial", entre las que destacan los siguientes cambios:

- Los trabajadores y las MYPES cuentan con un Régimen Laboral Especial, no obstante pueden pactar mejores condiciones laborales con sus empleadores MYPE.

- Se considera MICRO EMPRESA a aquella cuyas ventas brutas anuales no excedan de 150 UIT (S/607,500.00) para el 2,017.

- El número de trabajadores ya no será criterio para ser considerado micro empresa, pero solo para las empresas que se hayan formado a partir del 03 de Julio de 2,013.

- El empleador, no está obligado a pagar ESSALUD sino el Sistema Integral de Salud (SIS).

- El Empleador no está obligado a pagar CTS.

- El Empleador no está obligado a pagar gratificaciones ni en Julio ni en Diciembre.

- El periodo de vacaciones es de 15 días

- Se considera PEQUEÑA EMPRESA a aquella cuyas ventas brutas anuales excedan de 150 UIT hasta 1700 UIT (S/607,500.00 soles hasta S/6' 885,000 soles para el 2,017).

- El empleador, está obligado a pagar ESSALUD para sus trabajadores.

- El Empleador está obligado a pagar CTS: 15 remuneraciones diarias por año completo de servicios hasta alcanzar un máximo de 90 remuneraciones diarias.

- El Empleador está obligado a pagar gratificaciones en Julio y en Diciembre (50\% de la Remuneración del trabajador).

- El periodo de vacaciones es de 15 días. 
- El Trabajador debe optar por el Sistema Nacional de Pensiones o por el Sistema Privado de Pensiones (AFP).

- El Trabajador tiene derecho a un seguro complementario de trabajo de riesgo a cargo de su empleador; y a un seguro de vida.

- Los trabajadores y conductores de la Microempresa, incluyendo sus derechohabientes tienen cobertura de salud a través del SIS - Sistema Integral de Salud. El Estado asumirá el 50\% y el otro 50\% es de cargo del empleador. Los trabajadores de la Pequeña Empresa serán asegurados regulares de ESSALUD. (Gonzales, 2018).

Todo lo anterior tiene entre sus objetivos establecer el marco legal para la promoción de la competitividad, formalización y el desarrollo de las micro, pequeñas y medianas empresas

\subsubsection{Análisis Cultural.}

Los patrones de vida y de conducta cambian de manera continua y constante, y hace que lo que fue costumbre en épocas pasadas ahora sea totalmente lo contrario, especialmente en los valores culturales, de allí la importancia de analizar este factor externo que influye directamente al proyecto en estudio. Según Ipsos Perú (2014), el 59\% de los adultos jóvenes de Lima gasta en comer fuera de casa, mientras que el $28 \%, 25 \%$ y $13 \%$ lo hace para ir al cine, salir a bailar y tomar tragos, respectivamente. La tendencia responde, especialmente, al nivel socioeconómico B llegando a representar el 67\%, así como el 61\% del rango de edad de 26 a 30 años. El estudio también indica que el 34\% de adultos jóvenes de la capital asume los gastos de salir con su pareja el fin de semana, mientras que el 16\% comparte los costos. Por género, solo el 1\% de los varones afirma que su pareja asume los gastos.

Por su parte, Cortéz (2016), terapeuta familiar y sistémico, explica el exceso o el simple consumo de alcohol por "presión de grupo". Que significa esto, cuando el joven se rodea de un grupo en el que todos toman es más proclive a iniciarse. "Si en una fiesta o reunión en la que sus amigos toman y le ofrecen alcohol, difícilmente podrá negarse, ya que si lo hace lo van a fastidiar: 'ahí está el aguado que no quiere tomar', 'no seas niñita'", advierte Cortéz.

La psicóloga Sotomayor (2017, Julio), de la Comisión Nacional para el Desarrollo y Vida sin Drogas (Devida), el consumo excesivo puede tener serias consecuencias en los jóvenes, así como la presión de grupo puede llevarlos a aceptar alcohol y drogas ilegales pese a que no lo desean en ocasiones. 
Asimismo, no es que el consumo de alcohol sea malo de por sí, sino el consumo desmedido e inapropiado. "Transformar el alcohol en una sustancia de culto y que necesariamente tiene que estar presente en todo evento social es el gran error", afirma por su lado la doctora Lupe Maestre, psicóloga clínica, (RPP, Espacio Saludable, 2015)

Finalmente, el distrito de Barranco considerado como el distrito más bohemio de Lima Metropolitana, a través de su municipalidad lanzó el año 2017 la campaña: ¿Que huellas quieres dejar?, con el objetivo de prevenir accidentes de tránsito (Ver Figura 21 y 22.

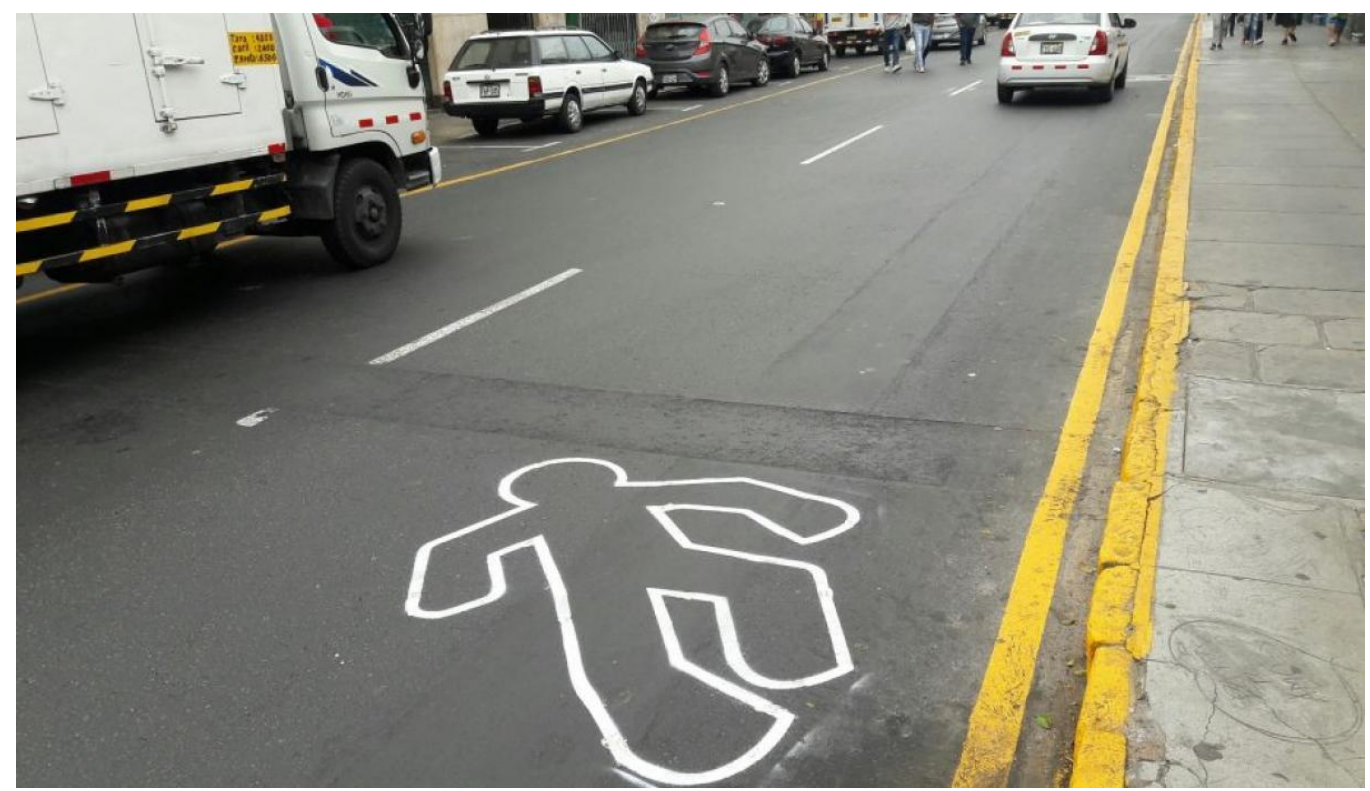

Figura 21. Campaña 1 ¿Qué huellas quieres dejar? Tomado de Diario Perú 21: Barranco, Lanzan campaña para prevenir accidentes. 2017 jul 16. Recuperado de: https://peru21.pe/lima/barranco-lanzan-campana-prevenir-accidentes-manejar-ebriedadfotos- 88325

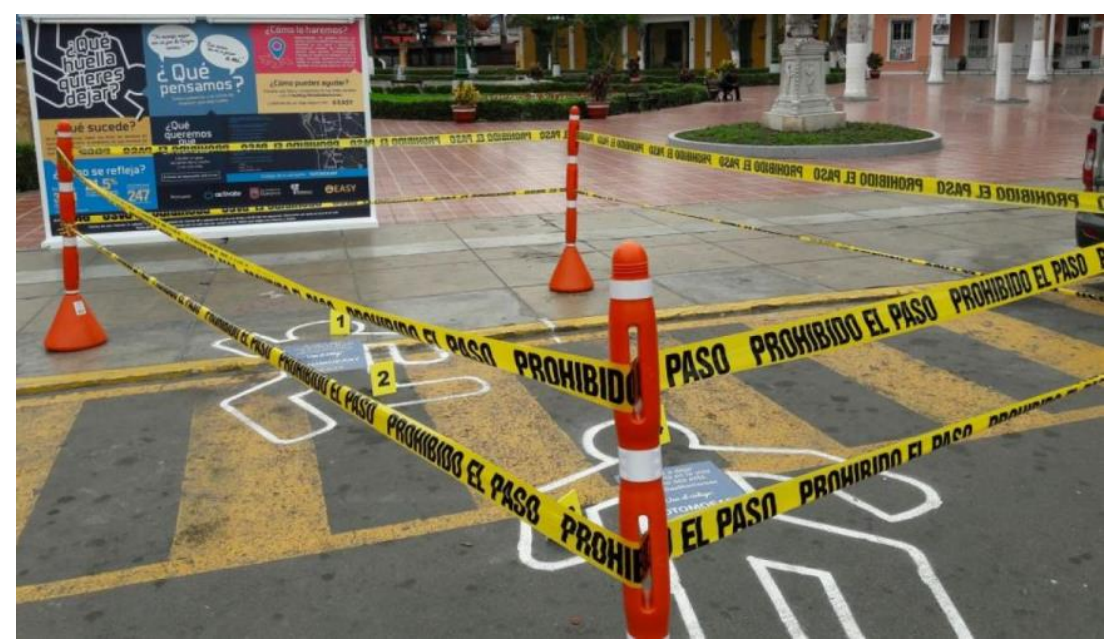

Figura 22. Campaña 2 ¿Qué huellas quieres dejar? Tomado de Diario Perú 21: Barranco, Lanzan campaña para prevenir accidentes, 2017 jul 16. Recuperado de: 
https://peru21.pe/lima/barranco-lanzan-campana-prevenir-accidentes-manejar-ebriedad-fotos88325

"Son 13 los espacios públicos intervenidos en el distrito con el pintado de una silueta forense en la pista y un mensaje de sensibilización para crear conciencia sobre la ingesta de bebidas alcohólicas al momento de manejar" manifestó su alcalde Antonio Mezarina Tong; apoyado por las estadísticas de altas cifras de jóvenes que pierden la vida por una diversión desenfrenada y sin control (Diario Perú 21, 2017, Julio).

\subsubsection{Análisis Tecnológico.}

"Los factores tecnológicos generan nuevos productos y servicios, y mejoran la forma en la que se producen y se entregan al usuario final. Las innovaciones pueden crear nuevos sectores y alterar los límites en los sectores existentes”. (Martínez \&Milla, 2012).

Actualmente la tecnología está empezando a crecer en todos los ámbitos, lo que hace más fácil el acceso a ella, lo que permite hacer más viable las ideas de negocios y permite hacer empresas más rentables, pues el costo de la maquinaria, herramientas, equipos, y dispositivos va disminuyendo no solo por el avance tecnológico sino también por la gran cantidad de oferta, que siempre está en crecimiento. (Consejo Nacional de Ciencia y Tecnología [CONCYTEC], 2016 Marzo)

Para el sector en estudio, el uso de la tecnología aplicada en el desarrollo de equipos innovadores y en el diseño de herramientas prácticas permite mejorar procesos en las empresas, trayendo como consecuencia una mejora de la atención así como un aumento de calidad.

Las pequeñas y medianas empresas que adopten algún tipo de tecnología en sus operaciones pueden incrementar sus ganancias hasta en 15 puntos porcentuales y crearán puestos de trabajo dos veces más rápido que aquellas que no lo hagan, señaló la compañía de software Microsoft (2014).

Para la compañía de software, las pymes han cambiado la forma de hacer negocios y necesitan desarrollarse en poco tiempo y con menos recursos que las compañías grandes. En ese sentido, se considera fundamental que estas empresas puedan contar con tecnología accesible y potente, como la nube, que les permita trabajar desde cualquier lugar y usando el dispositivo de su preferencia, manteniendo su productividad en todo momento.

Por otro lado, en Perú el consumo de servicio de telefonía móvil es cada más impresionante siendo una gran oportunidad para la Pymes, las estrategias móviles pueden ser una valiosa forma de lograr objetivos de posicionamiento, servicio y ventas. Aprovechando la tecnología y las plataformas de servicios disponibles hoy en día, pueden lograr campañas 
muy exitosas para sus objetivos de promoción, captación de prospectos o fidelización de clientes. (Marketing Digital, 2015). La popularidad de los smartphones ha hecho que muchas empresas apuesten por no solo tener una versión móvil de sus webs, sino de encontrar otras formas de estar siempre con su cliente.

Hasta ahora, solo las grandes empresas en el Perú han explorado este terreno. En el caso de las pymes, Polastri (2017), gerente general de Google Perú, sostiene que solo el 15\% de ellas las utiliza y un $60 \%$ no ha entendido aún el valor de estas. Cabe mencionar que ese $15 \%$ de esas pequeñas y microempresas que utilizan las Apps, vende $40 \%$ más que sus competidoras.

Los sistemas de planificación de recursos empresariales (ERP, por sus siglas en inglés) están siendo cada vez más usados por las empresas de menor tamaño, las cuales ven necesario incorporar la tecnología en sus procesos y gestión. Así, Miguel Díaz (2016), director de PHC Software Perú, describe algunos beneficios que los ERP podrían llevar a las Pymes. La información es uno de los primeros beneficios que, de manera inmediata, se pueden observar es que con una ERP se compila la información que se encuentra dispersa en la empresa para no perder tiempo en buscarla. Además, se pueden organizar todos los datos de los negocios por áreas. Asimismo, los costos se pueden reducir entre un $15 \%$ y un $20 \%$, los gerentes pueden supervisar mejor el presupuesto que elaboran a inicio de año haciendo que el uso de los recursos sea predecible y se tenga conocimiento de cómo y cuándo son usados estos.

Una Pyme, según Gerencia (2012), debe tener claro cuál es el objetivo de negocio, así como la manera en que la implementación de TI puede ayudar a optimizar sus recursos y procesos. La adopción de tecnología per sé no llevará al éxito si no se tiene definido qué se debe hacer. Por otro lado, la curva de evolución de una Pyme se ve acelerada al momento de la implementación de tecnología. Los aspectos fundamentales en que los pequeños y medianos empresarios deben centrar sus esfuerzos son: manejo de los clientes, manejo de las finanzas y productividad de los empleados.

\subsubsection{Análisis Ecológico.}

Estos factores pueden parecer que a priori sólo afectan a las empresas de sectores muy específicos, pero en realidad es todo lo contrario. Nos interesa estar al tanto no sólo sobre los posibles cambios normativos referidos a la ecología, sino también en cuanto a la conciencia social de este movimiento. El análisis debe de contemplar las cuestiones siguientes:

- Leyes de protección medioambiental 
- Regulación sobre el consumo de energía y el reciclaje de residuos

- Preocupación por el calentamiento global

- Concienciación social ecológica actual y futura

“Artículo 74.- De la responsabilidad general todo titular de operaciones (persona natural o jurídica) es responsable por las emisiones, efluentes, descargas y demás impactos negativos que se generen sobre el ambiente, la salud y los recursos naturales, como consecuencia de sus actividades. Esta responsabilidad incluye los riesgos y daños ambientales que se generen por acción u omisión" (Ley N² 28611, 2005).

Actualmente, en DIGESA se conduce el programa "Restaurante Saludable" que da un certificado a las empresas que tienen el compromiso de mejorar sus condiciones sanitarias de funcionamiento (Escalante, 2016).

Según Ordenanza 358 - MDB (2011) de la Municipalidad de Barranco, aprueba la formalización de Recicladores y la Recolección Selectiva de Residuos Sólidos, encargando a la Gerencia Municipal y a la Gerencia de Gestión Ambiental y Ornato el cumplimiento de dicha ordenanza.

Los factores ambientales del presente proyecto en estudio no son relevantes y críticos en su desarrollo, sin embargo, la supervisión por los organismos supervisores es cada vez más exigente en actividades como la que implementaremos. Por lo tanto, tenemos previsto cumplir con lo exigido en temas de manipulación desechos asi como el control para no contribuir con la contaminación acústica, en función a la Ordenanza 362 MDB (2012) de la Municipalidad de Barranco sobre normas de prevención de y control de ruidos molestos, y estipula especialmente a restaurantes y bares que no debe de exceder de los 70 decibeles, dentro de su horario de funcionamiento.

\subsection{Oportunidades y Amenazas}

Las oportunidades constituyen aquellas fuerzas ambientales de carácter externo no controlables por la organización, pero que representan elementos potenciales de crecimiento o mejoría. La oportunidad en el medio es un factor de gran importancia que permite de alguna manera moldear las estrategias de las organizaciones. Las amenazas son lo contrario de lo anterior, y representan la suma de las fuerzas ambientales no controlables por la organización, pero que representan fuerzas o aspectos negativos y problemas potenciales, como lo sostiene (Ponce, 2007). 
Entre las oportunidades y amenazas detectadas para el caso de estudio se pueden considerar las siguientes que se describen en la Matriz de Influencias de Factores Externos (ver Tabla 7): 


\section{Tabla 7}

Matriz de Influencia de Factores Externos (a)

\begin{tabular}{|c|c|c|c|}
\hline Factor & Elemento & $\begin{array}{l}\text { Oportunidad / } \\
\text { Amenazas }\end{array}$ & Comentario \\
\hline \multirow{7}{*}{$\begin{array}{l}\text { Político / } \\
\text { Gubernamental }\end{array}$} & Productividad & Oportunidad & $\begin{array}{l}\text { Existe política de estado para aumentar la } \\
\text { productividad de las empresas }\end{array}$ \\
\hline & \multirow[b]{2}{*}{ Innovación } & Oportunidad & $\begin{array}{l}\text { A través del programa de Innóvate - Perú se puede } \\
\text { postular a fondos concursables. }\end{array}$ \\
\hline & & Amenaza & $\begin{array}{l}\text { CEPLAN, fortalece las actividades productivas y no } \\
\text { incluye a las actividades de servicio }\end{array}$ \\
\hline & Formalización & Oportunidad & $\begin{array}{l}\text { Empresas formales (pymes) posibilidad de acceso al } \\
\text { sistema financiero }\end{array}$ \\
\hline & \multirow{2}{*}{ Tributación } & Oportunidad & $\begin{array}{l}\text { Incentivos tributarios a empresa formales que } \\
\text { tributen }\end{array}$ \\
\hline & & Amenaza & $\begin{array}{l}\text { IGV más elevado que el promedio de América } \\
\text { Latina }(15,2 \%)\end{array}$ \\
\hline & Seguridad Vial & Oportunidad & $\begin{array}{l}\text { Campaña de concientización como el de "Conductor } \\
\text { Seguro" para evitar manejar en estado de ebriedad }\end{array}$ \\
\hline \multirow{7}{*}{ Económico } & PBI & Oportunidad & $\begin{array}{l}102 \text { meses de crecimiento continuo incentiva el } \\
\text { consumo internos en los diversos sectores }\end{array}$ \\
\hline & & Amenaza & Crecimiento cada vez menor al 2017 \\
\hline & $\begin{array}{l}\text { Ingreso } \\
\text { disponible }\end{array}$ & Oportunidad & $\begin{array}{l}\text { Cada vez más jóvenes con altos ingresos } \\
\text { disponibles }\end{array}$ \\
\hline & Inflación & Oportunidad & Se encuentra controlada las presiones inflacionarias \\
\hline & Industria & Amenaza & Alta competencia identificada en la industria \\
\hline & Inversiones & Oportunidad & $\begin{array}{l}\text { La reconstrucción del Niño Costero, el campeonato } \\
\text { mundial } 2018 \text {, los Juegos Panamericanos (2019); } \\
\text { son motores que dinamizarán la economía. }\end{array}$ \\
\hline & Tipo de Cambio & Oportunidad & Se pronostica que no habrán oscilaciones relevantes \\
\hline \multirow{3}{*}{ Legal } & Fiscalización & $\begin{array}{l}\text { Oportunidad / } \\
\text { Amenaza }\end{array}$ & $\begin{array}{l}\text { Es una oportunidad porque norma las actividades } \\
\text { del sector, y amenaza por la exhaustiva fiscalización } \\
\text { que faculta realizar. }\end{array}$ \\
\hline & $\begin{array}{l}\text { Licencia de } \\
\text { Funcionamiento }\end{array}$ & Amenaza & $\begin{array}{l}\text { Debido a que para la entrega de licencias de } \\
\text { funcionamiento, la municipalidad es sumamente } \\
\text { estricta. }\end{array}$ \\
\hline & Ley Mype & Oportunidad & $\begin{array}{l}\text { Facilita la inversión e impulsa el desarrollo } \\
\text { productivo empresarial }\end{array}$ \\
\hline
\end{tabular}


Tabla 8

Matriz de Influencia de Factores Externos (b)

\begin{tabular}{|c|c|c|c|}
\hline Factor & Elemento & $\begin{array}{l}\text { Oportunidad/Amena } \\
\text { za } \\
\end{array}$ & Comentario \\
\hline \multirow{3}{*}{ Cultura } & Costumbre & Oportunidad & $\begin{array}{l}\text { El 59\% sale a comer fuera de casa y el } \\
13 \% \text { sale a bailar y tomar tragos }\end{array}$ \\
\hline & Consumo alcohol & Oportunidad & Campaña para evitar consumo de alcohol \\
\hline & $\begin{array}{l}\text { Campanas } \\
\text { preventivas }\end{array}$ & Oportunidad & La campaña: ¿Qué huellas quieres dejar? \\
\hline \multirow{4}{*}{ Tecnológico } & TICS & $\begin{array}{l}\text { Oportunidad } \\
\text { Oportunidad } \\
\end{array}$ & $\begin{array}{l}\text { Acceso fácil a la tecnología aplicada al } \\
\text { sector orientándola a un mejor servicio y } \\
\text { aumento de rentabilidad. } \\
\text { Nuevas formas de hacer negocio a través } \\
\text { de la aplicación }\end{array}$ \\
\hline & Innovación & Oportunidad & $\begin{array}{l}\text { Fortalecer y mejorar el desempeño de las } \\
\text { empresas a través de programas de } \\
\text { financiamiento de innovación (Innóvate } \\
\text { Perú). }\end{array}$ \\
\hline & Optimización & Oportunidad & $\begin{array}{l}\text { Nuevas formas de hacer negocio con } \\
\text { menos recursos }\end{array}$ \\
\hline & Telefonía Móvil & Oportunidad & Nuevas formas de estar con el cliente \\
\hline Ecológico & $\begin{array}{l}\text { Campañas de } \\
\text { certificación } \\
\text { Campañas Medio } \\
\text { Ambientales }\end{array}$ & Oportunidad & $\begin{array}{l}\text { Programa de "Restaurante Saludable", } \\
\text { promovido por el Ministerio del } \\
\text { Ambiente y Ministerio de Salud } \\
\text { Se cumplirá con todo los exigido, sobre } \\
\text { todo en temas de contaminación acústica }\end{array}$ \\
\hline
\end{tabular}

Nota. Adaptado de Administración de Pequeñas Empresas, por J. Longenecker, 2008, 13 Edición, México: Cengage Learning. 


\section{Capítulo III: Estudio de Mercado}

El objetivo de este capítulo es explicar y analizar la demanda, a través del perfil del consumidor, su comportamiento, y las tendencias que influyen en su actuar; así como también analizar la oferta, a través de las fuerzas que influyen en el micro entorno como son los competidores actuales y/o potenciales, los productos sustitutos, y los productos complementarios

Cabe anotar que el presente estudio tendrá como base la aplicación de técnicas de investigación cuantitativas (encuestas) y cualitativas (entrevistas de profundidad y Focus Group), a ser aplicado en un plan de marketing para finalmente poder estimar los ingresos o ventas que el proyecto generará dentro de su horizonte de evaluación.

\subsection{Descripción del Servicio}

Es un establecimiento comercial donde se servirán bebidas no alcohólicas y aperitivos, lugar de encuentro y reunión informal en un ambiente libre del consumo de alcohol y humo de tabaco. Con música contemporánea con un volumen que facilite la conversación ambientado con sobriedad y detalles de modernidad. La atención a brindar es un factor clave, en general el servicio comprende los siguientes aspectos:

Bebidas no alcohólicas

- Tragos vírgenes (cocteles preparados sin alcohol) agrupados en cocteles calientes, cocteles refrescantes y cocteles cremosos.

- Jugos naturales (chicha morada y limonadas)

- Café e infusiones

- Cerveza sin alcohol (bebidas importadas con Cero grados de alcohol, cerveza de raíz, de manzana, etc.)

- Gaseosas

- Bebidas energizantes

- Bebidas rehidratantes

- Agua

Piqueos fuertes:

- Chicharrón de pollo

- Alitas broster

- Papas fritas

- Brochetas de carne

- Pizzitas 
Piqueos ligeros

- Tequeños de jamon y queso

- Causitas

- Canapes de pollo

- Chifles, cancha serrana, cremas y salsas.

Música

- La música será contemporánea, combinaciones de música de moda que invite a tener un momento alegre, la idea es divertirse y pasarla bien sin consumir alcohol, sin que la música tenga que ser aburrida.

- Un DJ femenina podrá atender pedidos especiales de los asistentes.

- El volumen respetará los decibeles autorizados, permitiendo a su vez una amena conversación.

Lugar

- En Barranco principalmente por la concentración de bares.

Ambientación

- La ambientación será sobria pero con detalles de modernidad.

- Se habilitará un ambiente para escenario y pista de baile

Horario de atención

- La atención al público iniciará a las 17:00 horas hasta las 24:00 horas de domingo a miércoles.

- Los fines de semana, de jueves a sábado la atención será hasta las 02:00 horas.

\subsection{Selección del Segmento de Mercado}

Según Kotler \& Armstrong (2012), la segmentación de mercado es el proceso de dividir un mercado en distintos grupos de compradores, con necesidades, características o conductas diferentes, y quienes podrían requerir productos o programas de marketing separados. Un segmento de mercado se define como un grupo de consumidores que responden de manera similar a un conjunto dado de actividades de marketing

Bonta \& Farber, definen un segmento de mercado como "aquella parte del mercado definida por diversas variables específicas que permiten diferenciarla claramente de otros segmentos. A medida que se considera una mayor cantidad de variables para definir cualquier segmento de mercado, el tamaño del segmento se reduce y las características de este son más homogéneas". 
Tipos de Segmentación

Dentro de los criterios seleccionados para definir el segmento de mercado se considera los siguientes: Segmentación geográfica, Segmentación demográfica y Segmentación socioeconómica.

Segmentación geográfica

La segmentación geográfica implica dividir el mercado en distintas unidades geográficas como países, regiones, estados, municipios, ciudades o incluso zonas (Kotler \& Armstrong, 2012). En la propuesta se consideran nueve distritos de Lima Metropolitana.

El segmento de mercado al que está dirigida la propuesta se encuentra en la zona de Lima Metropolitana, especialmente en la zona geográficas 7 y 8 de acuerdo a la clasificación de la Asociación Peruana de Empresas de Investigación de Mercados (APEIM) que comprenden los distritos de: Barranco, La Molina, Miraflores, San Borja, San Isidro, Santiago de Surco, Surquillo, Chorrillos y San Juan de Miraflores; y sus poblaciones respectivas se observan a continuación (ver Tabla 9):

Tabla 9

Segmentación Geográfica

\begin{tabular}{llr}
\hline Zona & Distrito & Habitantes \\
\hline Zona 7 & Miraflores & 85,800 \\
& San Isidro & 56,800 \\
& San Borja & 116,700 \\
& Surco & 357,600 \\
& La Molina & 178,200 \\
\hline Total Zona 7 & & 795,100 \\
\hline Zona 8 & Surquillo & 94,900 \\
& Barranco & 31,200 \\
& Chorrillos & 335,600 \\
& San Juan de Miraflores & 416,000 \\
\hline Total Zona 8 & & 877,700 \\
\hline Total Zona 7 y Zona 8 & & $1,672,800$ \\
\hline
\end{tabular}

Nota: Tomado de Estimaciones y proyecciones de población del Instituto Nacional de Estadística, 2017, y Perú Población 2017, Departamento de Estadística de CPI.

Se parte del universo de Lima Metropolitana (CPI, 2017), con la cantidad de habitantes que se indica a continuación:

Perú 31,826,000 habitantes

Lima Provincias $\quad 11,181,700$ habitantes 
Lima y Callao $\quad 10,209,300$ habitantes

Lima Metropolitana 9,170,600 habitantes

\section{Segmentación Demográfica}

La segmentación demográfica divide el mercado en grupos según variables como la edad, género, tamaño de la familia, ciclo de vida familiar, ingreso, ocupación, escolaridad, religión, raza, generación y nacionalidad. (Kotler \& Armstrong, 2012). En la propuesta el rango de edades considerado es de 18 a 39 años (ver Tabla 10):

Tabla 10

Segmentación Demográfica

\begin{tabular}{llr}
\hline Zona & Distrito & \multicolumn{2}{c}{ Población } \\
& & 18 a 39 Años \\
\hline Zona 7 & Miraflores & 27,510 \\
& San Isidro & 16,679 \\
& San Borja & 38,943 \\
& Surco & 121,447 \\
& La Molina & 61,908 \\
\hline Total Zona 7 & & 266,487 \\
\hline Zona 8 & Surquillo & 29,725 \\
& Barranco & 8,818 \\
& Chorrillos & 113,673 \\
& San Juan de Miraflores & 141,955 \\
\hline Total Zona 8 & & 294,171 \\
\hline Total Zona 7 y Zona 8 & & 560,658 \\
\hline
\end{tabular}

Nota: Tomado de Estimaciones y proyecciones de población del Instituto Nacional de Estadística 2017, y Perú Población 2017 del Departamento de Estadística - Estudios de Mercado y Opinión Pública S.A.C. (CPI).

Segmentación Socioeconómica

Parte de la segmentación demográfica. Las clases sociales son divisiones relativamente permanentes y ordenadas de una sociedad, cuyos miembros comparten valores, intereses y conductas similares (Kotler \& Armstrong, 2012).

Dentro de las zonas mencionadas, la propuesta considera al Nivel Socio Económico A y B (ver Tabla 11). Cabe indicar la información de niveles por distritos no está disponible. El muestreo de INEI en la ENAHO (Encuesta Nacional de Hogares) no lo permite, por eso se realiza por zona. 
Aplicados los criterios de segmentación de mercado, se obtiene una población objeto de estudio de 300,780 habitantes. Cabe señalar se considera indistinto el género, así como su nivel ocupacional u otra característica sociodemográfica.

Tabla 11

Segmentación Socioeconómica

\begin{tabular}{lcrr}
\hline Zona & \multirow{2}{*}{ NSE } & \multicolumn{2}{l}{ Población } \\
\hline Zona 7 & $\mathrm{A}$ & $35.9 \%$ & 95,669 \\
& $\mathrm{~B}$ & $43.3 \%$ & 115,389 \\
\hline Total Zona 7 & & $79.2 \%$ & 211,058 \\
\hline Zona 8 & $\mathrm{A}$ & $3.9 \%$ & 11,473 \\
& $\mathrm{~B}$ & $26.6 \%$ & 78,250 \\
\hline Total Zona 8 & & $30.5 \%$ & 89,722 \\
\hline Total Zona 7 y Zona 8 & & $53.6 \%$ & 300,780
\end{tabular}

Nota: Tomado de Estructura Socioeconómica 2016 - APEHIM, y Perú Población 2017 Departamento de Estadística - Estudios de Mercado y Opinión Pública S.A.C. (CPI).

Si bien la propuesta es la creación de un Bar Cero Alcohol, está dirigido también a quienes consumen bebidas alcohólicas, puesto que aun siendo consumidor habitual de alcohol se tiene ocasiones en las que requieren compartir momentos agradables con amigos y/o familiares sin consumir alcohol; entre los principales motivos se encuentran enfermedad, compromisos deportivos, de trabajo o estudios que requieren lucidez.

\subsection{Investigación Cualitativa}

La investigación cualitativa es relevante cuando no existen datos históricos, cuando es difícil cuantificar las variables que explicarían la demanda o cuando los datos existentes no son confiables para extrapolarlos si no es posible asimilar las características del proyecto con otras. Los principales métodos cualitativos se basan en opiniones de expertos. En general, estas técnicas se fundamentan en el valor que se otorga a las experiencias pasadas y a la capacidad de las personas para intuir anticipadamente efectos sobre las variables más relevantes en la viabilidad de un proyecto, así como el conocimiento especializado de éxitos, fracasos y estándares de desempeño en materias similares (Sapag, 2014, p. 103).

\section{Entrevista a Expertos}


La opinión de los expertos es una de las formas subjetivas de estudiar el mercado más comúnmente usadas. Basada en la técnica de entrevista de profundidad individual, donde se sondean y producen respuestas detalladas a las preguntas. (McDaniel, 2014).

En la propuesta se consideran expertos a referentes de la industria de bares, con ellos se cubren diferentes tipos de clientes y modelos de negocios como son bares turísticos, bares culturales, bohemios y bares de cerveza artesanal como los más representativos de la zona de estudio.

\section{Objetivo General}

Identificar los factores de éxito para la implementación de "La Conversa" Bar cero Alcohol, obtener información del mercado actual de bares, y comportamiento de los consumidores.

Objetivos Específicos

- Obtener información de su empresa

- Obtener información del mercado de Bares
a. Tipo de clientes
b. Principales actores (Competencia)
c. Tipos de bares
d. Aspectos legales
e. Manejo Financiero
f. Procesos y Gestión

- Conocer la opinión sobre la propuesta "La Conversa” Bar cero Alcohol

- Solicitar recomendaciones para la implementación de un bar.

Focus Group

Es una entrevista del tipo personal en la que invitan de 6 o diez personas a hablar con un moderador que promueve un debate libre sobre un producto, servicio u organización. El entrevistador enfoca la discusión en los temas importantes (Kotler \& Armstrong, 2012).

En la propuesta se consideran dos focus group, de 7 y 8 personas correspondientes a la segmentación descrita en el punto anterior. El entrevistador o moderador es cada uno de autores, es decir un grupo por autor.

\section{Objetivo General}

Conocer las preferencias de los consumidores a sus centros de diversión habituales y su opinión sobre la propuesta "La Conversa" Bar cero Alcohol.

Objetivos Específicos 
- Conocer el proceso de compra desde el punto de vista de los consumidores.

- Explorar hábitos de consumo actual de centros de diversión y especialmente bares.

- Evaluación de la competencia entre los bares actuales.

- Conocer las opiniones sobre la Presentación de la propuesta "La Conversa" Bar cero alcohol

- Conocer las percepciones del potencial consumidor sobre:
a. Concepto
b. Ambientación
c. Promociones
d. Atención del persona
e. Servicios adicionales

\subsubsection{Proceso de Muestreo.}

En general, en los estudios cualitativos las muestras son no probabilísticas, lo que se busca son buenos informantes. En una muestra por conveniencia el investigador selecciona a los miembros de la población de quienes será más fácil obtener información. (Kotler \& Armstrong, 2012).

Participantes Entrevistas a Expertos

En el caso de las entrevistas a expertos, la invitación fue puntual tratando de conseguir citas con los mejores referentes del mercado de bares de Lima. Uno de los autores se contactó telefónicamente y vía correo electrónico.

Se logró entrevistar a los siguientes empresarios:

1. Ignacio Schwalb Pomareda

- Gerente General - Socio Cerveceria y Bar Barbarian (2013-Actualidad)

- Ingeniero de Oferta en Siemens (2013)

- Ejecutivo de ventas en Distribuidora Cummins Perú (2012)

- Sub Gerente Comercial en Intermaq (2008-2012)

- Ingeniero Industrial de la Universidad de Lima

2. Alexander Von Ehren

- Apoderado y Accionista de Ayahuasca

- Accionista de Huashca

- Accionista de Dama Juana

- Accionista de Discoteca Aura

- Candidato a la alcaldía de Miraflores 


\section{Giancarlo Gomero}

- Socio fundador de Bar Victoria

- Accionista de Residencia

- Accionista de Baruva

- Accionista de Inkanto

- Antropólogo de Profesión

- Docente Universitario

\section{Participantes Focus Group}

Se aplicó muestreo por conveniencia, con una invitación a participantes comprendidos en la segmentación de mercado definida previamente.

El estudio se llevó a cabo utilizando la técnica de Focus Group con una muestra de 15 personas, divididas en dos grupos de siete y ocho, respectivamente. Para la aplicación de esta técnica se consideró el siguiente perfil:

Geográfico: Residentes en los distritos comprendidos en la zona 7 y zona 8 de Lima metropolitana.

Socioeconómico: Pertenecientes a los Estratos A y B

Demográfico: Sexo Indistinto, Edad de 18 a 39 años

Consumidores de bebidas comerciales y asistentes a los diferentes establecimientos de diversión o entretenimiento (ver Apéndice 1). 


\subsubsection{Diseño de Instrumento.}

Los instrumentos de investigación cualitativa son las rúbricas, videograbación, Guía para entrevistas en profundidad y Guía de indagación o guía de preguntas focus groups, siendo estos últimos los más aplicados, se definieron los siguientes:

Guía para la Entrevista en Profundidad para Entrevistas a Expertos

La dirección de una entrevista en profundidad está guiada por la respuesta de los entrevistados. A medida que la entrevista avanza, el entrevistador sondea a fondo cada respuesta y la utiliza como una base para continuar con el interrogatorio. (McDaniel, 2014) (ver Apéndice 6)

Guía de Indagación o Guía de Tópicos o Guía de preguntas para Focus Group

Una guía de indagación es un compendio bien planeado y escrito de los temas a cubrir durante la sesión. Por lo general la guía está generada por el moderador y se basa en los objetivos de la investigación y en la información de las necesidades del cliente. (McDaniel, 2011)

La guía tiende a conducir la discusión a lo largo de tres etapas. En la primera, se establece una afinidad, se explican las reglas de la interacción del grupo y se proporcionan los objetivos. En la segunda, el moderador trata de provocar una discusión intensa. La última etapa, se dedica a resumir las conclusiones significativas y a poner a prueba los límites del convencimiento del compromiso (McDaniel, 2014) (ver Apéndice 2).

\subsubsection{Análisis y Procesamiento de Datos.}

\section{Entrevistas en Profundidad a Expertos}

Un factor que determinar el éxito de la investigación de profundidad es la interpretación apropiada. La forma no estructurada de la entrevista y la naturaleza clínica del análisis incrementan la complejidad de la tarea (McDaniel, 2014).

En base a la información recopilada se logró identificar los factores de éxito para la implementación del Bar Cero Alcohol, en orden de prevalencia son (1) Tener un concepto bien definido, (2) Buen Servicio al cliente, (3) Precio competitivo, (4) Promoción, (5) Ubicación y (6) la utilización de Marketing digital.

“A nosotros nos va súper bien con todo el concepto, yo creo que nuestro concepto es muy redondo, muy bien aterrizado, o sea tenemos música que va con la marca, tenemos murales, toda la parte visual va con la identidad de la marca y las cervezas, el personal, la comida que servimos, todo conversa entre sí, la comida que debería estar ahí, no son platos típicos peruanos por ejemplo, es maridaje de la cerveza artesanal, los que comían los 
bárbaros, es comida más de Bar, hamburguesas, Alitas, papitas, tacos, cosas así, cosas que comes cuando vas a un Bar y picas" (Schwalb, 2018).

Cada entrevistado brindó información general sobre su empresa, el tipo de cliente habitual de cada bar, cervecero, tradicional y temático cultural en cada caso; brindaron recomendaciones de tipo legal, financiero, control de gestión y procesos para el buen desenvolvimiento de un negocio de este tipo.

Al ser consultados sobre la propuesta de la implementación del Bar Cero Alcohol, dos de ellos manifestaron opinión favorable y en un caso cierto escepticismo.

"Este es un buen momento para probar cosas, y esto es novedoso, yo lo dirigiría a deportistas y personas que cuidan de su salud" (Schwalb, 2018).

"He vivido mucho tiempo en el extranjero y he visto muchas opciones de Bares para todo tipo de personas, a pesar que yo me incline por lago más hard y solo podría ser una opción más en mi carta, un bar exclusivamente sin alcohol sería focalizado y seguro hay quienes les guste" (Gomero, 2018).

"Bueno como un emprendimiento no es mala la idea, cada negocio tiene lo suyo, como por ejemplo hoy puedes hacer tus pollos a la brasa con pollo orgánico. Son estas ideas que a los emprendedores se les ocurre para diferenciarse. Hay tragos vírgenes y a lo mejor no necesitas a un "Bar Virgen" para tomar virgen. Puedes ir a un bar que no es virgen para tomar virgen también" (Von Ehren, 2018).

Asimismo se solicitó recomendación de los expertos para la implementación exitosa de un bar y en el caso específico del Bar Cero Alcohol, recomendaron ampliar el perfil de los consumidores potenciales.

"Yo creo que ahorita puede funcionar muy bien, sobre todo hay un tema de cuidado de la salud, todo el tema vegetariano, vegano, sin gluten, hay ahora un montón de estas corrientes, también hay corrientes sin alcohol, puede ser, se puede hacer marketing con deportistas, puedes juntarlo con carros que nosotros no podemos decir ven con tu carro, porque no pueden manejar saliendo de nuestro Bar, ahora yo creería que ustedes deberían de tener un estacionamiento" (Schwalb, 2018).

La transcripción de las entrevistas a expertos se encuentra detallada en la sección Apéndice al final del documento (ver Apéndice 6). Un análisis instantáneo de focus group es un interrogatorio del moderador que ofrece un foro para una sesión de lluvia de ideas entre el moderador y los observadores del cliente (McDaniel, 2014).

En base a los objetivos planteados se conoció la preferencia sobre los establecimientos habituales a los acuden los participantes, los cuales son principalmente bares, asimismo en 
general la opinión fue favorable con respecto a la propuesta de la creación del Bar Cero Alcohol.

Los puntos más relevantes del proceso de compra descritos por los participantes son salir a divertirse sin motivo especifico, aunque también desean conversar esto se hace difícil en el establecimiento elegido por el ambiente. Con respecto a los hábitos de consumo la cerveza es ligeramente la bebida preferida, en general prescinden del alcohol cuando están enfermos o son seleccionados como el amigo elegido. Aunque la preferencia es variada destacan bares como Ayahuasca, Barbarian y Barranco Beer Company, todos con un concepto bien definido.

Presentada la propuesta, las opiniones a considerar son reflejo de un ambiente cómodo y tranquilo, con un nombre que invita a la conversación y con respecto al precio promedio se encuentra en el rango de S/.15 a S/.20. Los participantes refieren elegancia y modernidad en la ambientación presentada y en general recomiendan la atención del personal debe ser con rapidez y amabilidad.

El focus group se encuentra transcrito en la sección de Apéndice al final del estudio (ver Apéndices 5 y 6). A continuación, en la Tabla líneas abajo se presenta un resumen de las respuestas de los participantes (ver Tabla 12): 
Tabla 12

Resumen Focus Group

\begin{tabular}{|c|c|c|}
\hline Variables & Componentes & Respuestas (15) \\
\hline & Decisión de salir a Divertirse & Celebraciones (1) \\
\hline & & Cumpleaños (4) \\
\hline & & Feriados y/o días no laborables (3) \\
\hline & & Aniversarios (1) \\
\hline & & Solo por diversión (6) \\
\hline & Motivo de elección del establecimiento & Estado de animo (2) \\
\hline & & Bailar (3) \\
\hline & & Tomar (3) \\
\hline & & Conversar (5) \\
\hline & & Sin razón especial (2) \\
\hline & Medios donde información para & Recomendación o Referencias (4) \\
\hline & entretenerse & Páginas Web (2) \\
\hline & & Redes Sociales (5) \\
\hline & & Correo electrónicos (1) \\
\hline & & Periódicos (1) \\
\hline & & Radios (2) \\
\hline & Cantidades de personas en salidas & Sólo (2) \\
\hline & & En Pareja (3) \\
\hline & & Grupos: \\
\hline \multirow{21}{*}{$\begin{array}{c}\text { Descripción del Proceso de } \\
\text { Compra }\end{array}$} & & 3 y 4 Personas (4) \\
\hline & & 5 y 6 Personas (4) \\
\hline & & Más de 6 Personas (2) \\
\hline & Quien toma la decisión & En pareja \\
\hline & & Varón (1) \\
\hline & & Mujer (2) \\
\hline & & En Grupos: \\
\hline & & El más amiguero (3) \\
\hline & & El más entusiasta (3) \\
\hline & Frecuencia & Todas las semanas (12) \\
\hline & & Cada 15 días (1) \\
\hline & & 1 vez al mes (1) \\
\hline & & Muy rara vez (1) \\
\hline & Consumo Promedio & Menor a S/40.00 (2) \\
\hline & & Entre S/.40.00 y S/.80.00 (6) \\
\hline & & Entre S/.80.00 y S/.120.00 (4) \\
\hline & & Mayor a S/.120.00 (3) \\
\hline & Promociones preferidas & Descuentos (5) \\
\hline & & Canje de puntos (2) \\
\hline & & $2 \times 1(3)$ \\
\hline & & Barra libre (5) \\
\hline
\end{tabular}




\begin{tabular}{|c|c|c|}
\hline Variables & Componentes & Respuestas (15) \\
\hline \multirow{18}{*}{ Hábitos de Consumo } & Tipo de bebidas preferidas & Cocteles (4) \\
\hline & & Trago corto (4) \\
\hline & & Cerveza (5) \\
\hline & & Tragos vírgenes (2) \\
\hline & Sustituto de bebidas preferidas & Juegos naturales (7) \\
\hline & & Gaseosas (4) \\
\hline & & Agua mineral (4) \\
\hline & Ocasiones de prescindir de comprar & Enfermedad (5) \\
\hline & OI & Compromisos Laborales (2) \\
\hline & & Evaluaciones de Estudios (2) \\
\hline & & Conducir 'amigo elegido' (4) \\
\hline & & Tramites (2) \\
\hline & Opinión de tragos vírgenes & Conoce (15) \\
\hline & & Probaron (12) \\
\hline & & Agradable (10) \\
\hline & Opinión de Cerveza sin alcohol & Conoce (10) \\
\hline & & Probaron (5) \\
\hline & & Agradable (3) \\
\hline \multirow{13}{*}{ Evaluación de la Competencia } & Bares (Top of Mind) & Ayahuasca (2) \\
\hline & & Barbarian (4) \\
\hline & & Barranco Beer Company (3) \\
\hline & & Otros (6) \\
\hline & Ventajas del TOP & Buen Concepto (3) \\
\hline & & Carta de Bebidas y Comida (4) \\
\hline & & Servicio al cliente (5) \\
\hline & & Promociones (3) \\
\hline & Desventajas del TOP & Infraestructura (3) \\
\hline & & Precios (2) \\
\hline & & Seguridad (4) \\
\hline & & Ambiente (4) \\
\hline & & Música (2) \\
\hline \multirow{13}{*}{ Presentación de la Propuesta } & Opinión sobre el concepto de BAR sin & Tranquilidad (4) \\
\hline & & Exclusivo para Abstemios (3) \\
\hline & & Ambiente Cómodo (5) \\
\hline & & Formal (3) \\
\hline & Opinión sobre el Nombre 'La Conversa & Invitar a Conversar (6) \\
\hline & & Referencia amistad (4) \\
\hline & & Innovador (3) \\
\hline & & Da curiosidad (2) \\
\hline & Precio a Pagar por Coctel sin alcohol & a. Menor a S/.15.00 (1) \\
\hline & & b. Entre S/.15.00 y S/.20.00 (10) \\
\hline & & c. Entre S/.20.00 y S/.25.00 (3) \\
\hline & & d. Mayor a $S / .25 .00(1)$ \\
\hline & Modalidad de Pago & Tarjeta (Todos) \\
\hline
\end{tabular}

Continua. 


\begin{tabular}{|c|c|c|}
\hline Variables & Componentes & Respuestas (15) \\
\hline \multirow{14}{*}{ Ambientación } & Diferencia con un Bar Tradicional & Elegante (4) \\
\hline & & Formal (3) \\
\hline & & Moderno (6) \\
\hline & & Otros (2) \\
\hline & Aspectos necesarios para poder & Volumen moderado (6) \\
\hline & conversar & Seguridad (5) \\
\hline & & Tranquilidad (4) \\
\hline & Zona para Fumadores & $\mathrm{Si}(4)$ \\
\hline & & No (11) \\
\hline & Stand Up comedy y Música en Vivo & $\mathrm{Si}(9)$ \\
\hline & & No $(6)$ \\
\hline & Horario Optimo & Hasta 12:am (8) \\
\hline & & Hasta 01:am (3) \\
\hline & & Hasta 02:am (4) \\
\hline \multirow{4}{*}{ Relaciones con el Cliente } & Grupo en Redes Sociales & $\mathrm{Si}(10)$ \\
\hline & & No $(5)$ \\
\hline & Contacto para medir satisfacción & $\mathrm{Si}(8)$ \\
\hline & & No (7) \\
\hline \multirow{11}{*}{$\begin{array}{c}\text { Atención al Personal y Servicios } \\
\text { Adicionales }\end{array}$} & Factores relevantes buen servicio & Amabilidad (5) \\
\hline & & Respeto (3) \\
\hline & & Rapidez (4) \\
\hline & & Conocimiento (3) \\
\hline & Wifi Gratis & $\mathrm{Si}(12)$ \\
\hline & & No (3) \\
\hline & Pedidos digitalizados & $\mathrm{Si}(10)$ \\
\hline & & No (5) \\
\hline & Servicios Adicionales & Recarga de Celular (7) \\
\hline & & Juegos de Mesa (3) \\
\hline & & Otros (5) \\
\hline \multirow{4}{*}{ Intención de Compra } & Acudiría a este tipo de Bar & $\mathrm{Si}(13)$ \\
\hline & & No (2) \\
\hline & Lo Recomendaría & $\mathrm{Si}(13)$ \\
\hline & & No (2) \\
\hline
\end{tabular}




\subsection{Investigación Cuantitativa.}

La investigación cuantitativa es la investigación que utiliza el análisis matemático. Investigación de mercados que se basa en muestras grandes y en altos niveles de importancia estadística, debido a que los datos se generan en una forma rigurosa y científica, en donde los resultados se analizan en una computadora y se resumen en tablas (McDaniel, 2014).

Objetivo General

El objetivo de la investigación cuantitativa es conocer el grado de aceptación de la propuesta de implementación de un bar cero alcoholes en Lima Metropolitana.

Objetivos Específicos

- Determinar la demanda potencial de la propuesta.

- Cuantificar las diferentes variables y factores de éxito descritos en los capítulos anteriores.

- Determinar la viabilidad comercial de la idea de negocio.

\subsubsection{Proceso de Muestreo.}

El termino muestreo se refiere al proceso de obtener información de un subconjunto (una muestra) de un grupo más grande (el universo o población). Luego, el usuario de la investigación de mercados toma los resultados de la muestra y calcula las características del grupo más extenso. (McDaniel, 2014)

Con las muestras probabilísticas, cada uno de los miembros de la población tiene las mismas probabilidades conocidas de ser incluido en la muestra, y los investigadores podrían calcular los límites de confianza del error de muestreo. No obstante, cuando el muestreo probabilístico es demasiado costoso o requiere de mucho tiempo, los investigadores de mercados suelen utilizar muestras no probabilísticas, incluso cuando no pueda medirse su error de muestreo. (Kotler \& Armstrong, 2012)

Para calcular el tamaño de la muestra utilizamos la fórmula estadística que permite conocerla, la cual es la siguiente:

$$
n=\frac{Z^{2} p q}{E^{2}}
$$


Dónde:

Z: nivel de confianza, valor en la distribución normal correspondiente a la probabilidad del error.

p: probabilidad de éxito

q: probabilidad de fracaso (1-p)

E: nivel de tolerancia

$\mathrm{N}$ : número de encuestas

Con un nivel de confianza (Z) de 95\%, una probabilidad de éxito (p) y una probabilidad de fracaso (q) de 50\% y nivel de tolerancia (E) de 5\%, el tamaño de la muestra preciso es de 384.

La técnica de muestreo utilizada fue Muestra probabilística estratificada por distritos (ver tabla 13) y polietápica, donde las etapas son las siguientes:

1. Manzanas

2. Viviendas

Tabla 13

Tamaño de la Muestra

\begin{tabular}{lccc}
\hline \multicolumn{1}{c}{ Distrito } & Habitantes & $\%$ & Encuestas \\
\hline Miraflores & 85,800 & $8 \%$ & 31 \\
San Isidro & 56,800 & $5 \%$ & 19 \\
San Borja & 116,700 & $11 \%$ & 43 \\
Surco & 357,600 & $29 \%$ & 112 \\
La Molina & 178,200 & $17 \%$ & 64 \\
Surquillo & 94,900 & $7 \%$ & 25 \\
Barranco & 31,200 & $2 \%$ & 9 \\
Chorrillos & 335,600 & $13 \%$ & 49 \\
San Juan de Miraflores & 416,000 & $8 \%$ & 31 \\
\hline Total Zona 7 y Zona 8 & $1,672,800$ & $100 \%$ & 384 \\
\hline
\end{tabular}

\section{Informantes}

Finalmente, dentro de la vivienda seleccionada se realizó un filtro para determinar el número de personas en el hogar que corresponden al grupo etario y NSE indicados en el segmento de mercado. En los casos en que más de una persona cumplía las condiciones del 
filtro, se procedió a seleccionar aleatoriamente al informante. Luego de ello, se aplicó el cuestionario propuesto.

\subsubsection{Diseño de Instrumento.}

Basado en los objetivos del estudio cuantitativo se definió utilizar el siguiente instrumento de investigación: el cuestionario (Ver Apéndice 4), y es por mucho el instrumento más común, y pueda ser administrado en persona, por teléfono, por correo electrónico o en línea. Los cuestionarios son muy flexibles, ya que hay muchas formas de

plantear las preguntas. Las preguntas cerradas incluyen todas las posibles respuestas y los sujetos eligen entre ellas. Algunos ejemplos son las preguntas de opción múltiple y las preguntas de escala. Las preguntas abiertas permiten que los sujetos respondan con sus propias palabras (Kotler \& Armstrong, 2012).

La aplicación del cuestionario se realizó tomando en cuenta lo siguiente:

a. El cuestionario se aplicó al grupo objetivo definido anteriormente aplicando las etapas de muestreo descritas en el punto anterior.

b. El rango de edad de 18 a 39 años fue considerado excluyente, es decir no se consideraron otras edades para la aplicación de la encuesta.

c. El cuestionario contó con 16 preguntas cerradas.

d. Los cuestionarios fueron administradas de forma asistida porque era necesario presentar la propuesta del Plan de Negocios.

e. El tiempo promedio de cada encuesta fue de 10 minutos aproximadamente.

Previamente se realizó la encuesta piloto para corregir las preguntas del cuestionario inicial con el fin de hacerlas más comprensibles. En la tabla, a continuación, se muestra la ficha técnica de la investigación cuantitativa: 
Tabla 14

Ficha Técnica de la Investigación Cuantitativa

\begin{tabular}{|c|c|}
\hline Población Meta & $\begin{array}{l}\text { Hombre o mujer de } 18 \text { a } 39 \text { años de edad, pertenecientes al nivel } \\
\text { socioeconómico A/B. }\end{array}$ \\
\hline Ámbito Geográfico & Los distritos comprendidos en las zonas 7 y 8 de Lima metropolitana \\
\hline Enfoque & La investigación será descriptiva, transversal e individual o simple \\
\hline $\begin{array}{l}\text { Técnica de } \\
\text { Investigación }\end{array}$ & Encuestas personales no auto administrados \\
\hline Instrumento & $\begin{array}{l}\text { Se utilizará un cuestionario estructurado y estandarizado con preguntas } \\
\text { cerradas, elaboradas de acuerdo a los objetivos de la investigación. }\end{array}$ \\
\hline Tamaño de la muestra & $\begin{array}{l}384 \text { encuestas efectivas }(*) \\
(*) \text { Este tipo de estudio tendrá un margen de error del } 5 \% \text { trabajando con } \\
\text { un nivel de confianza del } 95 \% \text {. }\end{array}$ \\
\hline Diseño & Probabilístico con muestreo estratificado y polietápico. \\
\hline $\begin{array}{l}\text { Distribución de la } \\
\text { muestra }\end{array}$ & $\begin{array}{l}\text { Distritos (Estratos), Manzanas, viviendas e informantes seleccionados } \\
\text { aleatoriamente. }\end{array}$ \\
\hline Trabajo de Campo & $\begin{array}{l}\text { El trabajo de campo fue desarrollado por los integrantes del grupo y dos } \\
\text { colaboradores adicionales }\end{array}$ \\
\hline Nivel de Supervisión & $\begin{array}{l}\text { La supervisión estuvo a cargo por el asesor de tesis y un experto en } \\
\text { investigación de mercados Urpi Torrado de DATUM. }\end{array}$ \\
\hline
\end{tabular}

\subsubsection{Análisis y Procesamiento de Datos.}

Recopilada la información de los cuestionarios se utilizó hojas de cálculo de Microsoft Excel para su procesamiento, esta base de datos de respuestas obtenidas fueron filtradas y codificadas para obtener las tablas y gráficos resumen de cada tema tratado en las preguntas del cuestionario aplicado.

Los resultados obtenidos en base a los objetivos planteados son principalmente la aceptación por un $42 \%$ (Definitivamente $\mathrm{Si}$ ) de la propuesta de implementación del Bar Cero Alcohol en Lima y específicamente en el distrito de Barranco dado que sólo un 7\% (24) prefiere otra ubicación.

Al haber realizado un estudio probabilístico es posible proyectar la demanda potencial para la propuesta presentada en base a las preguntas filtro (\% a aplicar). Estos resultados servirán de insumo para la proyección del mercado objetivo (ver capitulo IV). Asimismo se validaron los factores de éxito y preferencias de los consumidores obtenidas en el estudio cualitativo.

Como información general 53\% (203) de los encuestados son varones, mientras que el 47\% (181) son mujeres. La edad promedio es de 29 años, el número es casi uniforme en todas las edades, destacando únicamente 28 años y 39 años con un $\%$ cercano al 10\%, en este caso al ser características similares a la población, no ha sido necesario ponderar la desproporción 
con la población. Los resultados a detalle son los siguientes, y se muestran por cada tema tratado en el cuestionario con una breve explicación de cada una de ellas.

En la Figura 23 se identifica que la mayoría de persona sale a divertirse, lo cual representa una oportunidad para la propuesta, y sólo el 10.7\% (41) de personas No acostumbra salir a divertirse, a los cuales se les agradeció su participación.

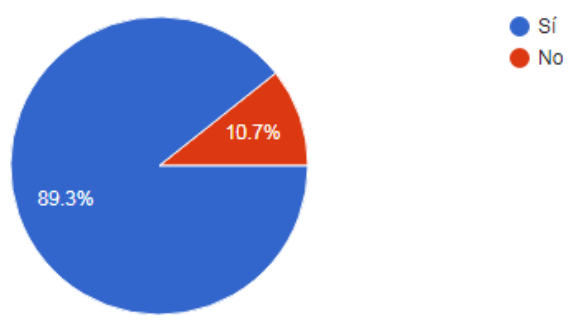

Figura 23. Pregunta Filtro: ¿Sale a divertirse?

Los principales establecimientos de preferencia son Restaurantes 51.8\% (178), Bares $43.2 \%$ (148) y Discotecas $41.1 \%$ (141) en ese orden, estos establecimientos son afines a al proyecto, dado que existen formatos denominados Resto Bar y Disco Bar (ver Figura 24.)

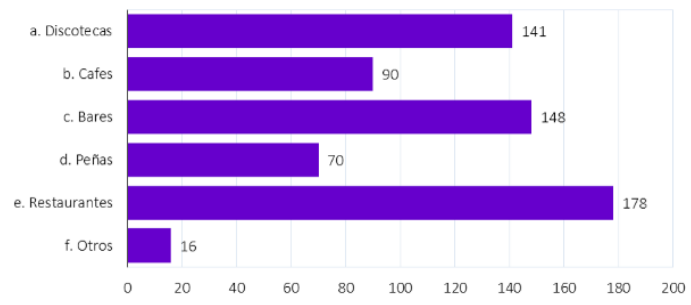

Figura 24. Tipos de Establecimientos de diversión o de entretenimiento que asiste.

Los principales motivos que impulsan a asistir a sus establecimientos favoritos son Diversión o relajo $75.5 \%$ (259), Celebraciones $45.2 \%$ (155) y Cumpleaños 29.2\% (100) en ese orden, esto es importante para poder comunicar correctamente relacionando los motivos con la propuesta a los potenciales clientes (ver Figura 25.). 


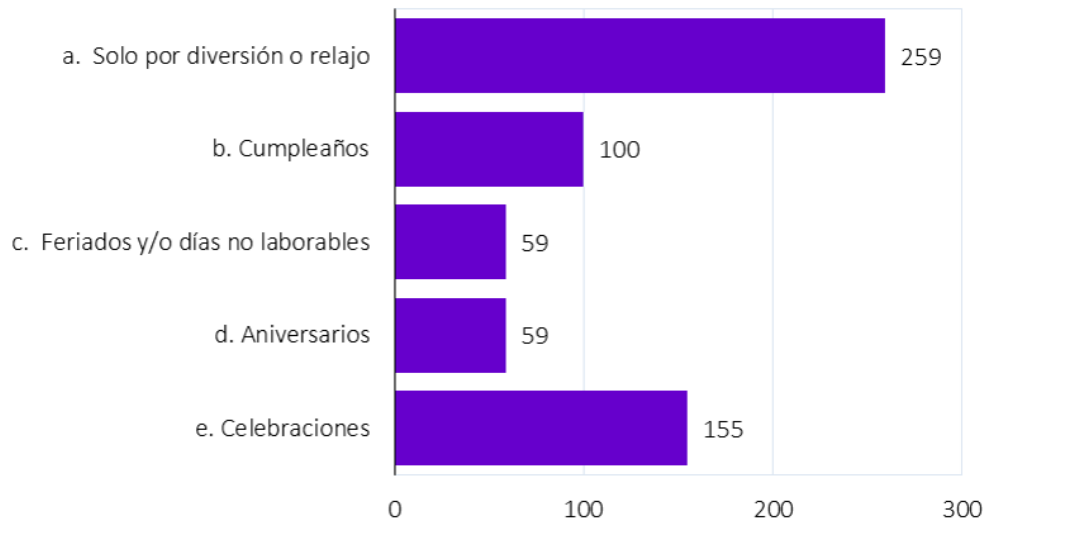

Figura 25. Motivos por el cual asiste.

La mayor frecuencia de salida es semanal y quincenal. El 36.4\% (125) indica salir todas las semanas, mientras que el $32.1 \%$ (110) lo hace cada 15 días y el $26.5 \%$ (91) lo hace cada mes y sólo el 5\% (17) lo hace muy rara vez (ver Figura 26).

La frecuencia de asistencia a sus establecimientos favoritos es clave para poder realizar las proyecciones de ventas.

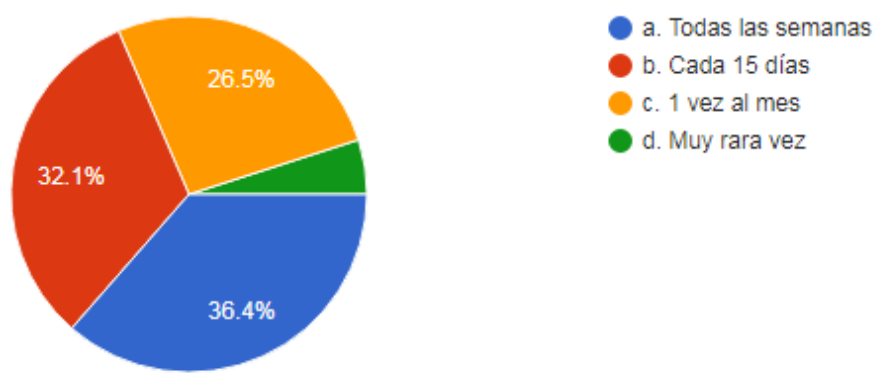

Figura 26. Frecuencia de asistencia a los establecimientos.

El tener un ambiente que para una buena conversación 52,8\% (181) y tener música y baile 44,6\% (153) son los principales criterios para la elección del establecimiento favorito, cuando tiene música y shows representan el 22,7\% (78) cada una de las opciones; cuando se expenden bebidas alcohólicas y otros no son respuestas exclusivas o únicas con respecto a las anteriores (ver Figura 27). 


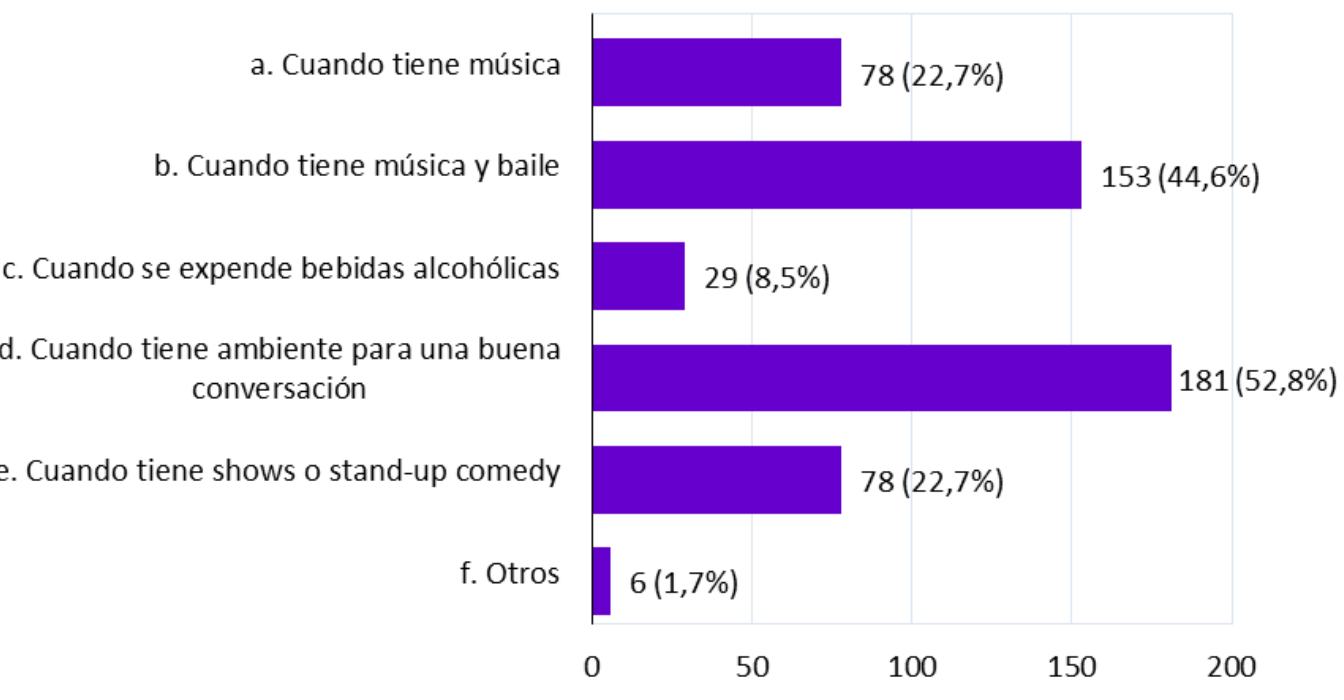

Figura 27. Criterios de distinción y de preferencia para la asistencia a los establecimientos.

El consumo promedio por persona mayoritariamente se encuentra entre S/40 y S/80 con $62,7 \%$ (215); menos de $\mathrm{S} / 40$ con $17,8 \%$ (61), entre $\mathrm{S} / 80$ y $\mathrm{S} / 120$ con $16 \%$ (55) y un consumo mayor a S/120 con 5\% (12). Este consumo promedio servirá como insumo para las proyecciones de ventas (ver Figura 28).
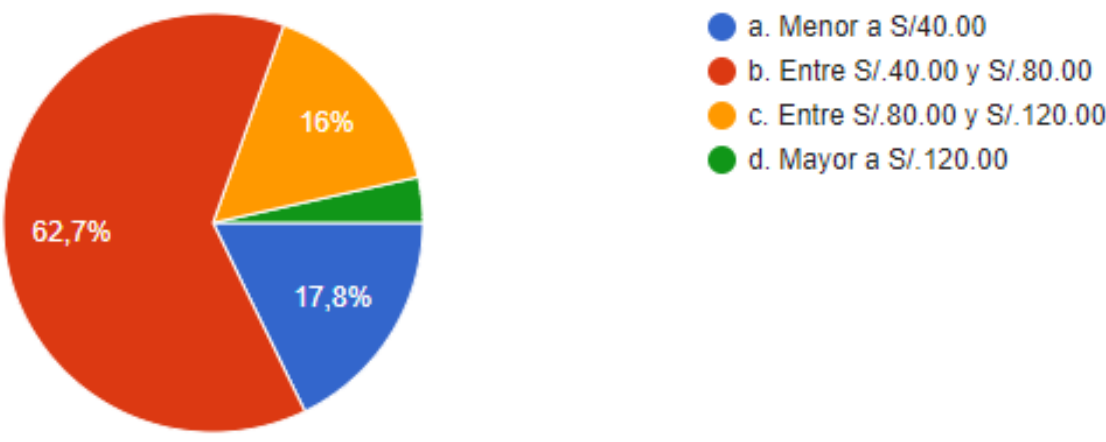

Figura 28. Consumo promedio por persona.

El promedio general del número de personas con las que se acostumbra salir es de 3 personas. La cantidad de personas con las que se acostumbra salir a divertirse es mayoritariamente en pareja o grupo de dos 44,6\% (153), seguidos de grupos de 3 y 4 con $19,8 \%$ (68) y $17,8 \%$ (61) respectivamente. El promedio general del número de personas con 
las que se acostumbra salir es de 3 personas (ver Figura 29).

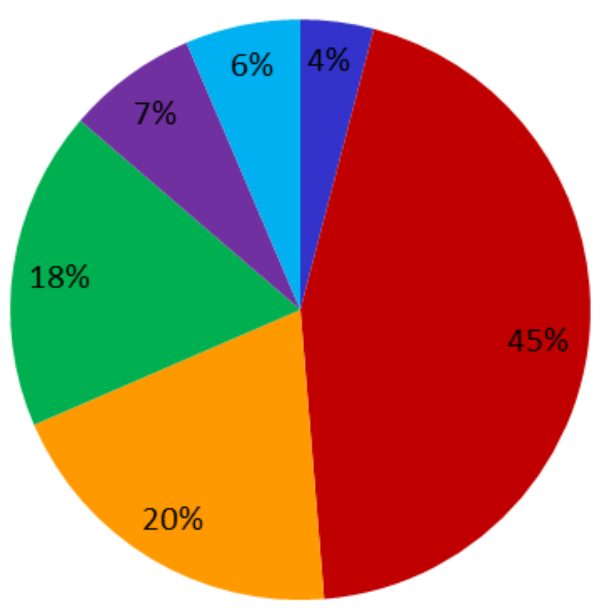
a. Sólo (1)
- b. Pareja / Grupo de 2
c. Grupo de 3
d. Grupo de 4
- e. Grupo de 5
च. Grupo de 6 a más

Figura 29. Cantidad promedio de personas en salidas.

Con respecto a las motivaciones para el consumo de bebidas alcohólicas el 31,5\% (108) indican hacerlo porque no hay otras opciones en la carta, también existe un 29,7\% (102) que "indica" no consumir bebidas alcohólicas, sin bien esta respuesta puede tener un sesgo de responder lo que podría estar bien, también podría validar las tendencias mundiales con respecto al menor consumo debidas alcohólicas especialmente en los jóvenes. Hacerlo porque todos toman o porque realmente les agrada equivalen al 19,5\% (66) y 19,5\% (67) respectivamente (ver Figura 30).

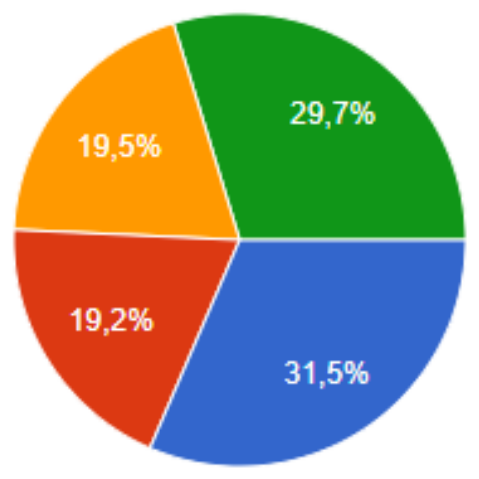

a. No hay otra opción en la carta

b. Porque todos toman

c. Realmente me agrada

d. No tomo Alcohol

Figura 30. Motivos para el consumo de bebidas alcohólicas. 
Los aspectos más valorados de la propuesta de un bar sin alcohol son primero la ambientación con 37,3\% (128), seguidos de la oferta de bebidas y aperitivos y la música con $34,4 \%$ (118) y $34,1 \%$ (117) respectivamente como los principales aspectos tener en cuenta; el siguiente asvecto valorado es el concepto con $28,3 \%$ (97) y en último lugar el horario con 7,9\% (27) (ver Figura 31).

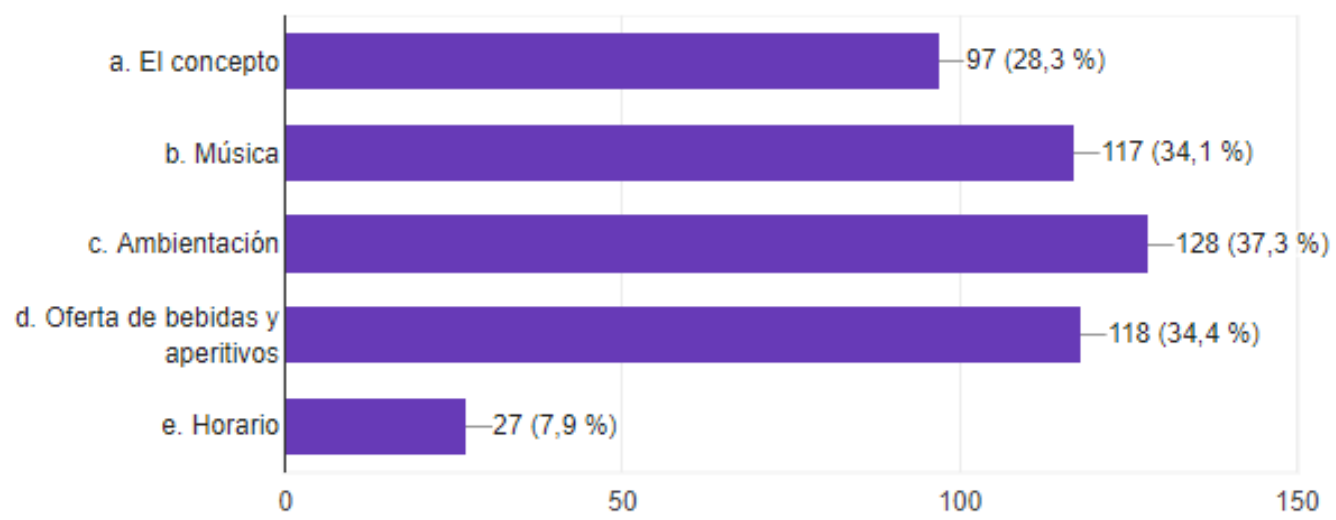

Figura 31. Aspectos más valorados en un Bar sin Alcohol.

De los nombres presentados como opciones para el bar sin alcohol destacaron "La Conversa Bar" con 37,3\% (128) seguido de "Bar Grado Cero" con 27,7\% (95) con lo cual la propuesta se mantendrá con el nombre original propuesto por los autores y se recomienda registrar ambos para una posible renovación de nombre en un horizonte mayor de tiempo; otros nombres fueron poco representativos menor a 10,0\% (ver Figura 32).
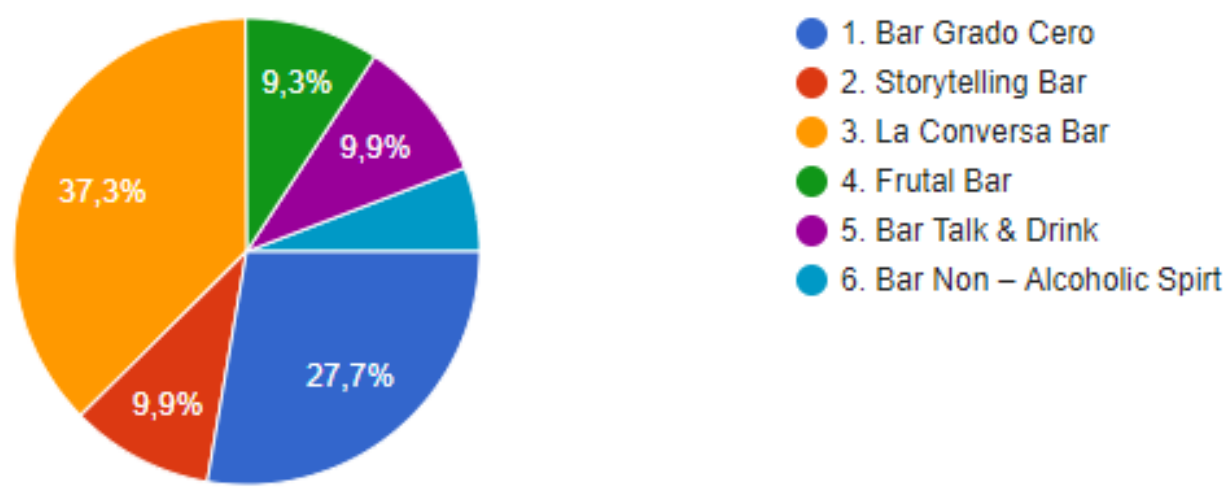

Figura 32. Alternativas de nombres para el nuevo concepto de Bar. 
El precio a pagar por un trago virgen o coctel sin alcohol está entre $\mathrm{S} / 15$ y S/20 con $55,4 \%$ (190), entre $\mathrm{S} / 20$ y S/25 y mayor a $\mathrm{S} / 25$ tiene $25,1 \%$ (86) y $0,6 \%$ (2) respectivamente. La respuesta que debe ser excluida de las proyecciones es un precio menos a $S / 15$ que representa el 19\% (65) de la disposición de pago puesto que en la propuesta los precios de las bebidas serán mayores a S/15 (ver Figura 33).

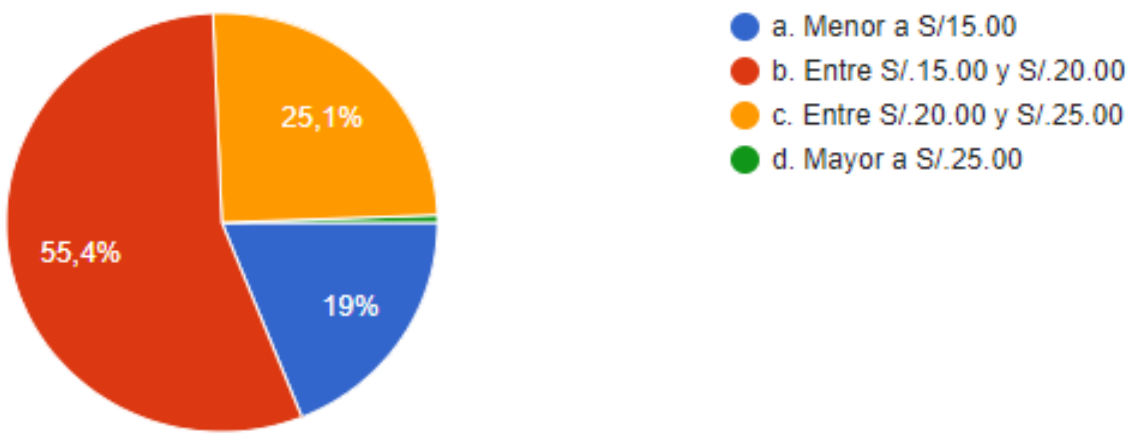

Figura 33. Rango de precio a pagar por un coctel sin alcohol.

Barranco es considerado óptimo para la ubicación del bar propuesto por la diversidad de oferta con 38,8\% (108), accesibilidad, tradicional/cultural y turístico $28,9 \%$ (80), 26,8\% (75) y $22,2 \%$ (62) respectivamente. Sin embargo el 7\% (19) prefiere otra ubicación, por lo cual este porcentaje debe ser excluido de las proyecciones, puesto que se definió hacerlo en este distrito (ver Figura 34).

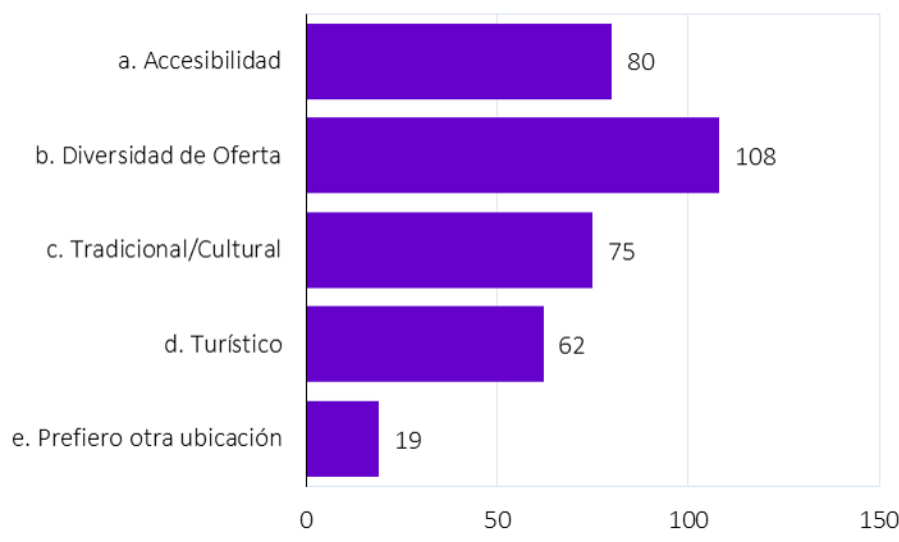

Figura 34. Factores relevantes para la ubicación de una propuesta del Bar sin alcohol en Barranco. 
La creación de bebidas es considerada el proceso más importante con 38\% (100), seguido de la atención del personal y la preparación de piqueos con $28 \%$ (72) y 26\%(67) cada uno como los procesos más importantes, Compras con 5\% (13) y Caja son considerados menos importantes (ver Figura 35).

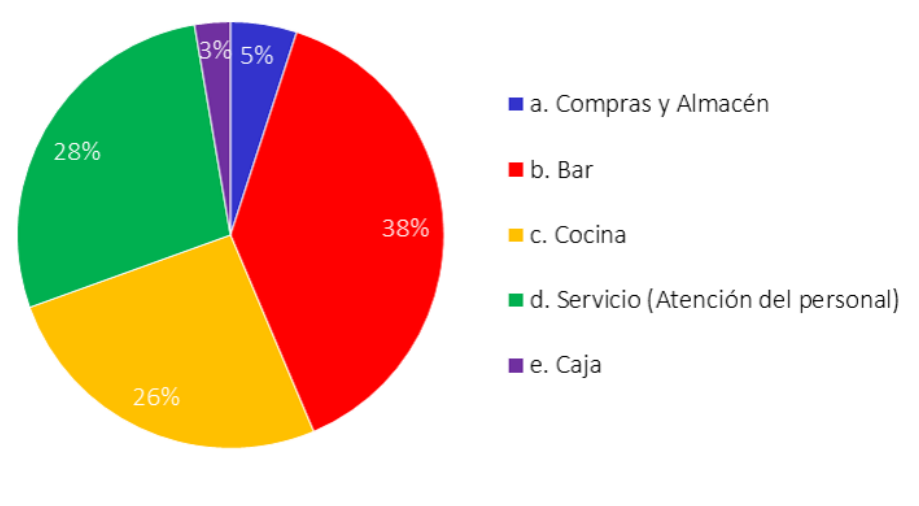

Figura 35. Procesos de importancia en este tipo de bar.

Una atención personalizada es el factor más relevante en la atención al personal con $43,7 \%$ (150), seguidos de la rapidez y la amabilidad con $41,1 \%$ (141) y $36,2 \%$ (124) respectivamente; la pulcritud con 17,8\% (61) y a diferencia de la información cualitativa el conocimiento del concepto de negocio no es considerado relevante (ver Figura 36).

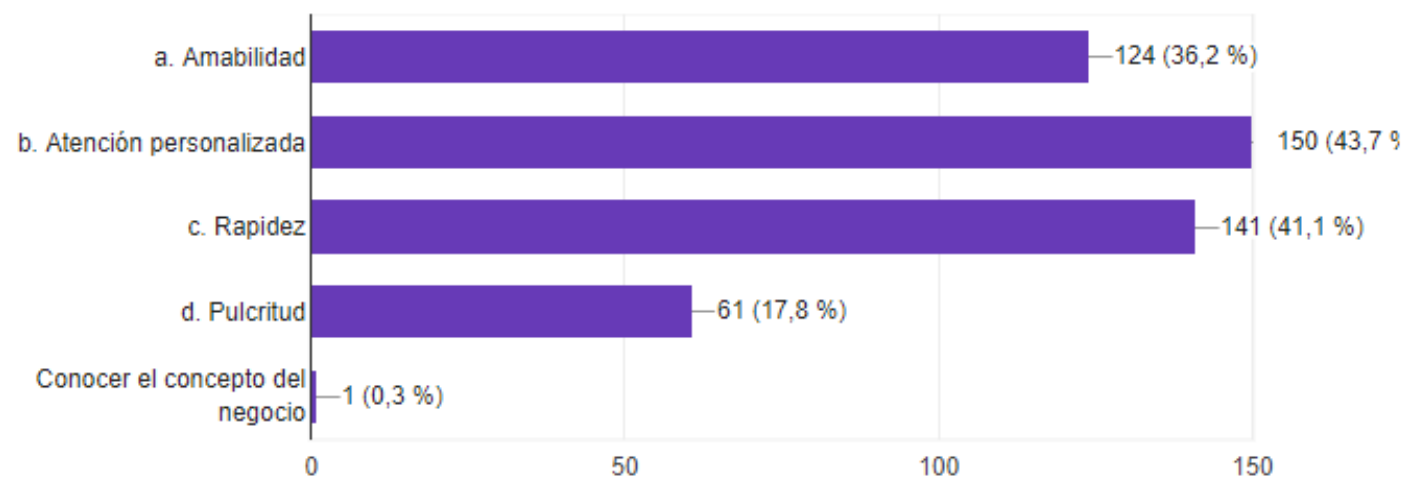

Figura 36. Factores relevantes en la atención del personal.

En general las redes sociales son el medio de contacto preferido con 61\% (158), seguidos de las recomendaciones o referencias también considerado "boca o boca" con 29,7\% (77), correo electrónico y páginas web con 23,6\% (61) y 19,7\% (51) respectivamente; periódicos y radios son menores al $11 \%$ y $5 \%$. Estas preferencias demuestran el avance de la publicidad en medios digitales y las buenas relaciones con los clientes (ver Figura 37). 


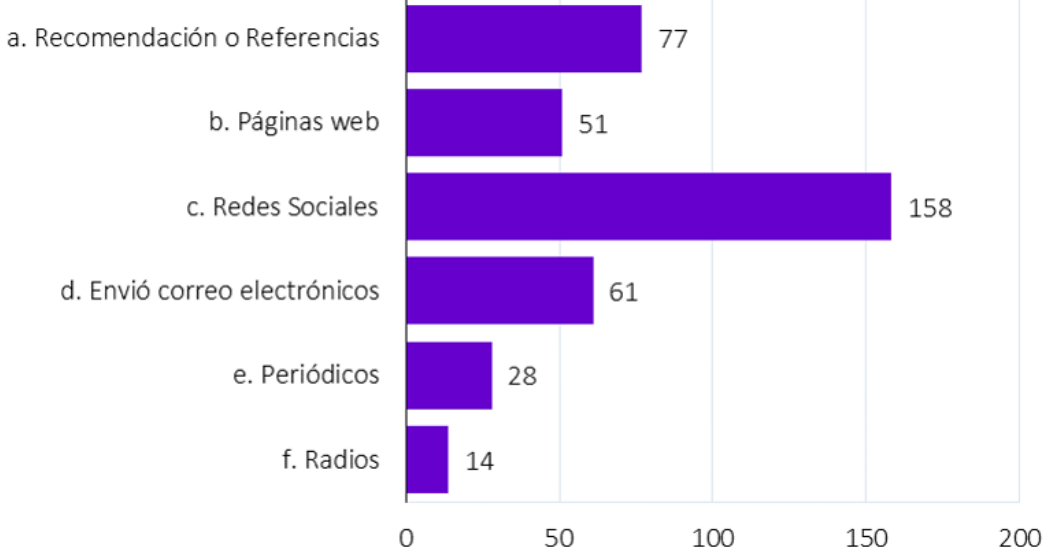

Figura 37. Medios preferentes para ser contactado.

El 42\% (109) Definitivamente lo haría y el 49\% (127) probablemente lo haría; sin embargo, para el $7 \%$ (18) y el $2 \%$ (5) es poco probable y Nada probable acudir a un establecimiento (Bar) donde solo se expenda cocteles y tragos sin alcohol con la misma presentación y ambientación de un bar tradicional (ver Figura 38).
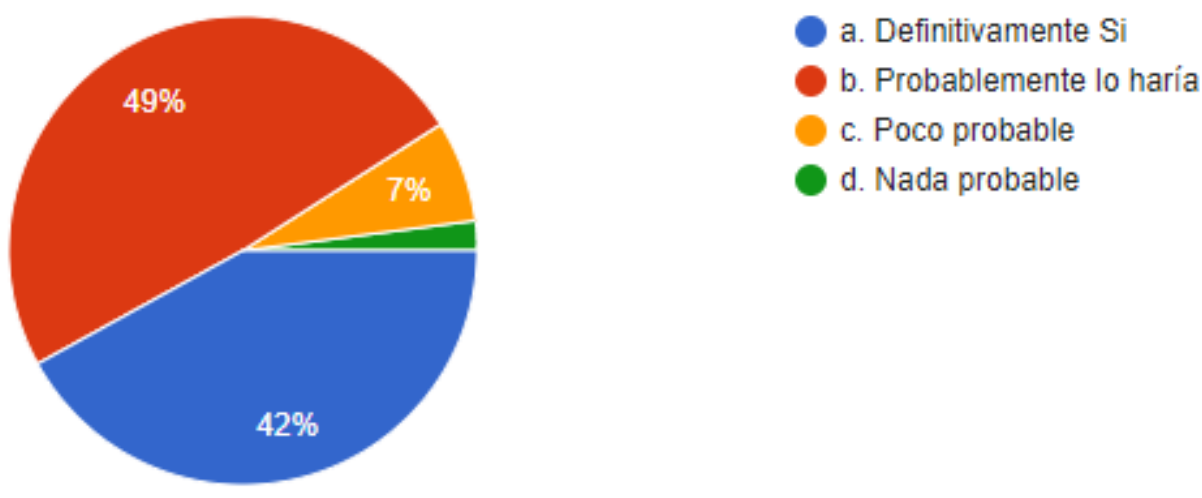

Figura 38. Intención de compra.

\subsection{Conclusiones y recomendaciones del Estudio Cualitativo y Cuantitativo.}

Conclusiones de Entrevista a Expertos:

- Las motivaciones para la formación de un bar son diversas, en algunos casos como extensión de negocios, como en el caso de Barbarian se trata de una extensión de la cervecería; en el caso del Bar Victoria una extensión de centros de arte y talleres; sin embargo, en otros casos la motivación es netamente empresarial como hacer un bar para turistas, realización de formación académica y/o por vocación. 
- Como todo negocio, los gestores de los bares tienen claro la propuesta de valor para sus respectivos clientes. Cada propuesta es particular para cada bar y esto lo hace distintivo.

- Cada bar tiene un tipo de cliente en particular, es decir son especiales para cerveceros, turistas, artistas, bohemios y para cada temática preferida. En su mayoría los expertos indican usar además de la segmentación geográfica y demográfica, la segmentación conductual o por estilos de vida, sin considerar restrictivo el nivel socioeconómico.

- La competencia debe ser identificada según ubicación geográfica y según el tipo de cliente al que van dirigidos; los bares tradicionales se refieren a los bares temáticos como modas pasajeras.

- Los tipos de bares identificados en Lima son los bares tradicionales, los Pub "public houses", disco bar, bares karaoke, bares cerveceros, bares cafés, bares cantinas, bares restaurantes "resto bar" y los bares temáticos.

- Dentro de los aspectos legales, los trámites municipales son los más engorrosos o difíciles de obtener, de manera especial la licencia de funcionamiento.

- El Manejo Financiero de los bares son un factor clave, de manera especial la gestión de costos de los productos y servicios, los expertos consideran La renta el principal costo.

- Los expertos consideran Procesos claves a la producción de bebidas y atención al cliente basado en un personal capacitado y motivado; asimismo recomiendan encargar la Gestión de los bares en manos de administradores profesionales.

- Los expertos opinan favorablemente sobre la propuesta de "La Conversa" Bar cero Alcohol, consideran es una alternativa para un segmento de mercado, alientan a los autores a llevarla a cabo en un futuro próximo, consideran una buena época para su implementación.

\section{Conclusiones de Focus Group:}

- El principal motivo para acudir a un establecimiento nocturno es sólo por diversión. Pasar el momento con una agradable compañía y poder conversar es importante. Actualmente las redes sociales son el principal medio de contacto y promoción. Las salidas en diferentes grupos de personas son más relevantes que las salidas en pareja. Es la pareja y el más amiguero del grupo quien propone o elige el 
establecimiento. La frecuencia de salida más relevante es semanalmente. El consumo promedio por persona se encuentra en el rango de $\mathrm{S} / 40$ y $\mathrm{S} / 80$ como el rango más representativo. El Happy hour y el 2x1 son las promociones preferidas en los bares tradicionales.

- En los bares tradicionales los cocteles y la cerveza son las bebidas preferidas. Los jugos naturales son el principal sustituto para las bebidas preferidas. La principal razón por la que un consumidor habitual no consume alcohol en su establecimiento favorito es haber sido designado como el "amigo elegido" para manejar y cuidar del grupo. El piqueo salado es el complemento de consumo preferido en los bares tradicionales. Independientemente del consumo los consumidores tienen una opinión favorable sobre los cocteles o tragos vírgenes. Los consumidores tienen opinión favorable son la cerveza sin alcohol.

- Entre los bares actuales existen diferentes tipos y destacan los cerveceros, pubs y temáticos. En el top of mind de bares resaltan Barbarian y Ayahuasca. Los diferentes tipos de bares usan las redes sociales como principal medio de promoción. La Carta de bebidas es la principal fuente de ventajas o desventajas de los bares tradicionales. En general se valora la experiencia como agradable para el establecimiento preferido. El público materia del estudio considera desagradable asistir a las cantinas en general.

- Sobre la Presentación de la propuesta "La Conversa" Bar cero Alcohol la opinión fue favorable considerándolo interesante. La ocasión para acudir son la conversación en general y los compromisos al día siguiente. La mayoría indica que el nombre "La Conversa" se encuentra acorde con el concepto. Al ser un lugar donde No se consumiría alcohol se requiere dar facilidades para el estacionamiento de vehículos. La mayoría pagaría más de S/15 por un trago sin alcohol. La modalidad de pago preferida es vía tarjeta de crédito o débito.

- En cuanto a la ambientación se considera elegante, algo formal pero acorde con la propuesta. En general no requiere una zona para fumadores puesto que relacionan la propuesta con un ambiente sano. La opinión sobre la inclusión de música y show en vivo es favorable con la indicación de bajo volumen que facilite la conversación. El horario acorde con la propuesta no requiere atención hasta la madrugada. 
- El tipo de promoción preferida es el happy hour y se requiere mantenerlo en la propuesta. Es necesaria la creación de una comunidad o grupo en redes sociales. Los consumidores están dispuestos a ser contactados para medir su satisfacción de preferencia en el mismo establecimiento.

- La amabilidad y buen trato del personal es clave en la atención del personal. El Servicio de Wifi gratuito es un servicio adicional que los consumidores dan por incluido. Se requiere rapidez en la atención de los pedidos y los pedidos digitalizados son valorados para su implementación. Adicional al estacionamiento se sugiere la facilidad para carga de celulares.

- En general los participantes del focus acudirían al bar y lo recomendarían entre sus familiares y amigos.

Conclusiones de Encuesta:

- En general las personas acostumbrar a divertirse, solo un $10,7 \%$ se abstiene de salir.

- Los principales establecimientos de preferencia son Restaurantes, Bares y Discotecas, estos establecimientos son afines al proyecto, dado que existen formatos denominados Resto Bar y Disco Bar.

- Los principales motivos que impulsan a asistir a sus establecimientos favoritos son Diversión o relajo, Celebraciones y Cumpleaños, esto es importante para poder comunicar correctamente relacionando los motivos con la propuesta a los potenciales clientes.

- La mayoría de encuestados indica salir todas las semanas, la frecuencia de asistencia a sus establecimientos favoritos es clave para poder realizar las proyecciones de ventas.

- Tener un ambiente para una buena conversación y tener música y baile son los principales criterios para la elección del establecimiento favorito.

- El consumo promedio por persona mayoritariamente se encuentra entre S/40 y $\mathrm{S} / 80$. Este consumo promedio servirá como insumo para las proyecciones de ventas.

- La cantidad de personas con las que se acostumbra salir a divertirse es mayoritariamente en pareja o grupo de 2, grupos de 3 y 4 . El promedio general del número de personas con las que se acostumbra salir es de 3 personas. 
- La principal motivación para el consumo de bebidas alcohólicas es porque no hay otras opciones en la carta, también existe \% menor que "indica" no consumir bebidas alcohólicas.

- Los aspectos más valorados de la propuesta de un bar sin alcohol son ambientación, la oferta de bebidas y aperitivos y la música.

- De los nombres presentados como opciones para el bar sin alcohol destacaron "La Conversa Bar" y "Bar Grado Cero" con lo cual la propuesta se mantendrá con el nombre original propuesto por los autores y se recomienda registrar ambos para una posible renovación de nombre.

- El precio a pagar por un trago virgen o coctel sin alcohol está entre S/.15 y S/.20. La respuesta que debe ser excluida de las proyecciones es un precio menos a S/15 puesto que en la propuesta los precios de las bebidas serán mayores a S/. 15.

- Barranco es considerado óptimo para la ubicación del bar propuesto. Sin embargo, el \% que prefiere otra ubicación debe ser excluido de las proyecciones, puesto que se definió hacerlo en dicho distrito.

- La creación de bebidas es considerada el proceso más importante, seguido de la atención del personal y la preparación de piqueos.

- Una atención personalizada es el factor más relevante en la atención al personal, seguido de la rapidez y la amabilidad, a diferencia de la información cualitativa el conocimiento del concepto de negocio no es considerado relevante.

- En general las redes sociales son el medio de contacto preferido seguidos de las recomendaciones o referencias también considerado "boca o boca". Estas preferencias demuestran el avance de la publicidad en medios digitales y las buenas relaciones con los clientes.

- Con respecto a la aceptación de acudir al establecimiento propuesto el $42 \%$ Definitivamente lo haría y el $49 \%$ probablemente lo haría; lo cual valida la aceptación obtenido en la fase exploratorio o estudio cualitativo.

Recomendaciones:

- Se recomienda el uso de las redes sociales para promocionar la propuesta.

- En cuanto a las promociones en el establecimiento se recomienda aplicar descuentos como el 2x1 para bebidas.

- Se recomienda mantener el precio promedio por bebida resultado del estudio $\mathrm{S} / .20$. 
- La carta de bebidas es un factor crítico por lo que se recomienda la contratación de un barman experimentando en cocteles sin alcohol y tragos vírgenes.

- La capacitación al personal es importante, así como un adecuado reclutamiento del personal de servicio, puesto que la atención del personal es otro factor crítico.

- El consumo de bebidas de bebidas sin alcohol está relacionado con buenos hábitos, evitar excesos, se recomienda establecer alianzas con instituciones que les interese fomentar consumo responsable.

- Se recomienda la implementación en el distrito de Barranco por la afluencia de público y por representar una alternativa diferente para el consumidor habitual actual.

- Se recomienda la inscripción de ambos nombres "La Conversa Bar" y "Bar Cero Grados" como marca registrada.

- Se recomienda un adecuado manejo financiero para asegurar abastecimiento y control de gastos y recursos en general.

- Se recomienda comunicar eficientemente el perfil de consumidor el cual no es solo personas que no consumen alcohol, si no también aquellos que siendo consumidores tienen ocasiones en las que deben privarse del consumo de alcohol.

\subsection{Perfil del consumidor tipo y sus variantes.}

El perfil del consumidor tipo se ha definido según ciertas características observables del público, el cual es un recurrente asistente a establecimientos de entretenimiento, especialmente a bares. De este modo, como resultado del estudio realizado se logró elaborar el perfil del consumidor específico para la propuesta de Bar Cero Alcohol.

Dado lo anterior, se identificó a consumidores residentes en los distritos comprendidos en la zona 7 y zona 8 de Lima metropolitana, pertenecientes a los Estratos A y B, de ambos sexos, comprendidos entre 18 a 39 años, consumidores de bebidas comerciales y asistentes a bares tradicionales y temáticos. No obstante, dadas las característica de la propuesta, para un futuro estudio no se descarta la inclusión de menores de edad.

Por otro lado, se validó la inclusión de consumidores habituales de alcohol dado que hay ocasiones en las que requieren compartir momentos agradables con amigos y/o familiares sin consumir alcohol; entre los principales motivos para abstenerse de consumir alcohol se encuentran tratamientos de enfermedad, embarazos, compromisos de índole deportivos, laboral o estudios que requieren lucidez. 


\section{Capítulo IV. Proyección del Mercado Objetivo}

Este capítulo nos servirá para definir en primer lugar al Mercado Potencial, al Mercado Disponible, al Mercado Efectivo y finalmente el Mercado Objetivo a partir de los resultados obtenidos a través del análisis cuantitativo. Adicionalmente se proyectará dicho mercado para todo el horizonte de evaluación del proyecto.

\subsection{El ámbito de la selección}

Según Sapag (2014), la dificultad mayor al pronosticar comportamientos radica en la posibilidad de la ocurrencia de eventos que no hayan sucedido anteriormente, como el desarrollo de nuevas tecnologías, la incorporación de competidores con sistemas comerciales no tradicionales, las variaciones en las políticas económicas gubernamentales, etcétera. Los antecedentes históricos serán, por lo tanto, variables referenciales para el analista de proyecto, quien deberá usar los métodos de proyección como técnicas complementarias antes que como alternativas estimativas certeras. Por ello, no siempre la existencia de información histórica es garantía de una proyección confiable.

La validez de los resultados de la proyección está íntimamente relacionada con los datos de entrada que sirvieron de base para el pronóstico. Las fuentes de información de uso más frecuente son las series históricas oficiales de organismos públicos y privados, las opiniones de expertos y el resultado de encuestas especiales, entre otras.

\subsection{Selección del método de proyección}

La elección del método correcto dependerá principalmente de la cantidad y calidad de los antecedentes disponibles, así como de los resultados esperados, del tiempo y del nivel de precisión deseados. La efectividad del método elegido se evaluará en función de su precisión, sensibilidad y objetividad.

Los métodos de carácter cualitativo, también denominados subjetivos, se basan principal-mente en opiniones de expertos. Su uso es frecuente cuando el tiempo para elaborar el pronóstico es escaso, cuando no se dispone de todos los antecedentes mínimos necesarios - lo que frecuentemente ocurre cuando se trata de proyectos de innovación - o cuando los datos disponibles no son confiables para predecir algún comportamiento futuro.

Los Modelos de pronóstico causales: técnica de proyección que busca pre-decir el comportamiento de una variable en función de relaciones causa-efecto observadas.

Los modelos de serie de tiempo se utilizan cuando el comportamiento que asuma el mercado a futuro puede determinarse en gran medida por lo sucesivo en el pasado, y siempre que esté disponible la información histórica en forma confiable y completa. (Sapag, 2014) 
Para la proyección de la demanda se utilizaron los resultados obtenidos del estudio de mercado, específicamente de la investigación cuantitativa. Los \% fueron aplicados al mercado potencial (segmentación de mercado) y este a su vez crece de manera lineal, es decir se aplicó el método de regresión lineal.

\subsubsection{Mercado Potencial}

Es el conjunto de consumidores al que puede llegar el producto o servicio. En esta línea, son aquellos consumidores que podrían necesitar el producto o servicio que se desea ofrecer. Así, este mercado lo conforman las personas que pueden consumir o no consumir el producto general que se desea ofrecer, no obstante, cumplen con los criterios de segmentación (Asesoría Asesoramiento en Planes de Negocio, 2016).

Para el primer año se toma la información obtenida de aplicar la segmentación propuesta (Ver Capítulo 3) es decir se tienen 300,780 personas (Ver Tabla 15); para los año siguientes se toma el crecimiento anual de la población de Lima 1.3\% (INEI, 2015).

Tabla 15

Mercado Potencial

\begin{tabular}{lcccccc}
\hline Número de Personas & $\%$ & Año 1 & Año 2 & Año 3 & Año 4 & Año 5 \\
Mercado Potencial & $1.3 \%$ & 300,780 & 304,690 & 308,651 & 312,663 & 316,728
\end{tabular}

Nota: Año 1 Tomado de Estimaciones y proyecciones de población, Instituto Nacional de Estadística 2017, y Perú población 2017 Departamento de Estadística - CPI

\subsubsection{Mercado Disponible.}

Es una parte del mercado potencial y está formada por el conjunto de consumidores que tienen la necesidad específica de comprar el producto o servicio que ofrece el nuevo negocio. Esto no quiere decir que todas estas personas compraran el producto que ofrecerá el nuevo negocio. De este total, una parte podría comprar al nuevo negocio y otro no, por diferentes razones (Ver Tabla 16).

Para determinar el mercado disponible se utilizaron las preguntas filtro del cuestionario de encuesta:

- Pregunta 1. ¿Acostumbra a salir de casa para divertirse o entretenerse?

Sí: $89.30 \%$

- Pregunta 11. ¿En este tipo de bar, cuánto pagaría por un trago o cóctel sin alcohol? 
- Pregunta 12. ¿Qué factores considera relevantes para la ubicación propuesta del Bar sin alcohol en Barranco?

Prefiero otra ubicación: 7\% Barranco Ok: 93\%

Para calcular el Mercado Disponible se ha utilizado la siguiente fórmula:

Mercado Disponible $=$ Mercado Potencial $*$ Preguntas Filtro $(1,11,12)$

Reemplazando

Mercado Disponible $=300,780 * 89.3 \% * 81 \% * 93 \%$

Mercado Disponible $=202,333$

Para efectos de proyección se mantienen los \% obtenidos para los siguientes años

Tabla 16

Mercado Disponible

\begin{tabular}{lcccccc}
\hline Número de Personas & $\%$ & Año 1 & Año 2 & Año 3 & Año 4 & Año 5 \\
\hline Mercado Potencial & $1.3 \%$ & 300,780 & 304,690 & 308,651 & 312,663 & 316,728 \\
Mercado Disponible & $67.3 \%$ & 202,333 & 204,964 & 207,629 & 210,327 & 213,062
\end{tabular}

\subsubsection{Mercado Efectivo.}

Es una parte del mercado disponible y está formado por el conjunto de consumidores que además de la necesidad específica, tienen la intención de compra del bien o servicio que ofrece el nuevo negocio. Este mercado es definido a través de la respuesta a la pregunta 16 del cuestionario de encuesta y el índice de Pope para ajustar la proyección (Ver Tabla 17), dando como resultado para el primer año 90,018 y 94,791 personas para el quinto año.

Tabla 17

Mercado Efectivo

\begin{tabular}{lccc}
\hline Intención & Respuesta \% & \multicolumn{2}{l}{ Criterio Pope } \\
\hline Definitivamente $\mathrm{Si}$ & $42 \%$ & $75 \%$ & $31.500 \%$ \\
Probablemente & $49 \%$ & $25 \%$ & $12.250 \%$ \\
Poco Probable & $7 \%$ & $10 \%$ & $0.700 \%$ \\
Nada Probable & $2 \%$ & $2 \%$ & $0.040 \%$ \\
& & $44 \%$ & $44.490 \%$ \\
\hline
\end{tabular}




\subsubsection{Mercado Objetivo.}

Es una parte del mercado efectivo que la empresa espera atender, es decir la parte del mercado efectivo que se fija como meta a ser alcanzada por el negocio (Asociación Pro bienestar y Desarrollo, 2008). En otras palabras, al realizar los esfuerzos y acciones de marketing de la empresa se espera captar a esta cantidad de personas. Este mercado también es definido a través del \% de mercado que se desea captar, y en esta oportunidad los autores han definido $2 \%$ basados en la opinión de los expertos consultados (ver Tabla 18).

Para efectos de proyección se mantiene el mismo porcentaje de captación para los siguientes años:

Tabla 18

Mercado Objetivo

\begin{tabular}{lcccccc}
\hline Número de Personas & $\%$ & Año 1 & Año 2 & Año 3 & Año 4 & Año 5 \\
\hline Mercado Potencial & $1.3 \%$ & 300,780 & 304,690 & 308,651 & 312,663 & 316,728 \\
Mercado Disponible & $67.3 \%$ & 202,333 & 204,964 & 207,629 & 210,327 & 213,062 \\
Mercado Efectivo & $44.0 \%$ & 90,018 & 91,188 & 92,374 & 93,574 & 94,791 \\
Mercado Objetivo & $2.0 \%$ & 1,339 & 1,808 & 1,831 & 1,855 & 1,879 \\
\hline
\end{tabular}




\section{Capítulo V: Plan de Marketing}

Habiendo definido el Mercado Objetivo, podremos en este capítulo plantear la estrategia general, así como las diferentes estrategias de marketing (Marketing Mix) que aplicaremos para ofrecer y hacer llegar la propuesta de valor de la mejor manera al respectivo mercado.

\subsection{Estrategias de Marketing}

El marketing empresarial abocado a satisfacer las necesidades de los consumidores mediante la adaptación de la oferta de bienes y servicios de la organización, es una función indispensable en las condiciones actuales de competencia y globalización. Es importante el análisis sobre la conducción de la organización en relación a la satisfacción de sus clientes. El marketing es el responsable directo sobre las decisiones relacionadas con la distribución, comunicación, precio, y producto (D’Alessio, 2013).

Por otro lado, el líder del "management" moderno, Peter Drucker, coincide afirmando que "el objetivo del marketing consiste en lograr que las ventas sean innecesarias" (Drucker, 2002). A ello, se podría agregar que el objetivo final de las ventas, que es obtener utilidades por volúmenes de ventas, es superado por el objetivo final del marketing que es la generación de utilidades por la satisfacción del cliente.

Una buena estrategia de marketing debe de ser un conjunto de actividades humanas que solo se enfoquen a buscar satisfacción de los deseos y necesidades de los usuarios mediante procesos de intercambio, y en el planteamiento debe de comprender que los usuarios no adquieran el servicio, solamente, sino soluciones a sus problemas o satisfacción de sus deseos (Franco, 2013). En el presente caso de estudio al ser un servicio se debe de tener claro lo que la gente valora al momento de consumirlo; y a su vez está relacionado con: el lugar donde se proporciona, la disponibilidad cuando lo requiera, la fijación de un precio adecuado y el esfuerzo en la atención que se haga para lograr la tal satisfacción.

En base a los anteriores enfoques conceptuales descritos, y luego de los anteriores estudios e investigaciones realizadas al presente estudio, se debe de encontrar la posibilidad de establecer estrategias, programas, y campañas, que permita llevar la propuesta de valor a los consumidores o influya en la demanda del producto o servicio; a través de la combinación de herramientas tácticas llamada Marketing Mix, que incluye las actividades de producción del servicio, asignación de precios, promoción, y distribución; que bien aplicados ayuda al posicionamiento de la empresa en el mercado objetivo. De esta forma se cumple con el principal concepto de marketing que es el proceso mediante el cual las empresas crean valor 
para los clientes y establecen relaciones sólidas para obtener a cambio valor de ellos traducido en relaciones redituables (Kotler \& Armstrong, 2012).

Sin embargo, para el presente caso de estudio, La Conversa Bar, no solo se debería de considerar la cuatro herramientas tácticas del Marketing Mix tradicional, sino más bien incluir herramientas adicionales que nos permitan diseñar estrategias acorde a la actividad de servicio a desarrollar; debido a las siguientes razones (SGM, 2016):

1. El Marketing Mix tradicional está enfocado a actividades de producción,

2. Las actividades de servicio son caracterizadas por su intangibilidad, deja sin alcance al Marketing Mix tradicional

3. El Marketing Mix no tiene las dimensiones amplias que permita cubrir la generación y entrega del servicio.

Existe la evidencia cada vez mayor, de que las dimensiones del Marketing Mix pueden no ser lo suficientemente amplia para el marketing de servicios, ya que no se consideran una serie de elementos esenciales para la generación y entrega del servicio.

En base a estas 3 razones, surge la idea de un Marketing Mix especialmente adaptado para el marketing de los servicios. Este nuevo Marketing Mix contendría 3 elementos adicionales, formando una combinación final de 7 elementos, que son: producto, precio, promoción, plaza, personas, evidencia física y procesos.

\subsubsection{Estrategia de Producto.}

El primer elemento de la mezcla del marketing es el producto o servicio. Cuando se le describe se hace referencia al diseño, sus características, sus atributos, la calidad del servicio, la calidad del servicio post-venta, la marca y los beneficios que aporta (Weinberger, 2009).

\subsubsection{Producto.}

Se entiende por producto cualquier bien que se ofrezca a un mercado para su atención, adquisición, uso o consumo, y que deben de satisfacer un deseo o una necesidad, y para la investigación que se viene realizando los clasificamos de la siguiente manera como se observa en la Tabla 19, y se presentará al cliente en la Carta de Productos que se ha diseñado (Ver Figuras 39, 40, 41, 42, 43): 
Tabla 19

Lista de Productos a Ofrecer

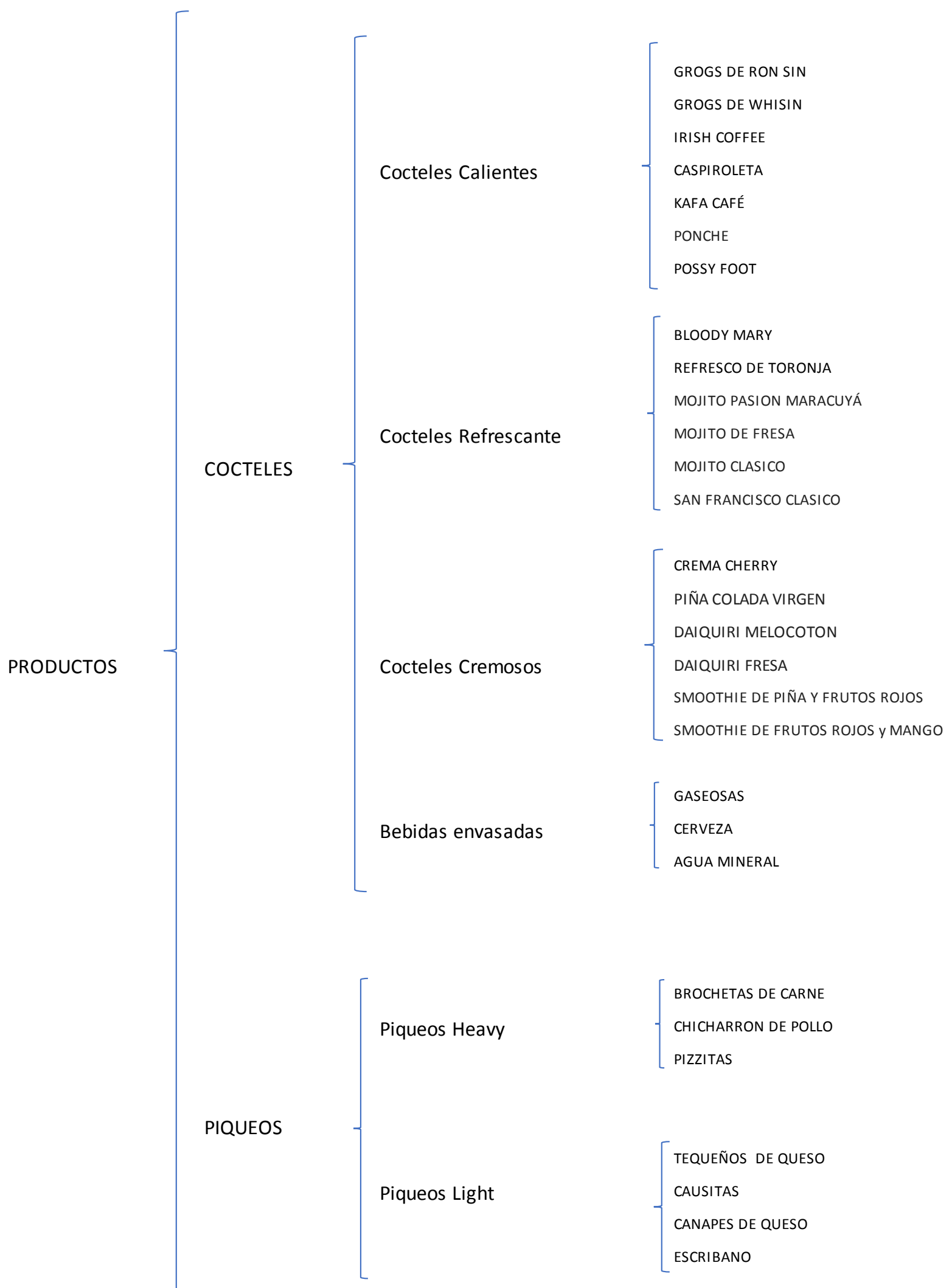




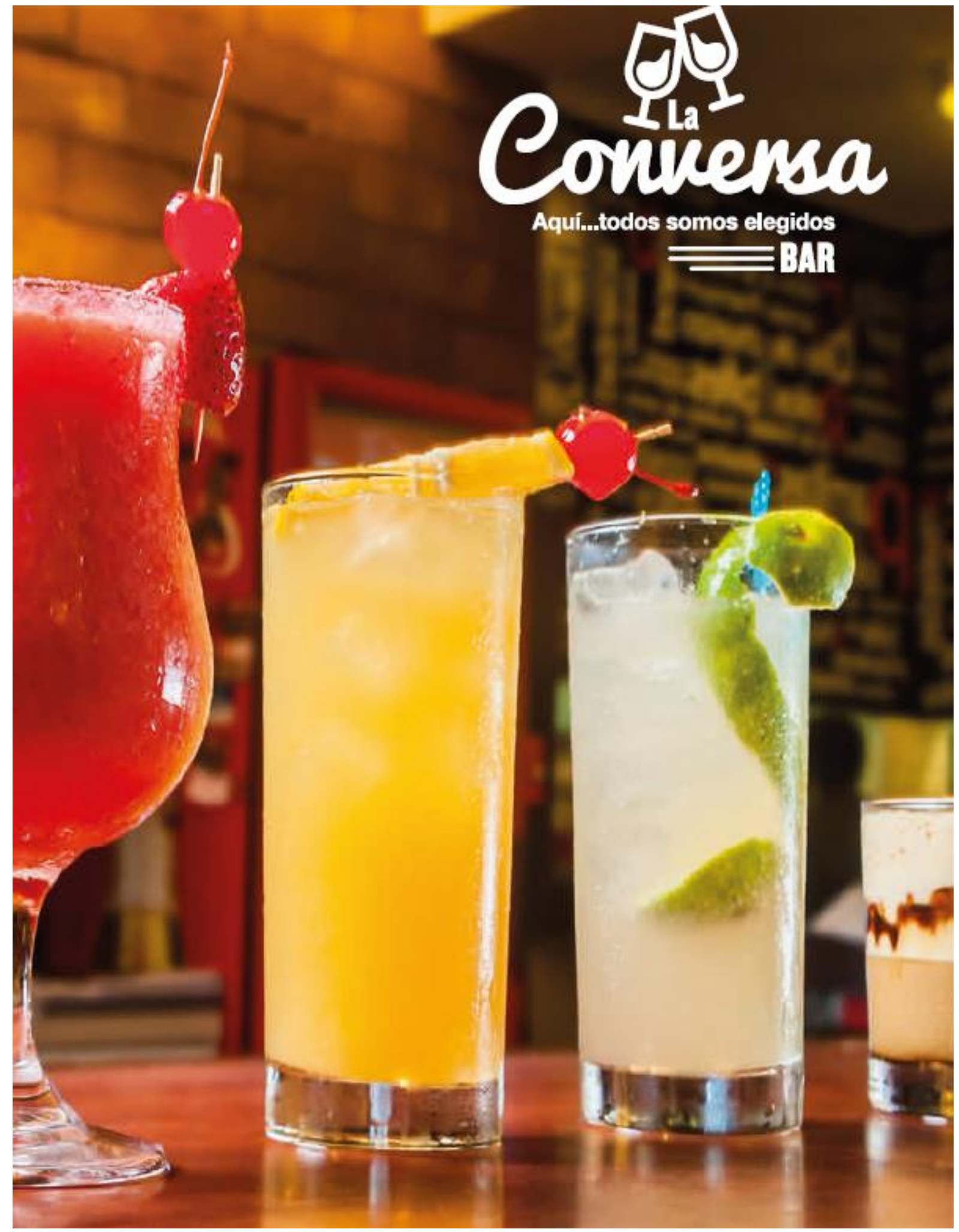

Figura 39. Carta de Productos (Parte 1). 

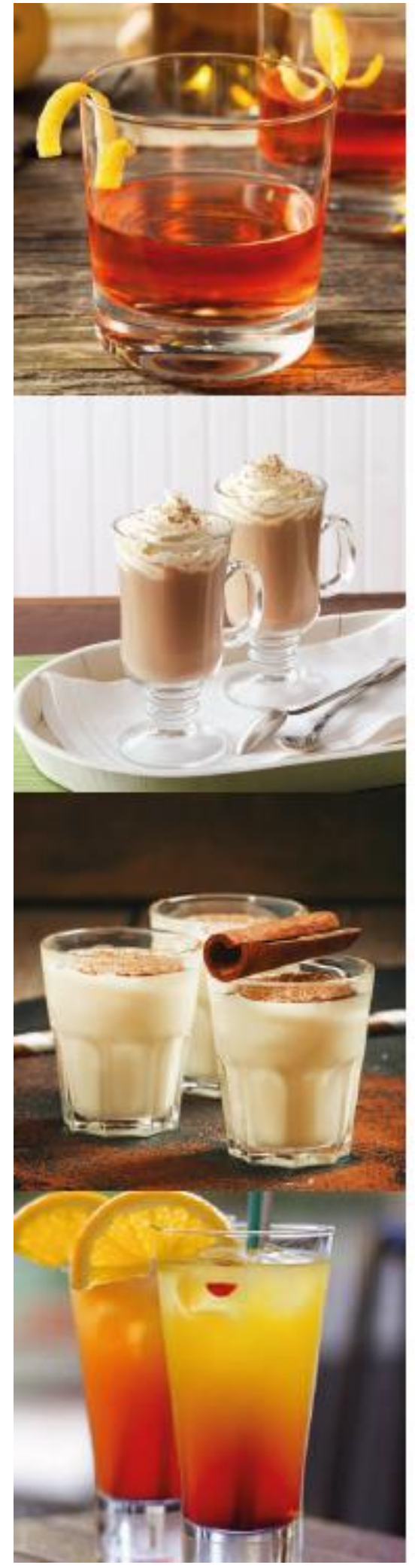

s/ 18.00

Coctel elogante perfecto de sabor inico, a temperatura ideal.

\section{Grogs de Whisin}

Delcioso Whisin (whisky sin alcohd) para poder disfrutarlo conjuntamente con amigos.

\section{Irish Coffee}

Sé parte de la tradición y estib de vida de mediados del siglo XVI.

\section{Caspiroleta}

Con la receta peruana y casera sin que hierva y batido a mano.

Coctel de sabor muy suave para converti lentamente un dia gris en un dla lluminado.

\section{Ponche}

Bebida tradicional de dia festivo para ser tomado en cualquier momento.

\section{Possy Foot}

Coctel helado / al tempo /callente para

Figura 40. Carta de Productos (Parte 2). 
Converse

Cocteles Refrescantes

\section{Bloody Mery}

Se mezcla d limón con tabasco, salsa inglesa, sal y pimienta. Agregue hielos y complete con jugo de tomate, Lo puede decorar con una ramita de apio, una rodiaja de limón y dos surbates.

\section{Refresco de Tononja}

Una buena alernativa para disfruta de manera responsable.

\section{Mojito Pasión Maracuyá}

Se trituran el azucar, la pulpa de maracuya.

el zumo de lima y $\mathbf{l}$ yerba buena, se sirve an vaso brgo ful hida y se completa con Sprite.

\section{Mojito de Fresa}

Sabor autentico para difrutarlo en cualnuier época del ario.

\section{Mojito Clásico}

El coctal mas aromático de Cuba, agul en Barranco.

\section{San Francisco Clásico}

Coctel colorido permitido para disfutab en cualquier momento del ă⿵人o.

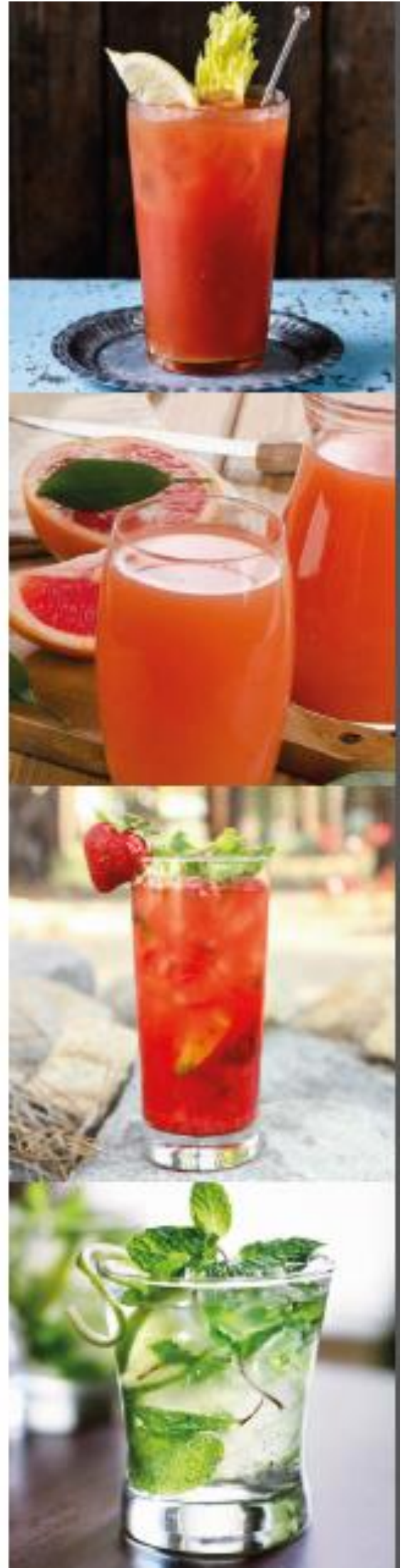

Figura 41. Carta de Productos (Parte 3). 

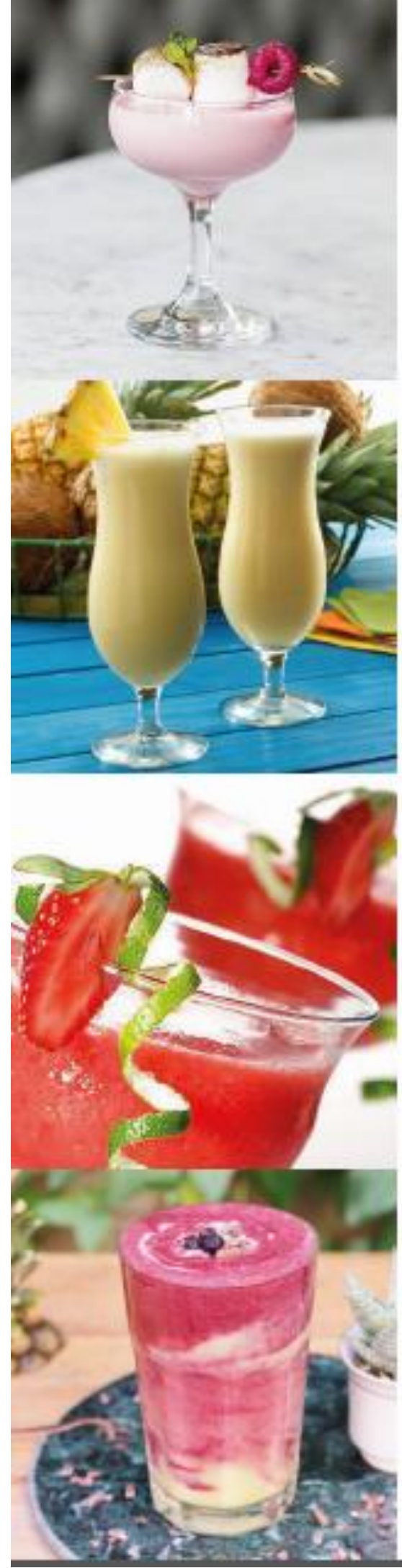

\section{Daiguini Fresa}

Coctel batido bajo en cabrias con frutas tropicales.
Con este coctd te sentrás como en un paraiso del caribe con la combinacion de fresa y sumo de limón.

\section{Smoothie de Piña y Frutor Rojos}

Delicioso coctel batido con furtas congahdas.

s/ 20.00

s/ 18.00

s/ 18.00

s/ 18,00

s/ 20.00

Smoothie de Frutor Rojos y Mango

s/ 20.00

Figura 42. Carta de Productos (Parte 4). 


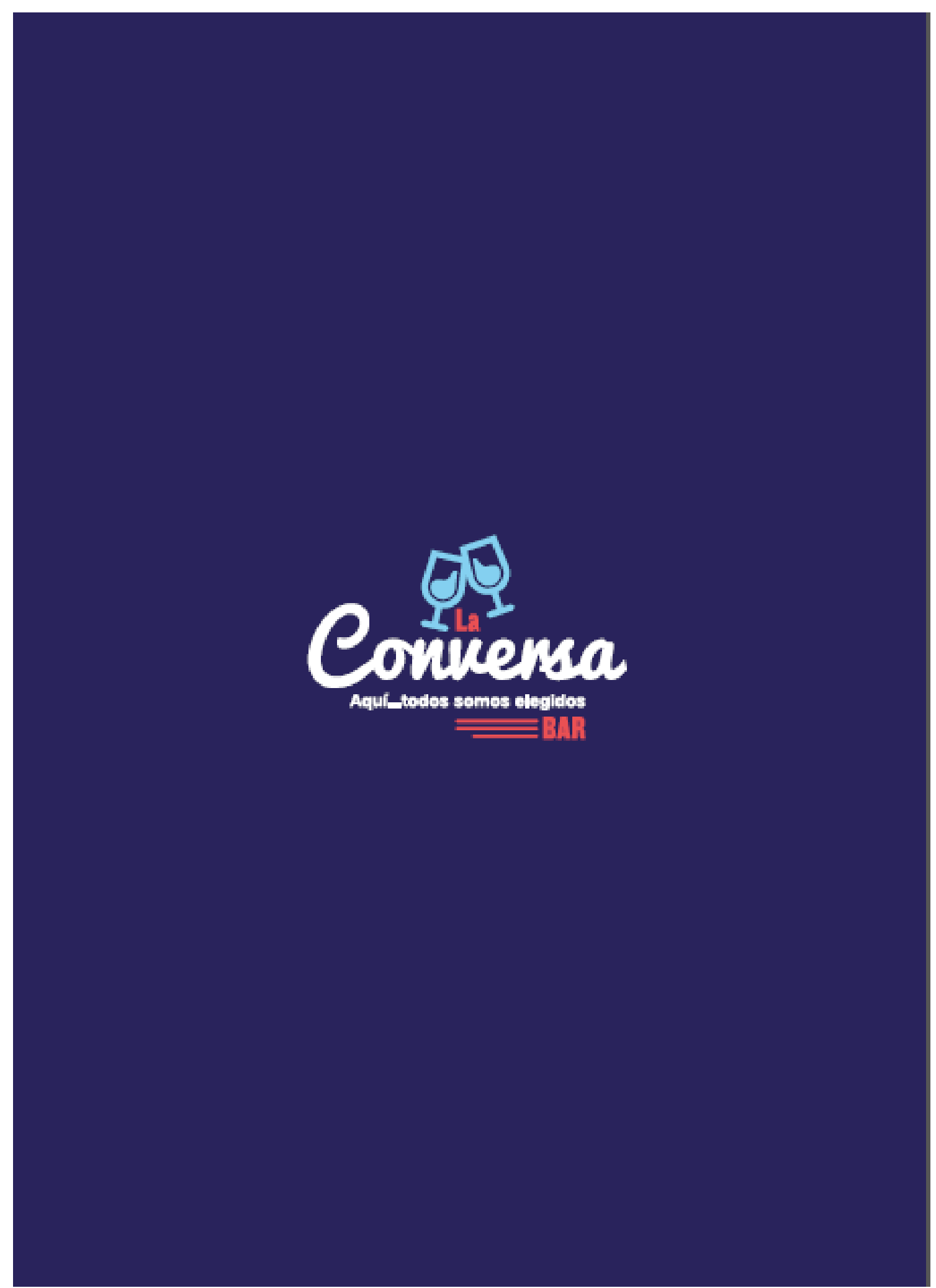

Figura 43. Carta de Productos (Parte 5). 
Asimismo, en el presente trabajo los servicios también son considerados una forma de producto adicional que consiste en actividades, beneficios o satisfacciones que se ofrecen en venta, y que son esencialmente intangibles. No obstante figurar en el propósito empresarial el servicio de preparación y atención de bebidas no alcohólicas así como la elaboración y venta de piqueos como productos secundarios este último, principalmente se ha considerado la actividad en mención considerarla como servicio. (Kotler \& Armstrong, 2013)

Y es justamente que debido a que muchas empresas vienen realizando actividades de servicio similares es que se ha optado en diferenciar la oferta indicada creando y entregando experiencias para los usuarios y clientes.

\subsubsection{Atributos del Servicio.}

El desarrollo de un servicio implica definir los beneficios que ofrecerá. Estos beneficios se comunican y entregan a través de los atributos del servicio como (Kotler \& Armstrong, 2013):

1. Calidad. Conocida en el mundo del marketing como una de las principales herramientas de posicionamiento, al tener un impacto directo en el desempeño del servicio y está vinculado con el valor a entregar al cliente y su satisfacción. Por lo general, la calidad se relaciona con la entrega de servicio libre de defectos, siendo más estrictos y según la American Society for Quality, (Castañeda, 2005), se puede definir la calidad como las características de un producto o servicio que sustentan su capacidad para satisfacer las necesidades explícitas o implícitas del cliente. En La Conversa Bar se puede afirmar que se cumple con un servicio de calidad, si es que realmente se da las condiciones de conformidad en términos de producto (cocteles y piqueos), de ambientación, de música, de ruido, y de atención; esperados por el cliente.

2. Características del Servicio. En La Conversa Bar, las características del servicio es lo que hará que se cumpla la diferenciación valorada frente a los competidores indirectos, al presentar los cocteles y bebidas sin alcohol así como insumos a utilizar en los piqueos sean de calidad y tenga presentaciones variadas, y por el lado del entretenimiento se cuente con una DJ de género femenino con música 
amena sin que interrúmpalas conversaciones originadas en el local, así como ambientación este a lo que se promocione.

3. Diseño del Servicio. Otra forma de añadir valor para el cliente es mediante un estilo y/o un diseño que sea distintivo con el servicio y que ayude a cumplir la estrategia de diferenciación planteada. Afirmando que el diseño describe la apariencia del servicio, entonces se puede indicar que la actividad en estudio tendrá un diseño moderno y suntuoso de tal forma que aparente un espacio que combina lo cálido, tecnológico, y metálico, que permita dar la sensación de ser un ambiente donde se puede dar una buena conversación y no sea interrumpida por factores externos.

4. Música. Existen factores que no son principales pero sirven de soporte o de complemento para que se dé la propuesta de valor al cliente, uno de ellos es la música. Esta será emitida de manera que no interrumpa la conversación y más bien, anime a interactuar entre los asistentes al establecimiento. Actualmente existen sistemas de audio que a pesar de encontrarse en un lugar público esta se pueda escuchar nítidamente sin que sea alterada por ruidos externos. Asimismo en el el horario de noche, se contará con una DJ de género femenino, encargada de amenizar las noches con música que tengan las características mencionadas anteriormente.

\subsubsection{Marca.}

Nombre Comercial del Servicio será: LA CONVERSA BAR

Una marca es un nombre, término, letrero, símbolo o diseño, o la combinación de estos elementos, que identifica al fabricante, vendedor, o proveedor de un producto o servicio.

Para el caso de estudio, entre las alternativas elegidas que se presentaron en la encuesta y en el focus group se encontraban:

\section{Bar Grado Cero}

2. Storytelling Bar

3. La Conversa Bar

4. Frutal Bar

5. Bar Talk \& Drink

6. Bar Non - Alcoholic Spirt

Entre los resultados obtenidos tenemos que la marca La Conversa Bar ha sido la más elegida. Cabe señalar que cada una de las alternativas representa propuestas y conceptos que 
el consumidor podría identificar en el proyecto, sin embargo, la más resaltante, La Conversa Bar, se relaciona con dos acepciones, por la que fue presentada:

1. Espacio que permite y da las condiciones en un ambiente agradable que se genere una buena conversación.

2. Sentido de conversión frente al alto consumo de alcohol que existe en la sociedad.

Lo anterior, representa las percepciones y los sentimientos que la marca, La Conversa Bar, genera en los consumidores del servicio, y es así como se desea que el valor de la marca se instale en la mente del consumidor creando un efecto diferencial positivo o una reacción de manera favorable, como mínimo.

Finalmente se puede indicar que la marca La Conversa Bar cumple con los aspectos que una marca debe de tener (ver Tabla 20):

- Debe sugerir algo acerca de los beneficios y las cualidades del producto.

- Debe ser fácil de pronunciar, reconocer y recordar

- Tiene que ser distintivo

- El nombre de marca debe poder ampliarse a otras categorías

- Tiene que registrarse y protegerse legalmente. Un nombre de marca no se puede registrar si afecta los nombres de marcas existentes.

Tabla 20

Marca 'La Conversa Bar'

LA CONVERSA

\begin{tabular}{llc}
\hline \multicolumn{1}{c}{ Aspectos } & Cumple \\
\hline a $\quad \begin{array}{l}\text { Debe sugerir algo acerca de los beneficios y las } \\
\text { cualidades del producto. }\end{array}$ & $\mathrm{SI}$ \\
b $\quad$ Debe ser fácil de pronunciar, reconocer y recordar & $\mathrm{SI}$ \\
c $\quad$ Tiene que ser distintivo & $\mathrm{SI}$ \\
d $\quad \begin{array}{l}\text { El nombre de marca debe poder ampliarse a otras } \\
\text { categorías }\end{array}$ & $\mathrm{SI}$ \\
e $\quad \begin{array}{l}\text { Tiene que registrarse y protegerse legalmente. Un } \\
\text { nombre de marca no se puede registrar si afecta los }\end{array}$ & $\mathrm{SI}$ \\
\hline
\end{tabular}

Nota: Adaptado de Fundamentos de Marketing P. Kotler, G. Armstrong, 2013. México DF, México: Editorial Pearson. 
Logo.

El logo por considerar para la Conversa Bar es el que se observa en la siguiente figura (ver Figura 44):

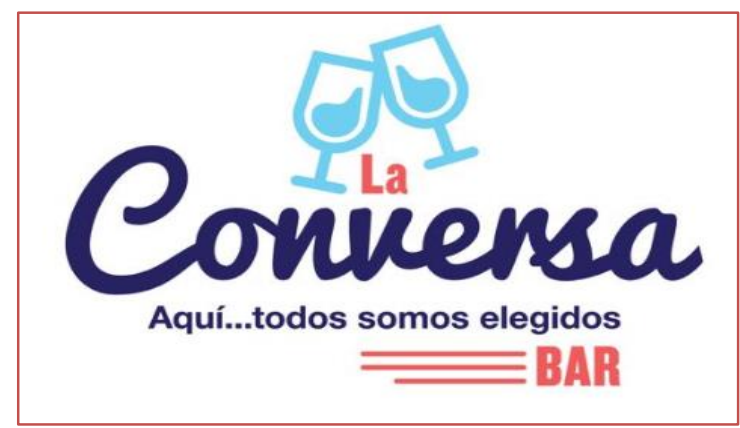

Figura 44. Logo del La Conversa Bar.

Eslogan.

El eslogan del servicio y que acompaña a la marca será: aquí... todos son elegidos

Horario.

El horario de atención será a partir de

Lun a Jue de : $\quad$ 12:00 a 23:00 hrs.

Vie y Sáb de : 12:00 a 23:00 hrs.

Domingo de : $12: 00$ a 23:00 hrs.

Lugar.

Se ha definido que el establecimiento se encuentra en el distrito de Barranco, especialmente en áreas de alta circulación y poyado en factores como: a) principal distrito cultural y pintoresco; b) se encuentra como la ciudad más visitada en América Latina, Lima, (Gestión, dic 2015); c) y por empuje de encontrarse en la capital gastronómica del país. Por estas razones, es una plaza importante para la actividad a desarrollar.

\subsubsection{4. $\quad$ Niveles de Productos y Servicios}

Según Kotler \& Armstrong (2013), en la planeación del servicio se debe de considerar tres niveles y cada uno agrega más valor para el cliente, como se observa en la Tabla 21: 
Tabla 21

Niveles de Productos y Servicios

\begin{tabular}{|c|c|c|c|}
\hline & Niveles & Concepto & Aplicación en La Conversa Bar \\
\hline 1 & $\begin{array}{l}\text {.- Valor Fundamental para el } \\
\text { Cliente }\end{array}$ & $\begin{array}{l}\text { Es el valor fundamental para el } \\
\text { cliente, y es donde se hace la } \\
\text { pregunta ¿Qué está } \\
\text { adquiriendo realmente el } \\
\text { comprador? }\end{array}$ & $\begin{array}{l}\text { Definimos entre los beneficios } \\
\text { principales a la ambientación } \\
\text { agradable y acondicionada que } \\
\text { tendría y posibilitaría un agradable } \\
\text { encuentro en pareja o grupal donde } \\
\text { la interacción y el departir no se vea } \\
\text { interrumpido por ruidos molestos o } \\
\text { excesos provenientes de otras mesas } \\
\text { ocupadas. }\end{array}$ \\
\hline & -- Servicio Real & $\begin{array}{l}\text { Se debe de tener como } \\
\text { objetivo, convertir el Beneficio } \\
\text { Central en un servicio real; } \\
\text { desarrollando características, } \\
\text { diseño del servicio, y nivel de } \\
\text { calidad, que se combinen para } \\
\text { brindar el valor principal para } \\
\text { el cliente }\end{array}$ & $\begin{array}{l}\text { La ambientación, los cocteles y } \\
\text { tragos sin alcohol, y una variedad de } \\
\text { piqueos, que acompañen al buen } \\
\text { momento deseado pasar por los } \\
\text { consumidores }\end{array}$ \\
\hline 3 & -- Servicio Aumentado & $\begin{array}{l}\text { Se debe de crear un servicio } \\
\text { aumentado en cuanto al } \\
\text { beneficio principal y al servicio } \\
\text { real, ofreciendo servicios } \\
\text { adicionales al cliente. }\end{array}$ & $\begin{array}{l}\text { En La Conversa Bar, el bar es más } \\
\text { que un lugar de entretenimiento o } \\
\text { diversión; es un alternativa para la } \\
\text { gente que no desea tener las } \\
\text { impertinencias en temas sociales, de } \\
\text { ruidos, de música, y de ambientación } \\
\text { que encuentra en un bar tradicional } \\
\text { de consumo de alcohol y pueda } \\
\text { disfrutar de la misma forma que lo } \\
\text { haría en uno tradicional; con la } \\
\text { diferencia que allí si podría } \\
\text { interactuar y departir momentos } \\
\text { sociales esperados. }\end{array}$ \\
\hline
\end{tabular}

Nota: Adaptado de Fundamentos de Marketing P. Kotler, G. Armstrong, 2013. México DF, México: Editorial Pearson.

Adicionalmente, se debería:

- Aprovechar el aumento de la demanda, especialmente, los jueves, viernes, y sábado

- Asegurar la fiabilidad de los productos que ofrecemos en la carta.

- Crear actividades o eventos respectos a temas de interés (con especialistas) donde se departa experiencias.

\subsubsection{Estrategia de Precio}

Precio es la suma de los valores que los consumidores dan a cambio de los beneficios de tener o usar el producto o servicio. Con el tiempo, el precio ha sido el factor que más influye en las decisiones de los compradores. En décadas recientes otros factores se han 
vuelto más importantes, aunque el precio continúa siendo uno de los elementos que determinan la participación de mercado y la rentabilidad de una empresa. El precio es el único elemento de la mezcla de marketing que produce utilidades; todos los otros elementos representan costos.

La forma en que los clientes perciben el valor del producto establece el límite máximo para los precios. Si los consumidores perciben que el precio del producto es mayor que su valor, no lo comprarán. Los costos del producto establecen el límite mínimo de los precios. Si la compañía fija un precio por debajo de los costos del producto, sus utilidades se verán afectadas. Para fijar un precio entre estos dos extremos, la compañía debe considerar varios factores internos y externos, incluyendo las estrategias y precios de los competidores, la estrategia y la mezcla generales de marketing, y la naturaleza del mercado y la demanda. (Kotler \& Armstrong, 2012).

En efecto, Kotler \& Armstrong, considera tres estrategias principales de fijación de precios: la fijación de precios basada en el valor para el cliente, la fijación de precios basada en los costos, y la fijación de precios basada en la competencia (p.50).

- Fijación de precios basada en el valor para el cliente: Es el establecimiento del precio basado en las percepciones del comprador y no en los costos que tuvo el vendedor, mientras que el precio se fija para que coincida con el valor percibido por los clientes; la combinación exacta de calidad y buen servicio a un precio justo. Por la connotación del servicio y productos a ofrecer, así como por la propuesta de valor expresada por el negocio, es que esta estrategia de fijación de precios es la que más se ajusta para los objetivos de La Conversa Bar.

- Fijación de precios basada en el costo: Trata de fijar precios a partir de los costos de producción, distribución y venta del producto, más una tarifa de utilidades por el esfuerzo y los riesgos. La Conversa Bar no califica para usar esta estrategia.

- Fijación de precios basada en la competencia: Es el establecimiento de precios con base en las estrategias, costos, precios y ofertas de mercado de los competidores. La Conversa Bar no califica para usar esta estrategia.

Por otro lado, desde el enfoque del comportamiento del ciclo de vida empresarial, en la etapa de introducción de un nuevo servicio es muy desafiante las empresas que lanzan un nuevo producto enfrentan el reto de fijar los precios por primera vez, y pueden utilizar dos estrategias generales: 
1. La de fijar el precio para capturar el nivel más alto del mercado existente o

2. La de fijar el precio para penetrar en el mercado (Kotler \& Armstrong, 2012).

En la primera estrategia muchas compañías que lanzan nuevos servicios fijan altos precios iniciales para "sacar" utilidades de cada capa del mercado. La captura del precio más alto sólo tiene sentido en ciertas condiciones. En primer lugar, la imagen y la calidad del producto deben sustentar este precio elevado, y debe haber una cantidad suficiente de compradores dispuestos a adquirir el producto por ese precio. En segundo lugar, los costos de producción de un volumen más pequeño no deberían ser tan altos que eliminen la ventaja de cobrar más. Por último, no debe ser tan fácil para los competidores penetrar el mercado y vender el producto más barato.

En la segunda estrategia, en lugar de establecer un precio inicial elevado para aprovechar segmentos pequeños de mercado pero redituables, algunas compañías fijan un precio bajo inicial para penetrar en el mercado con rapidez y profundidad, es decir, para atraer a una gran cantidad de compradores rápidamente y ganar una gran participación en el mercado. El alto volumen de ventas da como resultado la caída de los costos, lo que permite a la compañía reducir aún más su precio. (Kotler \& Armstrong, 2013).

En general, según Weinberger (2009), el precio del servicio se puede establecer en función a:

- La percepción que se tiene del servicio

- La intensidad de la necesidad insatisfecha

- El posicionamiento del servicio en la mente de los consumidores

- El poder adquisitivo del cliente

- La estructura de costos del servicio

- Precio de los competidores.

Para el caso de estudio, La Conversa Bar, estaremos estableciendo los precios en función a la percepción que se tiene del servicio y este será un espacio o lugar que permita la interacción ambientado de tal forma que dé la percepción de confort y relax degustando productos de calidad, cocteles y piqueos. No obstante, encontrarnos en una sociedad que considera el precio como factor importante de decisión, se optará por fijar el precio como una herramienta estratégica que permita crear valor para los clientes y obtener valor de los clientes para la empresa (ver Tabla 22).

Adicionalmente, se debería:

- Realizar descuentos en fechas específicas. 
- Publicitar las ofertas entre los seguidores.

- Hacer promociones por estación, reduciendo los precios del producto por un tiempo limitado.

- Aplicar el efecto de la "bolsa de Valores" a los precios de los productos según su oferta y demanda, en una sola noche.

- Ofrecer cupones o vales de descuentos.

En conclusión, fijar un precio bajo inicial sería la más adecuada estrategia en la etapa de introducción al considerar que se ofrece un servicio a un segmento bastante amplio, así como considerar que es un servicio innovador que necesita un intervalo de tiempo para adaptarse al consumidor.

Tabla 22

Lista de Precios 
LISTA DE PRECIOS DE PRODUCTOS

\section{COCTELES CALIENTES}

GROGS DE RON SIN

GROGS DE WHISIN

IRISH COFFEE

CASPIROLETA

KAFA CAFÉ

PONCHE

POSSY FOOT

\section{COCTELES REFRESCANTES}

BLOODY MERY

REFRESCO DE TORONJA

MOJITO PASION MARACUYÁ

MOJITO DE FRESA

MOJITO CLASICO

SAN FRANCISCO CLASICO

\section{COCTELES CREMOSOS}

\section{CREMA CHERRY}

PIÑA COLADA VIRGEN

DAIQUIRI MELOCOTON

DAIQUIRI FRESA

SMOOTHIE DE PIÑA Y FRUTOS

ROJOS

SMOOTHIE DE FRUTOS ROJOS Y

MANGO

BEBIDAS ENVASADAS

GASEOSAS

CERVEZA

AGUA MINERAL

\section{PIQUEOS HEAVY}

BROCHETAS DE CARNE

CHICHARRON DE POLLO

PIZZITAS

PIQUEOS LIGHT

TEQUEÑOS DE QUESO

CAUSITAS

CANAPES DE QUESO

ESCRIBANO
$\mathrm{S} / 18.00$

$S / 18.00$

$S / 16.00$

$S / 16.00$

$\mathrm{S} / 16.00$

$\mathrm{S} / 18.00$

$S / 18.00$

$\mathrm{S} / 12.00$

$S / 14.00$

$S / 14.00$

$S / 14.00$

$\mathrm{S} / 12.00$

$\mathrm{S} / 12.00$

$\mathrm{S} / 20.00$

$\mathrm{S} / 18.00$

$S / 18.00$

$\mathrm{S} / 18.00$

$\mathrm{S} / 20.00$

$\mathrm{S} / 20.00$

S/7.00

$\mathrm{S} / 10.00$

S/7.00

$\mathrm{S} / 20.00$

$\mathrm{S} / 16.50$

$S / 14.00$

$S / 12.00$

$\mathrm{S} / 15.00$

$\mathrm{S} / 12.00$

\subsubsection{Estrategia de Plaza y Distribución}

La estrategia de plaza y distribución hace referencia hace referencia a como se llegará al cliente o consumidor final a través de qué tipo de canales:

- ¿Se vende directamente a los canales? 
- ¿Se utiliza representantes de ventas, distribuidores, o agentes?

- ¿Cuáles son las ventajas o desventajas de utilizar, adicionalmente, terceros para vender?

- ¿Cómo se accede a clientes "valiosos"?

- ¿Los distribuidores tienen un poder de negociación? (Weinberger, 2009).

Una vez que la compañía revisó sus alternativas de canal y decidió cuál es el mejor diseño, debe poner en práctica y administrar el canal elegido. La administración del canal de marketing requiere seleccionar, administrar y motivar a los miembros individuales del canal, y evaluar su desempeño con el paso del tiempo. Algunas empresas ponen muy poca atención a sus canales de distribución, pero otras utilizan creativos sistemas de distribución para lograr una ventaja competitiva. Las decisiones de canal de una compañía afectan de manera directa todas las decisiones de marketing. La gerencia debe tomar estas decisiones de forma cuidadosa, incorporando las necesidades actuales con el probable entorno de ventas del futuro (Kotler \&Armstrong, 2012).

La distribución de un producto o servicio se realiza a través de una cadena de intermediarios o canal de distribución. Ella es la ruta que siguen los productos conforme pasan del productor al consumidor final, y que logra que los productos estén disponibles en el mercado para su uso o consumo. En la siguiente tabla, se presentan los canales típicos de distribución mediante los cuales los productos o servicios (bienes de consumo) llegan a los clientes (ver Tabla 23).

Tabla 23

Canales Típicos de Distribución

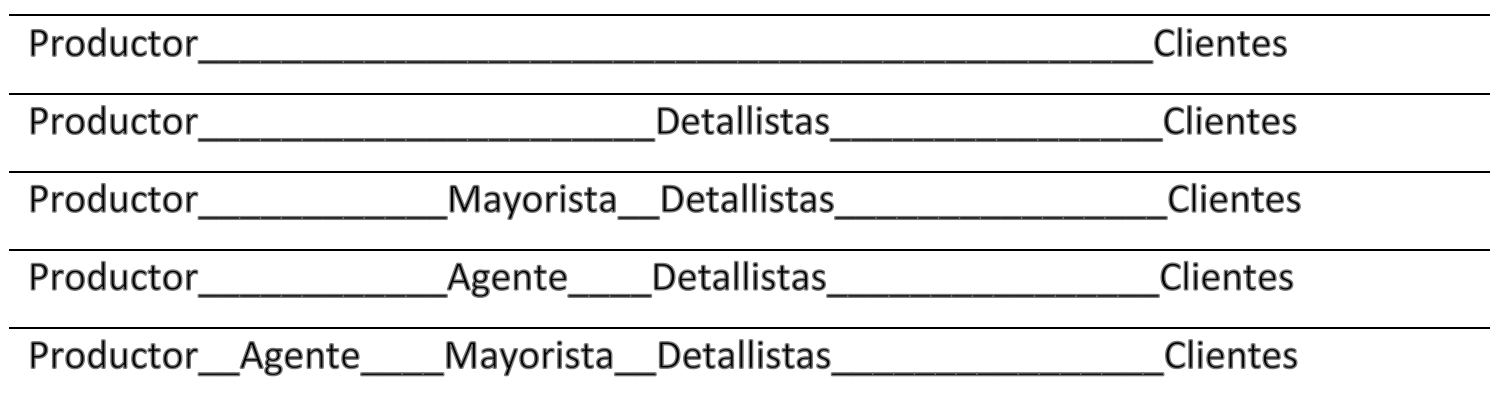

Nota: Adaptado de Fundamentos de Marketing P. Kotler, G. Armstrong, 2013. México DF, México: Editorial Pearson.

A diferencia de los productos, los servicios se ofrecen de manera directa y no existe intermediación, dado que el servicio no puede separarse del vendedor, es decir se crea y comercializa al mismo tiempo. (Franco, 2013) 
En La Conversa Bar se utilizará netamente el canal de marketing directo entendido como un canal de marketing que no tiene niveles de intermediarios, es por ello la importancia del uso de distintos medios de comunicación y redes sociales acerca de las distintas campañas al público objetivo de manera directa

\subsubsection{Estrategia de Promoción y Publicidad}

Vender significa convencer al cliente para que compren el producto o consuman el servicio aplicando diferentes estrategias en base a lo siguiente:

- ¿Se venderá por teléfono?

- ¿Se venderá por catálogo?

- ¿Se llamará y visitará al cliente?

- ¿Se hará publicidad por medios radiales y/o televisivos / Redes sociales? (Weinberger, 2009).

Todas estas formas de vender y promocionar son combinaciones personales, no personales, y especiales de técnicas de comunicación usadas en campañas promocionales. No existe fórmula matemática que determine a priori el presupuesto de promoción, sin embargo, hay cuatro métodos hasta cierto punto razonables para presupuestar los recursos destinados a promoción.

- Asignar un porcentaje de las ventas.

- Definir de cuanto se puede disponer.

- Gastar tanto como lo hace la competencia.

- Determinar cuánto se necesitará para realizar las actividades de promoción (Longenecker, 2007).

La mezcla de promoción de una compañía, también llamada mezcla de comunicaciones de marketing, consiste en la mezcla específica de publicidad, relaciones públicas, ventas personales, promoción de ventas y herramientas de marketing directo que utiliza la compañía para comunicar valor para el cliente de forma persuasiva y establecer relaciones con éste. Las siguientes son las definiciones de las cinco principales herramientas de promoción (Kotler \& Armstrong, 2013):

1. Publicidad: Cualquier forma pagada de presentación y promoción no personales de ideas, bienes o servicios, por un patrocinador identificado. Para el caso en estudio solo se estará considerando anuncios impresos y pago de publicidad por internet. 
2. Promoción de ventas: Incentivos a corto plazo que fomentan la compra o venta de un producto o servicio. Este es el medio más usado para La Conversa Bar, y se aplicara en descuentos, cupones, demostraciones, entre otras actividades.

3. Ventas personales: Presentación personal de la fuerza de ventas de la compañía, con el propósito de vender y de establecer relaciones con el cliente. Para el tipo de servicio a brindar, esta herramienta promocional no será considerada.

4. Relaciones públicas: Establecimiento de buenas relaciones con los diversos públicos de una empresa mediante la obtención de publicidad favorable, la creación de una buena imagen corporativa. En un inicio esta herramienta, para La Conversa Bar, se hace difícil aplicarla hasta que la empresa a través de su concepto y de su marca se encuentre posicionada.

5. Marketing directo: Conexiones directas con consumidores individuales seleccionados cuidadosamente, para obtener una respuesta inmediata y cultivar relaciones duraderas con el cliente. Esta herramienta es una de las principales consideradas para el caso de estudio, La Conversa Bar, se tiene planeado aplicarla en marketing mobile, internet a través de las redes sociales apoyado en el marketing por contenido.

De igual forma, la publicidad evoluciona, de la mano de la tecnología, a grandes pasos. Cada vez se puede notar que se van creando nuevas formas de dar a conocer o repotenciar la imagen de una marca. De la misma manera nace el "digital signage", conocido también como señalización digital o cartelería digital, la misma que tiene el poder de influir en el proceso de compra de hasta el 55\% de consumidores. Este novedoso formato publicitario consiste en la emisión de contenidos digitales a través de diversos tipos de pantallas como monitores LCD, paneles táctiles o proyectores, que se ubican al interior de las tiendas (indoor) o en el exterior (outdoor). (Rev .Mercado Negro, may 2018)

El hecho de que los dispositivos digitales signage pueda colocarse tanto al interior como fuera de él hace posible que las empresas puedan crear, administrar, distribuir y publicar contenidos originales combinando la tecnología digital con la tradicional, algo que siempre le dará un plus a la marca.

\subsubsection{Posicionamiento.}


Luego, siendo uno de los principales objetivos de promoción el posicionamiento de la marca y del servicio, en el caso de estudio La Conversa Bar aplicaremos el Marketing por Contenido o también conocido en el mundo del marketing como Content Marketing, y considerado como opción para lograr un buen posicionamiento SEO (Search Engine Optimization), que me permita interactuar con los clientes y crear notoriedad de marca.

La información está cada vez más al alcance de los clientes y la competencia con las demás empresas aumenta cada día. Por eso hay que optimizar al máximo el contenido y adaptarlo a las necesidades de los clientes.

A continuación, las principales canales de información que se empleará, (Macarena, 2018):

1. Vídeos

Los vídeos son un contenido que se consume cada vez más, de hecho. Hay muchas formas de crear contenido en vídeo adaptándolo a los distintos canales.

Contar una historia es una de las bases de un buen contenido vídeo. Una buena forma de realizar esta función es a través de las funciones "live" de Instagram o Facebook.

El objetivo que se persigue para el caso de estudio, Bar sin Alcohol, es mantener al usuario informado de lo que estás haciendo, una manera de retransmitir eventos relevantes o lanzamientos de nuevos productos.

2. Móviles

La utilización de dispositivos móviles es cada vez mayor en el Perú (Gestión, 2016).

Esto significa que para la idea en estudio se deba de estar muy atentos a este tipo de dispositivos y optimizar contenido para que sea fácil de transmitir las cualidades del negocio como estrategia de promoción. Entre la más recomendable a aplicar para La Conversa Bar es la técnica del "proximity" o del marketing mobile.

3. Redes sociales

Gran parte del esfuerzo debe estar orientado a crear contenido para redes sociales. Para ello, debes de tener claro qué intereses tienen tus usuarios para poder desarrollar un contenido que vaya acorde con ello. Se contratará a una persona, para que se desempeñe como comunity manager, especializada en el manejo de redes sociales y responsable del marketing digital así como de la comunidad on line de la marca propia de la idea de negocio

Para el caso de estudio, La Conversa Bar, se deberá estar atento a los cambios y nuevas tendencias que ofrecen, ilustrando y dando tips de aplicaciones acerca de la “coctelería funcional", así como de los servicios y beneficios que el bar ofrece a su clientela. 4. Página Web 
En la que se detallara las bondades del negocio así como los servicios que ofrece, haciendo énfasis en la propuesta de valor diseñada. Para que la página web este posicionada en la web se aplicará las técnicas SEO.

\section{Personalización}

Los usuarios cada vez reclaman un contenido más personalizado y afín a sus gustos. Tienes que entender a la perfección cuáles son sus intereses y qué tipo de contenido disfrutan más. Lo mejor para interactuar con los usuarios es a través de las funciones de reproducir videos en directo como Instagram Stories o Facebook Live. Esto hace que los clientes sientan que están conectando con la marca en el momento en el que se inicia la reproducción de vídeo, creando una conexión especial al sentir que las marcas se preocupa por ellos.

En La Conversa Bar, se hará sesiones de transmisión en vivo de elaboración de tragos sin alcohol con los temas y mismos ingredientes que se disfruta en el bar.

Finalmente la direccionalidad de la promoción, hace que existan dos estrategias que puede reforzar a las herramientas anteriormente expuestas (Franco, 2013):

Estrategia de empuje (Push) que "impulsa" el producto a través de los canales de marketing hacia los consumidores finales. El empresario dirige sus actividades de marketing (principalmente las ventas personales y la promoción comercial) hacia los miembros del canal para incitarlos a que trabajen el producto y lo promuevan ante los consumidores finales.

Con una estrategia de atracción (Pull), el productor dirige sus actividades de marketing (principalmente la publicidad y la promoción) hacia los consumidores finales para motivarlos a que compren el producto o servicio.

Para La Conversa Bar, el más acorde es el segundo, debido a que al ser considerado servicio se resume completamente el canal y se trabaja de manera directa con el cliente

Adicionalmente se debería:

- Invertir aproximadamente $30 \%$ de los ingresos en publicidad

- Diseñar y realizar campañas publicitarias acerca para dar a conocer un bar donde no se expende alcohol y tiene las bondades de un bar tradicional.

- Ganar visibilidad a través de los "influencers"

- Programar de manera coordinada la elaboración de los diseños publicitarios, html, landings, así como posts; con las fechas de comunicación considerando el lapso de diseño y difusión, para tener el efecto esperado.

- Adquirir dispositivos “digital signage" para una mejor publicidad outdoor e indoor. 
- Los días domingos se contará con mayores promociones y descuentos para un incremento de la demanda.

- Participación de ferias y publicidad en revistas leídas por este segmento de mercado.

- Crear puestos de degustación de los principales productos

- Crear carteles, volantes, presentaciones, folletos o calendarios publicitarios y sorteos o concursos entre los clientes.

- Participar activamente en las Redes Sociales en las que se encuentre nuestro mercado.

- Crear Video Marketing y/o un canal de Podcasts.

- Usar aplicaciones móviles para promocionarse a través de anuncios.

- Generar estrategias SEO y SEM así como crear un Blog y publicar artículos de interés para el mercado potencial o actual.

- Crear una Página Web atractiva y dinámica.

\subsubsection{Estrategia de Personas.}

El personal de servicio está compuesto por aquellas personas que prestan los servicios de una organización a los clientes. Ellos son importantes en todas las organizaciones, pero especialmente en aquellas circunstancias en que no existiendo las evidencias de los productos tangibles, el cliente se forma la impresión de la empresa con base en el comportamiento y actitudes de su personal. Por eso es definitivo que este personal del servicio realice su trabajo de manera efectiva y eficiente, por constituir, ellos, un importante elemento del marketing interno de la empresa.

La forma como se ofrece un servicio puede influir en la naturaleza de las relaciones que existen entre el personal de una organización de servicios y sus clientes, lo que finalmente influirá en la imagen de una empresa. Parte de este personal será visible para el cliente durante la compra y consumo de un servicio. El personal de contacto es el recurso clave de la organización (Franco, 2013).

Para La Conversa Bar, se analiza los valores más apreciados por los potenciales clientes, según los estudios de investigación cuantitativos y cualitativos aplicados y explicados, y en donde se han identificado a la rapidez, buena atención, pulcritud, y amabilidad como factores críticos de diferenciación que hacen que la experiencia vivida por el cliente sea la esperada y deseada. Todo esto responde a la cultura de "customización" en el servicio que se viene implantando. 
Para lograr lo anterior, se tendrá que poner énfasis en el desarrollo de un buen clima laboral en la organización, capacitación constante al personal para una mejora de calidad y rendimiento, así como una mayor supervisión y control a través de instrumentos de observación y de medición de satisfacción del servicio brindado, entre otros. Cabe señalar, que actualmente los consumidores perciben la existencia de desorganización en el servicio.

En un negocio de servicios, el cliente y los empleados de una empresa interactúan para crear el servicio. A la vez, una interacción eficaz depende de las habilidades de los empleados del servicio y de los procesos de apoyo que respalden a tales empleados. Por lo tanto, las empresas centran su atención tanto en sus clientes como en sus empleados; entendiendo que la cadena servicio-utilidades que vincula las utilidades de la empresa con los empleados y estos con la satisfacción de los clientes. Por lo tanto, para lograr las metas de utilidades y crecimiento gracias al servicio, es necesario empezar por cuidar a quienes atienden a los clientes.

El marketing interno consiste en que la empresa de servicios debe orientar y motivar a los empleados que tienen contacto con los clientes, así como al personal de servicio de soporte para que trabaje como un equipo y brinde satisfacción al cliente. De hecho, el marketing interno debe preceder al marketing externo (Kotler \& Armstrong, 2012) (ver Figura 45).

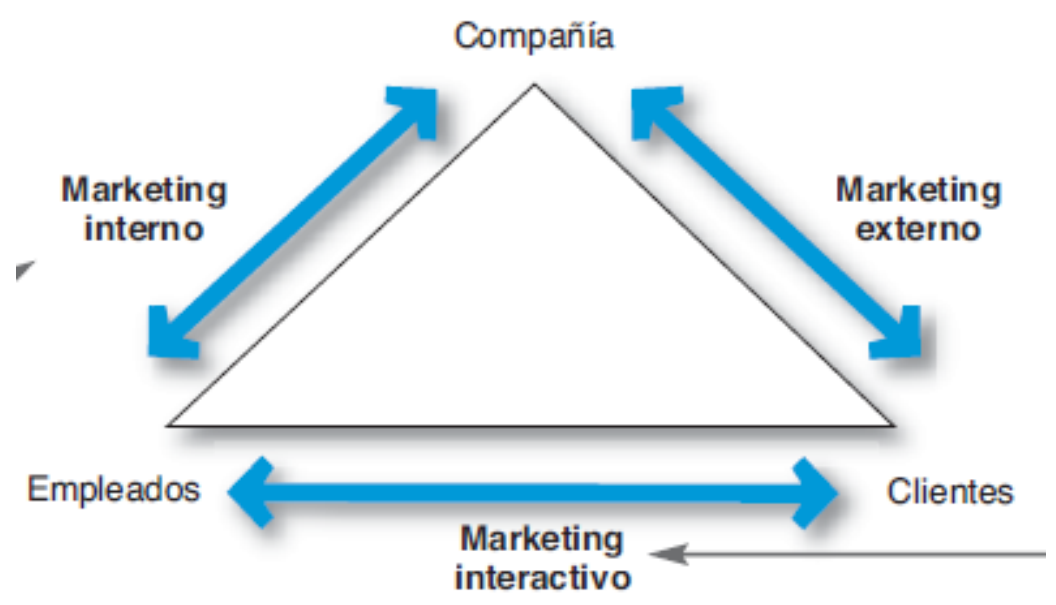

Figura 45. Marketing Interactivo. Tomado de Fundamentos de Marketing por P. Kotler \& G. Armstrong, 6ta Edición, Pág. 241.

Adicionalmente, se debería:

- Implementar programas de capacitación y entrenamiento en el área de ventas y al personal en general. 
- Priorizar la atención al cliente como punto clave para lograr superar sus expectativas.

- Establecer reuniones semanales del personal con los supervisores y elevar informes (logros, metas, incidencias, feedback) a la gerencia.

\subsubsection{Estrategia de Procesos.}

En las empresas de servicios, la cooperación entre marketing y operaciones es vital. Ambas deben trabajar conjuntamente, si es necesario, para satisfacer al cliente.

Los clientes de las empresas de servicios obtienen beneficios y satisfacciones de los propios servicios y de la forma como se prestan esos servicios, y la forma en que operan dichos servicios es algo relevante (Franco, 2013).

Para brindar un buen servicio a los clientes se hace necesario implementar un proceso de servicio al cliente desde el primer contacto que se tenga con el cliente, durante el consumo del servicio, hasta el momento del seguimiento que debe culminar con la fidelización y recomendación por parte del cliente. Muchas veces el cliente no conocerá a todo el personal de servicio pero si se llevará una imagen de ello que es lo que garantizará buenas o malas recomendaciones no solo del servicio sino del negocio en su integridad.

Asimismo, una eficiente aplicación del proceso de servicio, brindará dos beneficios relevantes al caso de estudio (Verdezoto, 2016):

1. A través de la personalización del servicio se hará que el cliente se sienta a gusto "como en casa" y genere un sentido de pertenencia con el establecimiento y se genere, a su vez, recomendaciones positivas en su círculo de influencia.

2. Que se retroalimente como estrategia de venta como factor de crecimiento en la primera etapa de su ciclo de vida.

Adicionalmente:

- Respecto a los productos se implementará la mixología molecular, así como la coctelera conceptual, dentro de la carta de productos a ofrecer. Con el respectivo cuidado de no elevar el costo promedio de los productos.

- Se debe garantizar el orden, la higiene y buen mantenimiento de todos los equipos y herramientas necesarias para la operación del negocio, incluyendo las áreas de cocina.

- Intensificar los esfuerzos de marketing en los mercados internos.

- Seleccionar proveedores estratégicamente, que me permita tener costos bajos y poder ofrecer los servicios a un nivel de precios promedio publicitado 
- Aplicar el Neuromarketing al proceso de creación y promoción de los productos

- Capacitar al personal sobre la atención al cliente de manera constante.

- Crear un buen proceso de Administración de Clientes a través de un CRM.

\subsubsection{Estrategia de Presencia Física.}

Uno de los factores que está adquiriendo más importancia es la cuantificación de los activos intangibles. La evidencia física puede ayudar a crear el "ambiente" y la "atmosfera" en que se compra o realiza un servicio, y puede ayudar a dar forma a las percepciones del servicio que tengan los clientes.

En el marketing de servicios, se debe realizar una distinción entre dos clases de evidencia física: La evidencia periférica y la evidencia esencial.

- Evidencia periférica: se posee realmente como parte de la compra de un servicio; sin embargo, tiene poco valor por sí sola. Simplemente confirma el servicio, no es un sustituto de él. Entre estos indicios se encuentran él ambiente del establecimiento (temperatura, ruidos cero, música, olor), uniformes, decoración, y apariencia del empleado. Cumpliendo de esta forma con lo ofrecido al entregar una propuesta de valor de ser un establecimiento con las mismas propiedades de un bar tradicional con la diferencia de poder tener la posibilidad de establecer una buena conversación sin la dificultas de comunicarse ni de ser interrumpido por ruidos propios de la música o de los clientes asistentes.

- Evidencia física: a diferencia de la anterior, no la puede poseer el cliente, sin embargo, su influencia es muy importante para la adquisición de un servicio, ya que constituyen indicios tangibles de oferta del servicio. Se puede mencionar que los mismos cocteles pueden ser considerados como evidencia de la entrega de propuesta de valor al ser similares con los encontrados en un bar tradicional con la diferencia de no contener alcohol

Las empresas de servicios con servicios competitivos pueden utilizar evidencia física para diferenciar sus productos en el mercado y dar a sus servicios una ventaja competitiva, porque cuando un consumidor intenta juzgar un servicio, especialmente antes de utilizarlo o comprarlo, ese servicio se conoce por la evidencia tangible que lo rodea.

A la larga, la evidencia periférica y la evidencia física, en combinación con otros elementos que conforman la imagen de una empresa de servicios, no sólo ayudan a visualizar el servicio sino también influyen en la opinión, post compra que tenga el cliente. Si bien es cierto que las imagines son difíciles de definir, medir y controlar, por el hecho de que la 
imagen es una estructura subjetiva y personal, el manejo de esas evidencias es conveniente para asegurar que la imagen transmitida esté conforme con la imagen deseada. (Franco, 2013).

\subsection{Estrategia de Ventas}

Según Lovelock (2015), la estrategia de ventas se relaciona con la creación, comunicación, y mantenimiento de las diferencias relevantes que los clientes observarán y considerarán valiosas, de esta forma la empresa tendría mayores probabilidades de desarrollar relaciones de a largo plazo con ellos. Una estrategia de ventas exitosa requiere que los gerentes entiendan las preferencias de sus clientes, sus conceptos de valor y las características de los ofertantes - competidores. Los atributos de precio y producto son dos de las 4 Ps del marketing que mas se relacionan con las ventas. Sin embargo en el caso de servicio, las ventas también se relacionan con las otras Ps del marketing de servicios, incluyendo los procesos de servicios, los sistemas de distribución, los horarios, y el personal de servicio.

\subsubsection{Plan de Ventas.}

La oferta de valor propuesta tendrá como pilares fundamentales para las ventas: La Ambientación, la Calidad de los Productos, el Servicio esperado.

\section{Objetivos:}

- Lograr una participación de mercado de $2 \%$ para el 5 to. año.

- Posicionar la marca "La Conversa Bar" en la mente del consumidor.

Cabe señalar que para el logro de estos objetivos se ha establecido una relación de estrategias y tácticas que se pueden observar distribuidas en las diferentes estrategias de marketing desarrolladas anteriormente.

\subsubsection{Políticas de Servicios y Garantías.}

El caso en estudio, establece sus políticas en relación a su responsabilidad de higiene y salubridad, control de procesos, y relaciones optimas con los clientes de forma duradera, que le permita obtener y recibir la propuesta de valor diseñada para el público objetivo. Por todo lo anterior se necesitará llevar a cabo los siguientes ítems:

- Conservar y realizar mantenimiento de los artefactos eléctricos como refrigeradoras, congeladora, parrillas y licuadoras que se utilicen en la elaboración de cocteles y derivados complementarios

- Mantener el depósito de insumos en óptimas condiciones de higiene y establecer la temperatura ideal para los insumos perecibles. 
- Realizar fumigaciones mínimo 1 vez al año para evitar cualquier tipo de insectos y roedores.

- Realizar la limpieza de las mesas una vez los clientes las hayan desocupado, así como mantener el local y los servicios higiénicos impecables.

- Seguir los procesos establecidos en caso se desee contratar a un nuevo proveedor.

- Cumplir con las características que deben tener los productos en cuanto a la calidad.

- La compra de fruta, aves e insumos se realizará 3 veces a la semana y/o dependiendo de la temporada de gran demanda de clientes.

- Al momento de realizar un pedido se respetarán los precios de la carta, la cual se encontrará en un lugar visible.

- El cliente deberá ser atendido en un plazo máximo de 7 a 10 minutos.

La implantación de estas políticas tendrá como fin establecer una relación de confianza con los clientes y sobre todo satisfacción del cliente, garantizando el compromiso de la empresa mediante el cumplimiento de tiempo, servicios, y estándares de calidad exigidos para este tipo de negocio. 


\section{Capítulo VI: Pronóstico de Ventas}

La cantidad demandada proyectada a futuro es quizá el factor condicionante más importante del tamaño del proyecto, aunque este no necesariamente deberá definirse en función de un crecimiento esperado del mercado, ya que, el nivel óptimo de operación, capacidad instalada, no siempre será el que maximice las ventas. Vender más no necesariamente es sinónimo de ganar más. Aunque el tamaño puede ir adecuándose posteriormente a mayores requerimientos de operación para enfrentar un mercado creciente, es necesario que se evalúe esa opción en contraste con la de definir un tamaño con una capacidad ociosa inicial que posibilite responder oportunamente a una demanda creciente en el tiempo. (Sapag, 2014, 103).

Según Sapag (2014), existen tres situaciones básicas del tamaño del proyecto que pueden identificarse respecto del mercado: (1) Que la cantidad demandada total sea claramente menor que la capacidad menor de las unidades productoras posibles de instalar, (2) Que la cantidad demandada sea igual a la capacidad mínima que puede instalarse y (3) Que la cantidad demandada sea superior a la mayor capacidad de las unidades productoras posibles de instalar.

\subsection{Fundamentos y Supuestos}

Para realizar el pronóstico de ventas se ha considerado los siguientes factores considerados fundamentales

1. El mercado objetivo

Un crecimiento “orgánico” el cual deriva del incremento poblacional, permitirá que el Mercado Potencial se incremente en una tasa de $1.3 \%$ partiendo de 300,780 en el año 1 y llegando a 316,728 al año 5; así como de igual forma se incremente el Mercado Objetivo de 1,785 a 1,879 personas del año 1 al año 5, respectivamente (ver Tabla 24):

Tabla 24

Mercado Objetivo

\begin{tabular}{lcccccc}
\hline Número de Personas & $\%$ & Año 1 & Año 2 & Año 3 & Año 4 & Año 5 \\
\hline Mercado Potencial & $1.3 \%$ & 300,780 & 304,690 & 308,651 & 312,663 & 316,728 \\
Mercado Disponible & $67.3 \%$ & 202,333 & 204,964 & 207,629 & 210,327 & 213,062 \\
Mercado Efectivo & $29.4 \%$ & 59,486 & 60,259 & 61,043 & 61,836 & 62,640 \\
Mercado Objetivo & $3.0 \%$ & 1,785 & 1,808 & 1,831 & 1,855 & 1,879
\end{tabular}

Nota: Tomado de los resultados obtenidos del procesamiento de datos elaborado para el cuestionario aplicado al segmento identificado. 
2. La frecuencia de compra

Para efectos de Pronóstico de Ventas se considera frecuencia 24 veces al año (Ver Tabla 25):

Tabla 25

Frecuenca de Compra Mercado Efectivo

\begin{tabular}{lrrr}
\hline Filtro: Mercado Efectivo & \multicolumn{2}{c}{ Frecuencia } \\
Frecuencia & $\%$ & 52 & 14 \\
\hline Todas las semanas & $26.36 \%$ & 24 & 7 \\
Quincenal & $30.91 \%$ & 12 & 4 \\
Mensual & $36.36 \%$ & 1 & 0 \\
Muy rara vez & $6.37 \%$ & & 25.0 \\
\hline Total & $100.00 \%$ & & \\
\hline
\end{tabular}

3. La capacidad instalada para calcular las unidades,

La capacidad instalada se explica a detalle en el capítulo 7.2 para la determinación del tamaño, para efectos de proyección se considera un incremento anual del $5 \%$ en la capacidad instalada ocupada, durante todo el horizonte temporal, que parte del 50\% de ocupación en el año 1 y llega a $70 \%$ en al año 5. Posteriormente se considera el número menor entre la proyección de visitas anuales y la capacidad esperada de ocupación del local.

En todos los años, como se observa en la Tabla 26, la proyección de unidades expresadas en visitas es menor que la capacidad esperada de ocupación, lo cual significa que hay capacidad de atender la demanda proyectada. Esto permite, manteniendo una frecuencia de visita quincenal (24 visitas al año) por persona, crecer de 42,840 visitas anuales a 45,096 visitas al año 5.

4. Consumo promedio para el pronóstico en Soles.

Para efectos de Pronóstico de Ventas se considera consumo promedio de S/45.00 (incluido IGV), no obstante, tener como resultado consumo promedio de S/47.00, como se observa (Ver Tabla 27), esto debido a la relación con los precios promedios de los productos (S/15.00) mostrados en la Carta. 
Dicho Consumo promedio se compone de la siguiente manera:

\begin{tabular}{lc} 
Consumo Promedio & Soles S/. \\
\hline Sin IGV & 38.14 \\
IGV & 6.86 \\
\hline Incluido IGV & 45.00
\end{tabular}

Tabla 26

Proyeccion de Unidades (Visitas)

\begin{tabular}{lccccc}
\hline Número de Personas & Año 1 & Año 2 & Año 3 & Año 4 & Año 5 \\
\hline Mercado Objetivo & 1,785 & 1,808 & 1,831 & 1,855 & 1,879 \\
Frecuencia Promedio & 24 & 24 & 24 & 24 & 24 \\
Total Visitas Anuales & 42,840 & 43,392 & 43,944 & 44,520 & 45,096 \\
Capacidad Total & 87,360 & 87,360 & 87,360 & 87,360 & 87,360 \\
\% Ocupación & $50 \%$ & $55 \%$ & $60 \%$ & $65 \%$ & $70 \%$ \\
Capacidad Esperada & 43,680 & 48,048 & 52,416 & 56,784 & 61,152 \\
Proyección \# & 42,840 & 43,392 & 43,944 & 44,520 & 45,096
\end{tabular}

Nota: Tomado de los resultados obtenidos del procesamiento de datos elaborado para el cuestionario aplicado al segmento identificado.

Tabla 27

Consumo promedio por Visita

\begin{tabular}{lrrcc}
\hline Filtro: Mercado Efectivo & & Consumo & \\
\cline { 1 - 1 } \cline { 5 - 5 } Consumo Promedio & \multicolumn{1}{c}{$\%$} & Medio & Ponderado \\
\hline Menor a S/40.00 & $35.45 \%$ & 20 & 7 \\
Entre S/40.00 y S/80.00 & $61.82 \%$ & 60 & 37 \\
Entre S/80.00 y S/120.00 & $1.82 \%$ & 100 & 2 \\
Mayor a S/120 & $0.91 \%$ & 120 & 1 \\
\hline Total & $100.00 \%$ & & 47.0 \\
\hline
\end{tabular}

Nota: Tomado de los resultados obtenidos del procesamiento de datos elaborado para el cuestionario aplicado al segmento identificado.

Finalmente la proyección de ventas en Soles es la siguiente que se muestra en la siguiente tabla (ver Tabla 28): 
Tabla 28

Proyeccion Total Ventas Soles

\begin{tabular}{lccccc}
\hline & Año 1 & Año 2 & Año 3 & Año 4 & Año 5 \\
\hline Proyección \# & 42,840 & 43,392 & 43,944 & 44,520 & 45,096 \\
Consumo Promedio & 38.14 & 38.14 & 38.14 & 38.14 & 38.14 \\
\hline Total Venta Anual & $1,225,211$ & $1,654,971$ & $1,676,024$ & $1,697,993$ & $1,719,961$ \\
\hline
\end{tabular}

Nota: Tomado de los resultados obtenidos del procesamiento de datos elaborado para el cuestionario aplicado al segmento identificado.

Para desagregar la proyección de ventas entre bebidas y piqueos se debe aplicar la mezcla de consumo de estos productos en los bares tradicionales. Gracias a las entrevistas a expertos se pudo conocer la mezcla de bar tradicional y su opinión con respecto a un bar sin alcohol (ver Tabla 29).

Tabla 29

Mezcla Consumo Promedio Bares

Bar Tradicional

\begin{tabular}{lcc}
\hline Tipo & Unidades & $\%$ \\
\hline Bebidas & 4 & $80 \%$ \\
Piqueos & 1 & $20 \%$ \\
\hline Total & 5 & $100 \%$ \\
\hline
\end{tabular}

Bar Sin Alcohol

\begin{tabular}{lcc}
\hline Tipo & Unidades & $\%$ \\
\hline Bebidas & 2 & $67 \%$ \\
Piqueos & 1 & $33 \%$ \\
\hline Total & 3 & $60 \%$ \\
\hline Nota: Tomado de los resultados obtenidos del procesamiento de datos \\
elaborado para el cuestionario aplicado al segmento identificado.
\end{tabular}

Aplicando la mezcla propuesta por los expertos la distribución en soles es la siguiente tabla (Ver Tabla 30): 
Tabla 30

Proyeccion Ventas Soles por Bebidas y Piqueos

\begin{tabular}{lcccccc}
\hline & $\%$ & Año 1 & Año 2 & Año 3 & Año 4 & Año 5 \\
\hline Total Venta & & & & & & \\
Anual Soles & $100 \%$ & $1,633,918$ & $1,654,971$ & $1,676,024$ & $1,697,993$ & $1,719,961$ \\
Bebidas & $67 \%$ & $1,089,278$ & $1,103,314$ & $1,117,349$ & $1,131,995$ & $1,146,641$ \\
Piqueos & $33 \%$ & 544,639 & 551,657 & 558,675 & 565,998 & 573,320 \\
\hline
\end{tabular}

Nota: Tomado de los resultados obtenidos del procesamiento de datos elaborado para el cuestionario aplicado al segmento identificado.

Para obtener las unidades por cada tipo de producto a vender se debe aplicar el precio unitario promedio obtenido de la encuesta y considerar las preferencias de los productos en cada visita de los clientes, indicada por los expertos (ver Tabla 31).

Tabla 31

Precio a Pagar por Unidad Mercado Efectivo

\begin{tabular}{lccc}
\hline Filtro: Mercado Efectivo & \multicolumn{3}{c}{ Consumo } \\
\hline Precio por Trago & $\%$ & Medio & Ponderado \\
\hline Menor a S/15.00 & $0.00 \%$ & 7.50 & 0.00 \\
Entre S/15.00 a S/20.00 & $91.82 \%$ & 17.50 & 16.00 \\
Entre S/20.00 y S/25.00 & $6.36 \%$ & 22.50 & 1.00 \\
Mayor a S/25 & $1.82 \%$ & 25.00 & 0.00 \\
\hline Total & $100.00 \%$ & & 17.00
\end{tabular}

Nota: Tomado de los resultados obtenidos del procesamiento de datos elaborado para el cuestionario aplicado al segmento identificado.

Para efectos de Pronóstico de Ventas, se considera un escenario donde el precio será de S/15 (Incluido IGV).

\begin{tabular}{lr} 
Precio Unitario & Soles \\
\hline Sin IGV & 12.71 \\
IGV & 2.29 \\
\hline
\end{tabular}


\begin{tabular}{ll}
\hline Incluido IGV $\quad 15.00$
\end{tabular}

Aplicando el precio unitario promedio, la distribución en unidades es la siguiente (ver Tabla 32):

Tabla 32

Proyeccion Ventas Unidades por Bebidas y Piqueo

\begin{tabular}{lrrrrrr}
\hline & $\#$ & \multicolumn{1}{c}{ Año 1 } & \multicolumn{1}{c}{ Año 2 } & \multicolumn{1}{c}{ Año 3 } & Año 4 & Año 5 \\
\hline Bebidas & $67 \%$ & 816,803 & $1,103,314$ & $1,117,349$ & $1,131,995$ & $1,146,641$ \\
Piqueos & $33 \%$ & 408,408 & 551,657 & 558,675 & 565,998 & 573,320 \\
& & & & & & \\
Bebidas & $\#$ & 64,248 & 86,784 & 87,888 & 89,040 & 90,192 \\
Piqueos & $\#$ & 32,124 & 43,392 & 43,944 & 44,520 & 45,096 \\
\hline
\end{tabular}

Nota: Tomado de los resultados obtenidos del procesamiento de datos elaborado para el cuestionario aplicado al segmento identificado.

\subsection{Justificación}

Un método más sistemático y objetivo, que se vale del método científico, es la investigación de mercado, la cual se utiliza principalmente en la recolección de información relevante para ayudar a la toma de decisiones o para aprobar o refutar hipótesis sobre un mercado específico, mediante encuestas, experimentos, mercados-prueba u otras formas.

Este método constituyó ser, un paso necesario para la aplicación y el uso de las proyecciones siguientes, dada la información sistematizada y objetiva que entrega

La principal característica del método es su flexibilidad para seleccionar e incluso para diseñar la metodología que más se adecue al problema en estudio, ya sea una investigación exploratoria, descriptiva o explicativa (Sapag, 2014).

La proyección realizada se justifica en la intención de compra obtenida del estudio de mercado, características del mercado actual y opinión sobre la propuesta obtenidas a partir de la aplicación de encuestas y la opinión de expertos.

Las técnicas utilizadas para obtener las variables han sido seleccionadas basadas en los requerimientos de información, si bien existe un mercado actual de bares, el modelo planteado de bar sin alcohol no dispone de información histórica, por lo que fue necesaria la aplicación de primera fuente a través de la investigación cuantitativa y cualitativa. 
La importancia de los métodos cualitativos en la predicción del mercado se manifiesta cuando los métodos cuantitativos basados en información histórica no pueden explicar por sí solos el comportamiento futuro esperado de alguna de sus variables, cuando no existen suficientes datos históricos o cuando se trata de investigar aspectos del comportamiento del consumidor que ni siquiera él mismo sabe, sobre todo cuando se trata de proyectos de innovación (Sapag, 2014).

\subsection{Análisis de los Riesgos y aspectos críticos que impactan en el negocio}

Se identifican los siguientes aspectos críticos que impactan el negocio y deben ser considerados para el seguimiento de la proyección realizada.

El riesgo es la disminución o incremento de estos factores que pueden afectar las ventas, los costos y por ende la utilidad y rentabilidad esperada. El impacto de este riesgo puede ser mitigado si es identificado oportunamente.

\subsubsection{Factores externos.}

- Desaceleración del crecimiento económico, disminuye el consumo interno, priorizando ingresos de la población a cubrir necesidades básicas.

- Inflación, ocasionaría aumento de precios de los insumos para la elaboración de tragos sin alcohol.

- Disminución de la población afluente en el distrito de Barranco. Aparición de Nuevos clúster de diversión en Lima.

- Nuevos competidores en la zona, al tener opciones la demanda se reparte entre todos los actores.

- Variaciones en el comportamiento del consumidor, de mantenerse la tendencia mundial por la alimentación saludable y consumo responsable este tendría un impacto positivo; sin embargo nuevos productos podría impactar negativamente.

\subsubsection{Factores internos.}

- Nivel de Novedad, la real aceptación de la propuesta podría ser menor de la obtenida en el estudio de mercado.

- Cambios en los procesos de producción, se debe estar al día con las tendencias en preparación de tragos para aplicarlos a la propuesta.

- Resultados de las estrategias de marketing, estas pueden ser de impacto positivo o negativo.

- Modificación de la capacidad instalada por exigencias propias o reglamentarias pueden afectar la atención de la demanda. 


\section{Capitulo VII: Ingeniería de Proyecto}

Con las ventas proyectadas nos encontraremos, en este capítulo, en la posibilidad de establecer los requerimientos técnicos así como los estudios de ingeniería que dispondremos para un buen desenvolvimiento de las actividades de abastecimiento, producción, y comercialización del servicio.

\subsection{Estudio de Ingeniería}

En este capítulo se toma en cuenta los recursos y equipos necesarios para la implementación del bar, así como el modelamiento, la selección de procesos productivos, la distribución de equipos y maquinarias; de igual manera se delimitan las consideraciones legales y jurídicas con el fin de:

- Establecer los procesos de producción y definir las operaciones que se requerirán.

- Establecer los estándares de producción, a fin de que estos sean eficientes y se logre satisfacer la demanda.

- Describir los recursos necesarios para La Conversa Bar, como los equipos, muebles, local e insumos.

\subsubsection{Modelamiento y Selección de Procesos Productivos.}

Según Baca (2013), proceso se define estrictamente como una secuencia de etapas o pasos que se utilizan para transformar un insumo o recurso en un resultado con un valor determinado para el cliente interno o externo. A su vez, administrar por procesos implica definir cada uno de los procesos que suceden a lo largo de la cadena de valor de la empresa. Este enfoque va hasta las entrañas mismas de la administración de la organización, analiza los pasos, etapas o actividades que generen valor para el cliente de modo que se realice solo las actividades generadoras de valor y eliminar aquellas que no lo hacen.

Cabe señalar, que las actividades tienen como principio trasversal la calidad, tanto en las actividades como en la adquisición de recursos, cumpliendo de tal manera con los objetivos planteados, anteriormente, de estándares y normas. A continuación, en las Figuras $46,47,48,4950$, y 51 se muestran los diferentes procesos productivos por la que atravesará la elaboración del servicio a brindar los visitantes del proyecto: 


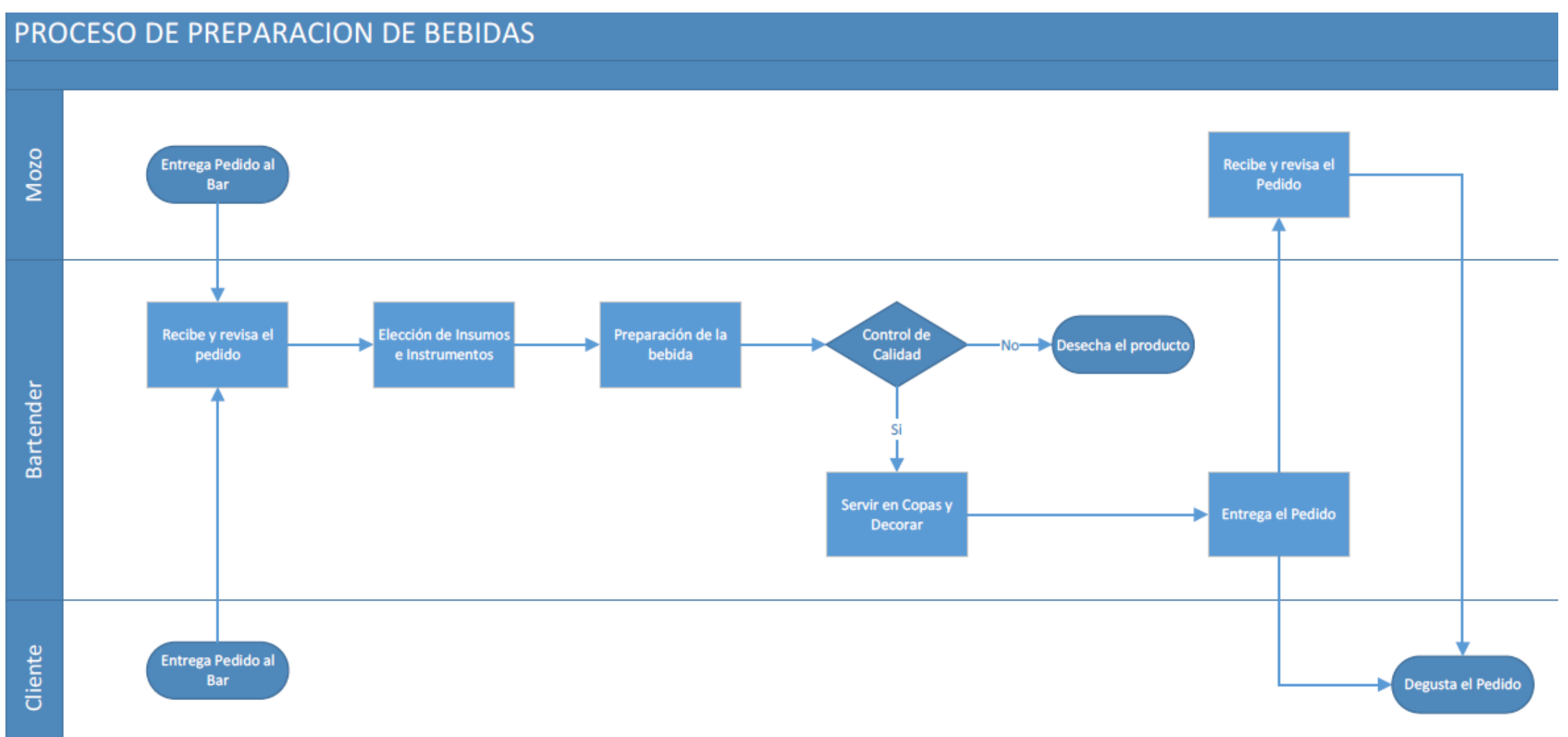

Figura 46. Proceso de Preparación de Bebidas. 


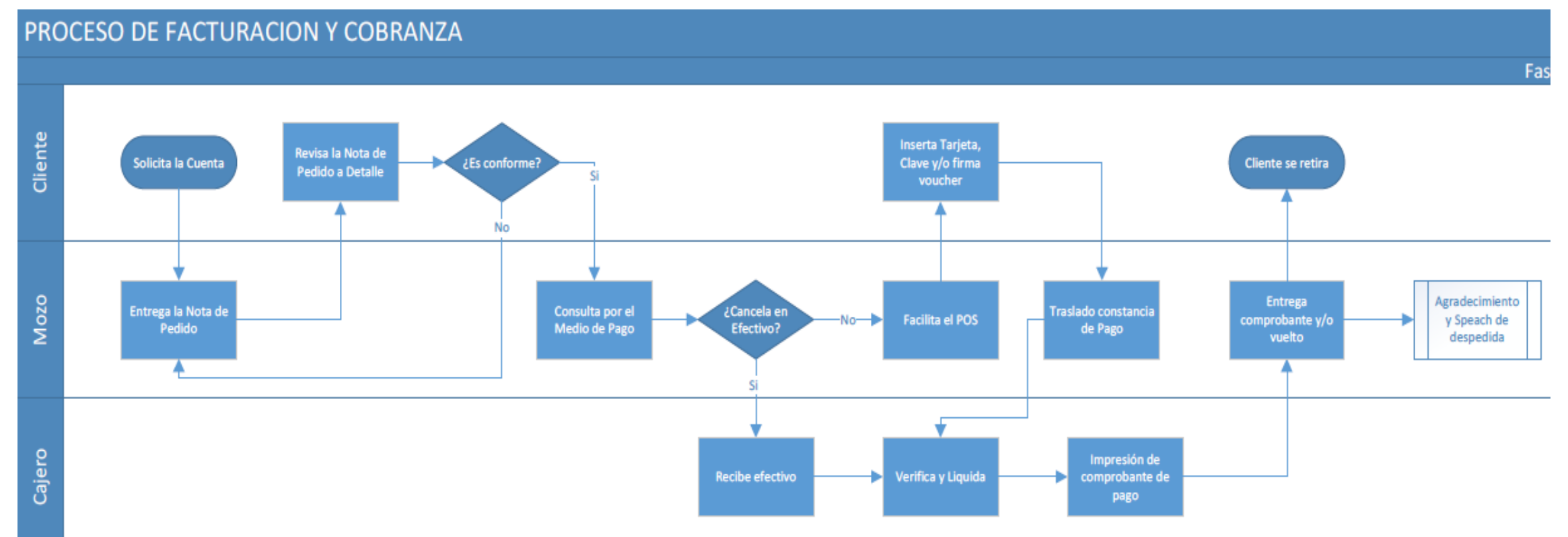

Figura 47. Proceso de Facturación y Cobranzas. 


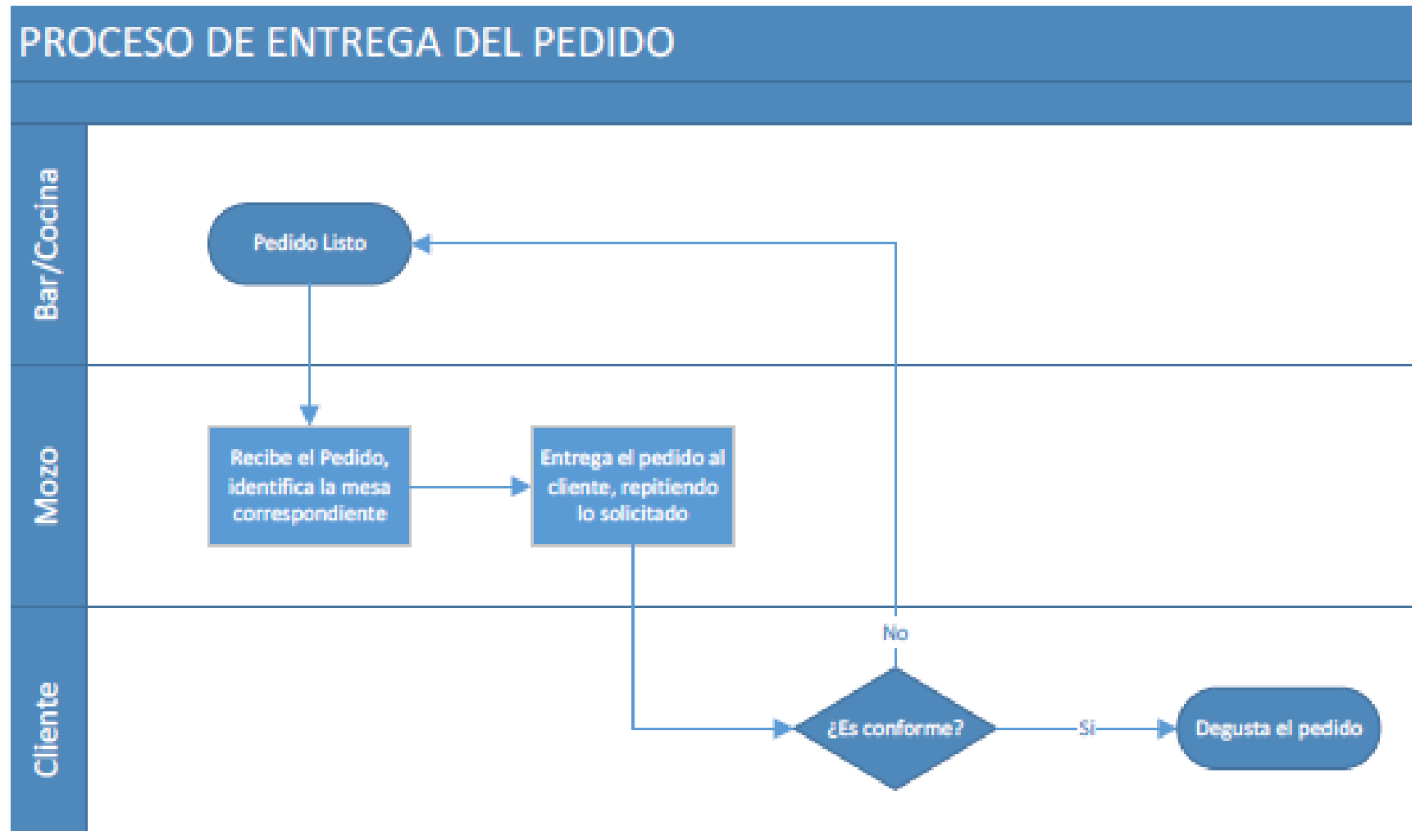

Figura 48. Proceso de Entrega de Pedido. 


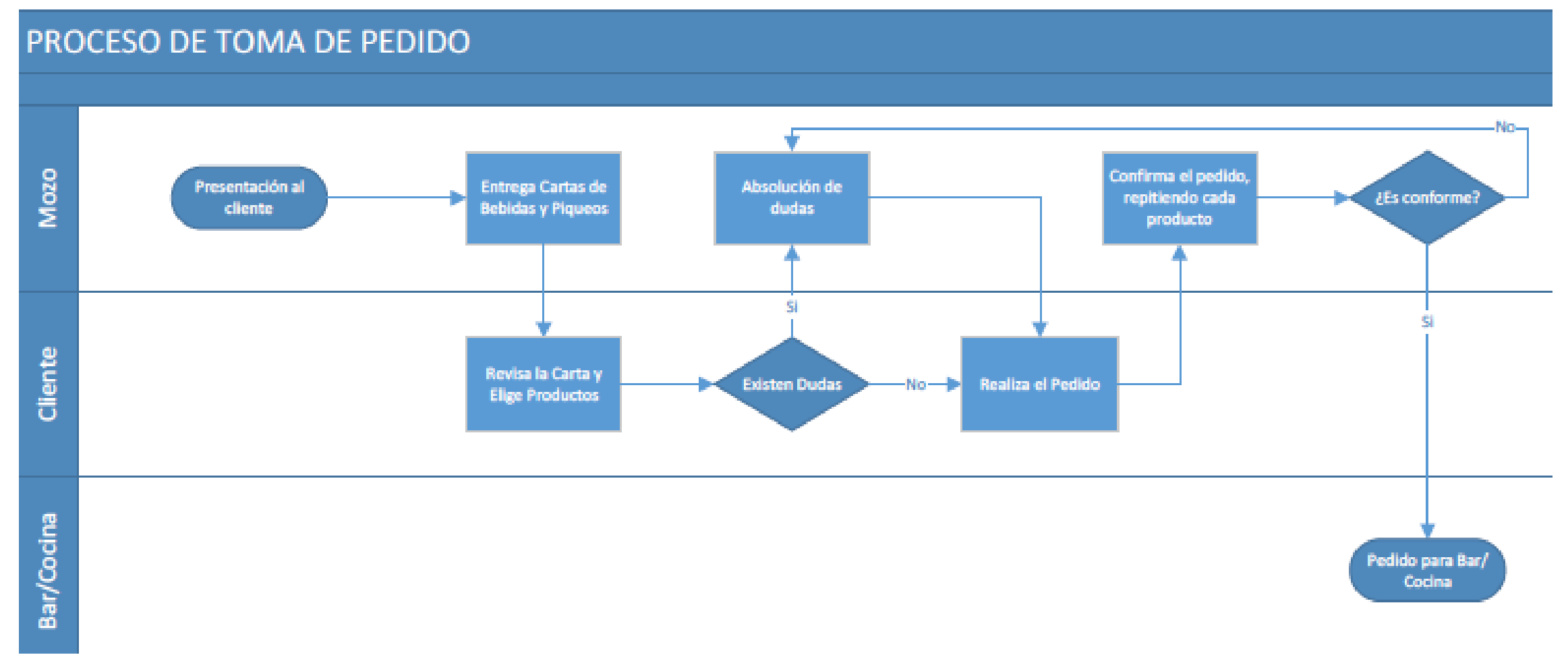

Figura 49. Proceso de Toma de Pedido. 


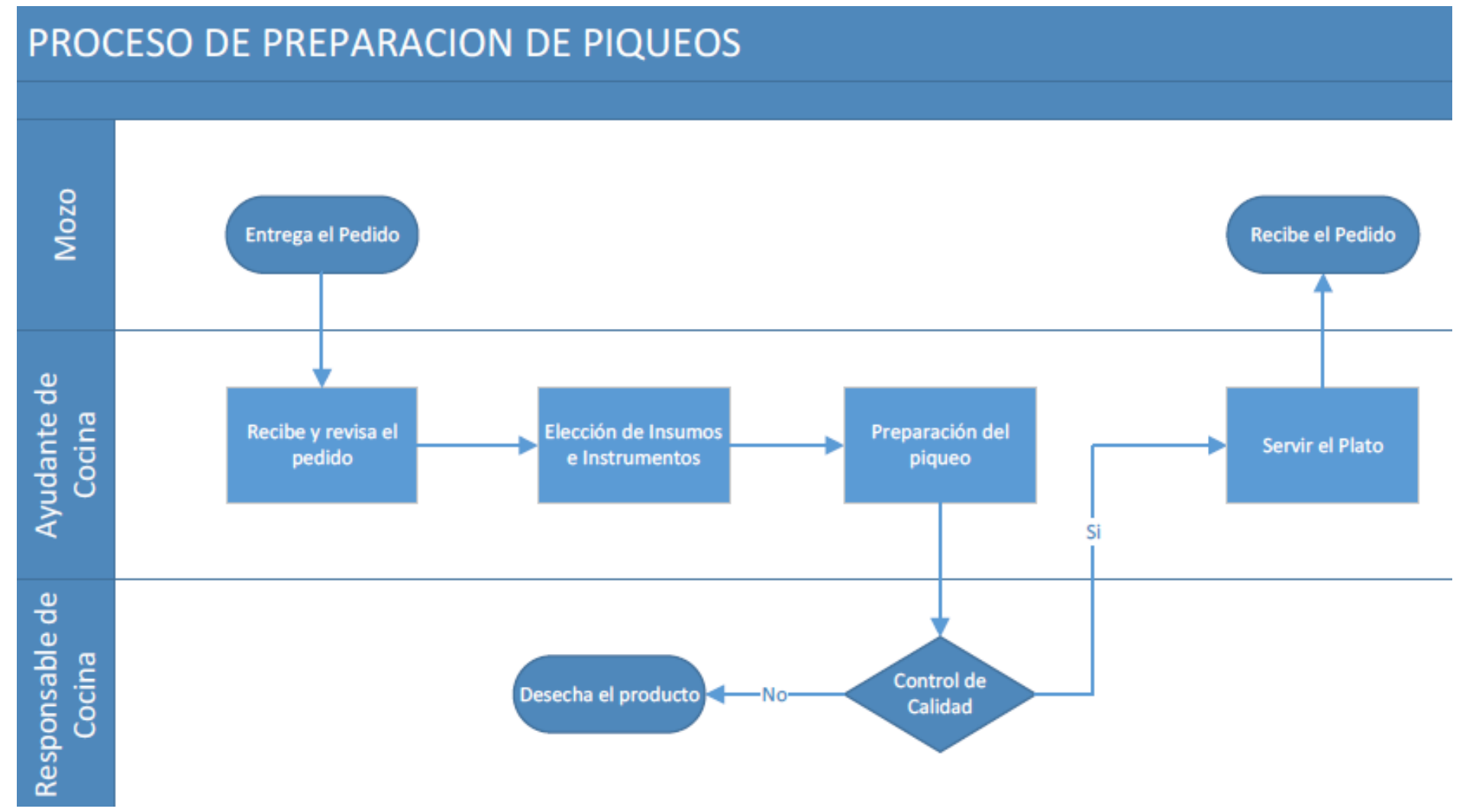

Figura 50. Proceso de Preparación de Piqueos. 


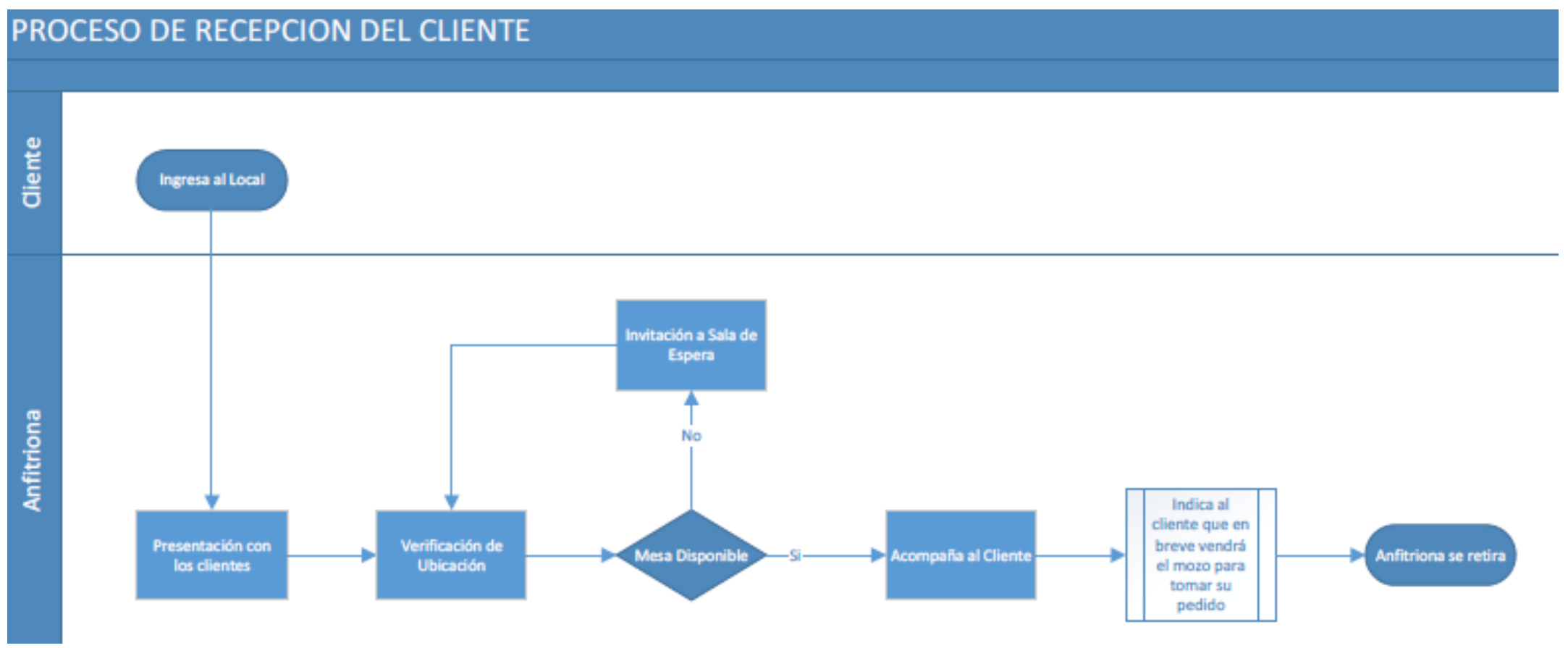

Figura 51. Proceso de Recepción de Cliente. 


\subsubsection{Selección del Equipamiento}

Para la selección del equipamiento, según Baca (2013), se deben de tomar en cuenta una serie de factores que afectan directamente a la elección, entre los que figuran:

1. Proveedor. Útil para la presentación de cotizaciones.

2. Precio. Sirve para el cálculo de la inversión inicial.

3. Dimensiones. Para que no afecte la distribución de las áreas.

4. Capacidad. De tal forma que no sea tan baja que genere cuellos de botella, ni tan alta que de paso a capacidad ociosa.

5. Flexibilidad. Saber la versatilidad que puede sostener ante los diferentes escenarios de funcionamiento.

6. Mano de obra necesaria. En caso de requerir capacitación previa.

7. Costos de instalación y puesta en marcha. Verificar si se incluye en el precio a pagar.

Considerando lo anterior, a continuación las siguientes tablas (ver Tablas desde la 33 a hasta la Tabla 43), se detalla el equipamiento y recurso necesarios para la implementación de local y para el buen funcionamiento de los procesos antes descritos.

Tabla 33

Equipamiento - Generales

\begin{tabular}{|c|c|c|c|c|c|}
\hline Cantidad Unidad & Descripción & Marca / Proveedor & Modelo / tipo & Precio Unit S/ & TOTAL S/ \\
\hline $120 \mathrm{mts}$ & PISO PORCELANATO COLOR CRUDO INSTALADO & CELIMA & COLOR CRUDO & 35.00 & $4,200.00$ \\
\hline $120 \mathrm{mts}$ & ZOCALO: MADERA CEDRO (ml) & & & 19.80 & $2,376.00$ \\
\hline $20 \mathrm{mts}$ & TRABAJOS EN DRYWALL & & Servicio & 90.00 & $1,800.00$ \\
\hline 1 Servicio & $\begin{array}{l}\text { ELECTRICA Y SANITARIAS (Instalacion, incluye } \\
\text { materiales) }\end{array}$ & & Servicio & $8,900.00$ & $8,900.00$ \\
\hline 1 Servicio & $\begin{array}{l}\text { REDES DE DATA, TELEFONIA, AUDIO Y ALARMA DE } \\
\text { INCENDIOS (instalacion, incluye materiales) }\end{array}$ & & Servicio & $9,450.00$ & $9,450.00$ \\
\hline \multirow{2}{*}{$\begin{array}{l}7 \text { galones } \\
4 \text { galones }\end{array}$} & PINTURA TECHOS & Vencedor & latex & 34.00 & 238.00 \\
\hline & PINTURA EPOXICA (m2) & & & 25.00 & 100.00 \\
\hline 12 galones & PINTURA PARED LATEX (m2) & Vencedor & Super Mate & 44.00 & 528.00 \\
\hline 1 unidad & PUERTA DE INGRESO PRINCIPAL DE MADERA & & Servicio & $2,500.00$ & $2,500.00$ \\
\hline 4 unidad & PUERTAS CONTRAPLACADAS DE $0.80 \mathrm{~cm}$ & Maestro & contraplacada & 300.00 & $1,200.00$ \\
\hline 3 unidad & PUERTAS CONTRAPLACADAS DE $0.90 \mathrm{~cm}$ & Maestro & contraplacada & 400.00 & $1,200.00$ \\
\hline 1 unidad & PUERTA $0.85 \mathrm{~cm}$ & Maestro & vaiven & 400.00 & 400.00 \\
\hline 1 unidad & PUERTA DE $0.90 \mathrm{~cm}$ ( INGRESO A COCINA) & Ambienta & Metal - PVC & 900.00 & 900.00 \\
\hline 1 unidad & PUERTA CORREDERA DE DOS HOJAS ( PRINCIPAL) & Puertas Sanchez & Metal zincada & $1,500.00$ & $1,500.00$ \\
\hline 1 unidad & PUERTAS HERMETICAS DE $0.70 \mathrm{~cm}$ ( ALMACENES) & Ivegas & Metal & $3,000.00$ & $3,000.00$ \\
\hline 1 unidad & AIRE ACONDICIONADO (equipo + instalación) & Frio Temp & York - helico-centrifugo & $12,000.00$ & $12,000.00$ \\
\hline 1 unidad & LETRERO EXTERIOR + instalación & Big Led & Letrero luminoso con leds & $7,600.00$ & $7,600.00$ \\
\hline 1 unidad & software & Sysco Perú & ERP & $6,250.00$ & $6,250.00$ \\
\hline 1 unidad & software & Sysco Perú & OFIBAR & $6,250.00$ & $6,250.00$ \\
\hline \multirow{2}{*}{$\begin{array}{l}1 \text { unidad } \\
5 \text { unidad } \\
\end{array}$} & Digital Signage & LG Electronis & indoor & $5,940.00$ & $5,940.00$ \\
\hline & Tablets & Samsung / Hiraoka & SM-T280NZWAPEO & 499.00 & $2,495.00$ \\
\hline & & & TOTALES & & $78,827.00$ \\
\hline
\end{tabular}


Tabla 34

Equipamiento Recepción

\begin{tabular}{|c|c|c|c|c|c|c|}
\hline Cantidad & Unidad & Descripción & Marca / Proveedor & Modelo / tipo & Precio Unit S/ & TOTAL S/ \\
\hline 1 & & LUMINARIA DECORATIVA & Ornalux & NFLQ311X 17 & 755.00 & 755.00 \\
\hline 1 & & COUNTER MADERA ENCHAPADA RETROILUMINADA & Arquit & enchapada / iluminada & $1,800.00$ & $1,800.00$ \\
\hline 1 & & BANQUETA ALTA & Ziyaz & barcelo & 220.00 & 220.00 \\
\hline & & & & TOTALES & & $2,775.00$ \\
\hline
\end{tabular}

Tabla 35

Equipamiento Caja

\begin{tabular}{|c|c|c|c|c|c|c|}
\hline Cantidad & Unidad & Descripción & Marca / Proveedor & Modelo / tipo & Precio Unit S/ & TOTAL S/ \\
\hline 1 & & CAJA REGISTRADORA & Level Store & Modelo-CM-01 & $2,500.00$ & $2,500.00$ \\
\hline 1 & & PC & LG & 24V570- All in one & $2,600.00$ & $2,600.00$ \\
\hline 1 & & impresora & Bother Hiraoka & DCP-1617NW & 549.00 & 549.00 \\
\hline 1 & & MUEBLE LATERAL EN MADERA & Proyecto 5 & Servicio + materiales & 800.00 & 800.00 \\
\hline 1 & & VENTANA C/VIDRIO PAVONADO Y ALUMINIO 1MT D & Industria El Cisne & Servicio + materiales & 250.00 & 250.00 \\
\hline 1 & & BANQUETA ALTA & Ziyaz & barcelo & 220.00 & 220.00 \\
\hline \multirow[t]{2}{*}{1} & & ILUMINACION & Proluxled & Servicio + materiales & 755.00 & 755.00 \\
\hline & & & & TOTALES & & $7,674.00$ \\
\hline
\end{tabular}

Tabla 36

Equipamiento Bar

\begin{tabular}{|c|c|c|c|c|c|c|}
\hline Cantidad & Unidad & Descripción & Marca / Proveedor & Modelo / tipo & Precio Unit S/ & TOTAL S/ \\
\hline 1 & & ILUMINACION & Proluxled & Servicio + materiales & $1,500.00$ & $1,500.00$ \\
\hline 1 & & & Servicio + materiales & $8,500.00$ & $8,500.00$ \\
\hline 1 & & \multicolumn{2}{|c|}{$\begin{array}{l}\text { BARRA MDF MAD. ENCH. } 5.00 \text { X } 2.13 \text { RETROILUMINAL Arauco Soluciones } \\
\text { ENCIMERA MARMOL CARRARA }\end{array}$} & Servicio + materiales & $1,500.00$ & $1,500.00$ \\
\hline 1 & & \multicolumn{2}{|l|}{ MESA DE FRIO / HIELERA } & ASTR-60 & $5,874.00$ & $5,874.00$ \\
\hline 240 & & COPAS Y VASOS & Union Ychikawa & Cristaleria fina (varios) & 11.50 & $2,760.00$ \\
\hline 1 & & LAVA COPAS & Alitecno Perú & gama electrónica & $5,544.00$ & $5,544.00$ \\
\hline 1 & & FRIGOBAR & Klimatic & KSs inox 160 & $1,200.00$ & $1,200.00$ \\
\hline 2 & & LICUADORA SEMI - INDUSTRIAL (encapsulada) & Skymsen & Deluxe & $2,200.00$ & $4,400.00$ \\
\hline 1 & & EXPRMIMIDORA DE CITRICOS & Skymsen & Deluxe & $1,555.00$ & $1,555.00$ \\
\hline 1 & & LAVATORIO + GRIFERIA & Sodimac & Record+ Moen & $1,550.00$ & $1,550.00$ \\
\hline 1 & & \multirow[t]{2}{*}{ MUEBLE ESTANTERIA EN LA PARED } & Torres Postformados & Servicio + materiales & $4,450.00$ & $4,450.00$ \\
\hline & & & & TOTALES & & $38,833.00$ \\
\hline
\end{tabular}

Tabla 37

Equipamiento Salon Principal

\begin{tabular}{clllrr}
\hline Cantidad & Unidad & Descripción & Marca / Proveedor & Modelo / tipo & Precio Unit S/ TOTAL S/ \\
\hline 7 & MESAS & Zillaz & Arianne & 310.00 & $2,170.00$ \\
28 & SILLAS & Zillaz & Arianne & 220.00 & $6,160.00$ \\
6 & BANQUETAS ALTAS & Zillaz & Barmster & 440.00 & $2,640.00$ \\
4 & MESAS DE CENTRO & Zillaz & Tricola & 580.00 & $2,320.00$ \\
4 & SOFAS & Zillaz & Wassina 2 cuerpos & 940.00 & $3,760.00$ \\
8 & SILLON & Zillaz & Wassina 1 cuerpos & 580.00 & $4,640.00$ \\
$70 \mathrm{mt2}$ & TAPIZON & Decorplas & Alto transito & 32.00 & $2,240.00$ \\
1 & EQUIPO DE MUSICA (Componente) & Panasonic & SC-PMX 100EGS & $1,980.00$ & $1,980.00$ \\
1 & PANEL CALADO & Decopanel Perú & diseño abstracto & $2,320.00$ & $2,320.00$ \\
\hline
\end{tabular}


Tabla 38

Equipamiento Baño Administración Vestuario

\begin{tabular}{|c|c|c|c|c|c|c|}
\hline Cantidad & Unidad & Descripción & Marca / Proveedor & Modelo / tipo & Precio Unit S/ & TOTAL S/ \\
\hline 1 & & INODORO & Sodimac & Khor - one piece & 160.00 & 160.00 \\
\hline 1 & & LAVATORIO & Sodimac & Trebol & 40.00 & 40.00 \\
\hline 1 & & GRIFERIA & Sodimac & Vainsa - Edge & 290.00 & 290.00 \\
\hline 1 & & EXTRACTOR DE AIRE & Sodimac & Volker - APB30B & 180.00 & 180.00 \\
\hline 1 & & ACCESORIO DE PUERTA - FRENO HIDRAULICO & Sodimac & Yale - alumnio $80 \mathrm{Kg}$ & 129.90 & 129.90 \\
\hline 1 & & ESPEJO & Sodimac & Monterrey - Viena & 49.00 & 49.00 \\
\hline 1 & & ACCESORIOS DE BAÑO & Sodimac & Varios & 80.00 & 80.00 \\
\hline
\end{tabular}

Tabla 39

Equipamiento Administración

\begin{tabular}{|c|c|c|c|c|c|}
\hline Cantidad & Descripción & Marca / Proveedor & Modelo / tipo & Precio Unit S/ & TOTAL S/ \\
\hline 1 & ESCRITORIO & Promart & Quito Gris & 279.00 & 279.00 \\
\hline 1 & INTERCOMUNICADOR & Promart & Belcom - PE 7846 D & 599.00 & 599.00 \\
\hline 1 & SILLON DE ESCRITORIO & Promart & Lyon Negro & 156.00 & 156.00 \\
\hline 2 & SILLAS DE VISITA & Promart & fija - negra & 79.00 & 158.00 \\
\hline 1 & LAP TOP + IMPRESORA & Promart & $\begin{array}{l}\text { Asus x } 54 \text { 2UA + Epson } \\
\text { XP2 } 41 \\
\text { Orange + Barra Led } 3\end{array}$ & $2,199.00$ & $2,199.00$ \\
\hline 1 & LUMINARIA DECORATIVA & Promart & luces & 109.00 & 109.00 \\
\hline & & & TOTALES & & $3,500.00$ \\
\hline
\end{tabular}

Tabla 40

Equipamiento Baño Damas

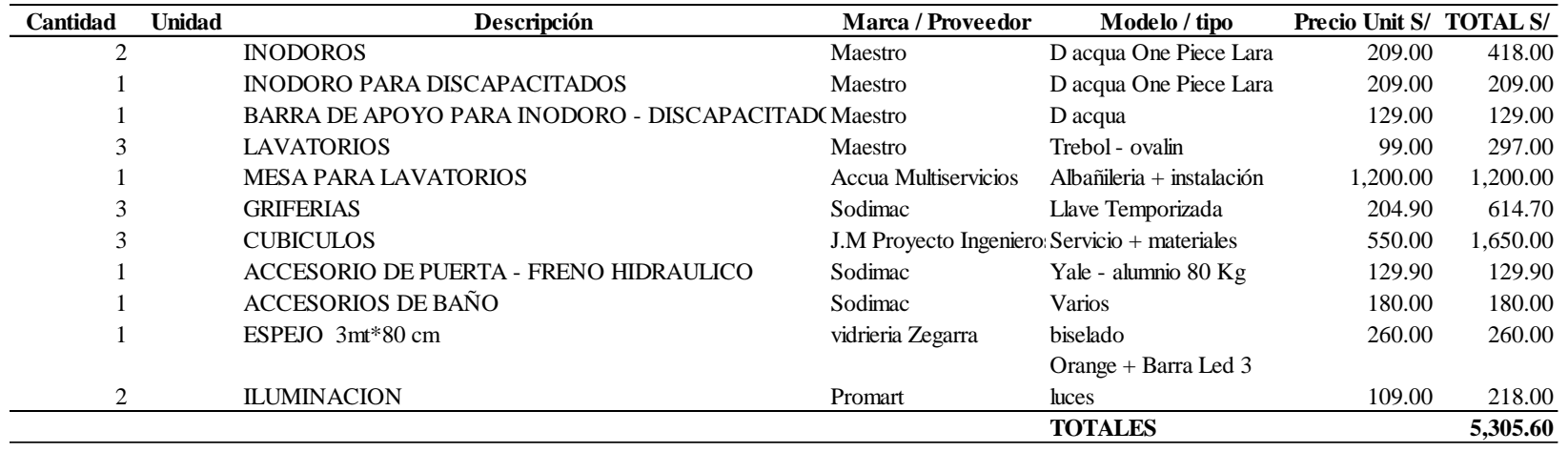

Tabla 41

Equipamiento Baño Caballeros

\begin{tabular}{|c|c|c|c|c|c|c|}
\hline Cantidad & Unidad & Descripción & Marca / Proveedor & Modelo / tipo & Precio Unit $\mathrm{S} /$ & TOTAL S/ \\
\hline 1 & & INODOROS & Maestro & D acqua One Piece Lara & 209.00 & 209.00 \\
\hline 2 & & URINARIOS & Maestro & Trebol - cadet & 159.00 & 318.00 \\
\hline 1 & & FLUXOMETRO PARA URINARIO & Maestro & Helvex - 185-19 & 384.90 & 384.90 \\
\hline 1 & & INODORO PARA DISCAPACITADOS & Maestro & D acqua One Piece Lara & 423.00 & 423.00 \\
\hline 1 & & CUBICULOS & J.M Proyecto Ingenier & Servicio + materiales & 550.00 & 550.00 \\
\hline 1 & & CUBICULO DISCAPACITADO & J.M Proyecto Ingenier & Servicio + materiales & 550.00 & 550.00 \\
\hline 1 & & MESA LAVATORIOS & Accua Multiservicios & Albañileria + instalación & $1,200.00$ & $1,200.00$ \\
\hline 1 & & ACCESORIOS DE BAÑO & Sodimac & Varios & 180.00 & 180.00 \\
\hline 3 & & GRIFERIAS & Sodimac & Llave Temporizada & 204.90 & 614.70 \\
\hline 1 & & ESPEJO $3 \mathrm{mt} * 80 \mathrm{~cm}$ & vidrieria Zegarra & $\begin{array}{l}\text { biselado } \\
\text { Orange + Barra Led } 3\end{array}$ & 260.00 & 260.00 \\
\hline 1 & & ILUMINACION & Promart & luces & 109 & 109.00 \\
\hline
\end{tabular}


Tabla 42

Equipamiento Cocina

\begin{tabular}{|c|c|c|c|c|c|c|}
\hline Cantidad & Unidad & Descripción & Marca / Proveedor & Modelo / tipo & Precio Unit S/ & TOTAL S/ \\
\hline 5 & & & Fukupark & lamparas industriales & 350.00 & $1,750.00$ \\
\hline 1 & & $\begin{array}{l}\text { ILUMINARIAS } \\
\text { MESA DE TRABAJO }\end{array}$ & $\mathrm{Hi}$ - Lite & $1.4 * 0.70 * 0.90 \mathrm{mts}$ & $1,500.00$ & $1,500.00$ \\
\hline 1 & & COCINA INDUSTRIAL & Cocinas Chasqui & 4 hornillas/plncha/horno & $3,800.00$ & $3,800.00$ \\
\hline 1 & & REFRIGERADORA & Samsung & RT 46k6631BS / Pe & $3,700.00$ & $3,700.00$ \\
\hline 1 & & CONGELADORA & EFE & Electrolux - H520 & $1,999.00$ & $1,999.00$ \\
\hline 2 & & HORNOS MICROONDAS & $\mathrm{Lg}$ & MH -8296 & 649.00 & $1,298.00$ \\
\hline 240 & & VAJILLA & Union Ychikawa & varios & 7.50 & $1,800.00$ \\
\hline 96 & & CUBIERTOS & Union Ychikawa & varios & 5.60 & 537.60 \\
\hline 24 & & UTENSILIOS DE COCINA & Union Ychikawa & varios & 22.00 & 528.00 \\
\hline 1 & & LAVATORIO DE 2 POZAS & Sodimac & Teka - premium 1 1/2 & 919.90 & 919.90 \\
\hline 1 & & GRIFERIA & Sodimac & Teka - monomando IN39، & 549.00 & 549.00 \\
\hline 1 & & EXTRACTOR DE AIRE & Sole & Ture $47 \mathrm{CO}$ & 949.00 & 949.00 \\
\hline 1 & & ESTANTERIA & Torres Postformados & Servicio + materiales & 950.00 & 950.00 \\
\hline 15 & & \multirow{2}{*}{ ACERO QUIRURGICO EN LAS PAREDES M2 } & JAHESA - Callao & $316 / 316 \mathrm{~L}$ & 222.00 & $3,330.00$ \\
\hline & & & & TOTALES & & $23,610.50$ \\
\hline
\end{tabular}

Tabla 43

Equipamiento Varios

\begin{tabular}{|c|c|c|c|c|c|c|}
\hline Cantidad & Unidad & Descripción & Marca / Proveedor & Modelo / tipo & Precio Unit S/ & TOTAL S/ \\
\hline 4 & & EXTINTORES & Vicsa & $6 \mathrm{KG}$ & 69.90 & 279.60 \\
\hline 1 & & EXTINTOR & Clute & $9 \mathrm{KG}$ & 99.00 & 99.00 \\
\hline 1 & & SEÑALETICA & Total & señalización - varios & 120.00 & 120.00 \\
\hline 5 & & AVISOS DE EMERGENCIA & Promart & Led & 146.00 & 730.00 \\
\hline 12 & & LUCES DE EMERGENCIA & Opalux & Premium & 99.00 & $1,188.00$ \\
\hline 1 & & SISTEMA DE SEGURIDAD & Sodimac & Kerui G18 & $1,200.00$ & $1,200.00$ \\
\hline 1 & & DECORACION VINIL EN PAREDES (diseño + instalación) & ZEstudio & Foto murales & $2,100.00$ & $2,100.00$ \\
\hline
\end{tabular}

\subsubsection{Lay Out.}

La correcta y eficiente distribución de espacios para la asignación de instalaciones, equipos, mobiliario, y recursos en general; permitirá un buen desenvolvimiento de los procesos descritos anteriormente.

La cantidad y calidad de maquinarias, equipos, mobiliario, y otras inversiones dependerán principalmente del proceso productivo elegido. Igualmente las necesidades de inversión en obras físicas e instalaciones se determinan en función de la distribución de los equipos productivos en el espacio físico, layout (Sapag, 2014).

Por lo tanto, lo ideal sería considerar un espacio de 120 metros cuadrados que nos permita tener una óptima distribución de las áreas operativas y funcionales, como se observa en la Tabla 44 , sin contar que el área contiene adicionalmente un área de retiro, se puede tener la siguiente estructura como alternativa: 
Tabla 44

Distribución por áreas

\begin{tabular}{lcc}
\hline \multicolumn{1}{c}{ Areas } & $\%$ & metros \\
\hline Cocina & $10 \%$ & $12 \mathrm{mt}$ \\
Administración & $10 \%$ & $12 \mathrm{mt}$ \\
Salón & $60 \%$ & $72 \mathrm{mt}$ \\
Baños & $8 \%$ & $9.6 \mathrm{mt}$ \\
Bar & $12 \%$ & $14.4 \mathrm{mt}$ \\
& & \\
\hline Total & $100 \%$ & $120 \mathrm{mt}$ \\
\hline
\end{tabular}

Para la distribución de áreas se ha considerado la siguiente forma (ver Figura 52):

Plano de Distribución La Conversa Bar

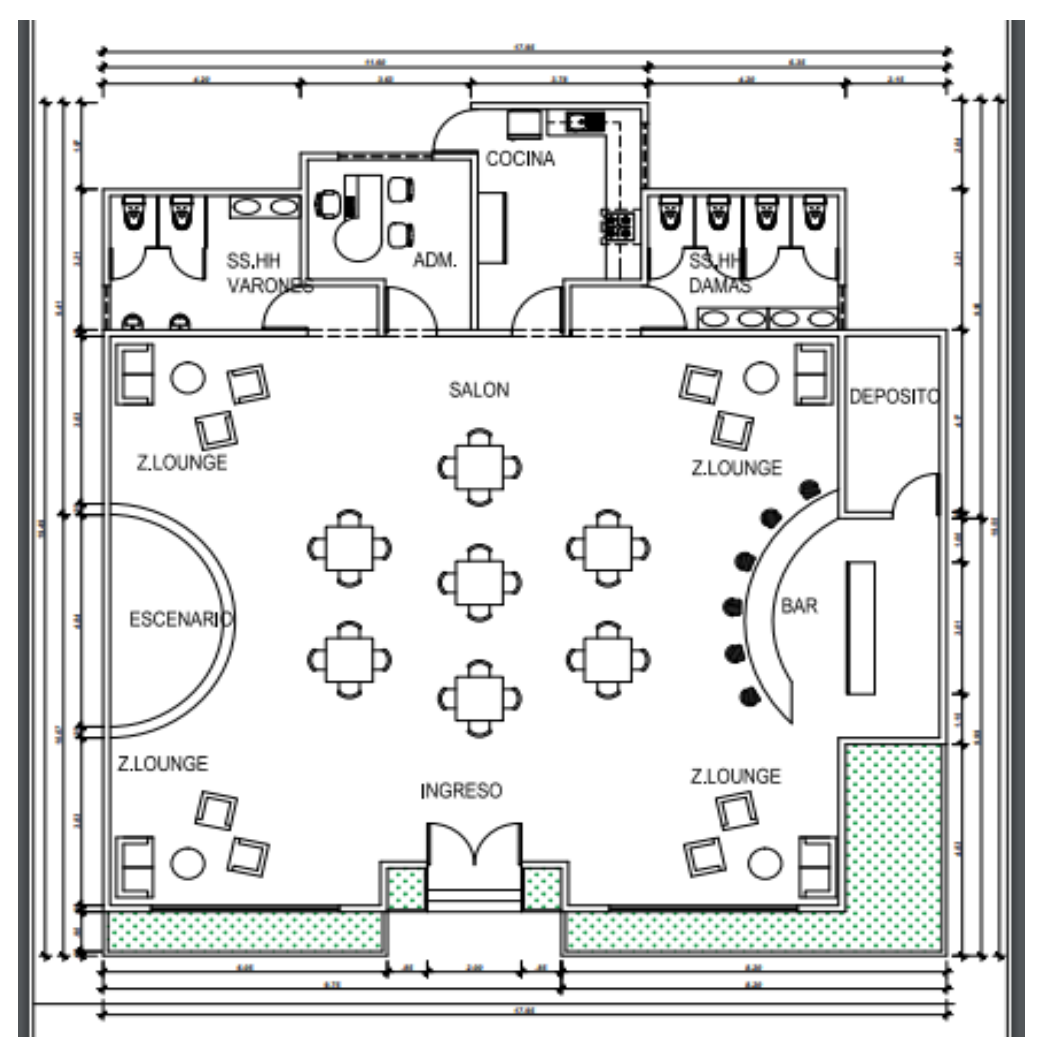

Figura 52. Plano de Distribución La Conversa Bar.

Cabe señalar, que la distribución descrita en la Figura 52 cumple con las normas establecidas según el Centro Nacional de Estimación, Prevención y Reducción del Riesgo de Desastres (CENEPRED, 2009), en la que indica que el área de mesas para cualquier tipo de restaurantes o bares debe tener como mínimo $1.5 \mathrm{~m} 2$ por persona. 


\subsubsection{Distribución de Equipos y Maquinarias.}

Las maquinarias, equipos, y mobiliarios necesarios para el buen funcionamiento del negocio se encontrarán distribuidos de la siguiente manera, tal como figura en la figura 52.

- Área de Salón. Lugar donde los visitantes podrán sentarse, departir, y consumir los productos y servicios que el negocio brinda. Comprende lo siguiente: Aire acondicionado, mesas, sillas, puf, tablets, sofás, sillón, equipo de música,

- Área de Cocina. Lugar de preparación de los piqueos que ofrece el Bar. Comprende lo siguiente: Mesa de trabajo, cocina industrial, refrigeradora, congeladora, hornos microondas, vajilla, cubiertos, utensilios, lavatorio, extractor de aire, estantería, extintor.

- Área de Bar. Lugar de preparación de la coctelería y bebidas a ofrecer en la misma barra o en mesa. Comprende lo siguiente: Barral de MDF, Mesa de frio, cristalería (Copas y Vasos), Maquina Lava-copas, Frigobar, licuadora semi-industrial, exprimidor de jugos, estantería.

- Área de Almacenamiento. Lugar de depósito de insumos y productos (refrigerados y no perecibles). Comprende lo siguiente: Estantería, congeladora, extintor.

- Área de SS.HH. Lugar de tocador, para damas y caballeros. Comprende lo siguiente: Inodoro, lavatorio, porta papel grande, espejos.

- Área de Administración. Lugar de administración, contabilidad, documentación legal, propio del giro del negocio. Comprende lo siguiente: escritorio, sillón, sillas, laptop, impresora.

- Área de Caja. Lugar de pago del servicio por parte del cliente. Comprende lo siguiente: Caja Registradora, PC, Mueble, impresora, banqueta

- Área de Recepción: Pequeño espacio de bienvenida y de antesala al Salón, con el fin de ubicación. Comprende lo siguiente: Counter de madera, banqueta.

\subsection{Determinación del Tamaño}

Para determinar el tamaño de la planta es necesario conocer con mayor precisión los movimientos predeterminados de los procesos. Es imposible desarrollar un método estandarizado para determinar de manera óptima la capacidad de producción, dada la complejidad de procesos que tiene cada empresa, así como la variedad de procesos productivos que existen, sin embargo, se dará una guía para realizar la determinación, se recuerda que es un acto de ingeniería, es decir el uso del ingenio personal para lograr la optimización. En la práctica, determinar el tamaño de la 
unidad de producción es una tarea limitada por las relaciones reciprocas que existen entre el tamaño, la demanda, la disponibilidad de recursos, tecnología, y equipos; contribuyendo todos estos factores a simplificar el proceso de aproximaciones sucesivas. (Baca, 2013)

Es por toda la información anteriormente descrita en el proyecto que se estima que el tamaño a ofrecer será en relación a las siguientes características:

1. El área a considerar será de 120 metros cuadrado, lo que nos da una capacidad máxima de atención de 48 personas en simultaneo, siempre y cuando cumplamos con el reglamento de 1.5 metro cuadrado por persona.

2. La distribución de la capacidad es la siguiente: 6 personas (en banquetas) en el bar; 4 juegos de lounge - sofás equivalente a 4 personas por juego, lo que da un total de 16; y siete mesas de 4 sillas equivalente a 28 personas (se considera una mesa de solo dos personas lo que da un total de 26 personas, y nos permite no exceder el aforo que el reglamento, según CENEPRED, 2009, lo exige en relación al metraje del local).

3. El horario de atención será entre las 14.00 horas y las 22.00 horas, dividido en tres turnos, con una rotación de clientes diferente en cada turno origina diferentes niveles de visitas; y con una capacidad máxima de 48 personas por turno da un total de 240 personas diarias.

4. Asimismo, por la naturaleza del negocio, el mantener una capacidad máxima de $100 \%$ (240 pers) es demasiado, haciéndose insostenible, y al preferir trabajar en un escenario moderado del $50 \%$, el atender a un número promedio de 120 personas se observas más factible en un inicio de operaciones (ver Tabla 45):

Tabla 45

Capacidad Instalada

\begin{tabular}{|c|c|c|c|c|c|c|c|c|c|c|}
\hline \multirow[t]{2}{*}{ Capacidad } & \multirow[t]{2}{*}{$\%$} & \multirow[t]{2}{*}{ Lun } & \multirow[t]{2}{*}{ Mar } & \multirow[t]{2}{*}{ Mie } & \multirow[t]{2}{*}{ Jue } & \multirow[t]{2}{*}{ Vie } & \multirow[t]{2}{*}{$\mathrm{Sab}$} & \multirow[t]{2}{*}{ Dom } & \multicolumn{2}{|c|}{ Total } \\
\hline & & & & & & & & & Semana & Año \\
\hline Cap. .Máxima & $100 \%$ & 240 & 240 & 240 & 240 & 240 & 240 & 240 & 1,680 & 87,360 \\
\hline Cap. Inst. Normal & $50 \%$ & 120 & 120 & 120 & 120 & 120 & 120 & 120 & 840 & 43,680 \\
\hline \multirow[t]{2}{*}{ distr. \% semanal } & & $10 \%$ & $10 \%$ & $10 \%$ & $20 \%$ & $20 \%$ & $20 \%$ & $10 \%$ & & \\
\hline & & 84 & 84 & 84 & 168 & 168 & 168 & 84 & & \\
\hline $\mathrm{N}^{\circ}$ de turnos & $\%$ & Lun & Mar & Mie & Jue & Vie & $\mathrm{Sab}$ & Dom & & \\
\hline Turno 1 & $20 \%$ & 17 & 17 & 17 & 34 & 34 & 34 & 17 & & \\
\hline Turno 2 & $20 \%$ & 17 & 17 & 17 & 34 & 34 & 34 & 17 & & \\
\hline Turno 3 & $60 \%$ & 50 & 50 & 50 & 101 & 101 & 101 & 50 & & \\
\hline
\end{tabular}

Nota. Adaptado en base a Norma A.130 Requisitos de seguridad por Cenepred, 2009. 
No obstante, el factor cultural nos indica que la sociedad limeña acostumbra a consumir estos tipos de servicios a ofrecer los días jueves, viernes, y sábados. Lo que hace que la distribución no sea uniforme a lo largo de la semana, como se observa en el gráfico.

5. De igual manera, durante el día los turnos tendrán diferentes afluencias de personas, siendo el turno de la noche, el turno 3, el de mayor concurrencia de público, como se observa en el gráfico.

\subsubsection{Proyección de Crecimiento.}

Respecto a la proyección del crecimiento, y manteniendo un escenario moderado, se considera dos tipos de incremento en las ventas que afectaría positivamente a los ingresos de la empresa y se encuentra en función a la capacidad instalada que presenta (Ver Tabla 46):

1. Un crecimiento "orgánico" que se deriva del incremento poblacional tal como se ha considerado en el capítulo VI. Esto permitiría que el Mercado Potencial se incremente en una tasa de $1.3 \%$ partiendo de 300,780 en el año 1 y llegando a 316,728 al año 5; asi como de igual forma se incremente el Mercado Objetivo de 1,785 a 1,879 personas del año 1 al año 5 , respectivamente.

2. Adicionalmente a la tasa anterior, se considera un incremento anual del $5 \%$ en la capacidad instalada ocupada, durante todo el horizonte temporal, que parte del $50 \%$ y llega a 70\% en al año 5. Esto permite, manteniendo una frecuencia de visita quincenal (24 visitas al año) por persona, crecer de 42,840 visitas anuales a 45,096 visitas al año 5.

Tabla 46

Proyeccion de Unidades (Visitas)

\begin{tabular}{lccccc}
\hline Número de Personas & Año 1 & Año 2 & Año 3 & Año 4 & Año 5 \\
\hline Mercado Objetivo & 1,785 & 1,808 & 1,831 & 1,855 & 1,879 \\
Frecuencia Promedio & 24 & 24 & 24 & 24 & 24 \\
Total Visitas Anuales & 42,840 & 43,392 & 43,944 & 44,520 & 45,096 \\
Capacidad Total & 87,360 & 87,360 & 87,360 & 87,360 & 87,360 \\
\% Ocupación & $50 \%$ & $55 \%$ & $60 \%$ & $65 \%$ & $70 \%$ \\
Capacidad Esperada & 43,680 & 48,048 & 52,416 & 56,784 & 61,152 \\
Proyección \# & 42,840 & 43,392 & 43,944 & 44,520 & 45,096 \\
\hline
\end{tabular}

Nota: Adaptado en base a Norma A.130 Requisitos de seguridad por Cenepred, 2009. 


\subsubsection{Recursos.}

Los recursos son insumos que permitirán ejecutar las estrategias seleccionadas. Asimismo, la correcta asignación de los recursos permite la ejecución de la estrategia y la determinación del plan a seguir, considerando una asignación basada en los objetivos de corto plazo (D’ Alessio, 2013).

Adicionalmente, según Weinberger (2008), existen cuatro tipos de recursos que deben de considerarse para el desarrollo de todo emprendimiento:

- Recursos Humanos: Tal como se indica en el capítulo 8 se deberá de contar con el equipo humano disponible que permita una eficiente producción, gestión, y comercialización de los productos y servicios a ofrecer. Todo lo anterior enmarcado en un buen proceso de reclutamiento, selección, contratación, inducción, y capacitación.

- Recursos Físicos: Tal como se indica en el capítulo 7.1 se deberá de contar con elementos visibles y fáciles de medir que permitan ser de apoyo a la operatividad integral del negocio así como poder cumplir de manera óptima con la demanda esperada

- Recursos Intangibles: Tal como se indica en el capítulo 9.1 para el buen desarrollo de la empresa se necesita de licencias, conocimiento, programas informáticos, permisos, marca, entre otros; que son recursos menos visibles, pero más difíciles de entender, imitar, sustituir por el competidor, convirtiéndose de esta manera en una ventaja competitiva difícil de alcanzar en el corto plazo.

- Recursos Financieros: Tal como se indica en el capítulo 9.1 lo suficiente para que la implementación se dé tal como ha sido planificado y para que en la ejecución sostenga los egresos que no puedan ser cubiertos de manera propia por los ingresos de explotación en la etapa inicial.

\subsubsection{Tecnología.}

La tecnología desempeña un rol muy importante en la mayoría de las organizaciones y proyectos. Sin embargo, para pequeñas empresas su uso es menos intensivo siendo diferente cuando se trata de tecnología aplicada a la gestión de la información. La gran capacidad que tienen los diferentes dispositivos para almacenar, procesar, y/o distribuir datos las convierte en elementos fundamentales en la gestión de cualquier tipo de negocios. Sin embargo, no puede suponerse que la tecnología resolverá los problemas automáticamente. La estrategia de tecnología debe de estar diseñada en función de los objetivos organizacionales. (Sapag, 2014). 
Para el caso de estudio, La Conversa Bar, la tecnología empleada para este tipo de establecimiento es de baja intensidad, y más bien solo se abstiene a venir incluida en los equipos a adquirir para las diferentes áreas y que permitirán que los procesos se cumplan en el tiempo optimo, así como se llegue al nivel esperado por los asistentes al local en términos de calidad en el servicio.

A continuación, se puede indicar que este proyecto se apoyará en la tecnología en los siguientes aspectos:

- Para la conservación de las frutas e insumos a utilizar en la preparación de cocteles, se considera que cada fruta necesita niveles de frio diversos por lo que contaremos con equipos que tengan sistema de refrigeración por niveles y la fruta e insumos no pierdan sus propiedades al momento de preparación. Es por ello que la congeladora tendrá doble sistema de enfriamiento, una para conservación y otra para congelamiento, adicionalmente dará el beneficio de una vida útil más prolongada.

- Los equipos de refrigeración cuentan con Controlador Digital permitiendo regular la temperatura fácilmente.

- Para la elaboración de cocteles se necesita licuar la fruta con sus complementos, adecuándose para este caso con una licuadora semi - industrial capaz de triturar y mezclar mejor las combinaciones necesarias.

- Para una adecuación mejor del ambiente, especialmente en el área de Salón, se contará con un equipo de aire acondicionado de 3 velocidades y con una capacidad 18000 btu.

- Para el mismo ambiente se contará con un equipo de sonido marca LG, con la característica de sonido envolvente y no dificulte la realización de una buena conversación en el Salón

- Para los dispositivos de pedido así como de registro de la caja se ha adquirido el software para Restaurante y Bares: Soluti-Rest. El mismo que brinda a los procesos del negocio la posibilidad de integrarse y simplificar pasos con el fin de optimizarlos y genere mejores escenarios de toma de decisiones.

- El lápiz y papel está en declive. Entre los dispositivos a adquirir para el punto f, se ha adquirido tablets, con el objetivo de ofrecer un mejor servicio al cliente y la mejor de las experiencias. Cabe señalar, que estarán conectados con el sistema a adquirir. 
Se contará con un CRM (Customer Relationship Management) es un software destinado a administrar la relación con los clientes y posibles clientes o leads que debe estar totalmente integrado en los diferentes procesos de la empresa

\subsubsection{Flexibilidad.}

En cuanto a la flexibilidad que tiene el tamaño de la empresa, se puede indicar que es mínima, esto debido a que el área de 120 mts 2 es utilizada al máximo ( $1.5 \mathrm{~m} 2$ por persona), y ha sido considerada en su máxima capacidad que se puede albergar y pueda estar en consistencia con un informe de inspección que se pueda presentar de manera inopinada por la Municipalidad de Barranco o por los organismos que velan por la prevención y reducción de riesgos de accidentes y desastres, y en caso de crecer podríamos incurrir en faltas administrativas según el Centro Nacional de Estimación, Prevención, y Reducción de Desastres ( CENEPRED) y es el órgano competente para sancionar a locales de naturaleza del presente estudio.

\subsubsection{Selección del Tamaño Ideal.}

Según la capacidad de la demanda y la oferta existente se llegó a considerar como tamaño ideal a un espacio de $120 \mathrm{mt}$, relacionando con la disponibilidad de espacios para alquilar que existe en la zona de Barranco, que oscilan en menor metraje siendo innecesario para los objetivos comerciales de la empresa. Asimismo, siendo las tarifas de alquileres elevados en la zona y cumpliendo con los aforos legales podríamos afirmar que el espacio de $120 \mathrm{mt}$ considerados como ideal, permite cumplir también con los objetivos financieros establecidos; dando la posibilidad de cubrir con la demanda manera holgada.

A continuación, presentamos una representación gráfica diseñada en 3d, como muestra del potencial negocio que se aspira realizar con la factibilidad del presente proyecto (ver Figuras $53,54,55$ у 56$)$ : 


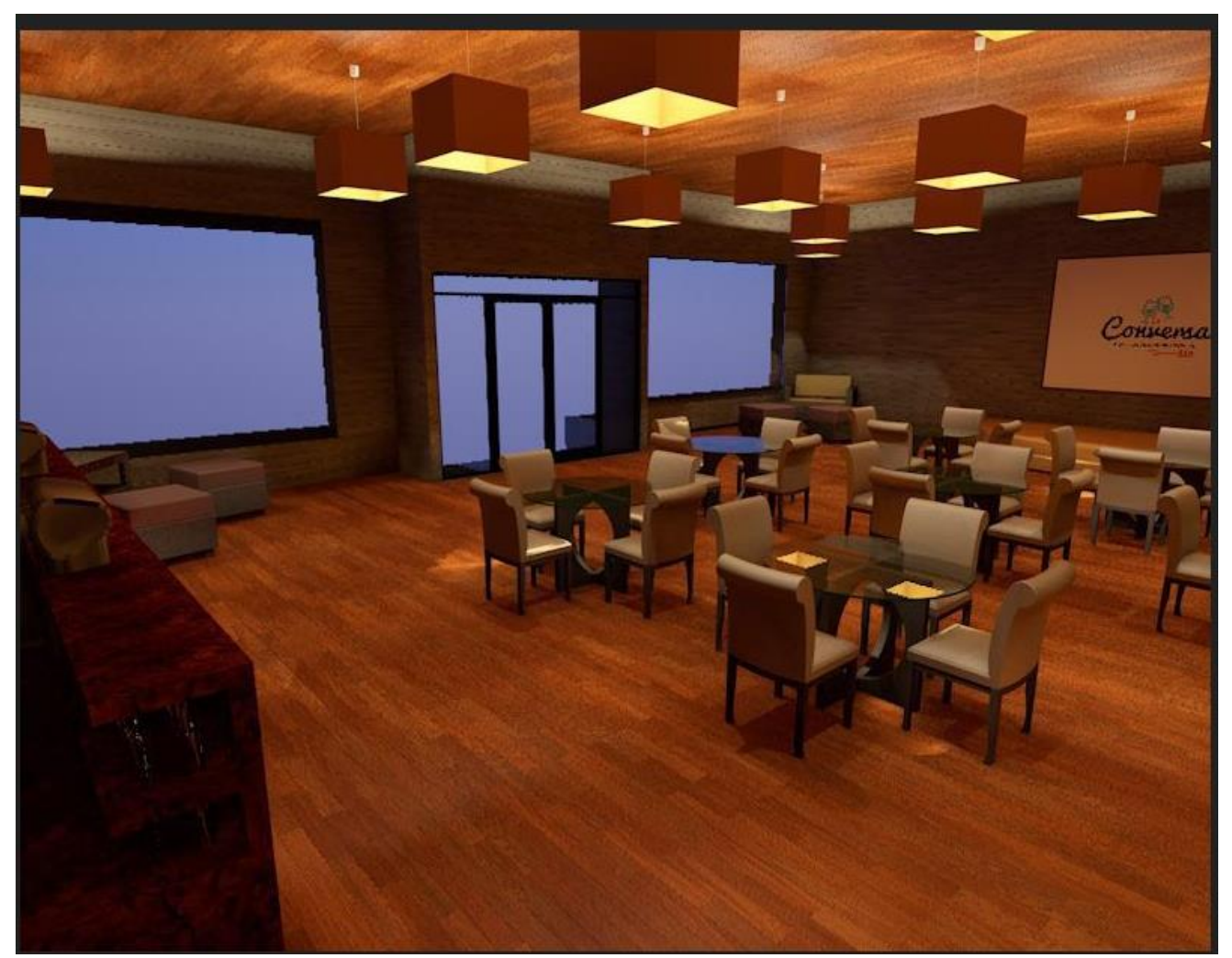

Figura 53. Diseño Gráfico de la parte interior del local en 3D (1).

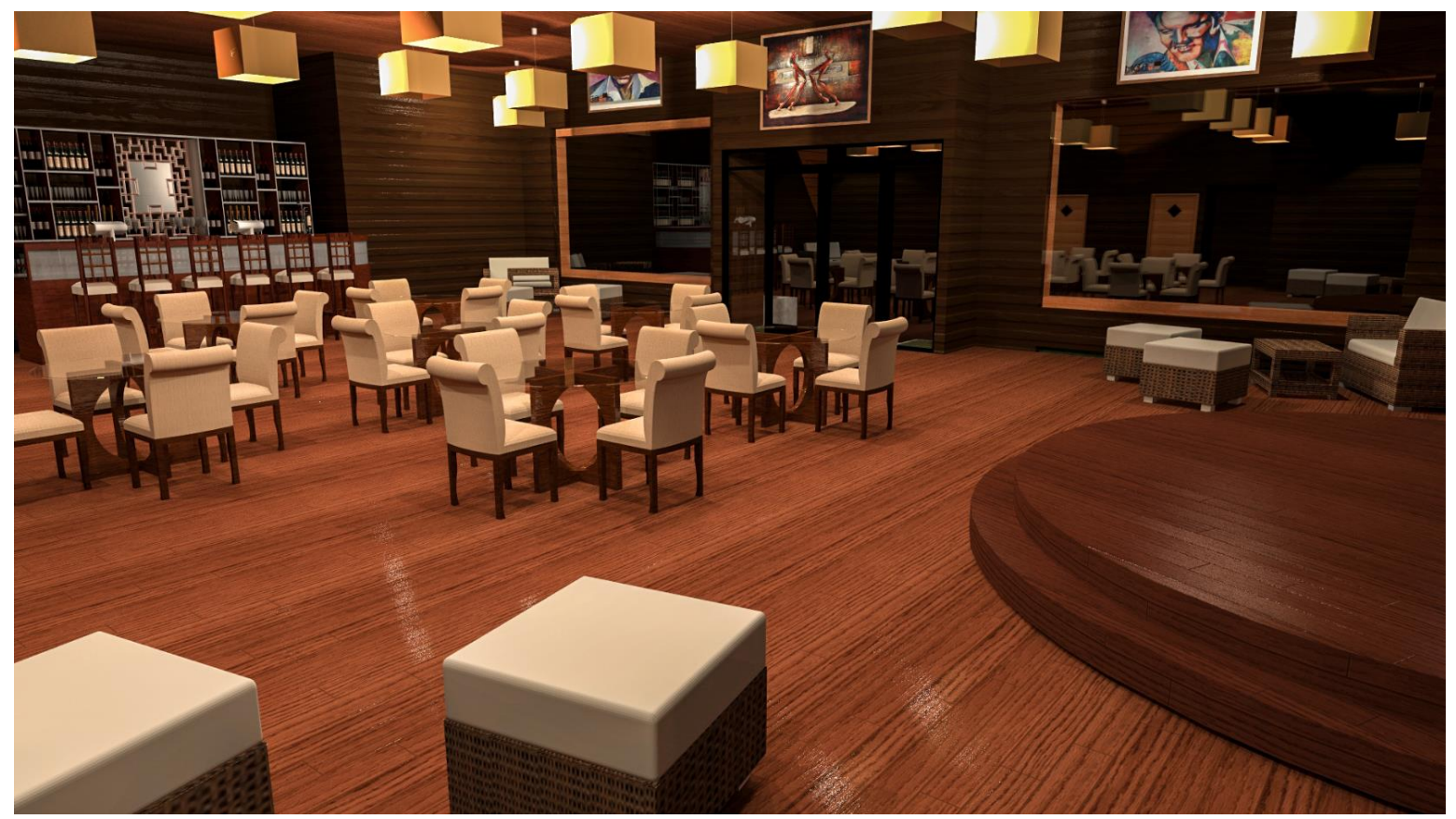

Figura 54. Diseño Gráfico de la parte interior del local en 3D (2). 


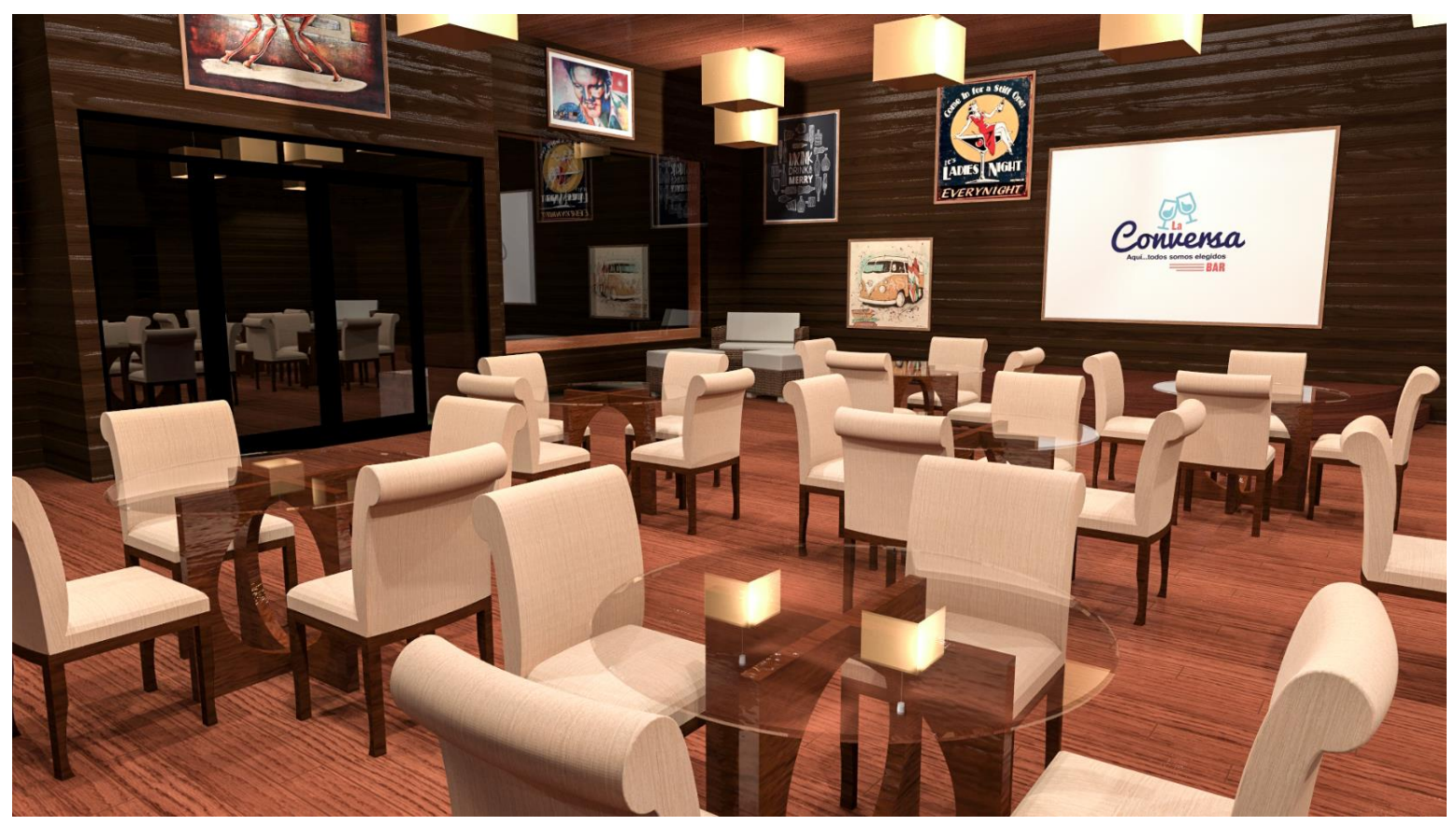

Figura 55. Diseño Gráfico de la parte interior del local en 3D (3).

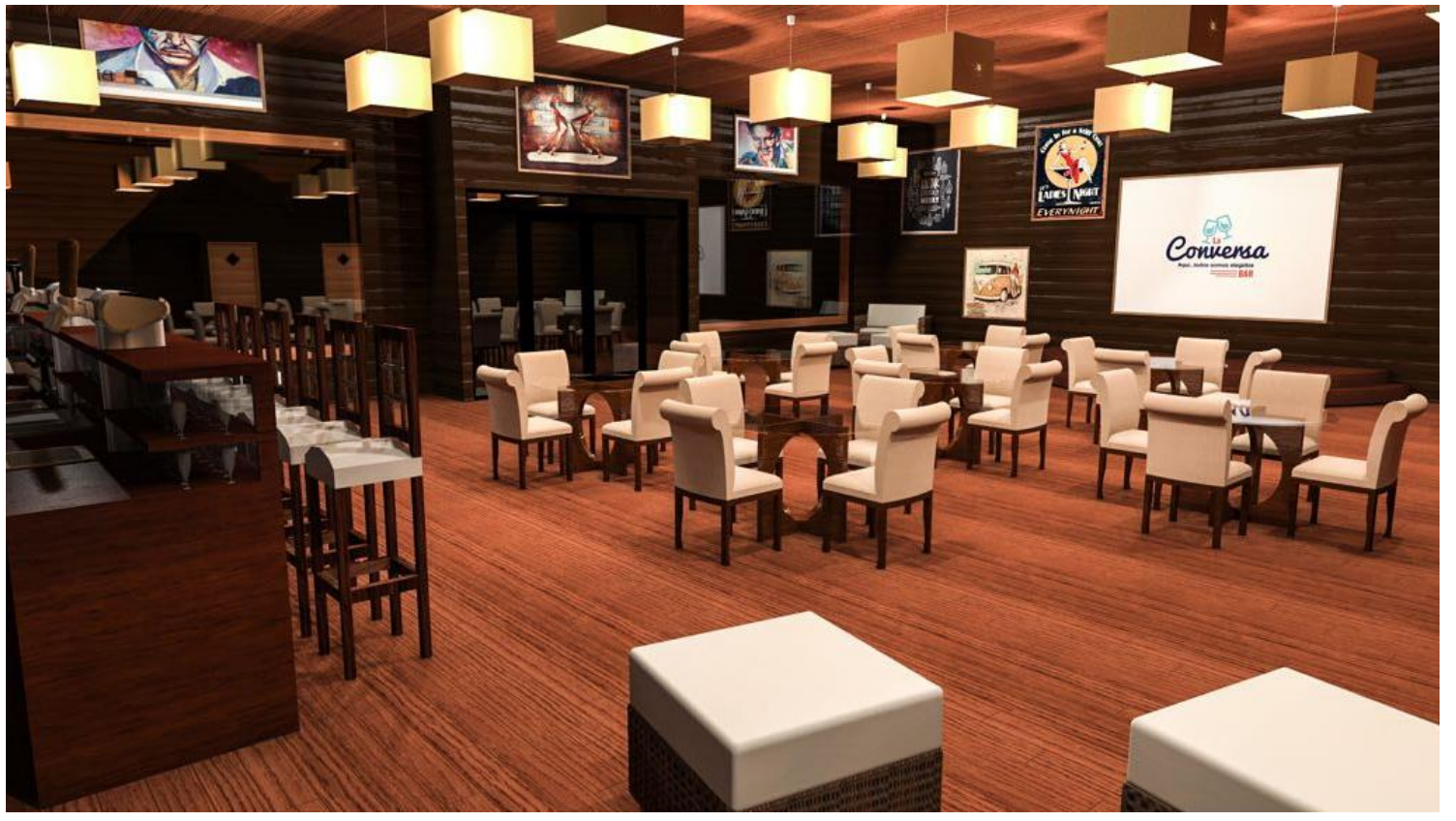

Figura 56. Diseño Gráfico de la parte interior del local en 3D (4). 


\subsection{Estudio de Localización}

La decisión de localización de un proyecto es una decisión de largo plazo con repercusiones económicas que deben de medirse con la mayor exactitud posible. Eso exige que el análisis de este aspecto se realice de manera integrada con las demás variables del proyecto, es por ello que la selección apropiada para la localización se manifiesta en diversas variables, cuya recuperación económica podría hacer cambiar el resultado de la evaluación, comprometiendo en el largo plazo una inversión de grandes cantidades de capital en un marco de difícil y costosa alteración. (Sapag, 2014)

En La Conversa Bar estará ubicado en la ciudad de Lima, especialmente en la Zona 8, zona elegida como más óptima para el desarrollo de las actividades comerciales. Tal como se vio en el capítulo 1 dicha zona comprende cuatro distritos:

1. Barranco

2. Chorrillos

3. San Juan de Miraflores

4. Surquillo

De los cuales, como mejores alternativas se han escogido a Barranco y Chorrillos como distritos potenciales de localización al tener características comunes a ponderar y a decidir como opción viable a los objetivos de la empresa.

Barranco: Distrito con muchos atractivos turísticos y con calles pintoresca (ver Figura 57), conocido como el distrito bohemio de Lima, por contar con restaurantes, discotecas, peñas, que dan intensa vida nocturna de diversión a público, principalmente, joven. Cabe señalar, que en mayor proporción sus visitantes a los locales de servicio no son del mismo Barranco sino de otros distritos de Lima. Parte del atractivo del distrito son sus restaurantes, bares y discotecas. (Viajandoalima.com). 


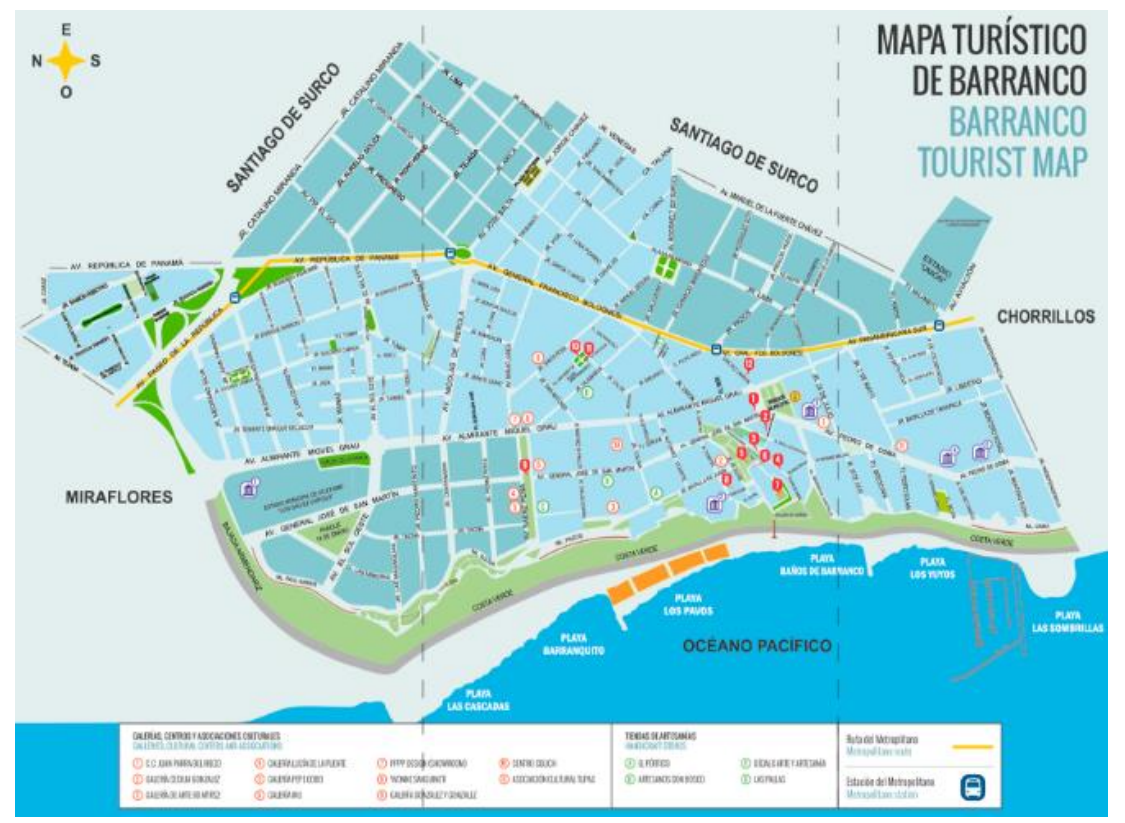

Figura 57. Mapa del Distrito de Barranco. Tomado de Información Turística de la Municipalidad de Barranco, 2018. Recuperado de: http://www.munibarranco.gob.pe/index.php/informacionturistica

Chorrillos: Distrito residencial y comercial, posee muchos atractivos turísticos. Hoy es una ciudad de contrastes donde se puede encontrar una variedad de cosas de parte del patrimonio histórico del distrito, pues refleja a través de sus calles antiguas su patrimonio cultural que se encuentra en lugares céntricos y no tan céntricos (ver Figura 58). Una de sus principales características es su malecón donde uno se encuentra con la mejor vista de la ciudad de Lima.

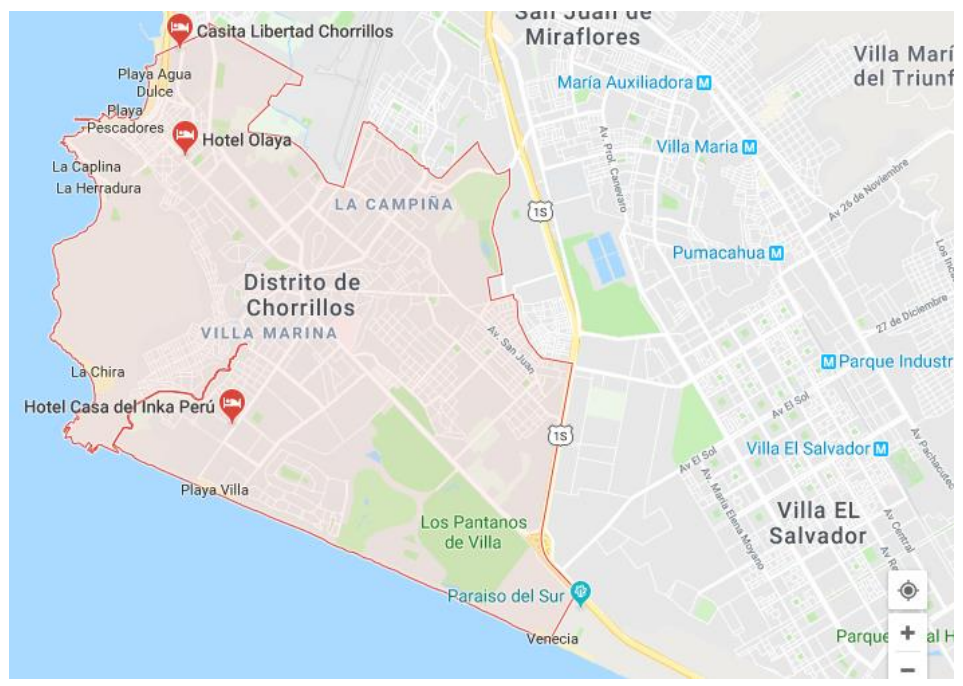

Figura 58. Mapa del Distrito de Chorrillos. Tomado de: Información Turística de Municipalidad de Chorrillos. Recuperado de http://www.munichorrillos.gob.pe/home/ubicacionpoblacion.php 


\subsubsection{Definición de Factores Locacionales}

La definición y determinación de factores locacionales ayudara a la toma de decisión de identificar la localización más óptima. Para ello, aplicaremos el Método Cualitativo por Puntos que consiste en definir los principales factores determinantes de una localización para asignarles valores ponderados de pesos relativos de acuerdo a la importancia que se le atribuya (sobre la base de una suma igual a 1). Si bien la asignación de la ponderación es subjetiva, igual que los puntajes, la fortaleza de este método radica en que es simple, rápido, y permite cuantificar aspectos cualitativos o estratégicos. (Sapag, 2014). En resumen, este método asigna factores cuantitativos a una serie de factores que se consideran relevantes (cualitativos) para la localización.

\subsubsection{Macrolocalización.}

Según N. Sapag, consiste en evaluar los posibles lugares, en el caso de estudio serian distritos, que ofrecen las mejores condiciones para la ubicación del proyecto, en base a factores que se describen en las Tablas siguientes (ver Tablas 47 y Tabla 48):

Como resultado de la evaluación de distritos, a través del método cualitativo por puntos, se determinó como mejor opción al distrito de Barranco (6.16 puntos), frente al distrito de Chorrillos (5.62 puntos).

Tabla 47

Calificación de Factores Macrolocalización

\begin{tabular}{cl}
\hline Calificación & Escala \\
\hline $1-2$ & Malo \\
$3-4$ & Regular \\
$5-6$ & Bueno \\
$7-8$ & Muy bueno \\
$9-10$ & Excelente \\
\hline
\end{tabular}


Tabla 48

Método Cualitativo por Puntos Macrolocalización

\begin{tabular}{|c|c|c|c|c|c|c|}
\hline \multirow{3}{*}{ Item } & \multirow{3}{*}{ Factores } & \multirow{3}{*}{ Peso } & \multicolumn{4}{|c|}{ Distritos } \\
\hline & & & \multicolumn{2}{|c|}{ Barranco } & \multicolumn{2}{|c|}{ Chorrillos } \\
\hline & & & Calificación & Ponderado & Calificación & Ponderado \\
\hline 1.- & Seguridad del distrito & 0.12 & 6 & 0.72 & 4 & 0.48 \\
\hline 2.- & Permisos Municipales & 0.15 & 4 & 0.60 & 7 & 1.05 \\
\hline 3.- & Zona Turistica & 0.20 & 9 & 1.80 & 5 & 1.00 \\
\hline 4.- & Afluencia de Público & 0.23 & 8 & 1.84 & 3 & 0.69 \\
\hline 5.- & Costo de alquiler & 0.30 & 4 & 1.20 & 8 & 2.40 \\
\hline & Totales & 1.00 & & 6.16 & & 5.62 \\
\hline
\end{tabular}

Nota: Adaptado de N. Sapag, Preparación y evaluación de proyectos, 2014. México D.F., México: Editorial McGraw-Hill Interamericana.

\subsubsection{Microlocalización.}

Para que la empresa La Conversa Bar pueda dar un servicio de calidad se requiere de un lugar amplio con excelente ubicación que además cumpla con los permisos y licencias para el objeto social no se vea interrumpido por infracciones legales y esto impida el alcance adecuado de los objetivos planteados para el proyecto.

Se ha planteado 03 opciones que se describen a continuación:

\section{Opción 1.}

Local Comercial, ubicado en calle Cajamarca 404 - Barranco a una cuadra de Av. Grau, a un precio de alquiler que asciende a \$ 1750.00 . Cuenta con un área de $120 \mathrm{mt}$ cuadrados (Ver Figura 59).

Opción 2.

Local Comercial, ubicado en Av. Almirante Grau - Barranco cerca a Rep. de Panamá, a un precio de alquiler que asciende a \$.2 200.00. Cuenta con un área de 250 metros cuadrados (Ver Figura 60).

Opción 3. 
Local Comercial, ubicado en Av. Pedro de Osma - Barranco cerca a la plaza de armas del distrito, a un precio de alquiler que asciende a \$. 1300.00 . Cuenta con un área de $60 \mathrm{mt}$ cuadrados (Ver Figura 61):

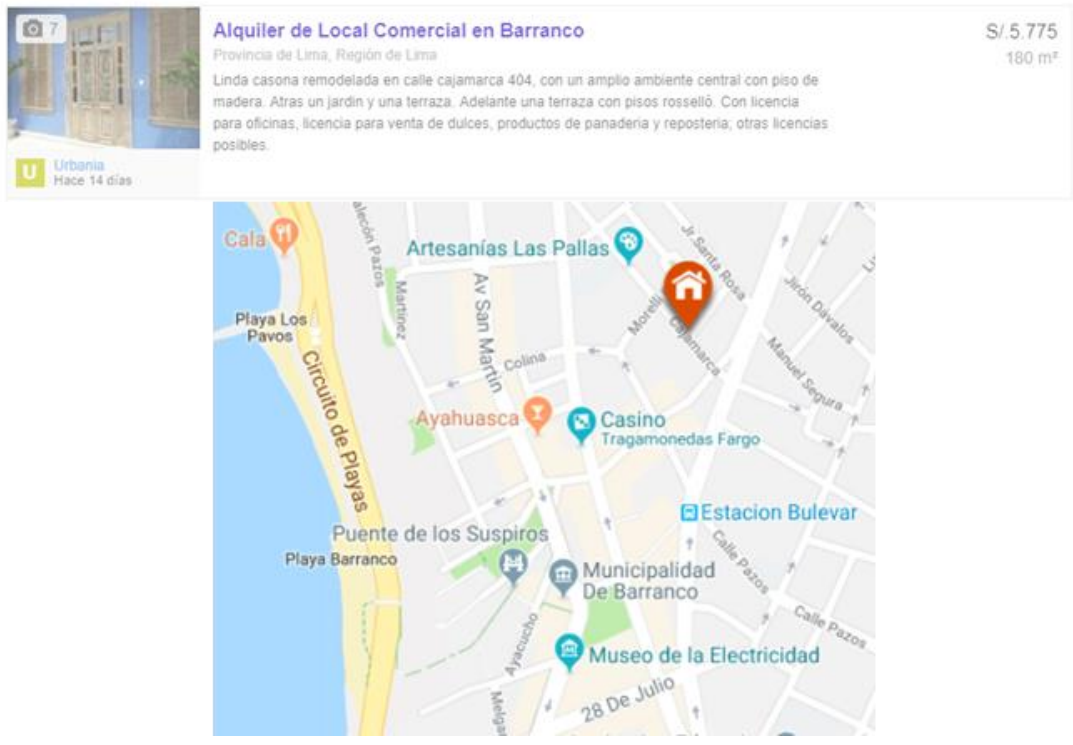

Figura 59. Opción 1 Local Comercial. Recuperado de https://urbania.pe/buscar/propiedades?freeSearch=locales\%20comerciales\%20barranco 


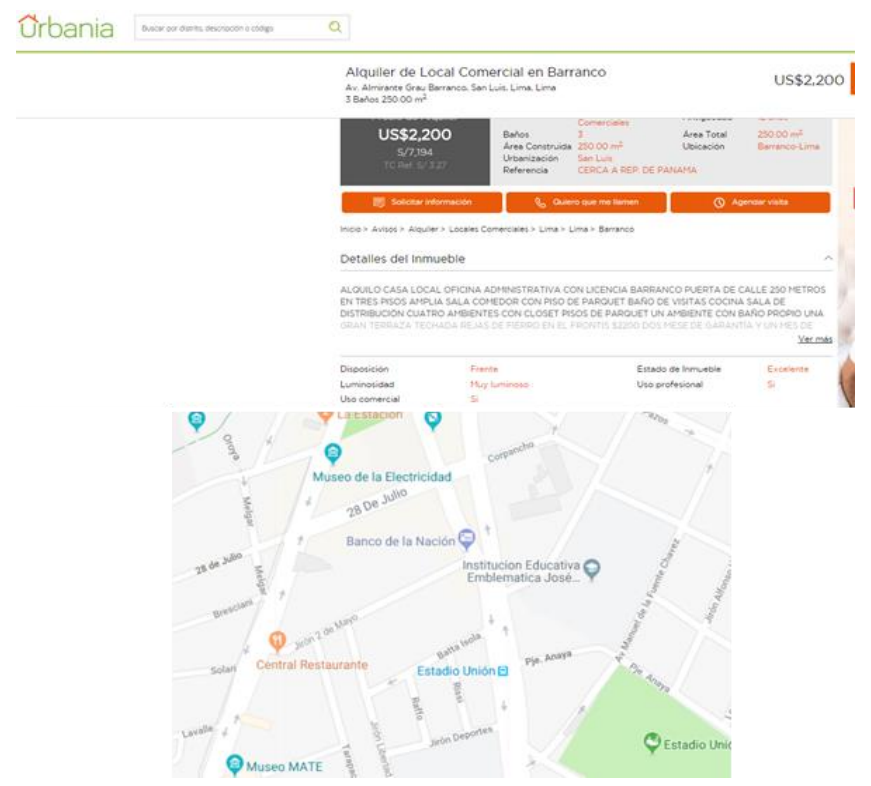

Figura 60. Opción 2 Local Comercial. Recuperado de:

https://urbania.pe/buscar/propiedades?freeSearch=locales\%20comerciales\%20barranco

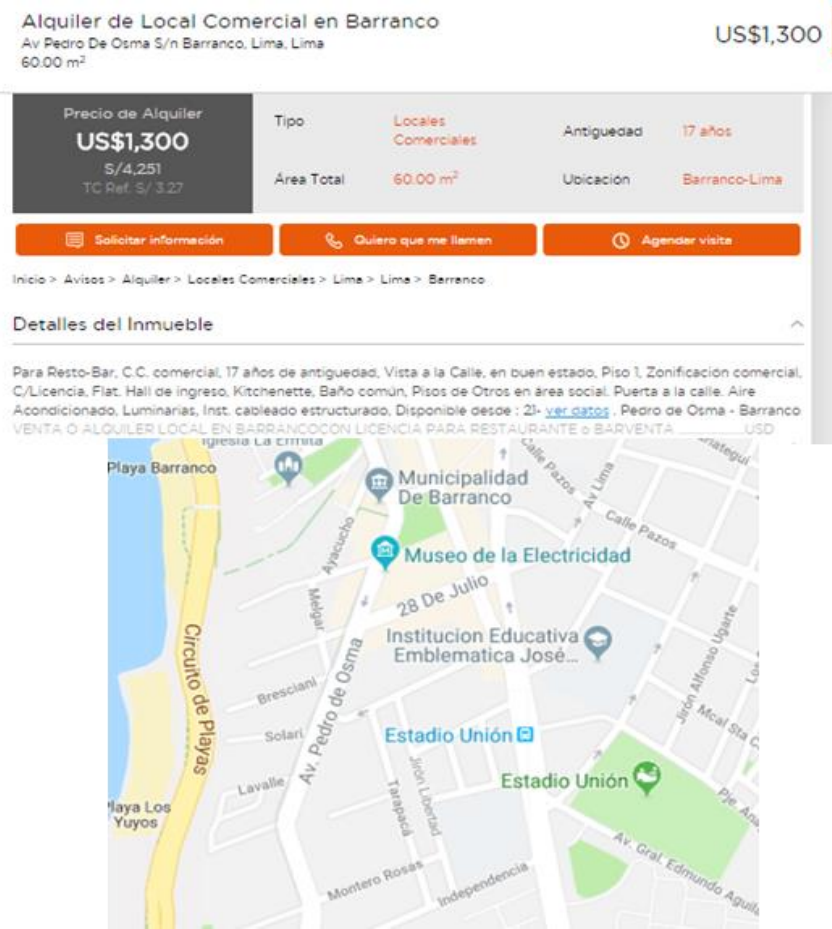

Figura 61. Opción 3 Local Comercial. Recuperado de https://urbania.pe/buscar/propiedades?freeSearch=locales\%20comerciales\%20barranco 
De igual forma que para la macrolocalización se aplicó el Método Cualitativo de puntos, para la microlocalización se aplicará el mismo método que permita determinar la opción óptima de ubicación (ver Tablas 49 y 50).

Tabla 49

Calificación de Factores Microlocalización

\begin{tabular}{cl}
\hline Calificación & Escala \\
\hline $1-2$ & Malo \\
$3-4$ & Regular \\
$5-6$ & Bueno \\
$7-8$ & Muy bueno \\
$9-10$ & Excelente \\
\hline
\end{tabular}

Tabla 50

Método Cualitativo por Puntos Microlocalización

\begin{tabular}{|c|c|c|c|c|c|c|c|c|}
\hline \multirow{3}{*}{ Item } & \multirow{3}{*}{ Factores } & \multirow{3}{*}{ Peso } & \multicolumn{6}{|c|}{ Distritos } \\
\hline & & & \multicolumn{2}{|c|}{ Opción 1} & \multicolumn{2}{|c|}{ Opción 2} & \multicolumn{2}{|c|}{ Opción 3} \\
\hline & & & Calificación & Ponderado & Calificación & Ponderado & Calificación & Ponderado \\
\hline 1.- & Tamaño local & 0.30 & 9 & 2.70 & 4 & 1.20 & 2 & 0.60 \\
\hline 2.- & Inv. en acondicionamiento adic. & 0.30 & 6 & 1.80 & 6 & 1.80 & 8 & 2.40 \\
\hline & Congestión Vehicular & 0.10 & 5 & 0.50 & 4 & 0.40 & 4 & 0.40 \\
\hline 4.- & Transito Peatonal (Flujo) & 0.15 & 6 & 0.90 & 4 & 0.60 & 7 & 1.05 \\
\hline & Seguridad en la Zona & 0.15 & 6 & 0.90 & 4 & 0.60 & 7 & 1.05 \\
\hline & Totales & 1.00 & & & & 4.60 & & 5.50 \\
\hline
\end{tabular}

Nota: Adaptado de N. Sapag, Preparación y evaluación de proyectos, 2014, México D.F., México: Editorial McGraw-Hill Interamericana.

Por lo tanto, la opción que más se ajusta a los requerimientos, accesos, recursos, del proyecto es la Opción 1, sito en calle Cajamarca 404 - Barranco, con las especificaciones antes descritas.

\subsubsection{Consideraciones Legales.}


Al iniciar un negocio, el empresario debe de elegir entre diferentes alternativas de jurídicas que conlleven a la realización de unidad económica formal, aprovechando de las diferentes ventajas como posibilidades de crecimiento; por ejemplo, acceso a crédito, proyectar confianza al cliente, así como brindar una imagen de responsabilidad social y empresarial, con más oportunidades de hacer negocio participando en concursos públicos y adjudicaciones como proveedor de servicios y bienes al Estado, y sobretodo evitar multas y sanciones por infracciones cometidas por omisión. (Longenecker, 2008)

\subsubsection{I Ientificación del Marco Legal.}

En la identificación del marco legal, la empresa La Conversa Bar, contempla constituir el negocio como una persona jurídica, en la que ejercerá derechos y tendrá obligaciones a nombre propio de la empresa, por lo que se deberá de registrarla ante la instancias respectivas (Superintendencia de Registros Públicos (Sunarp), y se tendrá que:

- Realizar la búsqueda y reserva de nombre de la empresa en SUNARP. Antes de constituir la empresa como persona jurídica se deberá de verificar que el nombre de tu empresa esté disponible para su uso. Al buscar los nombres existentes, asegurarse de que estos no se parezcan ni suenen igual al que vas a usar. Una vez realizada la búsqueda y confirmado que no existen nombres iguales o similares al que se va a usar, se debe reservar el nombre de la empresa por un plazo de 30 días.

- Elaborar la minuta de constitución de empresa. La minuta es el documento donde se describe las características de la empresa, y que contiene la descripción de la actividad económica a realizar.

- Llevar la minuta a una notaría que elabore la escritura pública respectiva

- Inscribir la escritura pública en SUNARP para registrar a la empresa. (Guía de Formalización, 2017).

Cabe resaltar que para la empresa La Conversa Bar el tipo de sociedad escogido sociedad anónima cerrada. Este tipo de sociedad es una sociedad de capitales, con responsabilidad limitada, en la que el capital social se encuentra representado por acciones, y en la que la propiedad de las acciones está separada de la gestión de la sociedad.

Una característica de la sociedad anónima cerrada es que la responsabilidad de los socios se encuentra limitada por el monto de su aporte, por lo que ordinariamente no responden personalmente con su patrimonio por las deudas u obligaciones de la empresa. 
Asimismo, el capital social está representado por acciones y se conforma con los aportes de los accionistas. Los socios tienen derecho de adquisición preferente de acciones en caso de que algún socio desee transferirlas a persona extraña a la sociedad o incluso a otro socio, salvo que el estatuto indique lo contrario.

Otra importante característica es que la empresa no puede inscribir sus acciones en el Registro Público del Mercado de Valores.

De este modo, se infiere que la S.A.C es la mejor alternativa para el La Conversa Bar ya que será una empresa pequeña que desea tener más flexibilidad para la transferencia de sus cuotas sociales (acciones).

\subsubsection{2. $\quad$ Ordenamiento jurídico de la empresa.}

Siguiendo con el ordenamiento jurídico los registros tributarios, registros laborales, y autorizaciones municipales; deberán de ser considerados para cumplir con el debido proceso de formalización.

Registro Tributario.

El Registro Único de Contribuyentes (RUC) es la identificación tributaria que otorga Sunat y contiene: el nombre de tu empresa, domicilio fiscal, la actividad a la que se dedicará, números telefónicos y otros datos. Todas las empresas que van a desarrollar actividades empresariales deben registrarse en él. Una vez registrado el negocio, se generará un número de RUC, el cual es único, consta de 11 dígitos e identifica como contribuyente y se debe utilizar en todo trámite que se realice ante la Sunat. (Guía de Formalización, 2017)

A partir del ejercicio 2017 los regímenes son 4: El nuevo régimen único

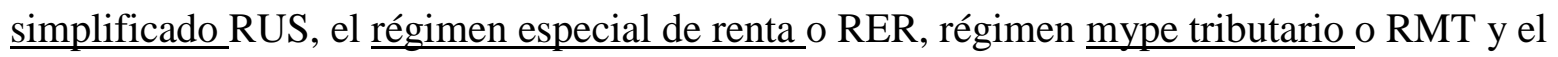
régimen general.

En el caso de la empresa La Conversa Bar, y debido a la potencialidad de crecimiento que presenta se ha optado por el Régimen Especial de Renta, el mismo que comprende a personales naturales y jurídicas domiciliadas en el Perú que obtengan rentas de tercera categoría; es decir, rentas de naturaleza empresarial como la venta de bienes que adquieran o produzcan y la prestación de servicios.

Se debe tener en cuenta las actividades no comprendidas en este régimen. Para estar comprendidos, los ingresos netos anuales o el monto de adquisiciones anuales no debe superar 
los S/ 525,000. El valor de los activos fijos, con excepción de predios y vehículos, no debe superar los S/ 126,000. Además, no se puede exceder de 10 trabajadores por turno de trabajo.

En este régimen solo se presentan declaraciones mensuales y se paga como renta la cuota de $1.5 \%$ de los ingresos netos; además, el IGV. En este régimen sólo se lleva el registro de compras y de ventas. (Gestión, 06.04.2018).

\section{Régimen Laboral.}

Se debe registrar a los trabajadores en planilla desde el primer día que se inicie la relación laboral, de acuerdo a ley. Actualmente, se utiliza frecuentemente la planilla electrónica. La misma que está compuesta por el T-REGISTRO y el PLAME (administrados por Sunat). La planilla electrónica sustituye a las planillas de pagos y remuneraciones, que son llevadas en libros.

La Conversa Bar, al no exceder sus ventas los 1700 UIT, tiene la facultad de acceder al Régimen Especial Laboral de la Pequeña Empresa con los siguientes beneficios laborales comunes para sus colaboradores:

- Remuneración Mínima Vital (S/ 930)

- Descanso semanal, de 24 horas continuas

- Descanso en días feriados no laborales

- Jornada laboral máxima de 8 horas diarias o 48 horas semanales

- Descanso vacacional de 15 días continuos por año de trabajo o la reducción hasta 7 días de goce, a través de la venta de vacaciones.

- Licencias, por salud por ejemplo

- Refrigerio, de 1 hora dentro de la jornada

- Sistema pensionario (ONP o AFP), aportación obligatoria

- Derechos colectivos

Así como los siguientes beneficios específicos, igualmente para sus colaboradores:

- Indemnización por despido arbitrario (20 remuneraciones diarias por cada año completo de servicios, el tope es 120 remuneraciones diarias)

- CTS, equivalente a 15 remuneraciones diarias por año completo de servicios

- Gratificaciones en Fiestas Patrias y Navidad, equivalente a media remuneración mensual

- Asegurados regulares de EsSalud (obligatoria)

- Participación en utilidades 
- Seguro de vida y seguro complementario de riesgo

Por último, se deberá registrar a los trabajadores en EsSalud, la aportación en estos casos corresponde al $9 \%$ del sueldo total percibido por el trabajador. Dicho costo es asumido por el empleador.

\section{Autorización Municipal.}

La licencia de funcionamiento es la autorización que te otorga la municipalidad para que puedas operar tu negocio. Debes obtenerla antes de realizar las actividades. Todos los requisitos se encuentran en el Texto Único de Procedimientos Administrativos (TUPA) de la municipalidad (Ver Figura 62).

\section{Registro de Marca y Lema Comercial.}

Se cree necesario, desde el punto de vista de la empresa La Conversa Bar, el registro de una marca ya que es la única manera de protegerla frente a posibles copias de los demás empresarios que se quieran aprovechar de su posterior prestigio. De este modo, el registro convierte al titular en el dueño de la marca, y es el único autorizado a usarla por los siguientes 10 años a partir de hecho el registro (los cuales pueden ser renovados). El registro de marcas está a cargo de la Dirección de Signos Distintivos del INDECOPI y dentro del plazo de 30 días hábiles de recibida la orden de publicación, el solicitante debe realizar su divulgación en el diario oficial El Peruano.

Si después de notificada la resolución, el solicitante deseara presentar un recurso de reconsideración, de apelación o adhesión, dispondrá de un plazo máximo de 15 días útiles desde la fecha en que dicha resolución le fue comunicada. 


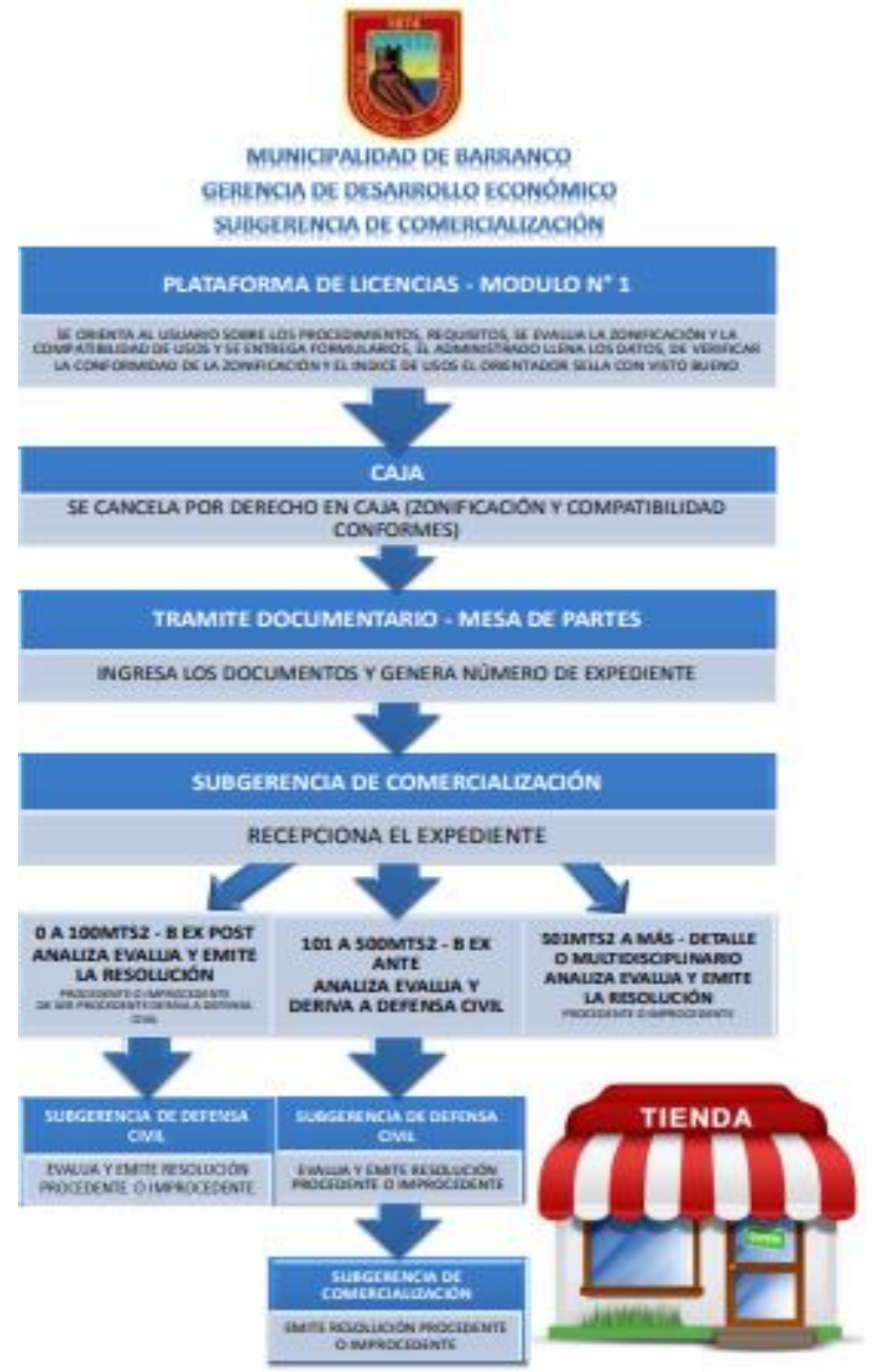

Figura 62. Proceso de Autorización de Licencia de Funcionamiento. Tomado de Tramite de Licencia de Funcionamiento por Municipalidad de Barranco. 2018. Recuperado de http://www.munibarranco.gob.pe/index.php/atencion-ciudadana/licencia-de-funcionamiento

\subsection{Determinación de la localización óptima}

Por lo tanto, luego de las investigaciones correspondientes y el análisis respectivo, se ha llegado a determinar cómo localización óptima para La Conversa Bar a la calle Cajamarca 404 en el distrito de Barranco (Ver Figura 63). 


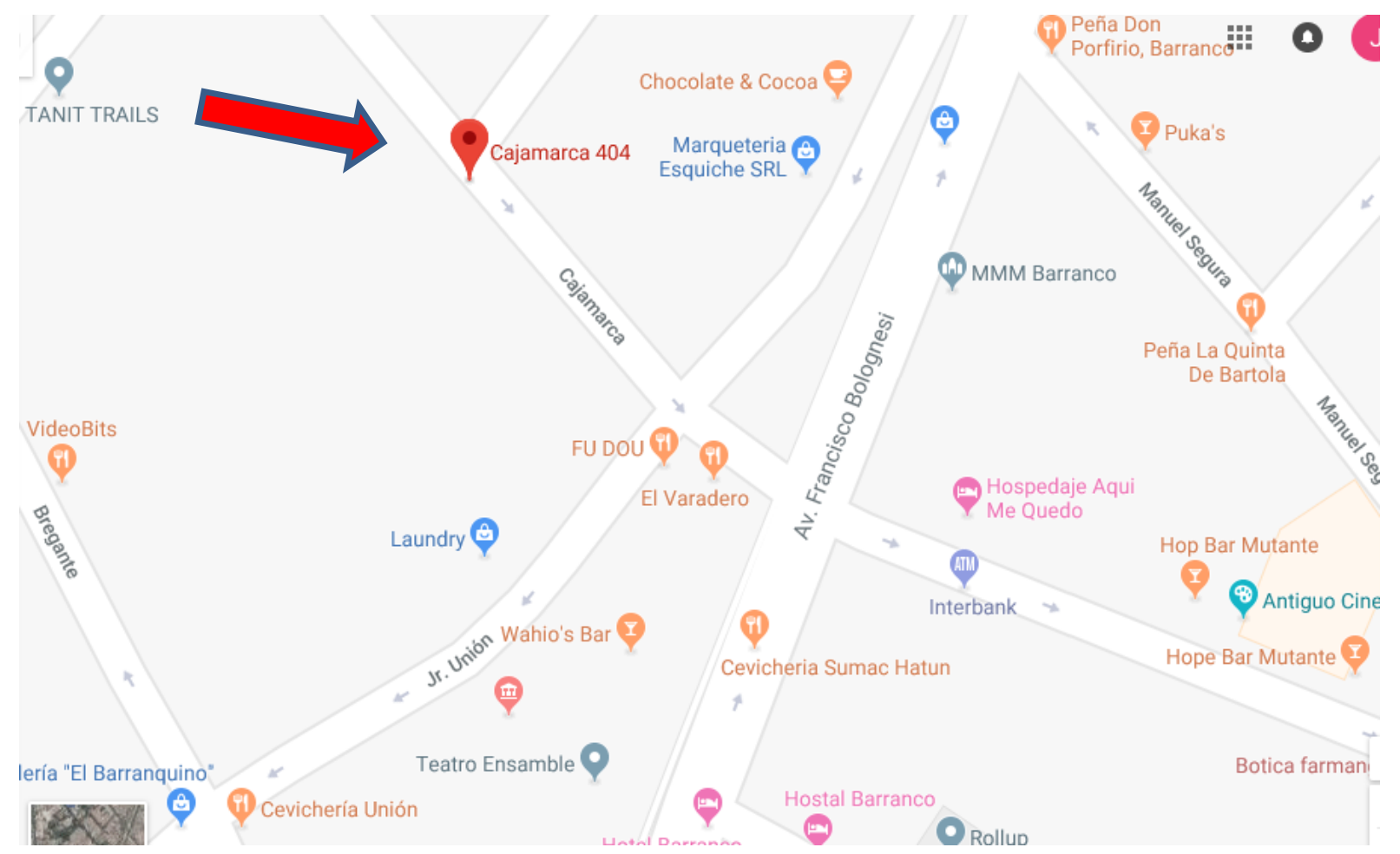

Figura 63. Localización Óptima. 


\section{Capitulo VIII: Aspectos Organizacionales}

La cultura organizacional que caracterizará al negocio, se describirá en este capítulo, a través de establecer su Visión, Misión, Principios y, asimismo, el tipo de estructura que tendrá y regirá para el capital humano que la conformará, definiendo para ellos sus respectivas responsabilidades y actividades a realizar cada uno.

\subsection{Caracterización de la cultura organizacional deseada}

Las relaciones, según David (2008) entre las actividades funcionales de negocio de una empresa quizás se ejemplifiquen mejor al enfocarse en la cultura organizacional, un fenómeno interno que se extiende por todos los departamentos y divisiones de una organización. La cultura organizacional se define como un patrón de comportamiento óptimo de una organización conforme va aprendiendo a manejar sus problemas de adaptación externa e integración interna, y que debe de funcionar lo suficientemente bien como para considerarse válido y transmitirse a los nuevos miembros como la manera correcta de percibir, pensar y sentir.

En ese mismo sentido, Lovelock (2015), también indica que una organización debe de relacionarse no solo con sus empleados, sino también con todos sus grupos de interés, siendo una función importante del marketing corporativo comunicar los valores fundamentales y la misión de la organización.

Siendo la visión, la misión, y los principios; la base para que se dé de manera natural el proceso estratégico esperado.

\subsubsection{Visión.}

La visión de una organización es la definición deseada de su futuro, responde a la pregunta ¿Qué queremos llegar a ser? Implica un enfoque de largo plazo basado en una precisa evaluación de la situación actual y futura de la empresa, así como del estado actual y futuro de la organización bajo análisis. (D’Alessio, 2013)

Es la aspiración de una organización de pasar de una situación actual a una situación superior en el muy largo plazo, es el sueño respecto a lo que quiere ser o lograr la organización en un plazo relativamente prolongado. Al definir el blanco "final" superior al cual apuntar en el futuro, representa el sueño alentador de la organización que suministra la energía emocional e invisible para el viaje y por lo tanto viene a ser el alma del planeamiento estratégico. En términos prácticos, la visión es "saber desde el principio, lo que se quiere" (Villajuana, 2003).

Se debe presentar con las siguientes características básicas: 
- Trascendente: Para nosotros, trascender es contribuir y disfrutar con los buenos resultados obtenidos o que obtendrán otros.

- Breve: Este atributo es consistente con la intención de lograr que la visión sea de fácil recordación y asimilación.

- Desafiante: Consiste en pretender mucho y muy poco

- Operativa: Esto equivale a claridad y sencillez en su significado para todos los involucrados entiendan.

- Relacionado con las competencias: De no asociarse la visión a lo que se sabe hacer bien, podría ser frustrante.

- Inspiradora: La visión debe sensibilizar y motivar fuertemente.

En base a los conceptos mostrados se puede entonces construir la visión para el presente proyecto y definiéndose de la siguiente manera:

"Ser reconocidos a nivel Lima Metropolitana como un espacio alternativo de interacción y entretenimiento sano y ameno con las mismas características de un bar tradicional”

\subsubsection{Misión.}

La misión establece la diferenciación de la organización con otras de la misma industria y la identidad que guiará a la organización en su propósito. También ayudará a no caer en el error de tomar demasiadas direcciones sino más bien fija hacia una sola. (D’Alessio, 2013)

Viene a ser el papel o rol que pretende desempeñar la organización o la unidad estratégica en el sector o mercado elegido. Si la visión es saber lo que quiere desde un inicio, la misión es saber por dónde ir desde el comienzo. De esta manera simboliza la razón de ser o lo que realmente desea ofrecer la organización o unidad estratégica. En esencia, responde a las preguntas: ¿Por qué y para qué estamos aquí? ¿O que somos y que hacemos? La misión, por tanto, es más voluntaria, que determinista. Más depende de nosotros que del sector o del mercado. (Villajuana, 2004)

Además, Villajuana, recomienda que los parámetros a utilizarse para el diseño de la visión son tales como (1) que sean breves -cuando la misión tiene esta cualidad el esfuerzo de tenerlo siempre presente en la mente de los colaboradores y personas es más fácil-, (2) que sean distinguibles - debe distinguirse de las misiones de otras organizaciones y de otros sectores-, (3) que sean relacionados a la necesidades -la misión debe transmitir rápida y claramente cómo la 
organización satisface una necesidad humana básica-, y (4) que sean operativos -la misión debe ser fácilmente traducible en acción.

Finalmente, para el diseño de la misión se puede elegir uno, o una combinación, de los siguientes estilos o caminos: (1) Orientado al producto, quiere decir enfocado a aquello que satisface la necesidad básica o impulso primario principal del mercado elegido; (2) Orientado al beneficio, Se relaciona al resultado esperado en la satisfacción de una necesidad; (3) Orientado a las capacidades clave, la misión puede concentrarse en aquello que se sabe hacer bien.

En La Conversa Bar se hará la combinación del producto y del beneficio, siendo la Misión del presente trabajo la siguiente:

Brindar una atención personalizada en un ambiente agradable fusionando el arte de la coctelería sin alcohol con productos de calidad para lograr una experiencia propicia que genere las condiciones de una amena conversación y entretenimiento de sus visitantes.

\subsubsection{Principios.}

Cada organización tiene la responsabilidad de crear un ambiente que fomente la correcta toma de decisiones; esto implica aplicar conceptos éticos a las acciones diarias. Para ello, cada empresa debe de redactar un código de ética, donde se establezca un sistema de principios de buena conducta, del buen vivir, y que fomente el accionar de sus empleados; y se convierta en una forma de mostrar a los constituyentes y comunidad vinculada que se cuenta con un patrón de accionar claro (D’Alessio, 2013).

Por lo anterior mencionado, identificamos los siguientes principios que regirán a la organización de la Conversa Bar:

- Reconocer y cumplir con la responsabilidad social que se tiene con los trabajadores, con la sociedad, y con la comunidad donde se realiza la gestión empresarial.

- Cultivar y promover un ambiente de mucha confianza y compromiso entre los colaboradores de la organización

- Generar las mejores condiciones para atraer y fidelizar a los clientes, que son la razón de ser de la organización.

- Innovar continuamente las estrategias, los métodos de trabajo y la propuesta coctelera, con el objetivo de crear valor sostenible. 
- Ejercer empresa con el fin supremo de obtener rentabilidad dentro del marco legal, cumpliendo con las obligaciones y ejerciendo los derechos.

- Dar empleo adecuadamente remunerado y capacitación considerada como inversión en capital humano.

- Promover un clima laboral que coadyuve al logro de la visión y al cumplimiento de la misión

\subsection{Formulación de Estrategias del Negocio}

Para el inicio de la formulación de la estrategia de negocio, el presente trabajo se ha basado en la identificación de oportunidades y amenazas como factores externos que ayuda en la conciliación para la formación de la estrategia compuesta por una serie de acciones siguientes (David, 2008):

- Aprovechar las oportunidades externas como las tendencias y acontecimientos

- Evitar o estar alerta ante las amenazas externas, pudiendo impedir el buen crecimiento de la organización cuando esté operando.

En base a lo anterior, se ha considerado una relación de oportunidades y amenazas, tal como se aprecia en la siguiente figura (ver Figura 64): 


\begin{tabular}{|c|c|c|c|}
\hline & Oportunidades & & Amenazas \\
\hline $\mathrm{O} 1$ & $\begin{array}{l}\text { A traves del programa de Innovate - Perú se } \\
\text { puede postular a fondos concursables. Facilita } \\
\text { la inversion y la producitvidad empresarial }\end{array}$ & A1 & Oferta laboral poco capacitada \\
\hline $\mathrm{O} 2$ & $\begin{array}{l}\text { Las empresas formales (pymes) tienen } \\
\text { posibilidad de acceso al sistema financiero }\end{array}$ & A2 & $\begin{array}{l}\text { Ingreso a una industria de alta competencia } \\
\text { identificada. }\end{array}$ \\
\hline $\mathrm{O} 3$ & $\begin{array}{l}\text { Campaña de concientización como el de } \\
\text { "Conductor Seguro" para evitar manejar en } \\
\text { estado de ebriedad. Campaña para evitar el } \\
\text { consumo de alcohol. }\end{array}$ & $\mathrm{A} 3$ & Alta Rotación de capital humano en la industria \\
\hline $\mathrm{O} 4$ & $\begin{array}{l}\text { Cada vez mas jovenes con altos ingresos } \\
\text { disponibles asi com oun mercado con mayor } \\
\text { tendencia al consumo de bebidas y de }\end{array}$ & A4 & $\begin{array}{l}\text { Debido a que para la entrega de licencias de } \\
\text { funcionamiento, la municipalidad es } \\
\text { sumamente estricta. }\end{array}$ \\
\hline O5 & $\begin{array}{l}\text { Facil acceso a la oferta de insumos y a la } \\
\text { oferta laboral relacionada al sector. }\end{array}$ & A5 & $\begin{array}{l}\text { Conceptos de negocio similares no antes visto } \\
\text { en el mercado }\end{array}$ \\
\hline O6 & $\begin{array}{l}\text { Acceso facil a la tecnolgia aplicada al sector } \\
\text { orientada a un mejor servicio y aumento de }\end{array}$ & & \\
\hline 07 & $\begin{array}{l}\text { Programa de Restaurante Saludable, } \\
\text { promovido por el Min. Del ambiente y Min. De } \\
\text { Salud }\end{array}$ & & \\
\hline
\end{tabular}

Figura 64. Oportunidades y Amenazas. Adaptado de Tomado de Conceptos de Administración Estratégica, por F.R. David, 2008.

\subsection{Determinación de las Ventajas Competitivas Críticas}

Según Porter (2009), la estrategia competitiva consiste en tomar posiciones defensivas y/u ofensivas que permita establecer una posición sostenible en el largo plazo; esto permitiría afrontar las fuerzas competitivas identificadas con el principal objetivo de conseguir el esperado rendimiento de la inversión. Es por lo anterior, que para lograr una ventaja competitiva en el mercado se debe considerar analizar la situación en base a tres estrategias genéricas, que permitiría colocar a la empresa en una posición defendible a largo plazo frente a la competencia; estas son:

1. El Liderazgo general en Costos

2. La Diferenciación

3. El Enfoque

En la primera, se exige un conjunto de políticas funcionales que permita el objetivo de tener costos bajos y que a su vez aporte rendimientos superiores al promedio de la industria y 
que le proporciones una defensa frente a la rivalidad de los competidores o lo proteja frente a clientes poderosos que ejercen presión para bajar precios al nivel del siguiente rival más eficiente, así como la defienda de proveedores poderosos al hacer a la empresa más flexible para encarar el incremento de los costos, y finalmente se auto-origina barreras de entrada a partir de economías de escala.

Por lo tanto, entre las maneras que se podría lograr tenemos:

- Establecer un proceso productivo bien definido para que sea eficiente y permita producir los mismos productos de la competencia, pero a menor costo.

- Implementar un proceso productivo altamente tecnológico que permita promover productos con mayor rendimiento que la competencia.

- Contar con personal calificado que permita alcanzar una alta productividad.

- Disminución en los costos de mano de obra directa, gracias al continuo aprendizaje adquirido por la misma.

- Establecer buenas relaciones y a largo plazo con los proveedores para obtener materia prima de calidad a mejor precio que los competidores.

En la segunda, se busca establecer un vínculo entre los compradores y la empresa, posicionando las cualidades del producto y minimizando el efecto precio. Esta estrategia sólo se debe seguir tras un atento estudio de las necesidades y preferencias de los compradores, a efecto de determinar la viabilidad de incorporar una característica diferente o varias a un producto singular que incluya los atributos deseados. Cuando se logra la diferenciación se convierte en una estrategia útil para lograr, también rendimientos superiores, así como brindar:

- Protección en contra de la competencia porque los clientes son leales a la marca y disminuye su sensibilidad al precio.

- Aumento en los márgenes de beneficio y prescindir de la posición de costos bajos

- Barreras de entrada gracias a la lealtad de los consumidores

- Márgenes mas altos de beneficio para enfrentarse al poder de los proveedores

- Un poder de negociación frente a los proveedores al no disponer de opciones similares.

- Una mejor posición frente a los productos sustitutos de la competencia. 
En la tercera, Porter explica el escenario de competencia es bastante estrecho en un sector industrial, por lo que es necesario ajustar la estrategia a un segmento muy reducido buscando lograr una ventaja competitiva general. Cabe señalar, que esta estrategia se hace más eficaz cuando los consumidores tienen preferencias o necesidades distintivas, y al mismo tiempo las empresas rivales no intentan especializarse en el mismo segmento de mercado.

En base a lo anterior, para La Conversa Bar, se considera a la Diferenciación como Estrategia Competitiva Genérica. Esto debido a que se ofrece un servicio singular en esa actividad industrial y que debería de recibir una alta valoración por parte del mercado objetivo al cumplir con los atributos y beneficios deseados, quiere decir que para los clientes del bar es más importante el valor percibido que el valor real del servicio. Adicionalmente, se puede afirmar que la base de diferenciación que hace más eficaz a la estrategia es que la competencia directa, al tener una propuesta de valor completamente diferente le resultaría indiferente o de difícil copia o imitación el concepto planteado en este estudio, por lo menos en el corto plazo.

En este sentido, y tomando en cuenta el análisis precedente, es necesario que las organizaciones sean conscientes de que la base de sus ventajas competitivas se cimenta en los recursos con los que cuentan y en el correcto uso que de estos hacen. VRIO es una matriz que se basa en el acrónimo de Valor, Raro, Imitable y Organización (Barney \& Griffin, 1992). A continuación, en la siguiente tabla se describe la Matriz VRIO de la propuesta de estudio (ver Tabla 51):

Tabla 51

Matriz VRIO

\begin{tabular}{|c|c|c|c|c|c|}
\hline Recurso & Valioso & Raro & Inimitable & Organización & $\begin{array}{l}\text { Implicación } \\
\text { Competitiva }\end{array}$ \\
\hline \multicolumn{6}{|l|}{ Tangible } \\
\hline $\begin{array}{l}\text { Diseño y } \\
\text { ambientación del } \\
\text { local }\end{array}$ & Sí & Sí & Sí & Sí & $\begin{array}{l}\text { Ventaja } \\
\text { Competitiva } \\
\text { Sostenible }\end{array}$ \\
\hline Ubicación & Sí & No & No & si & $\begin{array}{l}\text { Igualdad } \\
\text { Competitiva }\end{array}$ \\
\hline $\begin{array}{l}\text { Condiciones } \\
\text { Laborales }\end{array}$ & Sí & Sí & Sí & Sí & $\begin{array}{l}\text { Ventaja } \\
\text { Competitiva } \\
\text { Sostenible }\end{array}$ \\
\hline $\begin{array}{l}\text { Barman } \\
\text { especializado }\end{array}$ & Sí & Sí & No & Sí & $\begin{array}{l}\text { Ventaja } \\
\text { Competitiva } \\
\text { Temporal }\end{array}$ \\
\hline
\end{tabular}




\begin{tabular}{|c|c|c|c|c|c|}
\hline \multicolumn{6}{|l|}{ Intangibles } \\
\hline Marca & Sí & Sí & Sí & No & $\begin{array}{l}\text { Ventaja } \\
\text { Competitiva por } \\
\text { explotar }\end{array}$ \\
\hline Modelo de Negocio & Sí & Sí & No & Sí & $\begin{array}{l}\text { Ventaja } \\
\text { Competitiva } \\
\text { Temporal }\end{array}$ \\
\hline
\end{tabular}

\subsection{Diseño de la estructura organizacional deseada}

La estructura organizacional permitirá dividir las actividades del caso en estudio, así como establecer áreas y personal encargado que permita tener una estructura simple, que sea flexible y puede ser controlada.

Como indica Arbaiza (2015), encontrar organizar y mantener un equipo que otorgue valor a la organización es fundamental para alcanzar las metas propuestas por el plan de negocio. Se debe de procurar que todos los miembros cuenten con la capacidad de aportar sus conocimientos y experiencias en la implementación de la estrategia. Supone también la presencia de un liderazgo solido que sea capaz de lograr: la motivación, la interacción positiva, el compromiso, y la satisfacción en los trabajadores.

Con una estructura adecuada, se puede elegir cómo organizar a los empleados de acuerdo a sus funciones y responsabilidades y hacer frente, con éxito, a las demandas y los cambios del entorno. Antes de plasmar el organigrama se presenta los componentes que ayudarían a su esquematización para una mejor comprensión (ver Tabla 52): 
Tabla 52

Componentes Organigrama

\begin{tabular}{|c|c|}
\hline \multicolumn{2}{|c|}{ Factores que influyen Actividades Organizacionales } \\
\hline Componente & Descripción \\
\hline $\begin{array}{l}\text { Departamentización de } \\
\text { funciones }\end{array}$ & Tres áreas: Servicio al Cliente / Operaciones / Apoyo \\
\hline \multirow{3}{*}{ Especialización } & $\begin{array}{l}\text { Se requieren niveles de alta especialización en los puntos de } \\
\text { atención al cliente. }\end{array}$ \\
\hline & $\begin{array}{l}\text { Se requiere que el servicio no sea mecanizado, para ello el } \\
\text { personal debe de ser proactivo, empático, y carismático. }\end{array}$ \\
\hline & $\begin{array}{l}\text { Las actividades que no sean del "Core business" del negocio } \\
\text { que no se incluyan en la planilla sino más bien hay que buscar } \\
\text { la tercerización de áreas tales como Contabilidad, Limpieza, } \\
\text { Vigilancia, Publicidad, Mantenimiento y Asesoría Legal. }\end{array}$ \\
\hline \multirow{6}{*}{ Cadena Jerárquica } & Estructura Organizacional \\
\hline & Nivel 1 \\
\hline & Administrador y RR. PP \\
\hline & Encargado de Actividades \\
\hline & Ayudante \\
\hline & Se mantendrá relación horizontal en las actividades de nivel. \\
\hline \multirow{4}{*}{ No. de Personal } & 2 socios \\
\hline & Nivel 22 colaboradores \\
\hline & Nivel 210 colaboradores \\
\hline & Nivel 401 colaborador \\
\hline
\end{tabular}

Nota. Adaptado de Como elaborar un Plan de Negocio por L. Arbaiza, 2015. Lima, Perú: Editorial Universidad Esan, 
El organigrama es una representación tradicional de la estructura organizacional y no menciona nada acerca de las actividades de la empresa ni de su rubro, solo muestra la forma como encajan los puestos y quien reporta a quien (Arbaiza, 2015).

Por lo tanto, para el logro de los objetivos de la organización, se considera óptimo una organización de pequeña escala compuesto por cuatro niveles jerárquicos, como se enumeró en el cuadro anterior, y dividido en tres áreas: Servicio al cliente, Operaciones, Apoyo (Ver Figura 65).

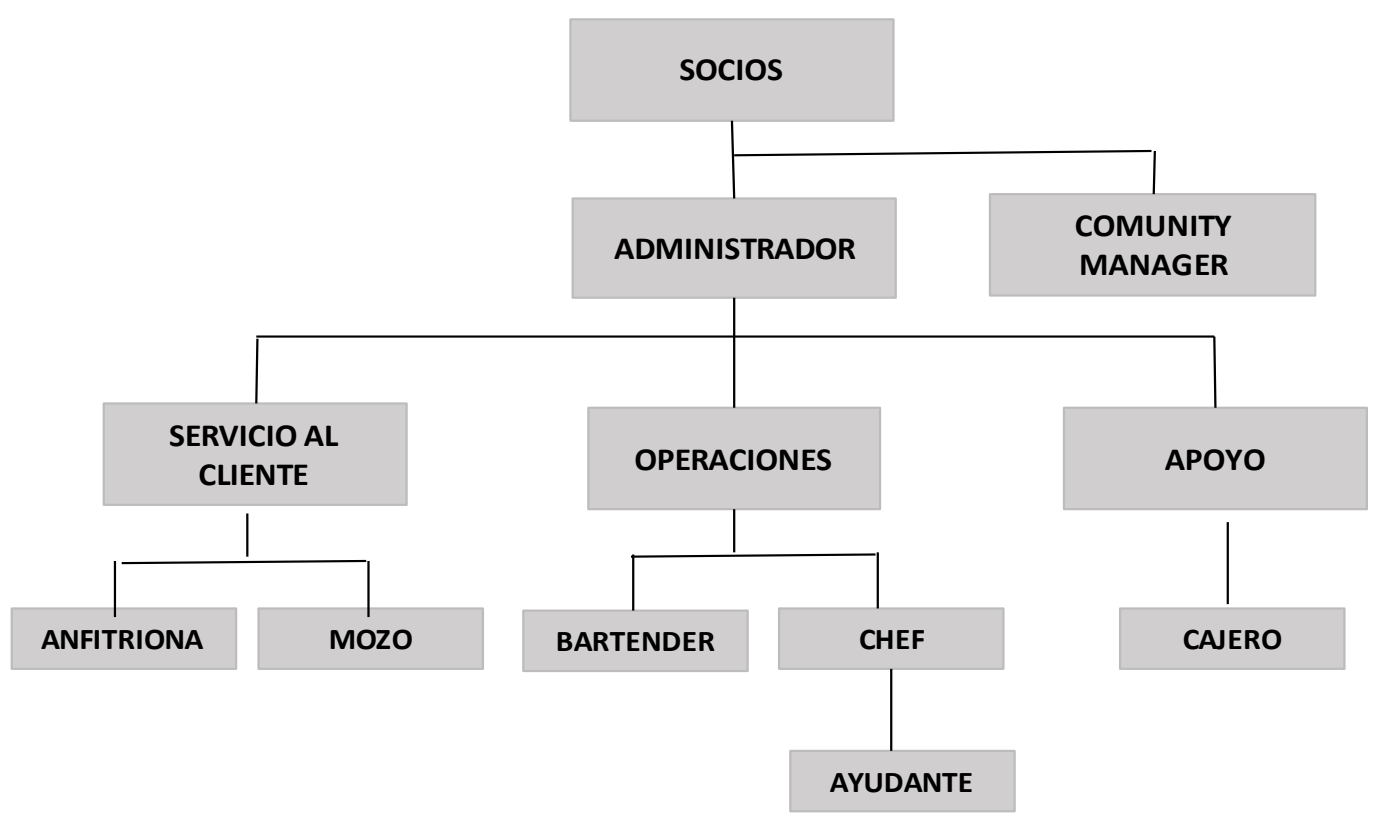

Figura 65. Estructura Organizacional. Adaptado de L. Arbaiza, Como elaborar un Plan de Negocio, 2015. Lima, Perú: Editorial Universidad Esan.

\subsection{Diseño de los perfiles de puestos clave}

El diseño de los perfiles de los puestos guarda relación con el número de colaboradores que se requerirá para llevar a cabo las actividades así como también de las necesidades de división de trabajo. Si la empresa es grande se deberá de emplear más personas para cumplir con la demanda; en cambio, con una empresa pequeña se contratarán menos personas, aunque ellas a su vez, deban de cumplir con más de una función relacionadas o no a sus actividades principales. (Arbaiza, 2015)

En cualquier caso, el personal debe de cubrir con la demanda del mercado sin contratiempo; y para cuando se tenga que aumentar la producción frente a requerimientos que 
sobrepase la capacidad, se preverá la capacidad de contratar personal temporal. (Proinversión, 2007).

Es por ello que se debe de considerar relevante las competencias que deben de estar presentes en cada perfil del colaborador con el propósito de que ellos mismos sean los diferenciadores, la personalización, y la calidad del servicio. Para La Conversa Bar se debe de identificar cuatro competencias para asegurar la ventaja competitiva, que a continuación se detalla: Orientación al Cliente, Compromiso, Iniciativa, e Integridad (Ver Tablas 52, 53, 54 y $55)$.

\subsection{Remuneraciones, compensaciones e incentivos}

El Ministerio de Trabajo y Promoción al Empleo, indica que las empresas actualmente no están obligadas a informar acerca de los montos de su estructura salarial, solo se les exige que no haya discriminación entre varones y mujeres. (Diario Gestión, 8 de marzo, 2018).

En el caso de la empresa La Conversa Bar los colaboradores recibirán sus sueldos en relación al puesto y su modelo de contratación plazo de seis meses con elección de renovación con todos los beneficios de ley, así como también se ha tomado como base las bolsas de empleo digitales (por ejemplo, Bumeran y Adecco) para identificar precios de mercado que se paga en empleos similares. (Ver Tabla 56).

Los servicios a ser tercerizado han sido considerado los siguientes: Limpieza / Seguridad / Contabilidad. Los contratos de trabajo para los colaboradores del caso en estudio deberán constar por escrito y por triplicado, debiendo consignarse su duración, causas, período de prueba y demás condiciones. 


\section{Tabla 53}

\section{Competencias identificadas para la Organización}

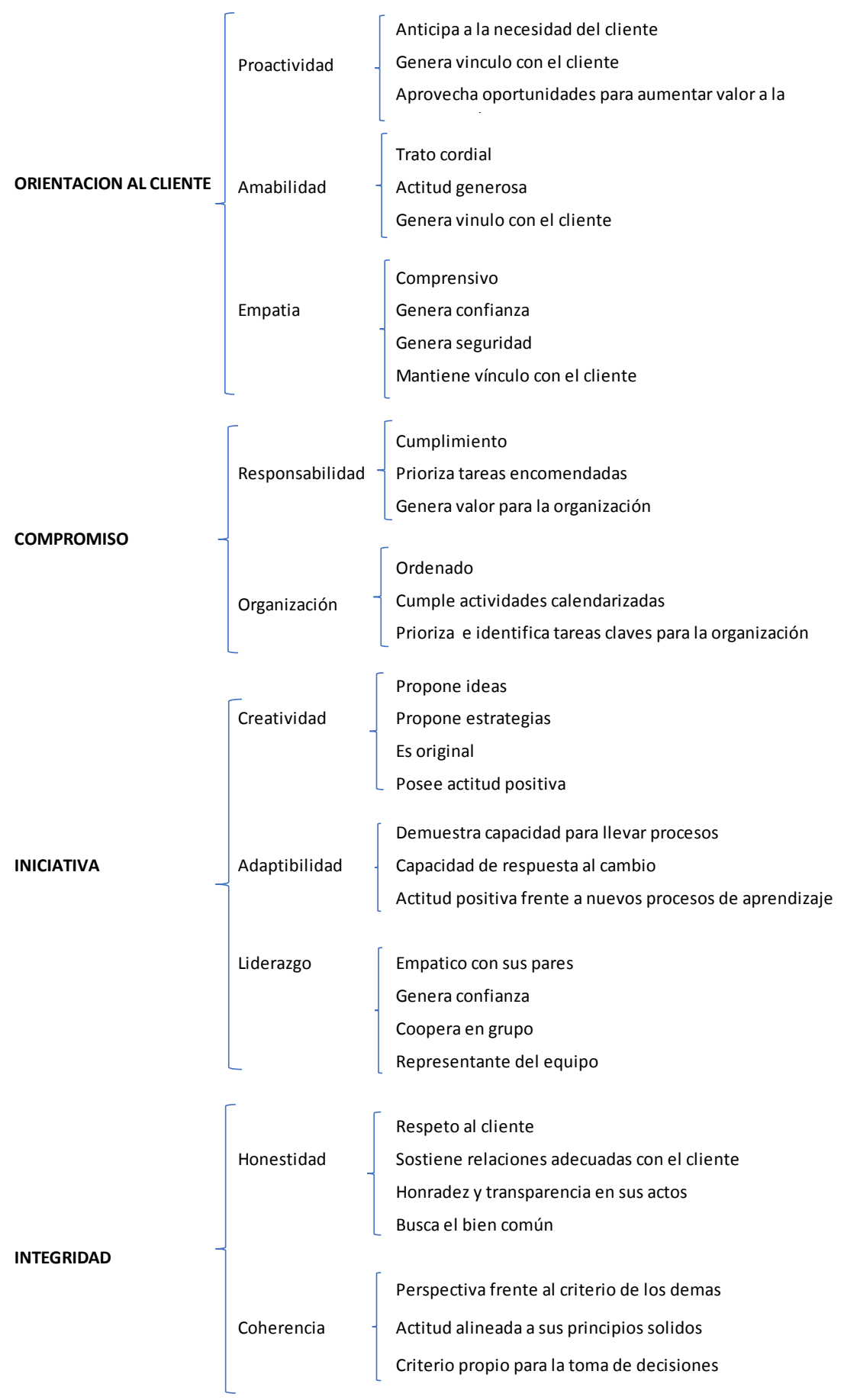


Tabla 54

Perfiles de los Puestos de Trabajo (1/3)

\begin{tabular}{|c|c|c|c|c|}
\hline Puesto & Administrador & Mozo & Anfitriona & Cajero \\
\hline Unidad & Administración & Area de Operaciones & Area de Operaciones & Area de Apoyo \\
\hline Jefe Inmediato & Socios & Administrador & Administrador & Administrador \\
\hline \multirow[t]{2}{*}{ Personal a Cargo } & Comunity Manager / Cheff / Mozos & No aplica & No aplica & No aplica \\
\hline & Bartender / Seguridad / Limpieza & & & \\
\hline \multirow[t]{2}{*}{ Responsabilidades } & $\begin{array}{l}\text { Administrar y supervisar el } \\
\text { cumplimiento de las políticas de la } \\
\text { empresa }\end{array}$ & $\begin{array}{l}\text { Brindar rapida y amable atención a los } \\
\text { clientes }\end{array}$ & $\begin{array}{l}\text { Brindar un trato cordial y amable a los } \\
\text { clientes como primera impresión del } \\
\text { negocio }\end{array}$ & $\begin{array}{l}\text { Realizar la eficiente gestion del flujo de } \\
\text { efectivo manteniendo el nivel esperado } \\
\text { de indicadores en relación con las } \\
\text { metas planeadas }\end{array}$ \\
\hline & Llevar a cabo la gestión de los bienes. & & & \\
\hline \multirow[t]{6}{*}{ Funciones } & $\begin{array}{l}\text { Dirigir el Area de Operaciones / Area de } \\
\text { Apoyo }\end{array}$ & Entrega de carta a los clientes & $\begin{array}{l}\text { Dar la bienvenida y recepción de los } \\
\text { clientes ingresan al local }\end{array}$ & $\begin{array}{l}\text { Realizar los cobros debidoa, productos } \\
\text { de las ventas a los clientes }\end{array}$ \\
\hline & Reponsable del buen manejo del negocio & Sugerir pedido a los clientes & $\begin{array}{l}\text { Ubicar a los clientes en mesas de su } \\
\text { preferencia }\end{array}$ & $\begin{array}{l}\text { Rececpión y seguimiento del efectivo } \\
\text { cobrado }\end{array}$ \\
\hline & Supervisar al personal & $\begin{array}{l}\text { Realziar y entregar pedido a la cocina } \\
\text { y/o barra }\end{array}$ & $\begin{array}{l}\text { Constante contacto con los mozos } \\
\text { para asegurar la rapida atención del } \\
\text { cliente que arriba al local }\end{array}$ & $\begin{array}{l}\text { Cierre de caja diario, cuadrando los } \\
\text { ingreso y egresos operativos del dia }\end{array}$ \\
\hline & $\begin{array}{l}\text { Atender los requerimientos que el } \\
\text { personal solicite }\end{array}$ & $\begin{array}{l}\text { Responder dudas e inquietudes a los } \\
\text { clientes referentes a los productos y }\end{array}$ & & \\
\hline & Coordinar con el personal & Atento a cualquier solicitud & & \\
\hline & Otros & & & \\
\hline \multirow[t]{5}{*}{ Requisitos } & Experiencia demostrada (2 años) & Experiencia en atencion al cliente & Secundaria completa & Experiencia en establecimiento afin \\
\hline & Conocimiento de Ofimatica & Manejo de comandas electronicas & Experiencia en establecimiento afin & Ingles Basico (obligatorio) \\
\hline & Conocimiento de Manejo de Inventarios & Disponibilidad de horarios & Disponibilidad horaria & No tener deuda en sistema financiero \\
\hline & Estudios en Hostelería o Restaurantes & Ingles Basico (opcional) & Ingles Basico (obligatorio) & Disponibilidad horaria \\
\hline & Experiencia en manejo de personal & Estudios relacionados a la actividad & Fluidez Verbal & No antecedentes penales / judiciales \\
\hline
\end{tabular}


Tabla 55

Perfiles de los Puestos de Trabajo (2/3)

\begin{tabular}{|c|c|c|c|c|}
\hline Puesto & Chef & Ayudante de Cocina & Bartender & Comunity Manager \\
\hline Unidad & Area de Operaciones & Area de Operaciones & Area de Operaciones & Apoyo \\
\hline Jefe Inmediato & Adminstrador del local & Chef & Adminstrador del local & Adminstrador del local \\
\hline Personal a Cargo & Ayudante de Cocina & No ap lica & No aplica & No aplica \\
\hline Responsabilidades & $\begin{array}{l}\text { Atencion y preparación de los } \\
\text { pedidos en los tiempo adecuados, } \\
\text { procurando la calidad, sabores, y } \\
\text { presentación de los mismos }\end{array}$ & $\begin{array}{l}\text { Apoyo en actividades que el Chef } \\
\text { requiera, generando eficiencia en la } \\
\text { generación de productos. }\end{array}$ & $\begin{array}{l}\text { Prepara bebidas de calidad y sabor de } \\
\text { acuerdo a las exigencias de las } \\
\text { poltiticas de la empresa }\end{array}$ & $\begin{array}{l}\text { Construir, gestionar y administrar la } \\
\text { comunidad online alrededor de } \\
\text { la marca, creando y } \\
\text { manteniendo relaciones estables y } \\
\text { duraderas con los clientes. }\end{array}$ \\
\hline \multirow[t]{5}{*}{ Funciones } & $\begin{array}{l}\text { Coordinar con el administrador para el } \\
\text { abastecimiento de los insumos de la } \\
\text { cocina }\end{array}$ & Recepción y almacenamiento de insumos & $\begin{array}{l}\text { Preparar y servir las bebidas } \\
\text { solicitadas }\end{array}$ & $\begin{array}{l}\text { Creación de contenido atractivo y de } \\
\text { calidad }\end{array}$ \\
\hline & $\begin{array}{l}\text { Recepción y almacenamiento de los } \\
\text { insumos de la cocina }\end{array}$ & $\begin{array}{l}\text { Lavar, descongelar, picar, etc los } \\
\text { insumos }\end{array}$ & Cotnrolar el stock de insumos del bar & $\begin{array}{l}\text { Publicación de contenido en el espacio - } \\
\text { tiempo adecuado }\end{array}$ \\
\hline & $\begin{array}{l}\text { Realizar el inventario de cocina de } \\
\text { manera diaria }\end{array}$ & $\begin{array}{l}\text { Constante revisión de los stocks de } \\
\text { los insumos, para la inmediata } \\
\text { comnicación al cheff cualquier } \\
\text { requerimiento }\end{array}$ & Organizar los elementos del bar & $\begin{array}{l}\text { Monitorizar todas las publicaciones y } \\
\text { novedades del sector de la empresa }\end{array}$ \\
\hline & Preparar los productos solicitados & Otras funciones que el Cheff designe & Atender a los clientes en la barra & $\begin{array}{l}\text { Seguir y monitorizar sus propias } \\
\text { publicaciones, }\end{array}$ \\
\hline & & & Emitir la comanda para el paga & Identificar a los prescriptores \\
\hline Requisitos & $\begin{array}{l}\text { Chef Ejecutivo de Instituto } \\
\text { Experiencia en Restuarantes } 2 \text { años } \\
\text { Conocimiento de costeo de productos } \\
\text { Manejo de inventarios } \\
\text { Manejo de Comandas electrónicas } \\
\text { Disponibilidad de horarios }\end{array}$ & $\begin{array}{l}\text { Estudios en gastronomía } \\
\text { Vivir en zonas aledañas } \\
\text { Experiencia en establecimientos afines } \\
\text { Disponibilidad horaria } \\
\text { carnet de sanidad }\end{array}$ & $\begin{array}{l}\text { Experiencia minima } 2 \text { años } \\
\text { Con estudios Bartender concluidos } \\
\text { Con disponibilidad horaria } \\
\text { Manejo de Comandas electrónicas } \\
\text { Ingles (opcional) }\end{array}$ & $\begin{array}{l}\text { Estudios concluidos en Comunicación } \\
\text { Experiencia en manejo de redes soc. } \\
\text { Ingles (obligatorio - intermedio) } \\
\text { Disponibilidad horaria }\end{array}$ \\
\hline
\end{tabular}


Tabla 56

Perfiles de los Puestos de Trabajo (3/3)

\begin{tabular}{lll}
\hline Puesto & Personal de Seguridad & Personal de Limpieza \\
\hline Unidad & Apoyo - Terceros & Apoyo - Terceros \\
Jefe Inmediato & Adminstrador del local & Adminstrador del local \\
Personal a Cargo & No aplica & No aplica \\
Responsabilidades & Estar atento a la seguridad de local & $\begin{array}{l}\text { Mantener limpioy desinfectado el } \\
\text { ambiente }\end{array}$ \\
& & \\
Funciones & & \\
& $\begin{array}{l}\text { Estar atento a la seguridad de local } \\
\text { ante posibles ocurrencias }\end{array}$ & Encargado de la limpieza de local \\
& $\begin{array}{l}\text { Estar ubicado en la entrada o salida del } \\
\text { local resguardando la seguridad del } \\
\text { cliente }\end{array}$ & Mantenimiento de SS.HH \\
& & \\
& & Supervisar que no falte implementos \\
Requisitos & $\begin{array}{l}\text { Experiencia demostrada 1 año } \\
\text { Disponibilidad horaria }\end{array}$ & y articulos de limpieza \\
& No antecedentes penales / judiciales & Disponibilidad horaria \\
& &
\end{tabular}


Tabla 57

Remuneraciones

\begin{tabular}{|c|c|c|c|c|c|c|c|}
\hline Cargo & Sueldo & Vacaciones & CTS & Gratificacion & Essalud & $\begin{array}{c}\text { Total Costo } \\
\text { mensual }\end{array}$ & $\begin{array}{c}\text { Total Anual } \\
\text { S/ }\end{array}$ \\
\hline 1 Administrador & 3,200 & 267 & 267 & 533 & 336 & 4,603 & 52,032 \\
\hline 2 Cheff & 2,400 & 200 & 200 & 400 & 252 & 3,452 & 39,024 \\
\hline 3 Bartender & 2,400 & 200 & 200 & 400 & 252 & 3,452 & 39,024 \\
\hline 4 Mozo 1 & 1,800 & 150 & 150 & 300 & 189 & 2,589 & 29,268 \\
\hline 5 Mozo 2 & 1,800 & 150 & 150 & 300 & 189 & 2,589 & 29,268 \\
\hline 6 Comunity Manager & 1,600 & 133 & 133 & 267 & 168 & 2,301 & 26,016 \\
\hline 7 Anfitriona & 1,600 & 133 & 133 & 267 & 168 & 2,301 & 26,016 \\
\hline 8 Cajero & 2,000 & 167 & 167 & 333 & 210 & 2,877 & 32,520 \\
\hline \multirow[t]{2}{*}{9 Ayudante } & 1,500 & 125 & 125 & 250 & 158 & 2,158 & 24,390 \\
\hline & 18,300 & 1,525 & 1,525 & 3,050 & 1,922 & 26,322 & 297,558 \\
\hline
\end{tabular}

\subsection{Política de recursos humanos}

La política de recursos humanos debe de estar alienada a los objetivos de la organización y como soporte a una eficiente gestión de personal se debe de considerar las siguientes:

\subsubsection{Reclutamiento y Selección.}

Se inicia una vez establecido la necesidad del puesto, haciéndose efectiva a través de diferentes bolsas de trabajo y/o diferentes reclutadores (outsourcing) en línea.

De acuerdo al postulante y a la necesidad se procede con la recepción, con el filtro, la elaboración de la terna, asentarlo en una base de datos, proceder con las citas y entrevistas, y terminar con la elección.

\subsubsection{Inducción.}

Se le expresará con el fin de internalizar la razón de ser de la empresa, a través de la misión y la visión, así como sus responsabilidades. Esto debe de llevarse a cabo el primer dia de labores y de forma obligatoria.

\subsubsection{Capacitación.}

Las capacitaciones deben de ser frecuentes, principalmente, en términos de atención al cliente, técnica de ventas, manejo de conflictos, y primeros auxilios.

\subsubsection{Evaluación de Desempeño.}

Se tendrá reuniones de mejoras de contingencias, donde la participación debe de ser de todos los integrantes, con ello también se podrá confirmar la calidad de servicio que se viene dando. No tendrá un sentido punitivo.

\subsubsection{Compensación y Motivación de Personal.}

Habrá bonos de soles al mejor calificado. En algunos casos, capacitación o compensación en horas de descanso. 


\subsubsection{Desvinculación.}

La desvinculación se dará con el debido respeto con el trabajador a quién se desea desvincularse, sin ocasionar molestias ni frustraciones, sino más bien persuadirlo para una renuncia voluntaria en caso se origine por el lado de la empresa para que no genere consecuencias negativas, y explicando el porqué de la decisión final.

\subsubsection{Uniformes.}

El personal de staff directamente vinculado con el cliente, utilizará uniformes que sean empleados como un sentido de pertenencia a la organización y de generar identidad a los colaboradores. Esto serán polos con cuello camisero blanco con la marca y el logo bordado en el pecho y serigrafiado el lema en la espalda.

Si bien es cierto que los uniformes pueden ser considerados como elemento de publicidad utilizando la comunicación no verbal, estos no deberían de denigrar ni perjudicar a los colaboradores.

\subsubsection{Discriminación.}

Actualmente, la Superintendencia Nacional de Fiscalización Laboral [SUNAFIL], viene realizando inspecciones a empresas en contra de la discriminación o maltrato laboral de cualquier tipo que se puede originar en estos centros: por raza, origen nacional, color, sexo, religión, edad, o discapacidad. Es por ello, que La Conversa Bar, cumplirá con las normas legales y evitará las sanciones y multas que podría perjudicar la rentabilidad del negocio.

Finalmente, la empresa contará con un Manual de Organización y Funciones (MOF) en la que se plasmará de manera detallada la forma de organización, el perfil de cada puesto, e indicadores de evaluación que se adoptarán y previamente se he venido desarrollando de manera específica en el presente capítulo. 


\section{Capítulo IX: Planificación Financiera}

En el presente capítulo se realizó el análisis financiero de La Conversa Bar con la información proveniente del estudio de mercado, estudio técnico y organizacional se determinó la inversión necesaria para iniciar el negocio, los costos, los gastos administrativos, el presupuesto de compras, marketing y ventas. Asimismo se proyectó los Estados de Resultados Integrales, Situación Financiera y Flujo de Efectivo del proyecto según norma internacionales de información financiera (NIIF)

\subsection{La Inversión}

\subsubsection{Inversión pre-operativa}

La inversión se distribuyó en Activo fijo tangible e Intangibles incluyendo los gastos pre-operativos necesarios para la puesta en marcha del proyecto (Ver Tabla 58).

Tabla 58

Inversión Pre Operativa

\begin{tabular}{|c|c|c|c|}
\hline \multicolumn{4}{|c|}{ Activos tangibles } \\
\hline Descripción & Monto S/ & IGV S/ & Total \\
\hline Edificios y Otras Construcciones & $51,779.7$ & $9,320.34$ & $61,100.00$ \\
\hline Equipos de Computo & $13,799.2$ & $2,483.85$ & $16,283.00$ \\
\hline Equipos diversos & $19,939.0$ & $3,589.02$ & $23,528.00$ \\
\hline Muebles y Enseres & $73,549.3$ & $13,238.88$ & $86,788.20$ \\
\hline Total & S/.159,067.1 & S/.28,632.08 & S/.187,699.20 \\
\hline \multicolumn{4}{|c|}{ Activos intangibles } \\
\hline Descripción & Monto S/ & IGV S/ & Total \\
\hline Licencias y Software & $10,593.2$ & $1,906.78$ & $12,500.00$ \\
\hline $\begin{array}{l}\text { Servicio de constitución de empresa } \\
\text { (Notaria, R. Públicos, Ins. RUC, } \\
\text { Minuta) }\end{array}$ & $1,562.29$ & & $1,562.29$ \\
\hline Libros de Contables y Legalización & $1,000.00$ & 180.00 & $1,180.00$ \\
\hline $\begin{array}{l}\text { Defensa Civil } \\
\text { Licencia de Funcionamiento - }\end{array}$ & 500.00 & & 500.00 \\
\hline $\begin{array}{l}\text { Barranco } \\
\text { Investigación de Mercado y Plan }\end{array}$ & 750.00 & & 750.00 \\
\hline $\begin{array}{l}\text { MKT } \\
\text { Registro de Marca y Logo en }\end{array}$ & $1,700.00$ & 306.00 & $2,006.00$ \\
\hline Indecopi & $1,603.28$ & & $1,603.28$ \\
\hline Creación página web & $1,434.00$ & 258.12 & $1,692.12$ \\
\hline Total & $19,142.79$ & 2650.90 & $21,793.69$ \\
\hline Total Activos & S/. 178,209.91 & S/. 31,282.98 & S/. 209,492.89 \\
\hline
\end{tabular}


El detalle de la inversión inicial en maquinarias, equipos y utensilios, se encuentra se encuentra en el estudio técnico.

\subsubsection{Inversión en Capital de Trabajo.}

Se estimaron los flujos de caja mensuales para identificar el déficit acumulado máximo sin embargo se observaron flujos positivos desde el primer mes, por lo que se opta por estimar los componentes del capital de trabajo, el monto de caja mínimo para operar, considerando las compras del primer mes de operación, los gastos a realizar, las garantías y un porcentaje de imprevistos (ver Tabla 59).

Tabla 59

Inversión en Capital de Trabajo

\begin{tabular}{lccc}
\hline \multicolumn{4}{c}{ Capital de Trabajo } \\
\hline Descripción & Monto S/. & IGV S/. & Total \\
\hline Costo de Ventas Mes & 30,095 & $5,417.01$ & $35,511.53$ \\
Cocteles Calientes & 4,763 & 857 & 5,621 \\
Cocteles Refrescantes & 3,113 & 560 & 3,673 \\
Cocteles Cremosos & 4,215 & 759 & 4,974 \\
Bebidas envasadas & 1,142 & 206 & 1,347 \\
Piqueos A & 11,109 & 2,000 & 13,109 \\
Piqueos B & 5,752 & 1,035 & 6,787 \\
Disponible & 35,487 & 275 & 35,762 \\
Sueldos & 26,322 & 0 & 26,322 \\
Alquiler & 5,775 & 0 & 5,775 \\
Seguridad y Limpieza (RxH) & 1,860 & 0 & 1,860 \\
Servicios (Luz, Agua y Teléfono) & 1,530 & 275 & 1,805 \\
Anticipo - Garantías & 11,550 & 0 & 11,550 \\
GARANTİA (2 MESES) & 11,550 & 0 & 11,550 \\
Imprevistos (5\%) & 4,141 & 0 & 4,141 \\
& & & \\
\hline Total Capital de Trabajo & 81,272 & 5,692 & 86,965 \\
\hline
\end{tabular}

\subsubsection{Costo del Proyecto}

La inversión inicial del proyecto está compuesta por la inversión tangible, intangible y el capital de trabajo (ver Tabla 60). 
Tabla 60

Costo del Proyecto

\begin{tabular}{lrrr}
\hline \multicolumn{4}{c}{ Costo del Proyecto } \\
\hline Descripción & Monto S/ & IGV S/ & \multicolumn{1}{c}{ Total } \\
\hline I. Inversión fija & 178,210 & 31,283 & 209,493 \\
1. Inversión fija Tangible & 159,067 & 28,632 & 187,699 \\
2. Inversión Fija Intangible & 19,143 & 2,651 & 21,794 \\
II. Capital de Trabajo & 81,272 & 5,692 & 86,965 \\
1. Existencias & 30,095 & 5,417 & 35,512 \\
2. Disponible & 35,487 & 275 & 35,762 \\
3. Anticipos & 11,550 & 0 & 11,550 \\
4. Imprevistos & 4,141 & 0 & 4,141 \\
\hline Inversión Total & $259,482.10$ & 36,975 & 296,457 \\
\hline
\end{tabular}

\subsubsection{Inversiones futuras.}

Para efectos del flujo de proyecto sólo se consideran inversiones adicionales la renovación de la vajilla para el 2do. y 4to. año de operación (ver Tabla 61).

Tabla 61

Inversion Futuras

\begin{tabular}{|c|c|c|c|c|c|c|}
\hline Inversiones Futuras & Año 0 & Año 1 & Año 2 & Año 3 & Año 4 & Año 5 \\
\hline \multicolumn{7}{|l|}{ Renovación de } \\
\hline Vajilla & & & 2,866 & & 2,866 & \\
\hline Depreciación & & & & & & \\
\hline Adicional & & & 1,433 & 1,433 & 1,433 & 1,433 \\
\hline Saldo Adicional & & & 1,433 & - & 1,433 & - \\
\hline
\end{tabular}

\subsection{Financiamiento}

\subsubsection{Endeudamiento y Condiciones.}

La Inversión total del proyecto será financiada de la siguiente manera (ver Tabla 62):

Tabla 62

Financiamiento

\begin{tabular}{lcc}
\hline \multicolumn{3}{c}{ Cuadro de Inversionistas } \\
\hline Estructura & $\mathrm{S} /$. & $\%$ \\
Aporte de Socios & 177,874 & $60 \%$ \\
Préstamo Bancario & 118,583 & $40 \%$ \\
\hline Total Inversión Inicial & 296,457 & $100 \%$ \\
\hline
\end{tabular}


El préstamo bancario propuesto es con BANCO BBVA Continental

TEA: $22.87 \%$

Producto: Capital de trabajo

Tiempo: 3 años

Requisitos: Negocio en Marcha y/o evaluación de Garantías

\subsubsection{Capital y Costo de Oportunidad.}

Se utilizó el modelo CAPM ajustándolo con el beta apalancado por el capital de la deuda del proyecto y considerando una prima de riesgo por tamaño de mercado.

Según diversos especialistas esta prima por riesgo de mercado oscila entre 4 y $6 \%$, para efectos conservadores hemos utilizado $6 \%$.

Se obtuvo un costo de capital de $18.25 \%$. Es decir, que el presente proyecto debe contar con un rendimiento como mínimo de $18.25 \%$ para que sea rentable en comparación al mercado, tal como se calculó en la siguiente operación:

\begin{tabular}{rrl}
\hline$R_{f}$ & $2.905 \%$ & Tasa libre de Riesgo (tasa rendimiento bonos americano) \\
$\beta_{a}$ & 0.981 & Beta re apalancado (Estructura de Deuda Proyecto) \\
$R_{m}$ & $11.20 \%$ & Rentabilidad del sector \\
$R P$ & $1.21 \%$ & pb del EMBI + plus ( Riesgo Pais) al 6 de Sep 2018 \\
Size Premium & $6.00 \%$ & Prima de riesgo por Tamaño de Mercado \\
$K_{S}=$ COK & $18.25 \%$ & \\
\hline
\end{tabular}

\subsubsection{Costo de capital promedio ponderado.}

Para estimar la tasa promedio de las fuentes de financiamiento, se usó la fórmula del WACC, considerando que las inversionistas financiarán un $60 \%$ con capital propio y el otro $40 \%$ a través del crédito bancario, tal y como se observa en la siguiente operación:

\begin{tabular}{lccc}
\hline Detalle & Valores & Peso & Rentabilidad \\
\hline Deuda (D) & 118,583 & $40.00 \%$ & $22.87 \%$ \\
& & & \\
Patrimonio (E) & 177,874 & $60.00 \%$ & $18.25 \%$ \\
& & & \\
Total Pas+Pat. & 296,457 & $100.00 \%$ & \\
Impuesto a la Renta & $29.50 \%$ & & \\
\hline
\end{tabular}




\subsection{Presupuesto Base}

\subsubsection{Presupuesto de Ventas.}

En el presupuesto de ventas se detallaron todos los productos que se ofrecen en La Conversa Bar, los cuales se agruparon en bebidas Cocteles Calientes, Cocteles Refrescantes, Cocteles Cremosos, Bebidas envasadas, Piqueos fuertes (A) y Piqueos ligeros (B), tal como lo muestra la tabla a continuación (Ver Tabla 63):

Tabla 63

Presupuesto de Ventas

\begin{tabular}{|c|c|c|c|c|c|c|}
\hline $\begin{array}{l}\text { Presupuesto de } \\
\text { Ventas }\end{array}$ & $\mathrm{S} /$. & Año 1 & Año 2 & Año 3 & Año 4 & Año 5 \\
\hline Cocteles Calientes & $29 \%$ & 233,381 & 315,243 & 319,253 & 323,438 & 327,622 \\
\hline Cocteles Refrescantes & $22 \%$ & 177,003 & 239,090 & 242,131 & 245,305 & 248,479 \\
\hline Cocteles Cremosos & $40 \%$ & 325,832 & 440,126 & 445,729 & 451,573 & 457,401 \\
\hline Bebidas envasadas & $10 \%$ & 80,587 & 108,853 & 110,236 & 111,680 & 113,131 \\
\hline Total Bebidas & & 816,803 & $1,103,311$ & $1,117,349$ & $1,131,996$ & $1,146,633$ \\
\hline Piqueos A & $62 \%$ & 252,744 & 341,370 & 345,719 & 350,254 & 354,775 \\
\hline Piqueos B & $38 \%$ & 155,664 & 210,287 & 212,957 & 215,746 & 218,546 \\
\hline Total Piqueos & & 408,408 & 551,657 & 558,676 & 566,000 & 573,320 \\
\hline Total Venta Anual & Soles & $1,225,211$ & $1,654,968$ & $1,676,026$ & $1,697,996$ & $1,719,954$ \\
\hline IGV & $18 \%$ & 220,538 & 297,894 & 301,685 & 305,639 & 309,592 \\
\hline Venta Incluido IGV & & $1,445,749$ & $1,952,863$ & $1,977,710$ & $2,003,635$ & $2,029,545$ \\
\hline
\end{tabular}

\subsubsection{Presupuesto de Costos de producción.}

Se consideraron los costos de materia prima e insumos de decoración para cada grupo de productos, tal y como lo muestra la siguiente tabla (Ver Tabla 64): 
Tabla 64

Presupuesto de Costos

\begin{tabular}{lrrrrrr}
\hline Presupuesto Costos & S/ & Año 1 & Año 2 & Año 3 & Año 4 & Año 5 \\
\hline Bebidas & & 238,283 & 321,865 & 325,960 & 330,232 & 334,503 \\
Piqueos & & 303,640 & 410,138 & 415,358 & 420,803 & 426,244 \\
\hline Total Costo Anual & Soles & 541,923 & 732,003 & 741,317 & 751,035 & 760,747 \\
\hline & & & & & & \\
IGV & $18 \%$ & 97,546 & 131,761 & 133,437 & 135,186 & 136,935 \\
Costo Incluido IGV & & 639,469 & 863,763 & 874,754 & 886,222 & 897,682 \\
\hline
\end{tabular}

\subsubsection{Presupuesto de Compras.}

Por la naturaleza del negocio para La Conversar No aplica tener un inventario de productos producidos o compras, puesto que la producción descrita en el punto anterior se realiza para venta inmediata.

\subsubsection{Presupuesto de Costo de Ventas.}

El costo de Ventas es similar al costo de producción de producción puesto que se produce para venta inmediata y este se refleja en el Estado de Resultados de manera similar al Flujo de Caja.

\subsubsection{Presupuesto de Gastos Administrativos.}

Se consideraron todos los gastos relacionados directamente con la administración de La Conversa Bar, como puede verse en la siguiente tabla (ver Tabla 65):

Tabla 65

Presupuesto de Gastos Administrativos 


\begin{tabular}{lrrrrrr}
\hline Gastos en Soles S/. & Mes & \multicolumn{1}{c}{ Año 1 } & \multicolumn{1}{c}{ Año 2 } & \multicolumn{1}{c}{ Año 3 } & \multicolumn{1}{c}{ Año 4 } & \multicolumn{1}{c}{ Año 5 } \\
\hline Sueldos & 26,322 & 297,558 & 297,558 & 297,558 & 297,558 & 297,558 \\
Alquiler & 5,775 & 69,300 & 69,300 & 69,300 & 69,300 & 69,300 \\
Seguridad y Limpieza (RxH) & 1,860 & 22,320 & 22,320 & 22,320 & 22,320 & 22,320 \\
Honorarios DJ & 1,620 & 19,440 & 19,440 & 19,440 & 19,440 & 19,440 \\
Servicios (Luz, Agua, Telefono e Intern & 1,530 & 18,360 & 18,360 & 18,360 & 18,360 & 18,360 \\
Servicio Contable & 930 & 11,160 & 11,160 & 11,160 & 11,160 & 11,160 \\
Combustible - Gas & 900 & 10,800 & 10,800 & 10,800 & 10,800 & 10,800 \\
Materiales de Limpieza y Utiles de Esc1 & 380 & 4,560 & 4,560 & 4,560 & 4,560 & 4,560 \\
Mantenimientos & & 2,240 & 2,240 & 2,240 & 2,240 & 2,240 \\
\hline Total Gastos Administrativos & $\mathbf{3 9 , 3 1 7}$ & $\mathbf{4 5 5 , 7 3 8}$ & $\mathbf{4 5 5 , 7 3 8}$ & $\mathbf{4 5 5 , 7 3 8}$ & $\mathbf{4 5 5 , 7 3 8}$ & $\mathbf{4 5 5 , 7 3 8}$ \\
\hline IGV & $18 \%$ & 8,482 & 8,482 & 8,482 & 8,482 & 8,482 \\
Total Gastos Incluido IGV & & $\mathbf{4 6 4 , 2 2 0}$ & $\mathbf{4 6 4 , 2 2 0}$ & $\mathbf{4 6 4 , 2 2 0}$ & $\mathbf{4 6 4 , 2 2 0}$ & $\mathbf{4 6 4 , 2 2 0}$ \\
\hline
\end{tabular}

\subsubsection{Presupuesto de Marketing y Ventas.}

Se determinó que el presupuesto de marketing es el $2 \%$ de la venta y contempla todos los gastos de las acciones de marketing descritas en el capítulo 5. Se presentan consolidados con los gastos de ventas 3\%, en total 5\% de las ventas (Ver Tabla 66).

Tabla 66

Presupuesto de Marketing y Ventas

\begin{tabular}{lrccccc}
\hline Gastos de Marketing y & & & & & & \\
Ventas & $5 \%$ & 61,261 & 82,748 & 83,801 & 84,900 & 85,998 \\
\hline IGV & $18 \%$ & 11,027 & 14,895 & 15,084 & 15,282 & 15,480 \\
Total Incluido IGV & & 72,287 & 97,643 & 98,886 & 100,182 & 101,477 \\
\hline
\end{tabular}

\subsubsection{Presupuesto de Gastos financieros.}

Los gastos financieros comprenden todos los intereses de créditos y préstamos. Como se observa en la Tabla 66, se muestra el resumen de pagos para un préstamo de S/.118, 583 soles financiados a 3 años con pagos mensuales.

\begin{tabular}{lr} 
Prestamos Bancario & \\
\hline TCEA & $22.9 \%$ \\
TCEM & $1.73 \%$ \\
Plazo & 36 meses \\
\hline
\end{tabular}

Tabla 67

Presupuesto de Gastos Financieros 


\begin{tabular}{lcccc}
\hline Resumen & & & & \\
Anual & Año 0 & Año 1 & Año 2 & Año 3 \\
\hline Saldo Inicial & 118,583 & 118,583 & 86,863 & 47,888 \\
Interés & & 21,726 & 14,472 & 5,558 \\
Amortización & & 31,720 & 38,975 & 47,888 \\
Pago Anual & & 53,446 & 53,446 & 53,446 \\
Saldo Final & 118,583 & 86,863 & 47,888 & - \\
\hline
\end{tabular}

\subsection{Presupuesto de Resultados}

\subsubsection{Estado de Resultados Integrales Proyectados.}

Los resultados proyectados consolidan la proyección de los ingresos, costos y gastos de forma creciente durante el horizonte de evaluación (Ver Tabla 68).

Tabla 68

Proyeccion de Resultados

\begin{tabular}{lccccc}
\hline Resultados en Soles S/. & Año 1 & Año 2 & Año 3 & Año 4 & Año 5 \\
\hline VENTAS & $1,225,211$ & $1,654,968$ & $1,676,026$ & $1,697,996$ & $1,719,954$ \\
COSTOS & 541,923 & 732,003 & 741,317 & 751,035 & 760,747 \\
UTILIDAD BRUTA & 683,289 & 922,966 & 934,708 & 946,961 & 959,207 \\
GASTO VENTA & 61,261 & 82,748 & 83,801 & 84,900 & 85,998 \\
GASTO ADMINISTRATIVO & 455,738 & 455,738 & 455,738 & 455,738 & 455,738 \\
Depreciación & 32,503 & 33,936 & 33,936 & 33,936 & 30,486 \\
Amortización & 3,829 & 3,829 & 3,829 & 3,829 & 3,829 \\
UTILIDAD OPERATIVA & 129,958 & 346,714 & 357,404 & 368,558 & 383,156 \\
GASTOS FINANCIEROS & 21,726 & 14,472 & 5,558 & - & \\
UTILIDAD antes de P.T. e I.R. & 108,232 & 332,243 & 351,846 & 368,558 & 383,156 \\
Impuesto a la Renta 29.5\% & 31,928 & 98,012 & 103,795 & 108,725 & 113,031 \\
$\begin{array}{l}\text { UTILIDAD O PERDIDA DEL } \\
\text { EJERCICIO }\end{array}$ & 76,303 & 234,231 & 248,052 & 259,834 & 270,125 \\
$\begin{array}{l}\text { UTILIDAD O PERDIDA } \\
\text { ACUMULADA }\end{array}$ & 76,303 & 310,534 & 558,586 & 818,419 & $1,088,544$ \\
\hline
\end{tabular}




\subsubsection{Estado de Situación Financiera Proyectado.}

En el Estado de Situación Financiera proyectado se presenta deuda corriente y no corriente según el plazo exigible del préstamo entregado por el banco; las compras son pagadas al contado, contra entrega y todo se vende al contado (ver Tabla 69).

Tabla 69

Proyeccion de Situación Financiera

\begin{tabular}{|c|c|c|c|c|c|c|}
\hline \multicolumn{7}{|c|}{ ACTIVO } \\
\hline Estado de Situación en Soles S/. & Año 0 & Año 1 & Año 2 & Año 3 & Año 4 & Año 5 \\
\hline \multicolumn{7}{|l|}{ Activo Corriente } \\
\hline Efectivo y equivalentes efectivo & 39,628 & 157,518 & 387,674 & 625,602 & 920,334 & $1,368,049$ \\
\hline \multicolumn{7}{|l|}{ Cuentas por Cobrar Comerciales } \\
\hline Existencias (Neto) & 30,095 & 30,095 & 30,095 & 30,095 & 30,095 & 30,095 \\
\hline Anticipos - Garantías & 11,550 & 11,550 & 11,550 & 11,550 & 11,550 & 11,550 \\
\hline Crédito tributario & 36,975 & - & - & - & - & - \\
\hline Total Activo Corriente & 118,248 & 199,163 & 429,318 & 667,246 & 961,979 & $1,409,693$ \\
\hline \multicolumn{7}{|l|}{$\underline{\text { Activo no Corriente }}$} \\
\hline \multicolumn{7}{|l|}{ Inversiones Inmobiliarias (Neto) } \\
\hline $\begin{array}{l}\text { Inversiones Activo Fijo (In. Maq. } \\
\text { Eq.) (Neto) }\end{array}$ & 159,067 & 126,564 & 95,493 & 61,557 & 30,486 & - \\
\hline Activos Intangibles & 19,143 & 15,314 & 11,486 & 7,657 & 3,829 & - \\
\hline \multicolumn{7}{|l|}{ Otros activos } \\
\hline Total Activo No Corriente & 178,210 & 141,878 & 106,979 & 69,214 & 34,315 & - \\
\hline TOTAL ACTIVO & 296,457 & 341,041 & 536,297 & 36,460 & 996,294 & $1,409,693$ \\
\hline \multicolumn{7}{|c|}{ PASIVO } \\
\hline Estado de Situación en Soles S/. & Año 0 & Año 1 & Año 2 & Año 3 & Año 4 & Año 5 \\
\hline \multicolumn{7}{|l|}{$\underline{\text { Pasivo Corriente }}$} \\
\hline Obligaciones Financieras & 31,720 & 38,975 & 47,888 & - & & \\
\hline \multicolumn{7}{|l|}{ Cuentas por Pagar Comerciales } \\
\hline Impuestos por Pagar & & 0 & 0 & 0 & 0 & 0 \\
\hline Total pasivo corriente & 31,720 & 38,975 & 47,888 & 0 & 0 & 0 \\
\hline \multicolumn{7}{|l|}{ Pasivo No Corriente } \\
\hline Obligaciones Financieras & 86,863 & 47,888 & - & - & & \\
\hline Total Pasivo no Corriente & 86,863 & 47,888 & 0 & 0 & 0 & 0 \\
\hline TOTAL PASIVO & 118,583 & 86,863 & 47,888 & 0 & 0 & 0 \\
\hline \multicolumn{7}{|c|}{ PATRIMONIO } \\
\hline Estado de Situación en Soles S/. & Año 0 & Año 1 & Año 2 & Año 3 & Año 4 & Año 5 \\
\hline Capital Social & 177,874 & 177,874 & 177,874 & 177,874 & 177,874 & 177,874 \\
\hline \multicolumn{7}{|l|}{ Reservas Legales } \\
\hline Resultados Acumulados & & 0 & 76,303 & 310,534 & 558,586 & 818,419 \\
\hline Resultado del Ejercicio & & 76,303 & 234,231 & 248,052 & 259,834 & 270,125 \\
\hline Total Patrimonio Neto & 177,874 & 254,178 & 488,409 & 736,460 & 996,294 & $1,266,419$ \\
\hline $\begin{array}{l}\text { TOTAL PASIVO + } \\
\text { PATRIMONIO }\end{array}$ & 296,457 & 341,041 & 536,297 & 736,460 & 996,294 & $1,266,419$ \\
\hline
\end{tabular}




\subsubsection{Flujo de Efectivo Proyectado.}

La proyección del flujo de efectivo, permitió planificar, ordenar y controlar la liquidez de La Conversa Bar. La Estimación se realizó por el método directo a partir de los resultados económicos (sin deuda) se obtuvo del Flujo de caja Operativo, flujo de caja económico, se incorporó el flujo de financiamiento y se obtuvo finalmente el Flujo de caja de Accionista (ver Tabla 69).

Tabla 70

Proyección Flujo de Efectivo

\begin{tabular}{|c|c|c|c|c|c|c|}
\hline Flujo de Caja en Soles S/. & Año 0 & Año 1 & Año 2 & Año 3 & Año 4 & Año 5 \\
\hline TOTAL INGRESOS & & $1,445,749$ & $1,952,863$ & $1,977,710$ & $2,003,635$ & $2,029,545$ \\
\hline COSTO VENTA & & 639,469 & 863,763 & 874,754 & 886,222 & 897,682 \\
\hline $\begin{array}{l}\text { GASTO VENTA } \\
\text { GASTO }\end{array}$ & & 72,287 & 97,643 & 98,886 & 100,182 & 101,477 \\
\hline ADMINISTRATIVO & & 464,220 & 464,220 & 464,220 & 464,220 & 464,220 \\
\hline IGV Neto por Pagar & & 66,508 & 142,757 & 144,682 & 146,689 & 148,696 \\
\hline Impuesto a la Renta & & 38,338 & 102,281 & 105,434 & 108,725 & 113,031 \\
\hline TOTAL EGRESOS & - & $1,280,822$ & $1,670,664$ & $1,687,975$ & $1,706,037$ & $1,725,106$ \\
\hline FLUJO OPERATIVO & - & 164,928 & 282,198 & 289,735 & 297,598 & 304,440 \\
\hline Activo Fijo & 187,699 & & 2,866 & - & 2,866 & 56,310 \\
\hline Intangibles & 21,794 & & & & & - \\
\hline Capital de Trabajo & 86,965 & & & & & 86,965 \\
\hline $\begin{array}{l}\text { FLUJO DE CAJA } \\
\text { ECONOMICO }\end{array}$ & $\begin{array}{c}- \\
296,457 \\
\end{array}$ & 164,928 & 279,333 & 289,735 & 294,733 & 447,714 \\
\hline PRESTAMO & 118,583 & & & & & \\
\hline INTERES (-) & & 21,726 & 14,472 & 5,558 & - & - \\
\hline AMORTIZACION (-) & & 31,720 & 38,975 & 47,888 & - & - \\
\hline ESCUDO FISCAL (+) & & 6,409 & 4,269 & 1,640 & - & - \\
\hline FLUJO DE CAJA DEL & & - & - & - & & \\
\hline FINANCIAMIENTO & 118,583 & 47,037 & 49,177 & 51,807 & - & - \\
\hline FLUJO DE CAJA & - & & & & & \\
\hline ACCIONISTA & 177,874 & 117,891 & 230,156 & 237,928 & 294,733 & 447,714 \\
\hline SALDO INICIAL & & - & 117,891 & 348,046 & 585,974 & 880,707 \\
\hline SALDO FINAL & & 117,891 & 348,046 & 585,974 & 880,707 & $1,328,421$ \\
\hline
\end{tabular}




\section{Capítulo X: Evaluación Económico Financiera}

Para determinar si la creación de La Conversa Bar resultó financieramente viable, se emplearon algunos indicadores de rentabilidad, como la tasa interna de retorno (TIR), el valor actual neto (VAN) y la rentabilidad financiera, a fin de demostrar que la elaboración del plan de negocios fue justificado.

De igual modo, se realizó un análisis de riesgo, que incluye la estimación de un estudio del punto de equilibrio y un análisis de sensibilidad de los posibles escenarios que puedan ocurrir a lo largo de la ejecución del proyecto.

\subsection{Evaluación Financiera}

El horizonte del proyecto es de cinco años, para efectos de evaluación financiera se considera liquidación de activos en el 5to. Año.

\subsubsection{TIR.}

La Tasa Interna de Retorno obtenida en el proyecto es de $75 \%$ y la TIRF es de $100 \%$, este resultado es mayor que el Cok y Wacc de $18.25 \%$ y $17.40 \%$ respectivamente, por lo tanto el proyecto se acepta.

\subsubsection{VAN.}

El VAN obtenido por La Conversa Bar es S/ 562,319; el cual es positivo; por lo tanto cumple con la regla de decisión de este indicador, el cual establece que si el VAN es mayor a cero, entonces es rentable para las accionistas invertir en el proyecto.

\begin{tabular}{lr}
\hline TIRE & $75 \%$ \\
VANE & S/ 562,319 \\
TIRF & $100 \%$ \\
VANF & S/. 592,450 \\
\hline
\end{tabular}

\subsubsection{ROE.}

La rentabilidad sobre el patrimonio es de $30 \%$ en el año 1 y $21 \%$ en el año 5 y se puede visualizar en el cuadro a continuación (Ver Tabla 70): 
Tabla 71

ROE del Proyecto

\begin{tabular}{lrrrrrr}
\hline RATIOS DE RENTABILIDAD & Año 0 & \multicolumn{1}{c}{ Año 1 } & \multicolumn{1}{c}{ Año 2 } & \multicolumn{1}{c}{ Año 3 } & \multicolumn{1}{c}{ Año 4 } & Año 5 \\
\hline ROE & & 0.30 & 0.48 & 0.34 & 0.26 & 0.21 \\
ROA & & 0.22 & 0.44 & 0.34 & 0.26 & 0.19 \\
Utilidad Activo & & 0.38 & 0.65 & 0.49 & 0.37 & 0.27 \\
Utilidad Ventas & & 0.11 & 0.21 & 0.21 & 0.22 & 0.22 \\
\hline
\end{tabular}

\subsubsection{Ratios}

Se presentan Ratios de Liquidez, Gestión y Solvencia, los cuales demuestran el buen desempeño de proyecto (Ver Tabla 72).

Tabla 72

Ratios del Proyecto

\begin{tabular}{lrrrrrr}
\hline RATIOS DE LIQUIDEZ & \multicolumn{1}{c}{ Año 0 } & \multicolumn{1}{c}{ Año 1 } & Año 2 & Año 3 & Año 4 & Año 5 \\
\hline Razón Corriente & 3.73 & 5.11 & 8.96 & N/A & N/A & N/A \\
Prueba Ácida & 2.78 & 4.34 & 8.34 & N/A & N/A & N/A \\
Razón de Efectivo & 1.25 & 4.04 & 8.10 & N/A & N/A & N/A \\
Capital de Trabajo & 86,528 & 160,188 & 381,430 & 667,246 & 961,979 & $1,409,693$ \\
\hline
\end{tabular}

\begin{tabular}{|c|c|c|c|c|c|c|}
\hline RATIOS DE GESTIÓN & Año 0 & Año 1 & Año 2 & Año 3 & Año 4 & Año 5 \\
\hline Rotación Caja y Bancos & & 46 & 84 & 134 & 195 & 286 \\
\hline Rotación Activos Totales & & 3.59 & 3.09 & 2.28 & 1.70 & 1.22 \\
\hline Rotación Activo Fijo & & 8.64 & 15.47 & 24.22 & 49.48 & N/A \\
\hline
\end{tabular}

\begin{tabular}{lcccccc}
\hline RATIOS DE SOLVENCIA & Año 0 & Año 1 & Año 2 & Año 3 & Año 4 & Año 5 \\
\hline Estructura de Capital & 0.67 & 0.34 & 0.10 & - & - & - \\
Endeudamiento & 0.40 & 0.25 & 0.09 & - & - & - \\
Cobertura de Gastos Financieros & & 5.98 & 23.96 & 64.30 & - & - \\
\hline
\end{tabular}

\section{Periodo de Recuperación}

Considerando los flujos descontados se obtiene un periodo de recuperación de la inversión de 1.79 años y 1.46 años para los Flujos económicos y financieros respectivamente.

\begin{tabular}{ll}
\hline PRIE & 1.47 \\
PRIE & 1.79 \\
PRIF & 1.26 \\
PRIF & 1.46 \\
\hline
\end{tabular}




\section{Índice Beneficio Costo}

El índice costo beneficio es mayor que 1 tanto para los flujo económicos como para los flujos financieros, 1.11 en ambos casos.

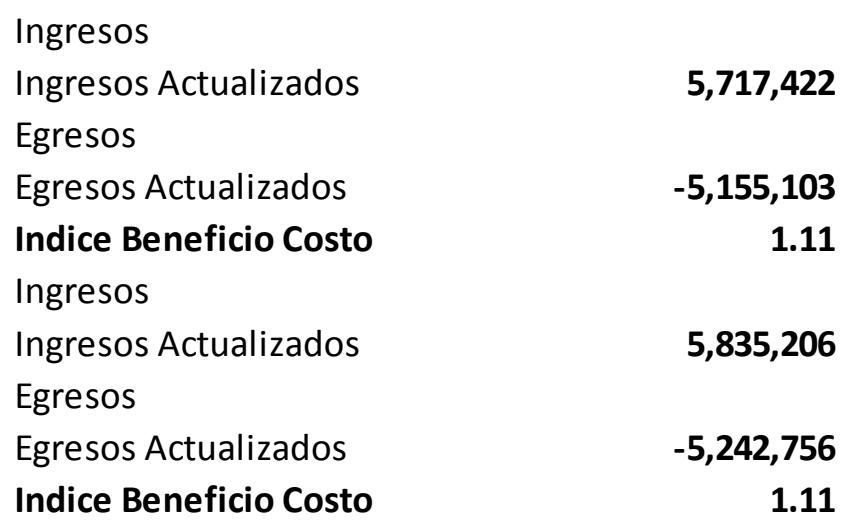

\subsection{Análisis de Riesgos}

\subsubsection{Análisis del punto de Equilibrio.}

Se determinó las unidades requeridas para obtener una utilidad cero por el método contable con la siguiente información:

$\begin{array}{lr}\text { Precio } & \mathbf{1 2 . 7 1} \\ \text { Costo } & 5.62 \\ 5 \% \text { Gasto de Ventas } & 0.64 \\ \text { Costo Variable Unitario } & 6.26 \\ \text { Costos Fijos } & \mathbf{4 9 2 , 0 7 0} \\ \text { Precio Menos Costo Variable } & 6.45\end{array}$

Aplicando la fórmula:

$(\mathrm{P} \times \mathrm{U})-(\mathrm{Cvu} \times \mathrm{U})-\mathrm{CF}=0$

Se obtuvo 76,237 unidades requeridas

\subsubsection{Análisis de Sensibilidad.}

Se realizó un Análisis de sensibilidad unidimensional para los siguientes Precios, lo cual concluimos que el precio podría disminuir desde S/ 15.0 hasta S/12.5 y generar VAN Negativo (ver Tabla 73). 
Tabla 73

Análisis de Sensibilidad Unidimensional

\begin{tabular}{cccccccc}
\hline \multicolumn{7}{c}{ Precio } \\
\hline VANE & 562,320 & 12.50 & 14.00 & 15.00 & 16.00 & 17.50 & 20.00 \\
Costo & 6.64 & S/. $-233,580$ & S/. 243,625 & S/. 562,320 & S/. 879,897 & S/. $1,357,102$ & $2,152,443$ \\
\hline
\end{tabular}

Asimismo se realizó un Análisis de sensibilidad bidimensional para las siguientes combinaciones de Precios y Costos, donde se observa adicionalmente que el costo podría subir de S/6.64 por encima de S/8.00 y generar VAN Negativo (ver Tabla $74)$.

Tabla 74

Análisis de Sensibilidad Bidimensional

\begin{tabular}{|c|c|c|c|c|c|c|c|}
\hline & & & & Precio & & & \\
\hline VANE & S/. 562,320 & 12.50 & 14.00 & 15.00 & 16.00 & 17.50 & 20.00 \\
\hline \multirow{5}{*}{ Costo } & 5.50 & S/. 199,134 & S/. 676,339 & S/. 995,034 & $\begin{array}{c}\mathrm{S} / . \\
1,312,611 \\
\mathrm{~S} / .\end{array}$ & $\begin{array}{c}\mathrm{S} / . \\
1,789,816 \\
\mathrm{~S} / .\end{array}$ & S/. 2,585,156 \\
\hline & 6.30 & S/. $-105,759$ & S/. 371,445 & S/. 690,140 & $1,007,718$ & $\begin{array}{c}1,484,922 \\
\text { S/. }\end{array}$ & S/. 2,280,263 \\
\hline & 6.64 & S/. $-233,580$ & S/. 243,625 & S/. 562,320 & S/. 879,897 & $\begin{array}{c}1,357,102 \\
\text { S/. }\end{array}$ & S/. 2,152,443 \\
\hline & 7.00 & S/. $-372,541$ & S/. 104,663 & S/. 423,358 & S/. 740,936 & $\begin{array}{c}1,218,140 \\
\text { S/. }\end{array}$ & S/. 2,013,481 \\
\hline & 8.00 & $\begin{array}{c}\text { S/. - } 753,658 \\
\text { S/. - }\end{array}$ & S/. $-276,453$ & S/. 42,242 & S/. 359,819 & $\begin{array}{c}837,024 \\
\text { S/. }\end{array}$ & S/. 1,632,364 \\
\hline
\end{tabular}

Adicionalmente, se aplicaron los siguientes métodos para considerar el riesgo del proyecto:

\section{-Incrementar la Tasa de Descuento}

Se simularon incrementos en la tasa de descuento hasta incluso aplicar la TIR de $75 \%$ y TIRF de $100 \%$ hasta obtener VAN igual a cero, es decir que se puede tener incremento de tasas hasta 4.1 veces y 5.7 veces respectivamente. 


\section{-Castigar el Flujo de Fondos}

Se realizó la simulación de disminuciones en los flujos finales obtenidos en el proyecto y estos pueden disminuir hasta $65 \%$ y $77 \%$ obteniendo el VAN igual a cero para los Flujos económicos y financieros respectivamente (Ver Tabla 75).

\subsubsection{Análisis de Escenarios.}

Se crearon los siguientes escenarios Optimista, Pesimista y Normal y se muestran como resultados VANE, TIRE y B/C (ver Tabla 75).

Tabla 75

Escenarios Evaluados

\begin{tabular}{lccc}
\hline & Optimista & Pesimista & Normal \\
\hline Precio & 16.00 & 14.00 & 15.00 \\
Costo & 6.30 & 7.00 & 6.64 \\
Unidades (1er. Año) & 100,000 & 90,000 & 96,372 \\
\hline
\end{tabular}

Utilizando la herramienta Administrador de Escenarios se obtuvieron los siguientes resultados mostrados en la siguiente tabla (ver Tabla 76):

Tabla 76

VANe, TIRe y BCe de los Escenarios

\begin{tabular}{lccc}
\hline \multicolumn{4}{c}{ Resumen de escenario } \\
\hline & Valores actuales: & Optimista & Pesimista \\
\hline Celdas cambiantes: & \multicolumn{3}{c}{} \\
\hline Precio & 15.00 & 16.00 & 14.00 \\
Costo & 6.64 & 6.30 & 7.00 \\
Venta & 96,372 & 100,000 & 90,000 \\
\hline Celdas de resultado: & & & \\
\hline VANe & S/. 562,320 & S/. 1,108,953 & S/. - 13,431 \\
TIRe & $75 \%$ & $127 \%$ & $17 \%$ \\
BCe & 1.11 & 1.21 & 1.00 \\
\hline
\end{tabular}




\section{Capitulo XI: Conclusiones y Recomendaciones}

\subsection{Conclusiones}

Para el presente Plan de Negocios La Conversa Bar se concluye lo siguiente:

1. El análisis de factores externos muestra un escenario propicio para la propuesta y, asimismo, el estudio de mercado realizado, de manera cualitativa y cuantitativa, ha demostrado que los criterios de segmentación elegidos permiten aplicar las estrategias de marketing considerada para alcanzar de exitosamente la propuesta de valor planteada para el mercado objetivo identificado.

2. Teniendo a la diferenciación como principal estrategia planteada, se establece como una prioridad lograr el rápido posicionamiento del servicio y tipo de productos a ofrecer.

3. La decisión de localización del estudio ha pasado por integrar a todas las variables influyentes para la actividad a realizar, de tal forma que sea una decisión a largo plazo, siendo el distrito óptimo Barranco.

4. La evaluación financiera ha brindado información respecto a que la inversión a realizar se pueda dar en un escenario de certeza y seguridad, al haberse considerado las variables que conforman de manera positiva los resultados de operación y los flujos de efectivo.

5. El resultado de los indicadores financieros muestra lo atractivo del negocio para los inversionistas, específicamente en términos de rentabilidad relacionado con el retorno de la inversión y en base una eficiente utilización de los recursos financieros.

\subsection{Recomendaciones}

Para el presente Plan de Negocios La Conversa Bar se recomienda lo siguiente:

1. Debido a la factibilidad comercial, técnica, legal, y económica - financiera; se recomienda llevar a la fase de ejecución el presente Plan de Negocios.

2. El posicionamiento de la marca relacionado como una alternativa diferente de encuentro, debería de ser considerado como principal factor crítico de éxito para la empresa.

3. El factor de diferenciación basado, no solo en los productos a ofrecer, sino también en la calidad de atención al cliente, debería ser otro criterio a considerar de acuerdo a los beneficios esperados por el mercado objetivo identificado. 
4. Al haberse identificado la ambientación (infraestructura, equipos, mobiliario) como elementos valorados por el público asistente, es que se recomienda la inversión en la adquisición de los mismos, tenga la mayor calidad.

5. Asimismo, que la contratación del capital humano, cumpla con las exigencias, requisitos, y filtros planteados en el plan desarrollado. Esto debido a lo sensible y determinante que es este factor.

6. Siendo el control empresarial, en el aspecto comercial y de gestión, una actividad importante para el buen posicionamiento y funcionamiento, respectivamente, se debería de incursionar en el mundo de transformación digital como soporte para el logro de objetivos. 


\section{Referencias}

Ahora - Perú (2018). Misión y Objetivos. Recuperado de http://www.ahoraperu.com/mision/

Alegría, L. (2018, Marzo 24). BCR: El crecimiento potencial del PBI se redujo de 4\% a 3,5\%. Diario El Comercio. Recuperado de https://elcomercio.pe/economia/bcrcrecimiento-potencial-pbi-redujo-4-3-5-noticia-506910

Alegría, L. (2018, Abril 05). MEF: ¿Qué piensa hacer David Tuesta para crecer 5\% al 2021? Diario El Comercio. Recuperado de https://elcomercio.pe/economia/peru/mef-sera-estrategia-david-tuesta-crecerpbi-5-2021-noticia-509734

Asociación Peruana de Empresas de Investigación de Mercado. (2017, Agosto). Niveles Socioeconómicos. Lima, Perú.

Arbaiza Lydia. (2015). Como elaborar un Plan de Negocio. Lima, Perú: Editorial Universidad Esan.

Asesoría Asesoramiento en Planes de Negocio. (2016, Agosto). Ejemplo de mercado potencial, disponible, efectivo y meta. Recuperado de http://www.plandenegociosperu.com/2016/08/ejemplo-mercado-potencialdisponible-efectivo.html

Asociación Pro Bienestar y Desarrollo. (2008). Manual de Emprendedores. Lima, Perú: Editorial USIL .Recuperado de https://www.probideperu.org/

Aumentan los bares que promueven el consumo de bebidas sin alcohol. (Marzo de 2018). Televisa News. Recuperado de https://noticieros.televisa.com/historia/estados/2018-03-08/bares-antros-saltillopromueven-consumo-bebidas-alcohol/

Baca, G. (2013). Evaluación de Proyectos. México: Ediciones Mc Graw-Hill.

BBVA Research. (25 de enero de 2018) PBI 2018: Los riesgos que empujan a la baja los estimados. Mercado y Regiones. Recuperado de http://mercadosyregiones.com/?s=pbi+2018

Bares con sabores e historias de antaño. (junio de 2004). Diario La República.

Recuperado de http://larepublica.pe/sociedad/362044-bares-con-sabores-ehistorias-de-antano

Barranco: Lanzan campaña para prevenir accidentes por manejar en estado de ebriedad. (16 de julio de 2017). Diario Perú 21. Recuperado de 
dehttps://peru21.pe/lima/barranco-lanzan-campana-prevenir-accidentes-manejarebriedad-fotos- 88325

Bonta, P., \& Farber, M. (2003). Preguntas sobre Marketing y Publicidad (p.30). Bogotá, Colombia: Editorial Norma.

Cámara de Comercio de Lima. (Mayo de 2017). En Perú existen 220 mil establecimientos dedicados al expendio de alimentos y bebidas. Andina. Recuperad de http://andina.pe/agencia/noticia.aspx?id=233203

Castañeda, L. (2005). La Calidad la hacemos todos.2005. Ediciones Poder. México.

Centro Nacional de Estimación, Prevención y Reducción del Riesgo de Desastres. (2009). Norma A.130 Requisitos de seguridad. Recuperado de http://www.vivienda.gob.pe/documentos/documentos_ds_010/4/Norma_A.130_ Requisitos_de_Seguridad.pdf

Centro Nacional de Planeamiento Estratégico. (2016). Ceplan entrega avances de Política Sectorial a gobernadores regionales. Recuperado de https://www.ceplan.gob.pe/documentos_/ceplan-entrega-avances-de-politicasectorial-a-gobernadores-regionales/

Chiappe, M. (Febrero de 2013). Conoce las tendencias de moda en coctelería. Diario El Comercio. Recuperado de http://archivo.elcomercio.pe/gastronomia/bares-ycopas/conoce-tendencias-moda-cocteleria-noticia-1543509.

Comisión Nacional para el Desarrollo y Vida sin Drogas. (02 de marzo de 2005). Alcoholismo en Lima aumentó en 164\% en los últimos 4 años. RPP Noticias. Recuperado de http://rpp.pe/lima/actualidad/alcoholismo-en-lima-aumento-en164-en-los-ultimos-4-anos-noticia-774133

Compañía Peruana de Estudios de Mercado y Opinión Pública S.A.C. (CPI) (17 de Agosto de 2017). Market Report. Perú: Población 2017. Lima, Perú.

Cortez, R. (2016, Julio 10). ¿Por qué los adolescentes quieren consumir alcohol? RPP Noticias, Espacio Saludable. Recuperado de http://vital.rpp.pe/salud/por-quelos-adolescentes-quieren-consumir-alcohol-noticia-815920

Cuáles son los Regímenes Tributarios según Sunat. (2018, Abril 06). Diario Gestión. Recuperado de https://gestion.pe/tu-dinero/son-regimenes-tributarios-230871

Cuartas, V. \& Escobar, H. (2006). Diccionario económico financiero, Universidad de Medellín. 
D’Alessio, F. (2013). El Proceso Estratégico: Un Enfoque de Gerencia. Lima, Perú: Ediciones Pearson.

David, F. R. (2008). Conceptos de Administración Estratégica. Edic. Pearson Educación de México. México

Díaz, A. (2015, diciembre). Se lanza curso intensivo sobre las nuevas tendencias de bar en el Perú y el mundo. Orbita Agencias de Noticias. Recuperado de https://agenciaorbita.org/se-lanza-curso-intensivo-sobre-las-nuevas-tendenciasde-bar-en-el-peru-y-el-mundo/

Díaz, M. (2016, Febrero 23). Cómo hacer uso de la tecnología en la gestión de PYMES. Diario Perú 21. Recuperado de https://peru21.pe/mis-finanzas/tecnologiagestion-pymes-211483

Drucker, P. (2002). El Management, Escritos Fundamentales. Buenos Aires, Argentina: Editorial Sudamericana,

Durand, J. (2018, Enero 23). Perú Económico en el 2018. Análisis de la economía peruana a enero de 2018. La cátedra del consumidor. Recuperado de http://blog.pucp.edu.pe/blog/competenciayconsumidor/2018/01/23/perueconomico-en-el-2018-analisis-de-la-economia-peruana-a-enero-de-2018/

Economía peruana: ¿Qué nos espera en el 2018? (01 de Enero de 2018). Diario El Comercio. Recuperado de https://elcomercio.pe/economia/peru/economiaperuana-espera-2018-noticia-485553

Empresas deberán informar a sus trabajadores sobre su política salarial desde este año. (Marzo 08 de 2018). Diario Gestión. Recuperado de: https://gestion.pe/economia/management-empleo/empresas-deberan-informartrabajadores-politica-salarial-ano-228905

Escalante, E. (2016, Setiembre 24). Reglamento Sanitario de Funcionamiento de Restaurantes y Servicios Afines (DIGESA/MINSA). Recuperado de https://mep.pe/reglamento-sanitario-de-funcionamiento-de-restaurantes-yservicios-afines-digesaminsa-3/

Franco, P. (2013). Planes de Negocio: Una Metodología Alternativa. Apuntes de Estudio 34. Universidad Pacifico. Lima, Perú.

Gerencia. (Enero de 2012). El ABC de la tecnología en las Pymes. Recuperado de http://www.emb.cl/gerencia/articulo.mvc?xid=457\&sec=7 
Gonzales, L. (05 de enero de 2018). Conoce las Características y Beneficios Recogidos en la Ley MYPE. Asesor Contable. Recuperado de http://asesorcontable.pe/conoce-las-caracteristicas-y-beneficios-recogidos-en-laley-mype/

Gomero (20 de junio de 2018). Entrevista a experto $\mathrm{N}^{\circ}$ 3: Socio Fundador Bar Victoria. Incentivos laboral y tributario son insumos del plan de formalización. (30 de julio de 2016). Diario La República. Recuperado de http://larepublica.pe/politica/959755-incentivos-laboral-y-tributario-soninsumos-del-plan-de-formalizacion

Instituto Nacional de Estadística. (2008, Febrero). Demografía Empresarial en el Perú. Informe Técnico. Recuperado de https://www.inei.gob.pe/media/MenuRecursivo/boletines/01-informe-tecnico-n01-demografia-empresarial-iv-trim2017_feb2018.pdf

Instituto Nacional de Estadística. (2018 Febrero). Negocios de restaurantes crecieron 2,10\% en enero de este año y acumuló 10 meses de crecimiento continuo. Recuperado de https://www.inei.gob.pe/prensa/noticias/negocios-derestaurantes-crecieron-210-en-enero-de-este-ano-y-acumulo-10-meses-decrecimiento-continuo-10660/

Instituto Nacional de Estadística. (2018 Febrero). Negocios de restaurantes (servicios de comidas y bebidas) crecieron 1,94\% en diciembre de 2017. Recuperado de https://www.inei.gob.pe/prensa/noticias/negocios-de-restaurantes-servicios-decomidas-y-bebidas-crecieron-194-en-diciembre-de-2017-10601/

Instituto Nacional de Estadística. (2018, Febrero 01). Inflación se reduce por quinto mes consecutivo. Mercado y Regiones. Recuperado de http://mercadosyregiones.com/2018/02/inflacion-se-reduce-por-quinto-mesconsecutivo/

Instituto Nacional de Estadística. (2018, Febrero 15). Economía peruana crece 1.32\% en diciembre y cierra el 2017 con avance de 2.50\%. Diario Gestión. Recuperado de https://gestion.pe/economia/economia-peruana-crece-1-32-diciembre-cierra2017-avance-2-50-227342

Instituto Nacional de Estadística. (2018, Febrero). Biblioteca Virtual. Recuperado de https://www.inei.gob.pe/biblioteca-virtual/boletines/encuesta-mensual-delsector-servicios-8536/1/ 
Instituto Nacional de Estadística [INEI]. (2018, Marzo). Producción Nacional.

Recuperado de https://www.inei.gob.pe/media/principales_indicadores/03informe-tecnico-n03_produccion-nacional-ene2018.pdf

Instituto Nacional de Estadística [INEI]. Producción Nacional. Informe Técnico No.03. (2018, Marzo). Recuperado de https://www.inei.gob.pe/media/principales_indicadores/03-informe-tecnicon03_produccion-nacional-ene2018.pdf

Ipsos Perú. (28 de junio de 2014). El 59\% de adultos jóvenes de Lima gasta en salir a comer los fines de semana. Diario Gestión. Recuperado de https://gestion.pe/tendencias/59-adultos-jovenes-lima-gasta-salir-comer-finessemana-64188

Kotler, P., \& Armstrong, G. (2012). Marketing. México DF, México: Editorial Pearson Educación.

Kotler, P., \& Armstrong, G. (2013). Fundamentos de Marketing. México DF, México: Editorial Pearson.

Ley N ${ }^{\circ}$ 28611. Ley General del Ambiente. Ministerio del Ambiente, Lima, Perú, 2005. Recuperado de http://www.minam.gob.pe/wp-content/uploads/2013/06/leygeneral-del-ambiente.pdf

Lima fue la ciudad de Latinoamérica más visitada. (2015, Diciembre 29). Diario Gestión. Recuperado de https://gestion.pe/economia/lima-ciudad-latinoamericavisitada-2015-107943

Longenecker, J. G. (2007). Administración de pequeñas empresas - Enfoque emprendedor. México D.F., México: Editorial Cengage Learning.

Lovelock, C., \& Wirtz, J. (2015). Marketing de Servicios - Personal, Tecnología, y Estrategia. México D.F., México: Ediciones Pearson.

Maestre, L. (2016, Julio 10). ¿Por qué los adolescentes quieren consumir alcohol? Espacio Saludable. RPP Noticias. Recuperado de http://vital.rpp.pe/salud/porqu http://www.minam.gob.pe/wp-content/uploads/2013/06/ley-general-delambiente.pdf e-los-adolescentes-quieren-consumir-alcohol-noticia-815920

Martínez, D., \& Milla, A. (2005). La elaboración del plan estratégico y su implantación a través del cuadro de mando integral. Madrid, España: Editorial Díaz de Santos. 
McDaniel, C., \& Gates, R., (2011). Investigación de Mercados. 8va Edición. México D.F., México: Cengage Learning.

Mi Empresa Propia - Escuela de Emprendedores. (Setiembre de 2016). Marco Legal e Institucional para las Micro y Pequeñas Empresas en el Perú. Recuperado de https://mep.pe/marco-legal-e-institucional-para-las-micro-y-pequenas-empresasen-el-peru/

Microsoft. (30de octubre de 2014). Una pyme con tecnología incrementa sus ganancias y crea empleos más rápido. Diario Gestión. Recuperado de https://gestion.pe/economia/pyme-tecnologia-incrementa-ganancias-creaempleos-rapido-79457

Ministerio de Comercio Exterior y Turismo. (2004). Reglamento de Restaurantes DS 009-2017 MINCETUR. Recuperado de https://www.mincetur.gob.pe/wpcontent/uploads/documentos/turismo/funciones_y_normatividad/normatividad/p restadores_servicios_turisticos/REGLRESTAURANT_2004.pdf

Ministerio de Comercio Exterior y Turismo (2004). Reglamento de Restaurantes Decreto Supremo $N^{a}$ 025-2004-Mincetur. Recuperado de https://www.mincetur.gob.pe/wpcontent/uploads/documentos/turismo/funciones_y_normatividad/normatividad/p restadores_servicios_turisticos/REGLRESTAURANT_2004.pdf

Ministerio de Trabajo y Promoción del Empleo. (2018). Guía de la Formalización. Formaliza Perú. Recuperado de http://wapaperu.mpdl.org/descargas/Guia_Constitucion_empresas.pdf

Ministerio de Transportes y Comunicaciones. (2017, Setiembre). Consejo Nacional de Seguridad Vial. Plan Estratégico Nacional de Seguridad vial Pensv 2017-2021. Recuperado de https://www.mtc.gob.pe/cnsv/documentos/PENsv_20172021.pdf

Municipalidad de Barranco. (Febrero, 2012). Ordenanza 358-MDB. Formalización de Recicladores y la Recolección Selectiva de Residuos Sólidos. Recuperado de http://www.munibarranco.gob.pe/jdownloads/Ordenanzas/Ordenanzas\%202011/ ORD-358.pdf

Municipalidad de Barranco. (Febrero, 2012). Ordenanza 362 - MDB. Aprueban Ordenanza para la Prevención y Control de Ruidos en el distrito de Barranco y su Reglamento. Diario El Peruano. Recuperado de 
http://busquedas.elperuano.pe/normaslegales/aprueban-ordenanza-para-laprevencion-y-control-de-ruidos-en-ordenanza-n-362-mdb-749493-1/

Municipalidad Distrital de Barranco. (2013). Ordenanza 387 - MDB. Recuperado de http://www.munibarranco.gob.pe/pdf/funcionamiento/LEGISLACION/ORD387.pdf

Perú: 9 de cada 10 personas conectadas a internet tiene un Smartphone. (26 de Octubre de 2016). Diario Gestión. Recuperado de https://gestion.pe/tecnologia/peru-910-personas-conectadas-internet-smartphone-148400

Pensato, B. (2011). El Origen de los bares. El Bartender. Recuperado de https://www.elbartender.com/el-origen-de-los-bares/

Polastri, G. (2017). Crece con aplicaciones móviles para tu negocio. CEPEFODES Centro de Negocios. Recuperado de https://cepefodes.org.pe/blog/crece-conaplicaciones-moviles-para-tu-negocio/

Ponce, H. (2007). La Matriz Foda: Alternativa De Diagnóstico Y Determinación De Estrategias De Intervención En Diversas Organizaciones. Consejo Nacional para la Enseñanza en Investigación en Psicología A.C. México. Recuperado de http://www.redalyc.org/pdf/292/29212108.pdf

Porter, M. (2009): Ser Competitivo. Barcelona, España: Barcelona Editorial Deusto. Proinversión. (2007). Mi pequeña empresa crece. Agencia de promoción privada. ESAN. Recuperado de ttp://www.uss.edu.pe/uss/eventos/JovEmp/pdf/Mype.pdf

Real Academia de la Lengua Española (RAE). (2014). Significado de la palabra bar. Recuperado de http://dle.rae.es/?id=509Y6Lw|509uDjx

Revista Mercado Negro. (25 de mayo de 2018). Digital Signage: El futuro de las tiendas. Recuperado de: http://www.mercadonegro.pe/digital-signage-el-futurode-las-tiendas/

Riquelme, M. (2017). La matriz del Perfil Competitivo. Recuperado de https://www.webyempresas.com/la-matriz-del-perfil-competitivo/

Sapag, N. (2014). Preparación y evaluación de proyectos. México: Editorial McGrawHill Interamericana.

Schawalb, I. (2016). La cerveza peruana que pasó del garaje al bar propio. Diario El Comercio. Recuperado de https://elcomercio.pe/economia/negocios/barbariancerveza-peruana-paso-garaje-bar-propio-261971 
Schawalb, I. (15 de abril de 2018). Entrevista Experto 1: Gerente General Cervecería y Bar Barbarian.

Servicios Globales de Marketing. (24 de marzo de 2016). El marketing mix de servicios: las 7 p's. Madrid, España. Recuperado de https://www.marketingsgm.es/marketing-mix-servicios-las-7-ps/

Sotomayor, K. (26 de julio de 2017). Fiestas Patrias: ¡Disfruta tu feriado largo pero sin excesos con el alcohol! Diario Trome. Recuperado de https://trome.pe/actualidad/fiestas-patrias-alcohol-consumo-peligro-feriado57354

Superintendencia de Administración Tributaría. (Febrero de 2016). Ingresos Tributarios del Gobierno Central. Recuperado de http://www.sunat.gob.pe/estadisticasestudios/index.html

Te presentamos 3 de las barras más innovadoras de Lima. (Diciembre de 2017). Diario El Comercio. Recuperado de https://elcomercio.pe/especial/diageo/noticias/tepresentamos-tres-barras-mas-innovadoras-lima-noticia-1992893

Vayá, M. (18 de marzo 2018). Las principales tendencias del marketing de contenidos en 2018. Recuperado de: http://www.mercadonegro.pe/las-principalestendencias-del-marketing-de-contenidos-en-2018/

Verdezoto, E. (16 de mayo de 2016). 12 Estrategias para mejorar el servicio en un bar. Recuperado de: https://es.linkedin.com/pulse/12-estrategias-para-mejorar-elservicio-en-un-bar-michuy-verdezoto

Villajuana, C. (2003). Gestión estratégica integral. Lima, Perú: Editorial Villajuana Consultores SAC.

Von Ehren, A. (10 de mayo de 2018). Entrevista Experto 2: Gerente General Bar Ayahuasca.

Weinberger, K. (2009). Estrategia. Lima, Perú: USAID Perú MYPE Competitiva. Weinberger, K. (2009). Plan de Negocios. Lima, Perú: Proyecto USAID/Perú/Mype Competitiva.

4 estrategias de Marketing Móvil para Pymes. (2015). Destino Negocio - Marketing Digital. Recuperado de http://destinonegocio.com/pe/negocio-por-internet-pepe/marketing-digital-pe/estrategias|-marketing-movil-pyme/ 


\section{Apéndice}

\section{Apéndice 1: Ficha de Reclutamiento}

\section{Presentación:}

Somos alumnos de la Escuela de Posgrado de la USIL, estamos organizando un Focus Group como parte de nuestro trabajo académico para graduarnos, por ello solicitamos su participación, y antes de iniciar la reunión le haremos unas preguntas de interés sólo para nosotros.

Agradecemos que haya venido y le invitamos a compartir una tarde agradable.

\section{Filtro \#1: Aspectos Comportamentales}

1. ¿Acostumbra a salir de casa para divertirse o entretenerse semanalmente?

$\mathrm{Si}$

No (Terminar)

2. ¿Prefiere establecimientos donde pueda interactuar socialmente?

$\mathrm{Si}$

No (Terminar)

3. ¿Cuál es el principal motivo que lo impulsa a realizarlo?
a. Celebraciones
b. Cumpleaños
c. Festejos
d. Feriados y/o días no laborables
e. Aniversarios
f. Solo por diversión
g. Otro (Especificar)

4. ¿Acostumbra a ir adonde?
a) Café'
b) Restaurante
c) Discoteca
d) Peña
e) Hoteles (lounge)
f) Bares 
g) Otro (Especificar)

5. ¿Con qué frecuencia asiste a estos establecimientos?

a. Todas las semanas

b. Cada 15 dias

c. 1 vez al mes

d. Muy rara vez

6. ¿Cuándo puede decir que el lugar es apropiado para divertirse o entretenerse?

a. Cuando tiene música

b. Cuando tiene música y baile

c. Cuando se expende bebidas alcohólicas

d. Cuando tiene ambiente para una buena conversación

e. Cuando tiene shows o stand-up comedy

f. Cuando tiene buena música y buen ambiente para conversar

g. Otra (Especificar)

7. ¿En caso de encontrar el lugar adecuado, el precio es un factor relevante?

a. Sí No

\section{Filtro \#2: NIVEL SOCIOECONOMICO}

1. Nivel de ingreso promedio familiar mensual (Nuevos Soles)
a) Más de S/. 7,000.00
b) Entre S/. 6,001.00 - S/. 7,000.00
c) Entre S/. 5,001.00-S/. 6,000.00
d) Entre S/. 3,001.00 - S/. 5,000.00
e) Entre S/. 0,00-S/. 3,000.00 (Terminar)

2. Grado de instrucción alcanzado por el jefe del hogar.
a) Ninguna (TERMINAR)
b) Primaria (TERMINAR)
c) Secundaria
d) Superior técnica 

e) Universidad
f) Estudios de postgrado

3. Distrito de residencia

4. ¿Cuántos cuartos de baño de uso exclusivo tiene en su hogar?
a) No tiene (Terminar)
b) Tiene 1 cuarto
c) Tiene 2 cuartos
d) Tiene 3 cuartos a más.

5. ¿Cuenta en su hogar con servicio de internet?

$\mathrm{Si}$, permanentemente

$\mathrm{Si}$, eventualmente

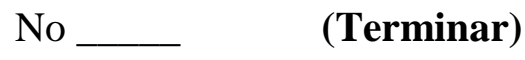

6. ¿Cuál es la ocupación del jefe del hogar?

7. ¿Con cuántos vehículos cuenta su hogar?
a) No tiene vehículo exclusivo para el hogar
b) Tiene 1 vehículo
c) Tiene 2 vehículos
d) Tiene 3 vehículos o más

Marca:

Año:

8. ¿La vivienda que ocupa este Hogar es:
a) Propia y totalmente pagada
b) Propia y la está pagando
c) Propia (regalada, donada, heredada por posesión)
d) Arrendada

9. ¿Cuántos dormitorios tiene su vivienda?

10. ¿Se ha ido de viaje al exterior por placer en el último año? SI NO 
DATOS DE CONTROL

Nombre del Entrevistado:

Dirección:

Distrito:

Ocupación:

Teléfono fijo:

Teléfono celular:

Edad:

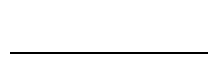




\section{Apéndice 2: Guía de Indagación o Guía de preguntas para el Focus Group}

\section{Introducción}

Saludo y Presentación

Muy buenos días/tardes/noches, somos un grupo de estudiantes de la Maestría de la USIL que estamos realizando una investigación de mercados con el objetivo de conocer sus gustos y preferencias de diversión y/o entretenimiento social. Por tal motivo, el día de hoy nos encontramos reunidos en esta sala con el fin de conversar con Uds. acerca de la creación de un establecimiento de servicios de bebidas. Le pedimos de su tiempo para conversar acerca de este tema tan importante y por favor siéntanse con libertad de dar su opinión sin ninguna restricción, ya que todo lo que Uds. nos digan servirá como información en la elaboración de la tesis. No hay respuestas buenas ni malas solo buscamos sus respuestas. Les damos las gracias por su participación.

Reglas de Juego: Relajarse, No tema estar en desacuerdo, Grabación y audio.

Calentamiento: Breve presentación de las participantes.

\section{Descripción del proceso de compra (10 minutos)}

- ¿En qué momento decide salir a divertirse?

- Cuando sale a divertirse o a entretenerse ¿De qué depende la elección del establecimiento a acudir?

- ¿En qué medios busca información de lugares para entretenerse?

- ¿Sale en pareja, en grupos o sólo?

- ¿Quién toma la decisión de definir el lugar a asistir?

- ¿Con qué frecuencia acude al establecimiento elegido? ¿Por qué?

- ¿A cuánto asciende el consumo por persona aproximadamente?

- ¿Qué tipo de promociones ayudarían en la toma de sus decisiones?

\section{Hábitos de consumo ( 7 minutos)}

- En los establecimientos que asiste ¿qué tipo de bebidas consume, mayormente? 
- Las veces en que no consume este tipo de bebidas, ¿con qué otro tipo lo reemplaza?

- ¿En qué ocasiones ha prescindido de tomar bebidas alcohólicas en su establecimiento preferido?

- ¿Qué opina de los tragos vírgenes o cockteles sin alcohol?

- ¿Conoce o ha consumido cerveza sin alcohol, qué opina?

3. Evaluación de la competencia (5 minutos)

- ¿Qué bares conoce?

- ¿Qué bares consideran que son las mejores? ¿Porque?

- ¿Qué ventajas le ofrece estos bares? ¿Por qué?

- ¿Qué desventajas tienen?

\section{Presentación de la propuesta, producto o marca de estudio específicamente (10} minutos)

- ¿Qué opina si existiera un local (Bar) donde se expenda cocteles y tragos sin alcohol con la misma ambientación de un bar tradicional?

- ¿Qué opina sobre el nombre "LA CONVERSA BAR"?

- En caso de que los productos sin alcohol sean idénticos a los que contienen alcohol. ¿Cuánto pagaría por ellos?

- ¿Qué modalidad de pago usa frecuentemente? ¿Por qué?

\section{Acerca de la ambientación (6 minutos)}

- ¿Qué diferencias de ambientación le gustaría encontrar en los bares tradicionales?

- ¿Qué aspectos considera necesario para que se dé un ambiente de buena conversación?

- ¿Qué espera acerca de la disposición de los ambientes? ¿debería incluir una zona para fumadores?

- ¿Qué opina de los stand-up comedy y de la música en vivo para conversar?

- ¿Cuál considera que debería el horario de atención optimo? 
6. Acerca de la Relaciones con el Cliente (5 minutos)

- ¿Sería relevante el pertenecer a una comunidad de clientes que acuden a bares que ofrecen cockteles sin alcohol?

- ¿Le gustaría ser contactado por la empresa para medir su satisfacción del servicio?

7. Acerca de la atención del personal y servicios adicionales ( 5 minutos)

- ¿Qué factores considera relevante para que la atención del personal sea calificada como buena?

- ¿Qué piensan del servicio wifi gratuito?

- ¿Los pedidos deberían de ser digitalizados para una mayor rapidez? ¿Lo valoraría?

- ¿Qué servicios adicionales considera deberían incluirse?

8. Intención de Compra (5 minutos)

$\square$ ¿Usted acudiría a este tipo de bares de tragos sin alcohol? ¿Por qué?

$\square$ ¿Lo recomendaría? ¿Por qué?

GRACIAS 


\section{Apéndice 3: Guía para la Entrevista en Profundidad}

Entrevistador:

Fecha:

Entrevistado:

Introducción

Buenos días/tardes, mi nombre es Quiero agradecerle por el tiempo que nos está brindando y quisiera pedirle por favor responder con toda confianza las preguntas, ya que la información que usted nos otorgue será utilizada únicamente para fines de investigación académica.

\section{OBJETIVO DEL ESTUDIO}

Investigar los factores críticos de éxito que tiene el propietario del establecimiento para conseguir tener un negocio posicionado y sostenible en el tiempo

\section{PREGUNTAS}

\section{A. Conocimiento de la empresa (5 min.)}

1. ¿Qué factores influyeron en Ud. para la formación de este negocio?

2. ¿Cuánto tiempo de experiencia y cuánto conocimiento considera Ud que tiene en este rubro?

3. ¿Cuál es la propuesta de valor que tiene Ud. para sus clientes?

4. ¿Qué dificultades encontró en la formación de este negocio?

\section{B. Conocimiento del Mercado}

a) Clientes (8 $\mathrm{min})$

1. ¿A Quiénes está dirigido su negocio?

2. ¿Qué características tienen sus clientes habituales?

3. ¿Qué acciones realiza para fidelizar a sus clientes?

b) Competidores (7 min)

1. ¿Quiénes son sus principales competidores? ¿Cómo obtiene información sobre ellos?

2. ¿Estaría preparado para afrontar una competencia cercana (geográficamente) muy similar al concepto que tiene? ¿Por qué?

3. ¿En un Benchmarking cuáles son los factores más importantes para Ud.? 


\section{c) Legal $(7 \mathrm{~min})$}

1. ¿Dentro de los requisitos legales, cuales le representaron mayor dificultad?

2. ¿Qué problemas se le ha presentado con el manejo del personal?

\section{d) Financiero (10 $\mathrm{min})$}

1. ¿Considera rentable este negocio?

2. ¿Cuánto tiempo le tomó recuperar su inversión?

\section{e) Estratégico (10 min)}

1. ¿A quiénes considera socios estratégicos dentro de su cadena de valor?

2. ¿Qué factores considera determinantes para el éxito de este negocio?

3. ¿Qué opina acerca de la creación de un bar cero alcohol?

\section{Datos Básicos}

Nombre de la Empresa:

Ubicación:

Cargo del entrevistado:

Número de trabajadores en la compañía: 


\section{Apéndice 4: Cuestionario}

\section{CUESTIONARIO}

Presentación: Agradecemos su atención. Somos alumnos de la Escuela de Posgrado de la USIL, hemos diseñado este cuestionario como parte de nuestro trabajo académico para graduarmos, por ello solicitamos unos minutos de su tiempo y nos pueda responder las siguientes preguntas:

PRESENTACION PROPUESTA BAR SIN ALCOHOL (Speech y/o ayuda visual)

1. ¿Acostumbra a salir de casa para divertirse o entretenerse?

9. Qué aspecto valora más de la propuesta de Bar sin alcohol? (Opción Múltiple)
$\mathrm{Si}$
No
Terminar!

a. El concepto

b. Música

2. ¿A que tipo de establecimientos de diversión o de entretenimiento asiste?

e. Horario

f. Otros
a

10. Qué nombre sugiere que es el más adecuado para este nuevo concepto de bar?

3. ¿Cual es el principal motivo que lo impulsa a realizarlo? (Opción Múltiple)

$\begin{array}{ll}\text { a. Solo por diversión o relajo } & \text { b. Cumpleaños }\end{array}$

c. Feriados $\mathrm{y} / \mathrm{o}$ dias no laborables d. Aniversario

e. Celebraciones

$\begin{array}{lll}\text { 1. Bar Grado Cero } & \text { 3. La Conversa Bar } & \text { 5. Bar Talk \& Drink } \\ \text { 2. Storytelling Bar } & \text { 4. Frutal Bar } & \text { 6. Bar Non- Alcoholic Spirt }\end{array}$

4. ¿Con que frecuencia asiste a estos establecimientos?

a. Todas las semanas $\quad$ b. Cada 15 dias

c. 1 vez al mes d. Muy rara vez

5. ¿Qué criterios hace que un establecimiento se distinga y se haga su preferido? (Opción Múltiple)

a Cuando tiene música

e. Cuando tiene shows o stand-up comedy

b. Cuando tiene música y bail

f. Otros (Especificar)

c. Cuando se expende bebidas alcohólicas

11. En este tipo de bar, cuánto pagaría por un trago sin alcohol?

\begin{tabular}{|c|c|}
\hline $\mathrm{S} / 15.00$ & Terminar! \\
\hline
\end{tabular}

d. Mayor a $\mathrm{S} / 25.00$

12. QQué factores considera relevantes para la ubicación propuesta del Bar sin alcohol en Barranco?
a. Accesibilidad
c. Tradicional/Cultural
e. Prefiero otra ubicación
Terminar!

b. Diversidad de Ofert

d. Turistico

13. ¿Qué proceso considera de mayor importancia para este tipo de Bar?

a. Compras y Almacén c. Cocina e. Caja

b. Bar d. Servicio (Atención del personal)
promedio (por persona) en los bares que asiste?
a. Menor a $\mathrm{S} / 40.00 \quad$ c. Entre $\mathrm{S} / .80 .00$ y S/.120.00
b. Entre $\mathrm{S} / .40 .00$ y S/ $/ 80.00$ d. Mayor a $\mathrm{S} / 120.00$

14. ¿Qué factores considera relevantes en la atención del personal? (Opción Mültiple)

7. ¿Cuándo sale a divertirse, con cuántas personas 1o hace? Especificar Número

Solo (1)

c. En grupos

b. En pareja / Grupo de 2

$\begin{array}{lll}\text { a. Amabilidad c. Rapidez } & \text { e. Otro }\end{array}$

b. Atención personalizada d. Pulcritud Especificar

8. ¿Qué motivaciones tiene para consumir bebidas alcohólicas?

a. No hay otra opción en la carta

c. Realmente me agrada

15. ¿Cómo le gustaria ser contactado y/o enterarse de nuestro servicio?: (Opción Múltiple)

b. Porque todos toman

$\begin{array}{ll}\text { a. Recomendación o Referencias } & \text { d. Envió correo electrónicos } \\ \text { b. Páginas web } & \text { e. Periódicos }\end{array}$

16. Acudiria a un establecimiento (Bar) donde solo se expenda cocteles y tragos sin alcohol con la misma presentación y ambientación de un bar tradicional 'La Conversa Bar'?

$\begin{array}{ll}\text { a. Definitivamente } \mathrm{Si} & \text { b. Probablemente lo haria } \\ \text { c. Poco probable } & \text { d. Nada probable }\end{array}$




\section{Apéndice 5: Focus Groups}

\section{Focus Numero 1 "La Conversa Bar"}

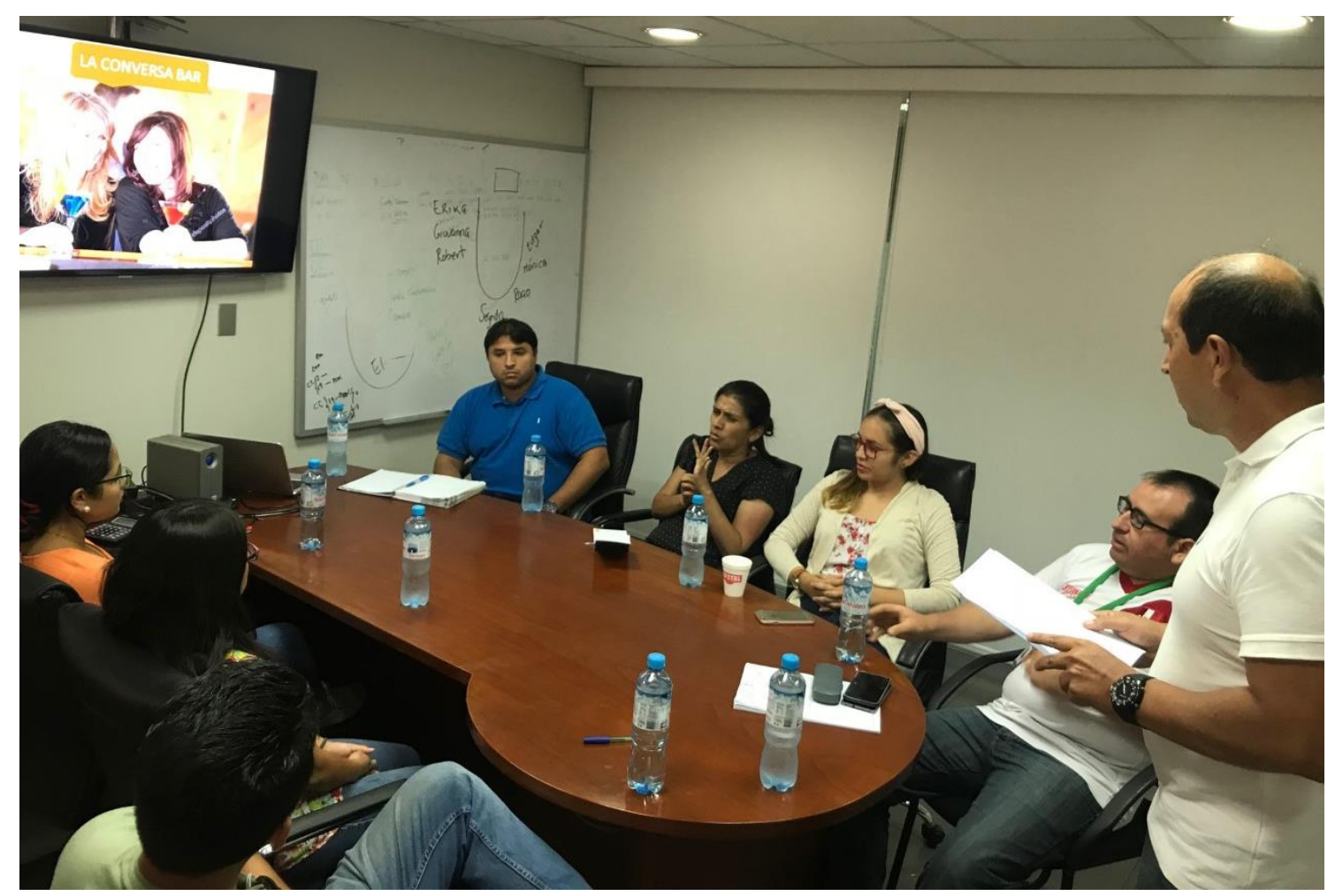

Moderador: Jaime Ampuero

Participantes

1. Robert (23 años, Soltera)

2. Giovanna (25 años, Soltera)

3. Ericka (29 años, Soltera)

4. Edgar (36 años, Soltero)

5. Monica (39 años, Casada)

6. Rocio (27 años, Soltera)

7. Segundo (39 años, Casado)

\section{Descripción del proceso de compra (10 minutos)}

- ¿En qué momento decide salir a divertirse?

Rocio: Cuando necesitamos relajarnos por mucho trabajo

Ericka: Cuando hay algún cumpleaños, entre los amigos, entonces siempre es motivo para celebrar.

Edgar: Cada fin de semana 
Monica: Salir con la pareja también

- Cuando sale a divertirse o a entretenerse ¿De qué depende la elección del establecimiento a acudir?

Segundo: No hay razón

Rocio: Depende de lo que queramos hacer no?, si por ejemplo se nos antoja ver un película vamos al cine, la mayoría de ves se nos antoja ir a bailar, tomar tragos Robert: De la coordinación que se haya hecho previamente con los amigos, pareja, familiares a donde se quiere ir.

Ericka: Coordinación y estado de ánimo, puede ser que ya hayas coordinado algo, pero resultado que pasó algo en el trabajo, en la familia y resulta que ya no estas de ánimo para hacer lo planeado.

Monica: Depende si es solo para conversar, o bailar

Giovanna: Puede ser un cafecito, un tragito

Rocio: cuando queremos hablar mucho, vas a un lugar donde la música no se muy subida, por ejemplo si es algo serio un lugar donde haya trago

- ¿En qué medios busca información de lugares para entretenerse?

Todos: Internet y referencia de amigos

Ericka: redes sociales

- ¿Sale en pareja, en grupos o sólo?

Todos: depende

Robert: generalmente en grupo

Giovanna: si es para divertirse es en grupo, no excluyo salidas con la pareja

- ¿Quién toma la decisión de definir el lugar a asistir?

Omitido

- ¿Qué factores fueron determinante para tal elección?

Robert: determinante son las ganas que tenga el grupo

- ¿Con qué frecuencia acude al establecimiento elegido? ¿Por qué?

Giovanna: 2 veces al mes

Rocio: los fines de semana

Monica: todas las semanas pero siempre haces algo diferente, viernes o sábado

- ¿A cuánto asciende el consumo por persona aproximadamente?

Rocio: Mínimo 50 soles

Todos: puede ser más, en general lo determina el lugar 
Edgar: cuando es de noche, es más de todas maneras

Robert: S/100

- ¿Qué tipo de promociones ayudarían en la toma de sus decisiones?

Todos: todas ayudan

Robert: si ayudan, por ejemplo si estas en grupo se puede alquilar un box y cada uno paga $\mathrm{S} / 200$ ó $\mathrm{S} / 3 \quad 00$

\section{Hábitos de consumo (7 minutos)}

- En los establecimientos que asiste ¿qué tipo de bebidas consume, mayormente?

Rocio: depende de la situación

Giovanna: si son pocas personas, en el caso de mujeres por ejemplo tomamos cocteles, tragos cortos

Rocio: lo más suave que hay

Giovanna: sin el grupo es mixto tragos más fuertes

- Las veces en que no consume este tipo de bebidas ¿con qué otro tipo lo reemplaza?

Robert: cerveza

Rocio: jugos con hielo que tienen un sabor rico

Ericka: tragos vírgenes que no tienen licor

- En que ocasiones ha prescindido de tomar bebidas alcohólicas en su establecimiento preferido?

Todos: si, hemos prescindido de tomar en alguna ocasión

Ericka: por ejemplo yo no tomo mucho y las veces que he ido algún lugar es por presión pero yo con agua y con gaseosa estoy bien, pero veo que amerita me tomo un tragito

Rocio: en esos lugares no hay otras bebibas que te ofrezcan que no tengan alcohol Ericka: siempre hay agua o gaseosa

- ¿Qué opina de los tragos vírgenes o cockteles sin alcohol?

Edgar: yo no he escuchado

Ericka, Giovanna, Monica: si

Rocio: las he tomado no sabía que se llamaban tragos vírgenes y me daban cuando era menor de edad

Todos: cockteles sin alcohol, no 
- ¿Conoce o ha consumido cerveza sin alcohol, qué opina?

Todos, No

Robert: cerveza artesanal si

\section{Evaluación de la competencia (5 minutos)}

- ¿Qué bares conoce?

Ericka: La Emolientera,

Rocio: El Munich

Edgar: Barbarian

Giovanna: El Estadio

Robert: Bar Público, La Destileria

Segundo: El rinconcito cervecero

Monica: El Bolivariano

- ¿Qué bares consideran que son las mejores? ¿Porque?

Robert: La destilería

Rocio: El Bolivariano

Edgar, Ericka: Barbarian

- ¿Cómo se informaron de estos bares?

Todos: por recomendación

- ¿Qué ventajas le ofrece estos bares? ¿Por qué?

Robert, Segundo: comodidad, la seguridad

Edgar, Rocio: la diversidad y calidad

- ¿Qué desventajas tienen?

Robert: punto en contrario el horario, 3am

Rocio: la gente toma mucho, encuentro muchos borrachos

Segundo: poca movilidad

Giovanna: mucha gente en espacios chiquitos

4. Presentación de la propuesta, producto o marca de estudio específicamente (10 minutos)

- ¿Qué opina si existiera un local (Bar) donde se expenda cocteles y tragos sin alcohol con la misma ambientación de un bar tradicional? 
Segundo: Una buena opción

Rocio: tengo amigas que no toman y ahí me acompañaría con ellas, porque si vamos a un bar donde venden alcohol y no toman no es cómodo.

Todos: es un concepto innovador, en lo personal iria para conocer, veria el ambiente como preparan los tragos vírgenes, el tipo de música, es un poco juvenil o más orientada a la adultez, mixta.

- ¿Cree usted que sería aburrido? O solo para ocasiones especiales?

Robert: no creo, porque si hay música y buen ambiente, estar con un grupo de amigos

Edgar: lo consideraría interesante como un lugar para ir a cenar, pero como bar no le veo mucho.

Todos: este concepto se puede aplicar a otro tipo de consumidores, porque si hay consumidores que no beben nada de alcohol por ejemplo ciertas religiones podría ser el lugar idóneo para que ellos acudan, ya que en la actualidad no suelen acudir a los abres comunes y corrientes.

- ¿Qué opina sobre el nombre "LA CONVERSA BAR"?

Monica: Invita a conversar

Rocio: algo tranquilo

Todos: bien

- En caso de que los productos sin alcohol sean idénticos a los que contienen alcohol. ¿Cuánto pagaría por ellos?

Rocio: yo pagaría igual

Monica: S/25

$<<<>>>$

Giovanna: al ser más para mujeres, los hombres no irían a tomar tragos vírgenes

Rocio: también hay hombres que no toman como los deportistas $<<<>>>$

Todos: debería ser un poquito menos que el trago que contiene alcohol

- ¿Qué modalidad de pago usa frecuentemente? ¿Por qué?

Todos: tarjeta

\section{Acerca de la ambientación (6 minutos)}


- ¿Qué diferencias de ambientación le gustaría encontrar en los bares tradicionales?

Robert: moderno

Rocio: que no sea muy serio porque no llamaría a la diversión

Segundo: los colores, la mayoría invita a emborracharse

- ¿Qué aspectos considera necesario para que se dé un ambiente de buena conversación?

Edgar: el volumen de la música no debería ser muy alto

Segundo: que tenga seguridad, privacidad

- ¿Qué espera acerca de la disposición de los ambientes? ¿debería incluir una zona para fumadores?

Giovanna: si

Segundo: ahí no deberían fumar

Edgar: yo tampoco pienso que debería tener

Monica: especialmente porque es un lugar tranquilo

- ¿Qué opina de los stand-up comedy y de la música en vivo para conversar?

Todos: Eso sí sería bueno

- ¿Cuál considera que debería el horario de atención optimo?

Todos: temprano, 3 am suficiente

\section{Acerca de la Relaciones con el Cliente (5 minutos)}

- ¿Qué tipo de promociones le gustaría recibir?

Todos: combos

- ¿Sería relevante el pertenecer a una comunidad de clientes que acuden a bares que ofrecen cockteles sin alcohol?

Todos: redes sociales si con un buen comunity manager

- ¿Le gustaría ser contactado por la empresa para medir su satisfacción del servicio?

Todos: en general antes no después

\section{Acerca de la atención del personal y servicios adicionales (5 minutos)}

- ¿Qué factores considera relevante para que la atención del personal sea calificada como buena? 
Todos: respetuosos, amables, carismáticos, atentos

- ¿Qué piensan del servicio wifi gratuito?

Todos: Ya es común, pero con una buena línea para que todos puedan conectarse

- ¿Qué piensan del tiempo de atención acerca de los pedidos de los productos que ofrece el bar a la mesa?

Rocio: rápido cuando estoy con hambre

Monica: rápido porque ahí se va a comer

Robert: atención rápida y que lleven bien la cuenta

- ¿Los pedidos deberían de ser digitalizados para una mayor rapidez? Lo valoraría?

Todos: si

- ¿Qué servicios adicionales considera deberían incluirse?

Rocio: alianza con empresas de servicios de transportes para mayor seguridad de los clientes, que este afuera del establecimiento para trasladarlos a su casa. DJ temprano y más tarde música en vivo

\section{Intención de Compra (5 minutos)}

$\square$ ¿Usted acudiría a este tipo de bares de tragos sin alcohol? ¿Por qué?

Robert, Giovanna: para las previas

Ericka, Monica, Segundo: si y si me gusta volvería

Edgar: solo para cenar pero como Bar no

$\square$ ¿Lo recomendaría? ¿Por qué?

Todos: $\mathrm{Si}$

$\langle<\langle>\rangle>$

Pueden incluir almuerzo, abriendo más temprano

$\langle<\langle>\rangle>$ 


\section{Focus Número 2 "La Conversa Bar"}

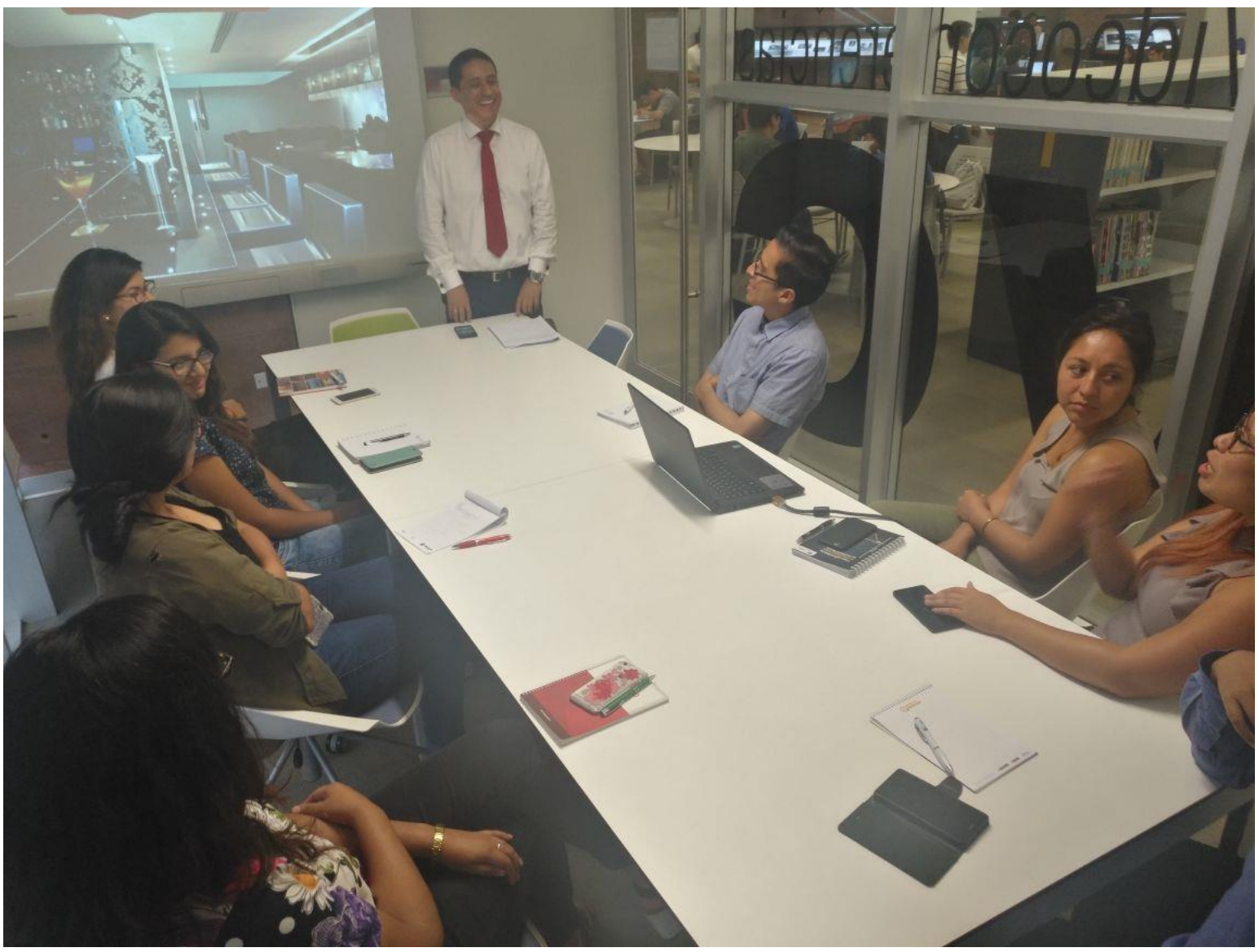

Presentador: Jaime Ampuero

Moderador: Manuel LLatance

\section{Participantes}

1.- $\quad$ Anita (Soltera, 24 años)

2.- $\quad$ Viviana (Soltera, 23 años)

3.- $\quad$ Carla (Soltera, 28 años)

4.- $\quad$ Cecilia (Casada, 30 años)

5.- Julio (Casado, 33 años)

6.- $\quad$ Jeannette (Soltera, 29 años)

7.- $\quad$ Gabriela (Soltera, 27 años)

8.- $\quad$ Raúl (Casado, 28 años)

\section{1.- Entretenimiento/ lugares donde las personas van a divertirse}

- Moderador Manuel: ¿En qué momento ustedes deciden salir a divertirse?

Anita: Cuando tengo dinero 
Julio: Cuando estoy estresado, para desestresarme

Viviana: Para ver encontrarme con amigos de otro circulo

Jeannette: Alguna ocasión especial cumpleaños, o frecuencia de vida

Raúl: Para desesterarme y que coincida con fines de semana

\section{Motivos}

- Moderador Manuel: ¿Los diferentes motivos se relacionan con un tipo de establecimiento en particular dependiendo de la ocasión para alguna cosa este lugar o es indistinto?

Jeanett: Para los cumpleaños vamos a un restaurant porque la mayoría puede escoger las cosas que le gusten, su propia comida y aparte el cumpleañero tiene un regalo por ahí, un ambiente donde todos pueden estar.

- Moderador Manuel: ¿Y si es específicamente para "divertirse", no estamos hablando de restaurant, centrémonos ahí?

Anita: Si quieres ir a bailar una discoteca

Gabriela: Por ejemplo si estas de lunes a viernes y estas muy tenso de la oficina o un día muy cargado puedes al cine o al teatro., o escuchar algo de música un concierto de repente, algo que le implique mucho tiempo de salir

- Moderador Manuel: El tiempo entonces también es un factor determinante

Gabriela: Si porque dependiendo de cuánto tiempo dure esa salida vas a sentir cansancio al día siguiente.

\section{Información}

- Moderador Manuel: ¿En qué medios buscan información, para saber a qué lugar ir, salir para entretenerse, distraerse, divertirse?

Todos: Redes sociales jeje

Gabriela: Internet, Google

Moderador Manuel: Básicamente creo que ahí está toda la información

\section{La Compañía}


- Moderador Manuel: ¿La compañía, solo, grupo pareja de repente o también depende de la situación, igual motivo?

Viviana: Por ejemplo cuando me voy a divertir con mi familia, fin de semana, o también con amigos jugando play, un Karaoke.

Moderador Manuel: Por eso nos centramos específicamente en la diversión, no hablaba de acompañamiento familiar como un restaurant por ejemplo sino en divertirse, divertirse específicamente, a eso me refiero, amigos, pareja.

Cecilia: ¿Tú te refieres solamente a diversión con amigos?

Moderador Manuel: Yo también me divierto con mi esposa, estoy casado jeje

Cecilia: Ella se divierte con su familia y esa es su forma de diversión.

Moderador Manuel: Si es correcto, es una opción, por eso para abrir las opiniones hablar de diversión en general por ejemplo Viviana puede gozar más con la familia. Tenemos claro entonces

Raúl: claro se entiende que cuando es más mixto, mas discoteca, o un restobar, mitad barra, mitad baile, en cambio cuando es un punto g saliendo de un partido es más un bar.

Moderador Manuel: Ok y especialmente centrándonos en grupo, ¿quién es el que toma la decisión, hay un líder de grupo, el mayor, el más antiguo o el que tiene plata?, esa parte si me gustaría que nos puedan expresar, ¿Quien toma la decisión, quien decide finalmente cual es el lugar? Alguien es el cabecilla.

Julio: Una o dos personas influyentes, los demás es como que se dejan guiar.

Moderador Manuel: Entonces qué características tiene ese decisor

Gabriela: El más entusiasta

Raúl: Mas pilas por decirlo así

Gabriela: Porque si este líder no entusiasma a todos en algún momento se va a caer esta fiesta.

Moderador Manuel: y los seguidores porque deciden seguirlo, valga la redundancia

Gabriela: Puede ser por relaciones, por que hace que todos lleguen a un consenso, puede ser porque tiene muchas ideas, porque te emociona, te emotiva salir.

Moderador Manuel: Alguien más que opina

Cecilia: Porque esa persona es más amigo de la mayoría puede ser que tú le tienes más confianza y sabes que él va a estar ahí y mas 
Moderador Manuel: Es el que jala a la gente no

Raúl: Claro

\section{Frecuencia}

- Moderador Manuel: Ahora hablando de divertirse ¿con qué frecuencia lo hacen? Momentáneamente me refiero.

Gabriela: Dos veces al mes

Moderador Manuel: Siguiendo la idea de Anita que no hay plata a fin de mes, jeje, en general

Gabriela: Puede ser dos veces al mes

Raúl: Dos veces al mes s el promedio

Gabriela: En ocasiones menos

Moderador Manuel: Por eso si alguien de acá sale todos los días, por favor en confianza

Gabriela: Que nos comparta el secreto

- Moderador Manuel: Y a cuánto asciende el consumo promedio por persona, a Anita no le vamos a preguntar pues porque

Anita: Pues dependiendo pues porque si es un restobar, pides tu pikeito y un traguito, 50 lucas pues

Moderador Manuel: Por persona, alguien dice algo más

Raúl: incluyen el taxi y todo

Todos: jejeje

Gabriela: No es el estadio oye

Todos: Jeje

Moderador Manuel: Algo 50, 50,..50 promedio, ahora si le metemos movilidad por ahí puede aumentar

Todos: $\mathrm{Si}$

Moderador Manuel: Y las promociones, ¿les ayuda ustedes a tomar alguna decisión?

Todos: Si claro jejeje

Moderador Manuel: ¿Qué tipo de promociones entonces? Incluye el taxi a la casa Todos: Jeje 
Gabriela: Hay ahora por ejemplo aplicaciones que tienen varias promociones, tenemos movistar, tenemos Prix ahí tenemos varias opciones, o lo que es continental, tenemos opciones de promociones también dependiendo de estas promociones que tenemos a disponibilidad podemos tomar una decisión.

Moderador Manuel: Ah pero ojo, qué tipo de promociones, no solo descuento, que tipo de promociones que no sea descuento.

Gabriela: El dos por uno que es

Raúl: Cupones

Viviana: Barra libre

Moderador Manuel: Barra libre

Todos: Jeje, si pues

Moderador Manuel: Aquí le voy a hacer una pregunta posiblemente se van a distraer un poquito o van a tener que recordar un poquito.

\section{Ocasiones}

- ¿En qué ocasiones han tenido que salir a divertirse o han querido incluso salir a divertirse pero han tenido que prescindir del alcohol? El amigo elegido o ese día no podían tomar, o precisamente porque no podían tomar no salieron, la pregunta es ¿En qué ocasiones han prescindido de tomar bebidas alcohólicas justamente en un momento de diversión?

Viviana: Cuando estaba con pastillas

Moderador Manuel: Cuando estabas medicada eso es uno

Raúl: Cuando estaba resfriado

Todos: jeje, mentira

Gabriela: Hay personas que tienen cólicos y cuando son día de semana no salen, Viviana: Yo soy católica, el viernes santo

Moderador Manuel: Por ejemplo el tema religioso, ahora en semana santa ok Gabriela: En las elecciones, ley seca

Moderador Manuel: En las elecciones ok, pero en lo personal, por ustedes por alguna razón, el tema de la medicación

Julio: Más que todo eso la responsabilidad del día siguiente por el trabajo o tengas que hacer un trámite, o acompañar a la mamá a algún lado y todo eso, es una responsabilidad, yo creo que eso pesa más fuerte conmigo. 
Gabriela: En casa si tienes a alguien que le impide que tomes, alguien que tenga una esposa.

Anita: Si vas a manejar carro

Moderador Manuel: A eso me refería en que caso hemos tenido que prescindir del alcohol, la idea es que no se quedaron en casa pero fueron el amigo elegido o estaba resfriada, en fin.

\section{Opciones}

- ¿Bueno ahora que no tomamos si no es alcohol o que otras bebidas u opciones ha tomado?

Gabriela: Hay trago virgen

Moderador Manuel: Todos conocieron los tragos vírgenes

Raúl: Yo soy feliz con mi San Luis

Todos: jeje

Moderador Manuel: Conocen la cerveza sin alcohol

Todos: Jeje hemos escuchado de eso

Moderador Manuel: ¿Qué opinan de esa cerveza sin alcohol, los que consumieron?

Gabriela: A mí siempre me gusto, lo acompañas con ceviche, si quiero acompañar con algo más que vaya con el ambiente pero no quiero tomar alcohol ya.

Moderador Manuel: Ahora si quiero que ustedes meden concejos lo primero que les venga a la mente como el top of mind.

\section{Bares}

- ¿Qué bares conocen bares, específicamente bares?

Anita: La boletería

Carla: Ayahuasca

Cecilia: Queirolo

Jeannette: Houss

Raúl: Bares que tienen rokola en el centro de Lima, el bar de Ciro

Moderador Manuel: Podríamos decir que hay uno mejor que otro, muy independientemente si es el que acuden o no.

Raúl: Cada uno tiene su estilo

Moderador Manuel: No se atreven a decir uno

Cecilia: Creo que Ayahuasca es el más break mas top 
Anita: Por la infraestructura también, porque es bonita pues

Carla: Creo que depende de los gustos Ayahuasca es bonita pero a mí me gusta ir a Florida

Gabriela: Bueno no sé pero si quieres música en vivo y estar bebiendo algo el de Rock te viene bien.

Raúl: Si depende porque en algunos solo hay música rock en otros cumbia no

\section{Ventajas y Desventajas}

- ¿Ahora pensando en estos bares o en su bar favorito, que ventaja o desventaja podrían tener estos bares?

Anita: Bueno yo he probado estos licores ya mí me han gustado, pero la infraestructura, si bien el techo es alto, las mesas son muy delgaditas, e incomodas. Viviana: La casona es bonito pero como esta en el centro de Lima la seguridad Moderador Manuel: Es importante también la seguridad.

Carla: Yo dije Ayahuasca, he una ventaja la variedad de cocteles los insumos, y la desventaja no tanto la ubicación, no tanto para las personas que vivimos por ahí.

Cecilia: yo había dicho Queirolo pero más va para el bolivariano

Moderador Manuel: Vale cambiar, no hay problema

Cecilia: bueno yo lo tomaba como referencia porque es el lugar más cercano como para esta zona no, pero lo que no me gusta mucho es la estructura es muy rustica y este podría modernizar también la música pues es para gente muy adulta.

Moderador Manuel: Muy clásico, alguien me quiere voluntariamente comentar de su bar favorito

Gabriela: Yo el Yerlow me gusta resaltar la música, bueno a mí me gusta el rock y la gente del centro de Lima le gusta el rock y es el ambiente que uno busca, y lo negativo sería el centro de Lima

\section{Concepto diferente}

- Vamos a presentar un concepto algo diferente, por si no queda claro, se llama "La

Conversa Bar" y su principal característica es un bar donde hay bebidas sin alcohol, todo tipo de bebidas, cerveza, tragos virgen, esta es su principal característica.

Moderador Manuel: Eso no es, justamente queremos evitar los excesos 
Ahora viendo este video este es el concepto que más o menos queremos proponer, el nombre propuesto La Conversa Bar es un lugar tranquilo donde se pueda conversar, con cualquier tipo de bebidas no alcohólicas, la cerveza, tragos virgen, piqueo tanto dulce como salado, aquí también algo diferente la música si bien es algo contemporánea pero se va a preservar la conversación para ello el volumen de la música adecuado para que puedan conversar y una living mujer si no se ve muy bien, un bar propuesto en barranco y una habitación sobria de 5 a 12 de domingo a miércoles y los fines de semana hasta las 2 de la mañana, básicamente esa es la propuesta, ahora la pregunta es la siguiente

\section{Opiniones}

- ¿Qué opinan ustedes si existirá un bar así, qué opinión les merece, casi casi una ambientación moderna pero el bar no tiene alcohol? Opiniones

Julio: Con respecto al bar porque barranco

Moderador Manuel: Hay que hablar ahorita del concepto, más que nada del concepto, si entran a google y ponen bar como concepto el bar es lugar o establecimiento donde se expende bebidas en una barra, dice bebidas, no dice bebidas alcohólicas, hay otro concepto en google como cantina y otros conceptos, el bar solo se refiere a la venta en barra.

- ¿Ahora este es un bar que opinión les merece?

Jeanett: Para relajarse si pues de repente la gente quiere un lugar más tranquilo que no quiere trabajar porque al día siguiente tiene que trabajar.

Raúl: No sé exactamente es para las personas que bueno ese día no pueden consumir alcohol, por lo general en un grupo de siete uno es el que no consume alcohol o es para aquellos que no consumen alcohol

Moderador Manuel: Eso es precisamente lo que queremos que sea visto para quien está enfocado, ya hemos hablado de las diferentes situaciones en las que no se consume alcohol.

Raúl: En lo personal iría siempre y cuando me atraiga más el sabor que el nombre y la naturaleza del producto, me encantaría un trago no sé cómo un chilcano sin alcohol y lo hacen muy rico y con un piqueo y algo, pero ahora si por un tema de tomar chilcano, solo por tomar chilcano no iría ósea por la naturaleza no iría, por el sabor es probable que sí. 
Jeanett: Mira lo que pasa es que cuando se sale muy pocas personas no toman y depende donde la mayoría quiera ir, hoy en día los bares tienen los tragos virgen y se puede adecuar (su carta extendida)

Moderador Manuel: O sea el grupo se reduce quieres decir

Carla: No creo que se reduzca se mantendría, y las personas que no toman optarían por otras opciones en otro lugar.

Moderador Manuel: Por eso centrémonos en ese concepto, que opinan de ese concepto

Cecilia: Yo lo veo más para empresa, porque como dice los chicos al día siguiente trabajas en un lugar bonito pero es algo más formal

Moderador Manuel: Ósea es más formal

Cecilia: Es como para empresa están todos en terno han salido de trabajar y van para ahí.

Viviana: Puede ser para un brindis de una empresa, que no puedes tomar licor.

- ¿Qué otra opinión se les viene a la mente, el nombre por ejemplo?

Gabriela: Si exacto, con respecto al nombre a mí me llama como por ejemplo un lugar donde no me llama al lado de la bebida, porque a mí no me llama la atención, sino voy a ir a un lugar donde voy a estar cómoda y voy a poder conversar con personas pueden ser mis amigos y sobre todo que el ambiente sea cómodo para conversar.

\section{Precio}

- Ahora les voy a hacer una pregunta talvez en la línea del sabor de probarlo y que pueda ser rico por decirlo así ¿Cuánto pagarías por un trago con alcohol y cuanto pagarías por un trago rico pero sin alcohol?

Raúl: Un consumo mínimo de 20 soles

Moderador Manuel: ¿Cuánto pagas por un trago con alcohol?

Raúl: Con alcohol 15 a 18 por ahí están

Moderador Manuel: Ósea vas a pagar casi lo mismo

Raúl: Ahora si excede de los 20 soles ahí si no

Moderador Manuel: Ósea no puede costar más de los 20 soles, alguna opinión diferente

- ¿Alguien cree que debería costar menos? 
Cecilia: Si debería costar menos, porque es un trago más sencillo, más sencillo que los otros tragos, pondría menos ingredientes por eso podría ser más barato.

Moderador Manuel: ¿Para ti más natural son menos ingredientes?

Cecilia: Si

Gabriela: Yo pienso que en líneas generales lo que pensamos es que lo que cuesta es el licor.

Moderador Manuel: Es un tema de concepto.

Gabriela: Igual cuando vamos a un lugar, un bar o una discoteca lo que te venden es el licor, eso es lo más caro porque la gaseosa si lo combinas es más cómoda, es mi concepto, y obviamente si pedimos un trago sin alcohol va a costar menos.

- ¿Qué medio de pago usan normalmente?

Todos: Visa

\section{Ambientación}

- ¿Con respecto a la ambientación, que diferencia les gustaría encontrar en este tipo de concepto?

Anita: Más elegante, mesas para adulto

Julio: Un ambiente para parejas

Gabriela: Esa barra me parece muy bonita, parece una serie norteamericana.

Moderador Manuel: El modelo

Gabriela: A mí me gusta

- ¿Creen que esa habitación si fomenta una buena conversación?

Gabriela: Si las luces son bajas

Todas: je je

- ¿A pesar que no hay alcohol, creen que debe haber una zona de fumadores?

Gabriela: $\mathrm{Si}$, lo que pasa es que hay gente que fuma tomando café, entonces el fumador no necesariamente, combina el alcohol con el cigarro-

- Creen que si debería haber una zona de fumadores, reservada, ¿y que opinan del show de música en vivo o los stand up comedy, se presta para marcar la conversación, podrían incluirse en este concepto?

Anita: No porque estarían más pendientes de ello 
Gabriela: Solo música

Cecilia: Interacción con el público no solo que escuches sino que les inviten a cantar.

Moderador Manuel: Que puedas hacer tu pedido

Gabriela: Como en algunos lugares que pones una moneditas

Todos: Rockolas jeje

Gabriela: Puede ser muy popular porque nosotros vamos a elegir lo que vamos a escuchar.

Moderador: Claro así cada uno escucha su pedido

\section{Horario}

- ¿Cuál debería ser el horario de tiempo, hay una propuesta pero ustedes cual creen que debería ser el horario?

Gabriela: Los fines de semana, o días de semana

Todos: Jeje

Moderador Manuel: Como lo que tu decías es días de semana sin alcohol y fines de semana con alcohol

Viviana: Podría haber una carta pequeña sin alcohol

Moderador Manuel: O sea a la inversa

Viviana: Una carta grande con alcohol y algo pequeño sin alcohol, o solamente los días de semana.

Jeanett: Feriados.

\section{Promociones}

- ¿Qué tipo de promociones les gustaría recibir en este tipo de bares?

Carla: Happy Hour

Gabriela: Si porque es para empresas nomas

Cecilia: Si para empresas

- ¿Sera necesario hacer un grupo de Facebook para este tipo de clientes para este bar?

Anita: Podría tener una página en Facebook

- ¿En general cuando van a un bar les gustaría ser contactados para que midan su satisfacción al día siguiente, que los contacten los llamen? 
Viviana: Hay veces te piden tus datos y te mandan promociones para tu cumpleaños jeje

Moderador Manuel: Ósea que les gusta, porque hay gente que no le gusta

Raúl: que te contacten tu Facebook

Todos: Correo jeje

\section{Atención}

- Ok, ahora opiniones sobre el personal, para que ustedes, califiquen como bueno la atención que características debe tener este personal o que cosas relevantes debe hacer para que ustedes digan que bueno

Carla: Debe ser atento

Viviana: Carisma

Jeanett: Conocer lo que vende

Cecilia: Así como en el santo del fraile tú te das cuenta que ellos realmente quieren ayudarte, te preguntan, estoy aquí, este es mi nombre, ese enfoque no, que sea uno a uno, no que estén ahí como que vas a tomar, que vas a comprar y ya, que estimen que estás ahí porque eres un cliente.

Moderador Manuel: Alguien más otro tipo de detalle sobre la atención del personal.

Julio: Que estén en la puerta y te reciban

Jeannette: Que te lleven, no estés caminando, que te consigan la mesa

Raúl: que incluya seguridad la zona

Moderador Manuel: Bueno eso es importante que incluya seguridad

- Y el tiempo de atención de los pedidos, creen que estos pedidos digitalizados agilizan la atención, se valora eso.

Julio: Si claro que si

Moderador Manuel: Wi fi gratis

Todos: Si claro que si

Moderador Manuel: Todos están de acuerdo

\section{Servicios Adicionales}

- ¿Y qué servicios adicionales ustedes propondrían?

Cecilia: Si en algunos restaurantes dan el servicio de cargar tu celular, no sé cómo es yo no lo he dejado. 
Moderador Manuel: Hay una opción de tenerlo ahí en la mesa

Cecilia: También lo pueden poner en la mesa

- ¿Algún servicio adicional que piensen que debe incluirse?

Anita: He escuchado de algunos que te dan juegos, cartas, juegos de mesa

Moderador Manuel: Juegos de mesa, interesante

Gabriela: La Yenka

Todos: La yenka

Moderador Manuel: Algún otro servicio, por favor con total libertad

Gabriela: Yo no sé pero deseo hacer una consulta porque la DJ

Moderador Manuel: Por hacerlo algo diferente y segundo porque es la conversa, tratar de pensar...

Gabriela: Ósea una DJ femenina

Cecilia: Es con estilo no jeje

Moderador Manuel: En otro focus no han presionado, es solo para señoritas nomas para ti Gabriela que es distinto.

Jeannette: que tenga buena música

Raúl: Si estas en un bar y no ponen la música que quieres, es indistinto quien lo está haciendo mal si es hombre o mujer

Todos: Jeje

\section{Aceptación}

- La pregunta para ir cerrando ¿Ustedes acudirían a este tipo de bar y por qué?

Anita: Creo que si porque mi hermana esta en esta honda natural, y tiene amigas que toman todo natural, entonces como dices que hay bebidas que no tienen alcohol es bueno para ellas que salen del trabajo y ellas van a ir recomendando a estos grupos que hacen dieta, o grupos veganos, de ese mundo que mi hermana conoce jeje

Moderador Manuel: Como que es un lugar para ir con tu hermana

Anita: Si y con las amigas de mi hermana, claro exactamente.

Viviana: Si podría ser más que todo el compartir cuando alquilen no puede tomar Carla: Si iría entre semanas, mis papas

Gabriela: Pero los fines de semana puede ser con alcohol jeje 
Cecilia: Yo también iría pero por la foto se ve un lugar muy caro, tuviera que tener unos precios relativos para que todos puedan acceder, y si sería día de semana con grupos de trabajo, más que nada para eso

Moderador Manuel: Ósea lo recomendarías solo a ese grupo

Raúl: Ósea la verdad, la verdad no, así en lo personal por el hecho de que el presupuesto que se gasta en eso es casi tan similar o un poco más bajo que gastar en un sitio con alcohol no, entonces siempre se van a presentar las alternativas, como sándwich y maracuyá, pero al menos que tenga algún imagen exclusivo o atrayente en su local o en o en los piqueos en sabor como digo, creo que sería la forma de atraer.

Moderador Manuel: Si llegas a probar, si te gusta

Raúl: Si me llegara gustar un sabor en específico, siempre se me abre el otro abanico de opciones.

Gabriela: Yo si iría, me gusta todo lo de conversa, y conversando o conociendo a las personas me desestreso, más que si toman o no toman, el hecho de conversar, el ambiente tranquilo, me parece cálido, si la música es baja me parece bien, es bueno para conversar.

Moderador Manuel: Ósea lo recomendarías

Gabriela: Si

Jeanett: Si también, no sé si recurrentemente, pero si lo tengo como opción y al día siguiente no quiero tener resaca, voy escucho música, converso.

Moderador Manuel: Ósea irías si no quieres tener resaca, y por las mismas razones lo recomendarías.

Jeanett: Si

Julio: Bueno yo también iría, siempre y cuando haya una opción en la carta, para personas que si desean tomar bebidas con alcohol, porque creo que así se estaría reduciendo que hay personas que toman alcohol, y siempre y cuando el precio se mantenga en lo que hemos venido hablando, de igual, el precio es un factor fundamental si se mantiene ese y lo puedo recomendar.

\section{Recomendación /Sugerencia}

- Alguna otra recomendación, sugerencia que quieran dar sobre este concepto, para nosotros es de verdad valiosísimo. 
Gabriela: Creo que los tragos deberían parecerse mucho a los tragos con alcohol, no en la bebida sino en lo logístico, siempre llama mucho la atención y los jueguitos de niños.

Moderador Manuel: Muchísimas gracias chicos.

Presentador Jaime Ampuero: Si chicos muchísimas gracias por la información que nos han, esta información es bastante valiosa para nosotros, la vamos a tener en reserva, Manuel es gerente financiero de ATV, les va a conseguir entradas para combate -dice-

Moderador Manuel: Si quieren tomarse fotos me avisan

Todos: jeje

Presentador Jaime Ampuero: Muchas gracias por la información que nos han dado, un aplauso. 
Apéndice 6: Entrevistas a expertos

\section{Entrevista Experto 1. Gerente General Cervecería y Bar Barbarian "Ignacio}

\section{Schwalb Pomareda"}

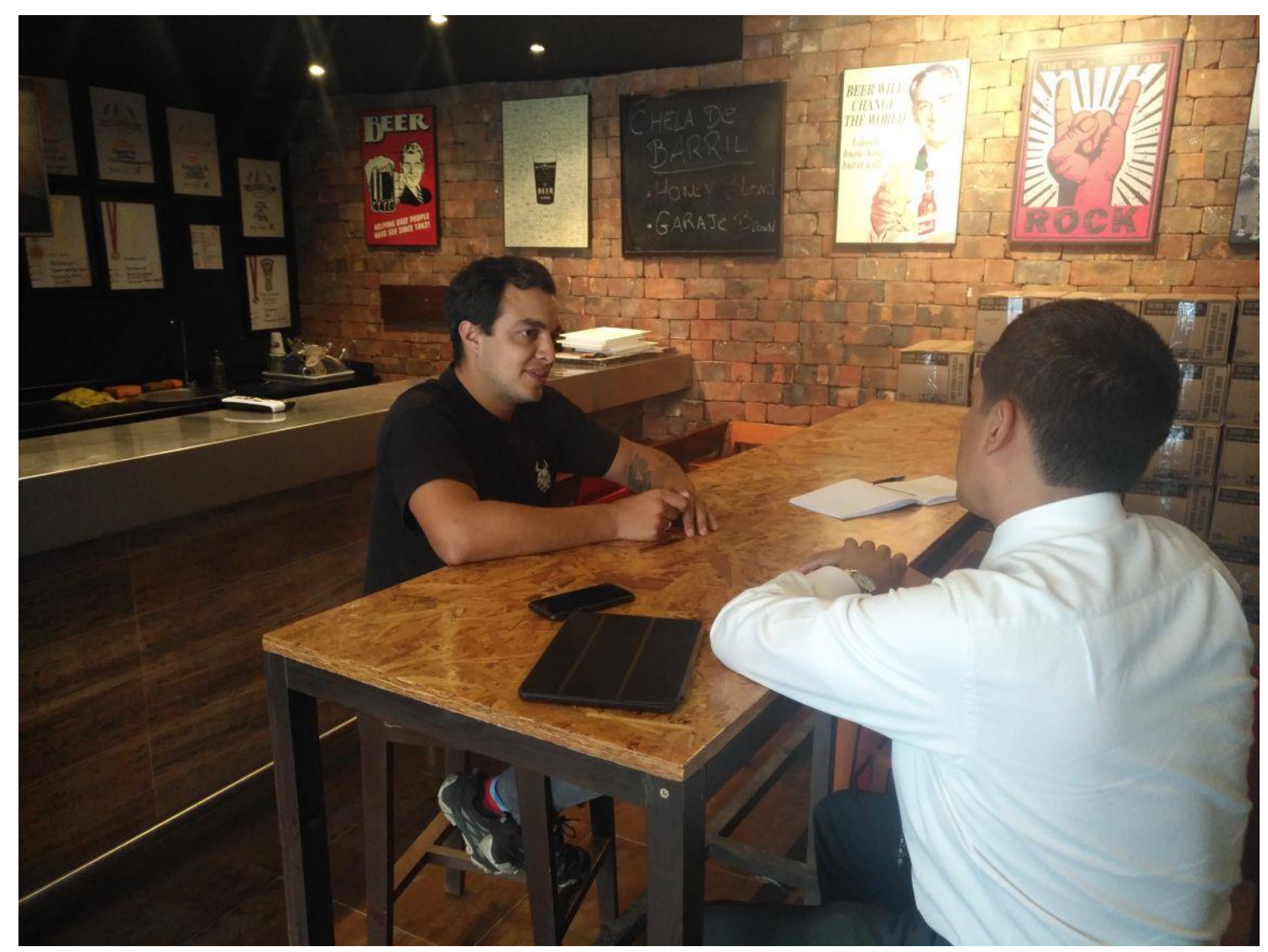

E: ¿Cuál es el concepto? 2. ¿Cuánto tiempo de experiencia y cuánto conocimiento considera Ud. que tiene en este rubro?

D: Es hacer la cerveza en el mismo sitio y venderla en el mismo sitio "Beer house"...

Tú haces la cerveza y la vendes en el mismo sitio, es mucho más chiquito, no es una fábrica gigantesca de cerveza normalmente es una fábrica de cerveza chica que abastece el bar y para eso sirve las cervezas que tiene, eso se hace en muchas partes del mundo, en Estados Unidos en Europa. Entonces dijimos: ¡Ya!

Hay que hacer algo así, pero primero hay que ver cómo se hace la cerveza porque no sabíamos y comenzamos así haciendo la cerveza y nos quedamos pegados con el tema de la cerveza y después de bastante tiempo cuatro años después ya se dio la oportunidad de hacer el Bar, ¿No?

D: El Bar nosotros lo vemos como una expansión vertical lógica. Teníamos muchos clientes y muchos de estos eran bares también, restaurantes y dijimos: “Ya sabemos 
más o menos como funciona la cosa, hay que venderla directamente al público ahí está el margen de todo...". Resulta que es un negocio completo de todo, uno es producción y el otro es servicio y es, completamente, otra cosa pero lo bueno es que lo pudimos manejar bien y, bueno, salieron una serie de retos ¿No?

E: Y cómo Bar, ¿cuál es tu propuesta de valor? ¿Cómo te diferencias de otros?

D: Como Bar especialistas en cerveza artesanal, nuestra carta y sobre todo cervezas de barril, en Perú no está todavía muy difundido el tema de barril. La gente no confía tanto en la cerveza de barril, creo que eso se arrastra de haber tenido muchas experiencias de haber tenido muchas cervezas que le ponen agua, un montón de gente tiene la impresión de que las cervezas de barril son mucho más suaves porque les ponen agua pero no, o sea nosotros metemos estos barriles, la cerveza una parte la metemos en nuestros barriles y otra parte va a la embotelladora y sale la misma cerveza en diferentes empaque,s por decirlo así, y después se sirve directo, o sea no se licúa con nada, una cerveza de barril resulta ser más fresca y queríamos ofrecer una experiencia Premium, que el producto mantenga la calidad lo mejor posible. Entonces, nuestros barriles salen de la fábrica, llegan al local al Bar y entran de frente a la cámara de frío en donde se mantienen a temperatura controlada todo el tiempo y ahí sale directamente por los caños, o sea que desde que entra a la cámara de frío está en frío hasta que la sirves en el vaso, se mantiene siempre de la mejor manera. Podemos enfocarnos siempre en dar un producto que está en la mejor condición que puede estar.

E: Es diferente a los que se embotellan en los supermercados?

D: Lo malo de las botellas primero es de que tienen más manipuleo para poder embazarla, pasa a una máquina y esa máquina se embotella, se ponen las tapas, va a cajas, las cajas tienen mucho más movimiento, van en los camiones a veces se quedan en un sitio con más temperatura

E: ¿Y eso hace que baje su sabor?

D: $\mathrm{Si}$, o sea nosotros cuidamos mucho la calidad de nuestras botellas, ¿no?; pero una vez de que entregamos al cliente ya no depende de nosotros sino de cómo las traten ellos, si las dejan en un sitio muy caliente sufren, si se mueven mucho, una serie de cosas...

E: Y como servicio, ¿tú crees que el concepto del Bar si engancho con los clientes, aceptó tu propuesta?

$\mathrm{D}$ : $\mathrm{Si}$, primero nuestra marca ya era fuerte como cervecería artesanal, nosotros somos líderes del mercado lo hemos sido todo el tiempo y eso ha hecho que apenas salgamos 
como Bar la gente haya estado a la expectativa, ¡El Bar de Barbarían! ¡Ah, ok! y desde el comienzo en Miraflores hemos tenido una fuerte acogida, en Barranco ha sido un poco más suave la acogida, no ha explotado tanto pero está en crecimiento poco a poco. E: Y por qué crees la diferencia, ¿por la proliferación de bares en Barranco? D: Yo creo que por la ubicación, Miraflores es inmejorable estamos en la calle Bonilla, es una calle con mucha actividad, está al costado del parque Kennedy que tiene mucho tránsito de turistas, de gente que va a buscar fiesta, a buscar un sitio para tomarse unas cervezas, la ubicación es súper importante.

$Y$ en barranco estamos igual a una cuadra de la plaza pero estamos en una vereda al frente, a penas abrimos nos cerraron toda la calle hasta hace tres semanas entonces recién como que se está reactivando la zona, recién hemos puesto el cartel en la puerta, recién es como un comienzo nuevo.

E: ¿Fue difícil conseguir ese local?

D: Si, en el local de Miraflores tuvimos mucha suerte porque estábamos viendo otro más chiquito y se abrió uno al frente y la verdad es que no teníamos el dinero para hacer una inversión como la que suponía el Bar de Miraflores, nos juntamos con el socio, al final se retiró y nos quedamos con la pregunta si nos quedamos solos o buscamos otro socio y al final nos fuimos somos y fue una súper decisión porque tuvimos mayor manejo

E: ¿Qué características tiene tu cliente?

D: El centro del Target al que nos dirigimos nosotros es 50\% hombre y $50 \%$ mujer, al inicio pensábamos que iba a ser más hombres, pero no es así; es súper igual de 25 a 35 años más que por nivel socio económico, la verdad no me gusta ver esa diferenciación, yo veo gente que quiere tomar algo diferente. Tú te puedes ir a tomar 5 chelas Pilsen, te metes una bomba o puedes ir al bar y te tomas dos por el mismo precio en vez de 5 te tomas dos pero las disfrutas, las tomas un poco más lento, estás con tus amigos conversando, no te metes una bomba sino que es salir al bar a tomar cervezas no necesariamente a emborracharte sino que puedes pasarla bien un rato.

Por eso cuando me dicen a veces: "es más cara tu cerveza ", sí, es más cara; pero tu ticket puede ser parecido al que vas a tener en una discoteca en donde vas a tomar Pilsen porque no vas y te tomas 5 de golpe sino al mismo tiempo te tomas unas dos o tres y te termina causando lo mismo.

E: ¿Te refieres al consumo promedio a la salida en general? 
D: Sí, claro, o sea tú vas, sales , dices: "ok hoy día me voy a gastar 50 soles" - que nunca sales pensando eso-, pero digamos que tu presupuesto es 50 soles y tienes para comprarte 5 chelas industriales de 10 soles cada una o tres chelas nuestras que cuestan 15 soles cada una.

E: ¿Hay algunas estrategias para fidelizar a tus seguidores?

D: Sí, tenemos algunas estrategias. Tenemos merchandising, usamos mucho el movimiento de redes sociales, que cuelguen sus fotos, hacer sorteos, la gente invita a sus amigos, la marca tiene una personalidad muy fuerte con mucha actitud que a la gente le gusta; es una marca actual, cool, moderna, joven, la gente la sigue por eso, a la gente le gusta tener una cerveza Barbaría en la mano.

E: ¿Fue muy pensada tu marca?

D: 'Sí, nosotros iniciamos haciendo cerveza hace 9 años en un garaje y queríamos hacer cervezas diferentes a las que podíamos encontrar, entonces la marca fue pensada en hacer algo distinto, en enfocarla diferente, en no hacer una etiqueta dorada y súper elegante sino en hacer algo más disruptivo algo que vaya un poco más en contra de lo que ya existe y todo el tiempo nos hemos posicionado así, como algo distinto, algo que no sigue, digamos, los patrones de la cerveza que ya existe.

E: Y como Bar, ¿consideras que tienes competidores directos?

D: Sí, directos bueno los bares de otras cervecerías artesanales como Nuevo Mundo, Curaca, Barranco Beer Company, lo bueno es que es una competencia con la que nos llevamos súper bien, no es una competencia violenta si no es una competencia que nos impulsa a seguir a crear más marca y tener un concepto.

E: Hace un rato mencionaste que eres líder del mercado, ¿esa es una estimación personal o hay una estadística?

D: No, pero tenemos una asociación en la que somos parte de las cervecerías más grandes y ahí tenemos los números de todas las cervecerías.

E: ¿Cómo cervecerías artesanales?

D: Sí. Nosotros producimos cerca de 30,000 litros al mes, la siguiente produce cerca de 20,000 litros al mes.

E: Entonces, ¿los otros bares serían tu competencia indirecta?

D: Sí. El Ayahuasca, la Cachina, son muy importantes para nosotros y para el sector. Son [competidores] indirectos porque puedes elegir irte a esos en lugar del nuestro, pero si quieres ir a tomar cerveza artesanal [es] normal que te vayas a uno de los bares que tengan sus propias cervezas. 
E: ¿También te consideras el líder del mercado?

D. En esta categoría, sí. De bares que tienen sus propias cervezas artesanales, sí.

Debemos de estar ahí con Barranco Bear company. No, incluso ellos deben de estar más grandes ahorita, porque ellos tienen módulos chiquitos en otras partes, pero

Barranco Bear. Implant es un híbrido porque ellos son este Bear house que te digo que hacen sus propias chelas y las venden ellos mismos.

E: ¿Cuando dices “módulos” te refieres a otros locales más pequeños?

D: Sí. Ellos tienen módulos como unos bares portátiles, como unos camioncitos, los tienen en unos centros comerciales en Lima y otros, en provincias.

E: ¿Crees que eso les debe dar otro impulso?

D: Sí. Pero si nos comparas como grupo, o sea cervecería más bar, sí seriamos más grandes.

E: Si saliera otro Barbarían, mismo concepto pero con otro nombre, Bar con cerveza artesanal...

D: El Bar de. Ir o Mundo está justamente al frente de Nuestro Bar de Miraflores. Está, literal, cruzando una calle chiquitita, ahí está el Bar de ellos

E: Hay mercado para todos, ¿no les ha afectado?

D: No, normal. Hay mercado, no han bajado las ventas.

E: ¿Por qué crees? ¿Cuál es Benchmark?

D: El de ellos es un poco más chico, es un bar que ya es un restaurante, que ya está como el restaurante, que ya lo han remodelado un poquito. A nosotros nos va súper bien con todo el concepto, yo creo que nuestro concepto es muy redondo, muy bien aterrizado, o sea tenemos música que va con la marca, tenemos murales, toda la parte visual va con la identidad de la marca y las cervezas, el personal, la comida que servimos, todo conversa entre sí, la comida que debería estar ahí, no son platos típicos perua,nos por ejemplo, es maridaje de la cerveza artesanal, los que comían los bárbaros, es comida más de Bar, hamburguesas, Alitas, papitas, tacos, cosas así, cosas que comes cuando vas a un Bar y picas

E: ¿Tú tampoco conocías ese concepto, ese mundo de piqueos?

D: Nosotros conocemos eso porque realmente somos fanáticos de lo que hacemos. Si no estuviéramos haciendo esto, estaríamos yendo a un sitio igual, sería donde yo voy el fin de semana. Pero yo creo que ha salido que lo que buscamos nosotros sea lo que hemos hecho nosotros. 
E: La parte legal es un poco importante por las dificultades que hay que afrontar. Tú como empresario, ¿qué dificultades legales has atravesado en cuanto los permisos, las licencias...?

D: Un montón de problemas, para las licencias de bares casa distrito es diferente. Es muy complicado. Distritos como barranco [por ejemplo] simplemente no te dan la licencia, tienes que conocer gente.

E: Ahora que está de moda la corrupción...

D: Lamentablemente muchas cosas en el Perú funcionan así. No es un tema fácil, no es como debería ser, digamos, cumples todas las normas,[pero] en Miraflores nos pidieron muchas cosas ¿Si?, pero apenas las tuvimos nos dieron la licencia. En barranco no fue así, ya tenías todo y no venían los inspectores, nos pedían otras cosas, el edificio que lo habían construido recién, ósea nosotros lo estábamos inaugurando, entiendo que les han dado todos los permisos a la construcción pero decían: "No, Esa escalera es muy chica". Ya estaba aprobado anteriormente, pero "no se puede", "y eso tampoco se puede", y “acá no puede a ver una salida”. etc. Te ponen 1,000 peros y nos demoró cuatro meses o cinco mesas así.

E: ¿Conoces quiénes son tu personal?

D: Son estudiantes que sabes no van a estar ahí para siempre, hay otros que simplemente se meten y no les gusta trabajar tanto y se van, se pelea uno con otro y se van, cuando manejas gente es el tema más complicado de cualquier negocio.

E: Y me imagino en tu caso tienen que comprarte el concepto...

Digamos que quieren trabajar pero no lo entienden o no lo comparten, es un filtro que usas o se terminan de convencer, como haces esa parte ?

De hecho ahorita estamos implementando un manual de servicio interesante que era nuestro punto más flaco, siempre las quejas iban por el lado del servicio, entonces ahora estamos haciendo capacitaciones, tenemos una persona que se dedica a capacitar al personal y de explicarles justamente de que se trata Barbarian, como somos en Barbarian

Es una marca con actitud, nosotros los meseros tenemos actitud, no tratamos de usted a la personas que vienen, si bien somos respetuosos los tratamos más cercanos, o sea todas esas cosas de la velocidad, no vas a correr, tienes que ser rápido sin correr, estar atentos in parecer desesperado, muchas cosas que se les enseña al persona para que compartan todos la actitud Barbarian. 
Con respecto a tus socios estratégicos dentro de la cadena de valor del bar, quienes consideras que sin ellos sin ese socio no podría funcionar bien el bar?

Primero que nada Barbarian la cervecería es una gran parte de nuestras ventas son nuestras propias cervezas y ahí nuestros proveedores de comidas, nosotros aparte de nuestras cervezas vendemos cervezas de otros productores, de la competencia vendrían a ser, de las otras cervecerías artesanales, solo vendemos cervezas artesanales peruanas de barril

Las que son tu propia competencia?

$\mathrm{Si}$, y en botellas si tenemos algunas importadas, y también botellas de la competencia, eso es básico.

Pero otros proveedores estratégicos, la internet, es un tema súper importante para nosotros porque todo nuestro sistema está en la nube, si se cae internet nos quedamos sin sistema, estos dos trabajando juntos son súper importantes

Están interconectados porque está en la nube, el sistema está en la nube, no se puede facturar ni cerrar comandas ni se puede boletear.

Y no tienes un plan B?

$\mathrm{Si}$, boletas manuales pero demora un montón, pero igual ahora es un internet dedicado, no se cae, o no debería caerse, si pasa sería muy rara

Crees que tu propuesta incluye esa inversión en tecnología?

Interesante porque al ser un bar artesanal cualquiera pensaría que los procesos son manuales.

Imposible, demora muchísimo, el servicio se hace contable.

El mozo va con su tablet y en la mesa te toma el pedido, entonces desde que tú le pides termina de tomar el pedido y manda una comanda y mientras él ya se está volteando ya se está preparando, ya comienza el servicio de la cerveza.

En barra les dar la comanda y ellos comienzan a servirla y a la cocina le mandan otra comanda, es aparte. Comida va para la cocina y cerveza va para la barra a la vez, no tienes que ir y decirle a cada uno.

Sin gritar a la cocina, gritar las cervezas !!!

Entonces sea mucho más rápido

Que opinarías tú de un Bar cero alcohol?

Has escuchado que en Buenos Aires hay cerveza sin alcohol Quilmes

Qué opinas de un bar exclusivamente sin alcohol porque el concepto de Bar no incluye el alcohol? 
Yo creo que ahorita puede funcionar muy bien, sobre todo hay un tema de cuidado de la salud, todo el tema vegetariano, vegano, sin gluten, hay ahora un montón de estas corrientes, también hay corrientes sin alcohol, puede ser, de puede marketear con deportista, puedes juntarlo con carros que nosotros no podemos decir ven con tu carro, porque no pueden manejar saliendo de nuestro Bar, ahora yo creería que tendrías que tener un estacionamiento

Todas tus cervezas tienen alcohol?

Las nuestras sí, pero vendemos una sin alcohol que es importada

Esa sin alcohol es porque no ha fermentado el lúpulo?

Hay como tres formas de hacerlo, que son complicadas hay que tener mucho cuidado, hay una que es sin fermentar, ósea que se hace la cerveza y después se pasteuriza, no fermenta, hay otra que tiene una destilación o sea fermenta y luego se le quita el alcohol y hay otra más que es con un filtro especial que le quita el alcohol

Leí la descripción de Quilmes, sí tiene alcohol?

Hasta $0.5 \%$ puede considerarse sin alcohol, no te ocasiona nada $\mathrm{Y}$ en general a alguien que quiere emprender un Bar que recomendaciones le darías ?

Primero mucha persistencia, mucha paciencia, no prende de la noche a la mañana, tener una estrategia de comunicación, tener un concepto claro, los conceptos sirven muchísimo

Abrir un bar lo abre cualquiera, pero un Bar donde tengas una temática, una razón de ir, yo creo que es ahí donde te diferencian

Yo si abriera un bar sin alcohol lo promocionaría full con deportistas, vida sana que está súper de moda y marketearlo con diviértete y no tengas resaca al día siguiente sin pensar en las cosas malas de los otros bares, sin ir en contra, yo creo que nada funciona si vas en contra de otras cosas, si atacas al alcohol no va, porque hay un montón de gente que toma alcohol de manera responsable y te podrían ver muy cucufato si es que te vas de frente a atacarlos, verlo como que esto es beneficioso es mucho más atractivo que irte en contra.

Por ejemplo, nosotros no decimos; No tomes cerveza industrial, que la cerveza industrial es mala, sino que decimos que nuestra cerveza es buena, suficiente la gente lo entiende, no tienes que decírselo y creo que si nos ha funcionado Muchas gracias 


\section{Entrevista Experto 2 Gerente General Bar Ayahuasca “Alexander Von Ehren"}

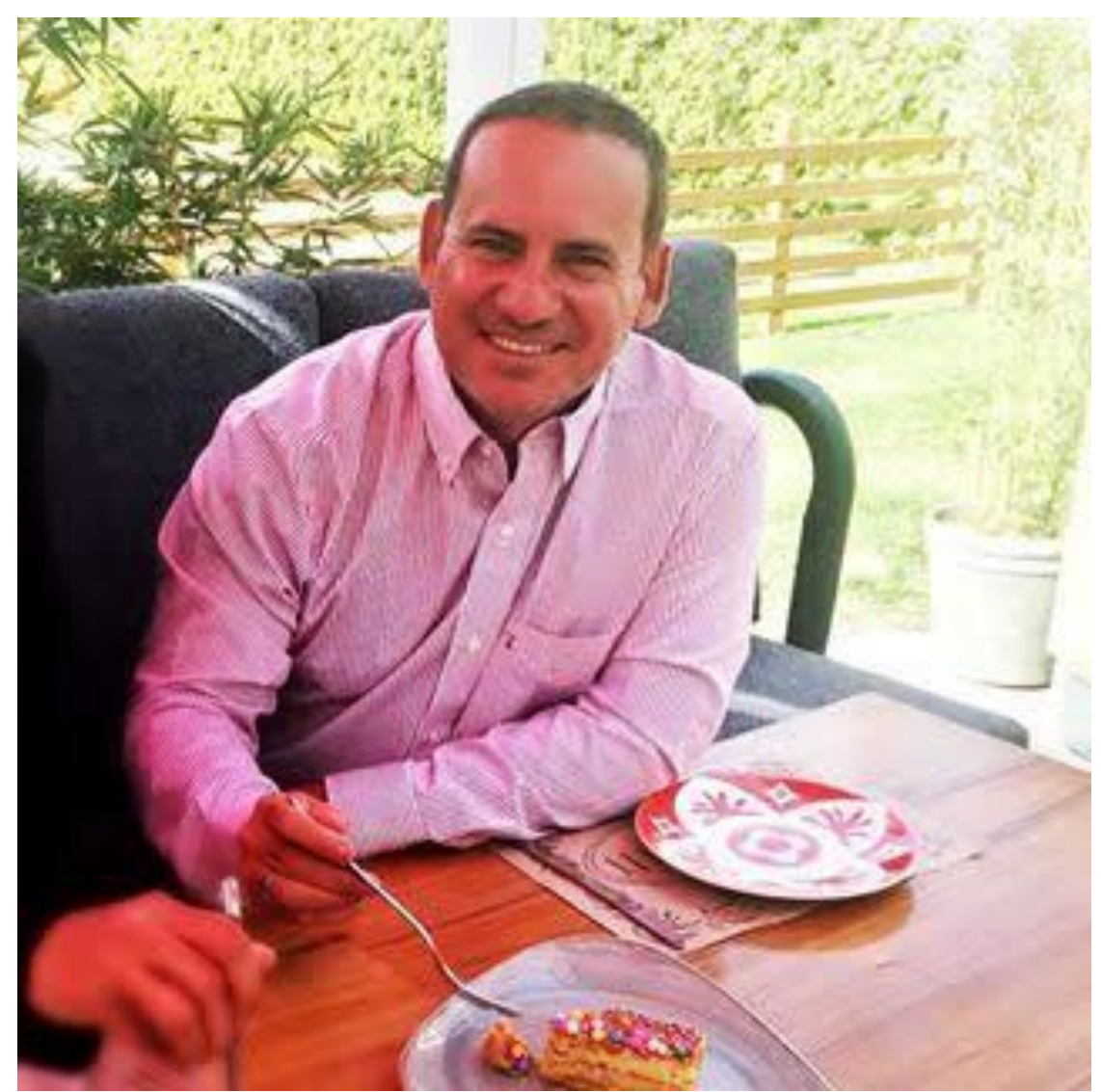

E: ¿Cuál es el concepto? ¿Cuánto tiempo de experiencia y cuánto conocimiento considera usted que tiene en este rubro? ¿Qué te llevó a formar ese negocio?

AVE: Soy apoderado y accionista de Ayahuasca. Mira, ayahuasca, sino me equivoco, hace 10 años aproximadamente, en el 2008, cuando lo inauguramos todo arrancó a raíz de un amigo que se llama Hugo Huerta quien invirtió en la remodelación de la casona que está protegida por el Ministerio de cultura como una de estas propiedades protegidas, la cual es de 1800 y pico es una de las pocas que no se quemaron en la guerra y fue debido que la esposa del propietario era chileno. Entonces, cuando entraron los chilenos pusieron la bandera chilena y no la tocaron. Esa es una de las anécdotas de la casona berninsone y de ahí fue pasando para otros propietarios Inclusive la municipalidad en un tiempo lo alquiló para un centro cultural creo Entonces ese señor hubo de mi edad incursionó en el negocio gastronómico y lo remodeló hizo ese restaurante que se llama Maximiliano lamentablemente no le fue bien se empezó a llenar de deudas y no buscó para invertir o ver qué posibilidades había para hacer dentro 
de la casona entonces quería un inversionista que se asocie con él para seguir invirtiendo en el restaurante, Pero el restaurante ya tenía un año abierto pero no le estaba bien yendo bien y no le estaba alcanzando ni para el alquiler, entonces viendo los documentos le dije:

Hugo pero tu contrato vence en un año o sea nadie va a invertir para estar 12 meses acá y de repente el propietario te pide la casona otra vez y por las puras.

Y leyendo el contrato había una opción de compra justo fue la época del boom inmobiliario entonces la casona no estaba a un valor muy costoso y le dije:

Oye porque no vamos y compramos la casa?

O sea ejecuta tu opción de compra, invertimos y ya dependiendo como nos va, nos va bien o nos va mal por último hasta me mudo acá porque el precio está súper cómodo. Entonces se animó nos asociamos compramos la casa por medio de un leasing que se ha pagado en 5 años y dijimos: ¿Qué hacemos entonces? en esa época ya estaba de moda las Brujas de Cachiche, entonces yo era cliente de las Brujas de Cachiche como muchos miraflorinos año 2007-2008.

El problema con las Brujas de Cachiche es que los espacios eran muy apretados y se veía una tendencia a grupos grandes o sea la gente iba a tomarse unos tragos pero ya no en parejitas, bueno también hay parejas pero se veía muchos grupos grandes de 4 parejas, 5 parejas y el espacio de las Brujas de Cachiche eran tan pequeños que uno estaba arrinconado con su traguito apenas en un puffcito y era incómodo. Entonces yo le dije:

Por qué no hacemos algo así acá?

Tenemos los espacios, tenemos los ambientes, la casona tiene áreas distintas y busquemos una decoración.

Se habló de una decoración bastante moderna, se habló de una decoración antigua y salió la idea de una decoración Novo Andina, que si bien no existe el concepto Novo andino, pero era la mezcla de lo andino con lo nuevo.

Y si bien encontramos el concepto para hacer algo novo andino como decorativo como decoración y buscamos comprar la casa, faltaba el nombre y aquí y a qué público y vamos a atacar entonces mis padres en el callejón de huaylas tenían una Hacienda que se llamaba wacha entonces ... Mis padres en el callejón de Huaylas tenían su hacienda que se llamaba Huashca, entonces plantee ponerle el nombre Huashca porque necesitábamos ponerle un nombre Novo andino. 
Y entre mis socios conversando que Huashca Huashca, salió Ayahuasca, porque por ahí salió.

Y yo les digo: pero Ayahuasca no tiene nada que ver con lo Novo andino, es un brebaje selvático, ancestral.

Ellos dijeron que eso pega, entonces fuimos a Indecopi con la posibilidad de ser rechazados por el nombre y nos aceptaron.

De repente en esa época el nombre Ayahuasca como nombre no estaba muy bien posicionado y lo que queríamos era un nombre para el restaurante.

Entonces nos dieron el nombre, nos aceptaron para el rubro 41 - 42 que es el restaurante, entonces así nació el nombre Ayahuasca, vino de Huashca, de la hacienda de mis padres del callejón de huaylas .

Y si bien nosotros no tenemos nada que ver con el brebaje y nada de que ver con eso, era un hombre que era un gancho, entonces dijimos: Nos vamos para un bar de moda? Cómo es la típica limeña o vamos a un bar meramente típico y decidimos ir a un bar meramente turístico porque eso te da continuidad en el tiempo, los bares de moda como lo dice el nombre moda es moda, 2 años y tienes que cambiar, cambiar nombre, cambiar decoración.

Y apostamos por ese lado, entonces entramos a la decoración Novo andina, le pusimos un hombre gancho, turístico y a su vez decidimos ir al lado de turistas con nuestro marketing que va dirigido a turistas y no a moda, y bueno el primer año nos fue muy bien, en 5 años pudimos pagarle al banco el prestamos de Leasing y si no me equivoco, este año cumplimos ya los 10 años, Cuál ha sido el factor que podríamos decir así la propuesta de valor que has tenido?

Yo creo que Barranco estaba muy mal visto en esa época, la inversión en Barranco era más que todo de huariques, de barcitos, de callejones. Ahora hay muy buenos espacios que lideran las actividades que hacemos nosotros como Barbarian, La Posada del Pisco entre otros.

El mismo alcalde me decía que estaba cansado de que acá se abran garajes y sean unos chupódromos, No, yo quiero gente que invierta, quiero un corredor turístico, quiero gente que invierta y que de el valor agregado al Distrito bohemio que es Barranco y qué mejor que una casona como en que está protegida y mantener el mantenimiento constante con los mismos ingresos del negocio.

La casona es el factor típico de ese sector? 
Sí yo creo que sí yo creo que sí ayahuasca fuera cualquiera en cualquier sitio alquilado creo que no sería exitoso, como está en una casona antigua colonial que tiene una historia y ubicada en Barranco.

Se cierra el círculo no?

Entonces cuando nos han planteado inclusive ir a otros lados .... si no consigues una casona como esa perderías el concepto porque no es sólo una decoración sino es una mezcla de decoración, de locación y el público al cual atacas y como todo negocio de este tipo tú puedes hacer estudio de factibilidad, te puede salir muy bueno, muy malo, al final hay un factor suerte en todo el tema gastronómico.

Aparte de la calidad que puedes dar a tu servicio, tú puedes tener un súper restaurante con súper buena comida, con buenos precios y no necesariamente va a ser exitoso, Entonces si hay un factor bastante grande de suerte creo yo en este tipo de negocios y eso mezclado con una buena casa con una buena atención con buenos insumos, esa mezcla y esa unión hizo que el local sea exitoso y ahorita justamente después de 9 años o 10 años estamos haciendo bastantes cambios internos de remodelación.

Por ejemplo el mobiliario está un poco gastado, entonces estamos cambiando los tapices, estamos cambiando las plantas, hemos remodelado la cocina, invertirle a la casa que ya está 9 años trabajando tal cual.

Dificultades que hayas encontrado en todo este trayecto legal, tributaria, comercial ?

Dificultades como cualquier otro tipo de restaurantes la cual tengo y e tenido, los típicos problemas municipales, defensa civil, las mismas licencias, muchas veces los cambios de zonificación en los distritos de alteran el tema de licencias, tú puedes querer hacer algo en una casona y de repente un año antes cambiaron la zonificación y ya no es comercial, entonces uno dice todo esto es comercial Cómo no va a ser comercial ? Ya lo cambiaron entonces, las casas sin criterio.

En el tema de defensa civil cuando vienen los inspectores creen que están en Suiza y te buscan la sin razón, al extremo de que el tomacorriente es blanco cuando tiene que ser amarillo y por eso te dilatan y te dilatan y te pasas meses y meses sin poder abrir un local comercial por cosas que yo le llamó absurdas, No porque si tú ves el plan de seguridad el concepto de seguridad está bien, tiene salida de escape, tiene extintores, tiene sistemas de aspersión, tienes luces de emergencia, puedes tener de todo pero siempre estos señores te buscan la sin razón porque pues creen que te vienen a inspeccionar un local en Disneylandia no sé, cuando el 99\% del país está que se cae a pedazos y no tienen ningún tipo de medida de seguridad pero basta no más cumplir con 
la ley para que te traten como si estuvieras en Suiza Es algo que ocurre en todos lados, no solamente a nosotros sino en cualquier local que uno quiere invertir en el negocio, siempre pasa eso y los mismos problemas de siempre que abres, te viene Indecopi, te viene Apdayc, te viene Unimpro, te viene el Ministerio de Trabajo, te vienen todas las maquinarias legales, tienes que estar en regla y lo estás pero siempre buscándote el pequeño detalle, la pequeña infracción para multarte.

No hay una política de ayuda, al menos nunca lo he sentido, una política de ayuda al pequeño y mediano empresario, hoy estoy dando trabajo a $40 ; 50 ; 100$ personas y encima vienes acá y me estás metiendo cabe?

Y Mincetur?

Sí pero son áreas distintas promueve el turismo pero a la misma vez no tienes a un área que te pueda apoyar como empresario e invertir tu dinero en temas turísticos como gastronómicos porque siempre tienes a 10 ó 11 o 12 personas Mirando a ver de dónde te saco plata, ese es el problema que podrías tener.

¿No hay una comunicación, no están engranados?

En otro país es más fácil en otro país vienen y te dicen:

¿Vas a invertir?

¿Qué necesitas?

Tienes que cumplir esto tienes que cumplir todo bajo los mismos parámetros, bajo los mismos tiempos y todo encamina perfecto.

Acá es equipo de defensa civil !!!

cuando vendrá?

viene, te levantan las observaciones, regresan al mes, ya levanté las observaciones, Viene otro tipo de inspector cuando deberían de verificar que han levantado las verificaciones te cambian el equipo y te dicen:

Ahhhh señor Ya levantó, pero oye y esto ?

Ahh ...Pero esto no me lo dijo el otro y Boom foja cero al expediente cuando las leyes son claras el equipo Inspector tiene que ser el mismo Inspector que regresa a ver qué has arreglado, las cosas que te han pedido arreglar pero no te pueden estar viniendo a arreglar, a ver qué arreglaste, lo que debiste arreglar y después te salen con otra cosa. Y además te digo si son cosas peligrosas soy el primero en decir:

No, hay que arreglarlo pero no puedes tener pues inspectores que probablemente han hecho un curso de 20 días y ya son los expertos en seguridad y por eso que tanto locales al menos acá en Miraflores estamos hablando de un año para abrir un local y tienes que 
estar pagando un alquiler un año, tengo amigos que tienen restaurantes hace más de un año pagando alquiler y no pueden seguir con el expediente porque es una cosa tras otra y te cambian y te cambian.

Eso es cuando me hablas de traba, pero locales que cumplen con todo lo de la ley tienen a todo tu personal en planilla, tratas de llevar todo en regla pero en vez de que te aplaudan, te ves con todo este bloqueo constante de distintas entidades.

Con respecto al público, está direccionado a los turistas no?

Sí, lo que pasa es que no

me gusta ir por el lado de la moda, con la experiencia que he tenido estos últimos 20 años en este negocio, La moda es muy voluble, muy cambiante. Entonces el tema turístico es constante, es como veo Cancún, tú vas a Cancún tres veces y ya te aburriste porque es lo mismo, vas a los mismos locales, a centros de diversión y es la misma temática y es la misma cosa y la misma cosa pero cuando vas por primera vez es una maravilla, entonces es lo mismo en Lima, pones algo de moda y va a pasar de moda y Cómo atraes a tu gente ?en cambio el turista viene se pasa unos días en Lima, se van a Cusco, se van al norte o se van a nazca y se vuelven a ir y aplauden y dicen que lindo no pueden dejar de conocer este local.

¿Pero siendo turistas deben tener ciertas características para ir a Ayahuasca y no ir a otro lugar?

Estás en todo !!!

$\mathrm{Si}$, aparte de eso tenemos el marketing dirigido a hoteles con incentivos a los taxistas que puedan captar algún turista que diga a dónde puedo ir ?

y ese tipo de cosas y como el servicio es bueno y los insumos son buenos no estamos engañando a nadie, la gente opina correctamente y eso hace de que otra gente se anime a venir porque Barranco es un Distrito al igual que Miraflores que es recomendado a cualquier turista que pase unos días en Lima.

Y quién consideras que son tus principales competidores si es que los consideras? Ahorita no tengo, si hay algunos otros locales, hay mercado para todos pero lo que puede golpear siempre son estos bares nuevos de moda, estos resto bares de moda que hace que se te vaya un porcentaje no muy grande pero sí se refleja en las ventas y después regresa, o sea locales de moda, especialmente el público limeño que sale los fines de semana y busca espacios, siempre el local de moda va a traer a la gente y hasta que llega a su equilibrio la gente vuelve a regresar a lo que le gusta. 
Pero tienes una estrategia? y la gente te deja opciones en ese lapso o esperas nomas que pase?

No, yo espero, el marketing me ha enseñado a qué para qué vas a atacar o hacer unas campañas cuando mejor es que pase el ciclo cuando algo está de moda.

Mira, aunque sea un "pampón” con tierra lo vas a llenar y sencillamente es cíclico.

Es rentable el negocio?

$\mathrm{Si}$, si es rentable, no los márgenes que mucha gente podría pensar pero definitivamente si es si vas a tener tu dinero a plazo fijo, si es rentable definitivamente y aparte de eso que a mí me gusta o sea hago algo que me gusta, estás en contacto con la gente y yo mismo soy un poco de todo. Yo a mis locales si bien ya están gerenciados por otras personas y he delegado casi el $90 \%$ de las cosas que yo hacía antes .... me meto a la cocina, me meto al bar, me meto a la caja, camino hablo con la gente, $\mathrm{O}$ sea me gusta el contacto, no soy de escritorio, no estoy sentado en una computadora todo el día, me muevo, vengo de un local de la playa que estoy cerrando porque ya cerró la temporada, regreso acá, hago una reunión, aquí de repente en la noche me junto en la dama Juana, sino en ayahuasca, sino me voy a otro local.

Es ayahuasca, la dama Juana y otro local?

Bueno la playa y acabo de cerrar uno en el aeropuerto que se venció mi contrato después de 12 años que me tomaba más tiempo de ir al Arohuasca, era un restaurante en la zona internacional y el lobo fué Machu Picchu que no tenía nada que ver pero era turísticamente, se vendía era la figura de Machu Picchu y la palabra Huasca que es una palabra que en quechua, significa nudo.

E: ¿Es sociedad lo que tienes?

D: Sí, lo que pasa es que en cada negocio tengo distintos inversionistas, o sea lo que trato yo es cuando presentó un proyecto como éste por ejemplo: yo soy socio del club entonces presentó el proyecto de agarrar la concesión de estos restaurantes entonces busco inversionistas que busquen una rentabilidad por su dinero y sencillamente lo aplico, lo armó, lo presentó, invierto y cada uno está esperando sus utilidades anuales. E: ¿No participan de la gestión?

D: No participan, inversionistas no más, que es algo que me ha funcionado muy bien porque muchas veces yo no he puesto plata. Si bien al principio ponía plata, ahora ya no pongo plata o sea presentó un proyecto junto a los inversionistas, presentó al equipo ya sea de cocina, de la administración todo, todo se arma y yo me quedo con un porcentaje de la empresa, yo les presento balances y proyecciones cada cierto tiempo. En vez de 
meter tu plata al banco Oye... está haciendo un nuevo local en tal sitio entonces vienen intervienen.

E: Aparte de eso, ¿tienes un Background?

D: Sí, y una trayectoria pues que no soy un estafador, nunca he engañado a nadie hasta el día de hoy. Felizmente todos mis inversionistas han ganado y, entonces, hablan bien y yo creo que la trayectoria y el nombre es lo mejor que uno puede lograr en estos tipos de negocio, basta no más que uno te diga que este es un estafador y éste me robó, éste me engañó, se quedó con mi plata y moriste.

E: Son socios estratégicos, no de una parte financiera ni profesional sino que dentro de tu cadena de valor hay alguien de quien dependas que sea estratégico?

D: Mucho me ayudan los auspiciadores, no a raíz de la trayectoria de los 20 años me ido ganando un hombre, entonces al igual que cuando uno busca inversionistas, también llamo a mis amigos auspiciadores, entonces si no es Marlboro, es Lucky-stray, si no es Chivas es Johnny Walker, si no es Backus era Amber Si no es pisco cuatro gallos, es pisco tabernero entonces busco la competencia entre los insumos para lograr auspicios económicos para una publicidad digamos de sus productos dentro de la exclusividad que le podríamos dar, si bien la exclusividad no Es legal porque digamos Yo podría vender otra marca, no me amarran pero mi compromiso verbal es yo voy a vender tus productos y eso no es ilegal.

En dónde hay mayores márgenes, ¿En el restaurante o en el bar?

Depende de los platos en el bar tú puedes vender al igual que una cajetilla de cigarrillos tu margen de una cajetilla es de 7 soles la puedes vender a 10 pero si vendes una botellita de agua de un sol a 7 estás hablando 7 veces más que tu costo en una cajetilla de cigarros al igual que en un redbull no la llegas a duplicar, Entonces es una mezcla, en tus platos es lo mismo, en los platos caros buscas un margen mucho menor porque sino sería no accesible y hay platos económicos como una milanesa con papas fritas que puede estar en un plató promedio pero el costo es ridículo a comparación de un lomo Huayllu.

Hay buenos márgenes pero si al final tu sumas tus costos, planillas, alquileres, etc. para lograr estar en azul tiene que hacer una mezcla de comida y bebida. En algunos casos sacrificas márgenes de uno u otro producto.

Alex ¿Qué opinas de un bar cero alcohol?

Bueno como un emprendimiento no es mala la idea, cada negocio tiene lo suyo, como por ejemplo hoy puedes hacer tus pollos a la brasa con pollo orgánico. Son estas ideas 
que a los emprendedores se les ocurre para diferenciarse. Hay tragos vírgenes y a lo mejor no necesitas a un "Bar Virgen" para tomar virgen. Puedes ir a un bar que no es virgen para tomar virgen también.

Para qué dejar de lado la posibilidad de vender algo cuando tu marketing o tu teoría es cero alcohol, si ya hiciste la parte más difícil de hacer un bar, permisos, ya lograste y no dejarías la posibilidad de tener otros ingresos vendiendo alcohol. Somos un país que no está tan reglamentado para obtener permisos para vender alcohol, en otros países hay que tener un permiso especial, y esta sectorizado geográficamente, en ese caso costaría más la licencia.

Hay tendencias y pueden funcionar, finalmente es un tema de marketing, los restaurantes y bares son difíciles de aperturar, yo lo haría sin descartar el resto, para no reducir tu número de clientes sin afectar el cliente. Si no es ilegal fumar, hoy no podría tener un bar solo para fumadores. La ley me lo restringe.

Al no tener limitaciones legales, no habría problema de vender alcohol, quizá para evitar que alguien pasado de copas te moleste, lo puedes pedir en cualquier lugar; al final es un tema de riesgo y emprendimiento, cualquier temática. Al final hay un factor suerte.

Mi recomendación a un emprendimiento, los pilares son buenos insumos, tener gente capacitada, incentivada constantemente y bien remunerada porque al final es un negocio donde te pueden robar. Cuando hay confianza las personas que has tratado humanamente te pueden salvar de una urgencia, yo recojo platos sin ningún problema. También el que mucho abarca poco aprieta, franquicias y crecer desmedidamente para qué, tengo lo suficiente y siento satisfacción por lo que hago.

Muchas gracias 


\section{Entrevista Experto 3 Socio Fundador Bar Victoria "Giancarlo Gomero"}

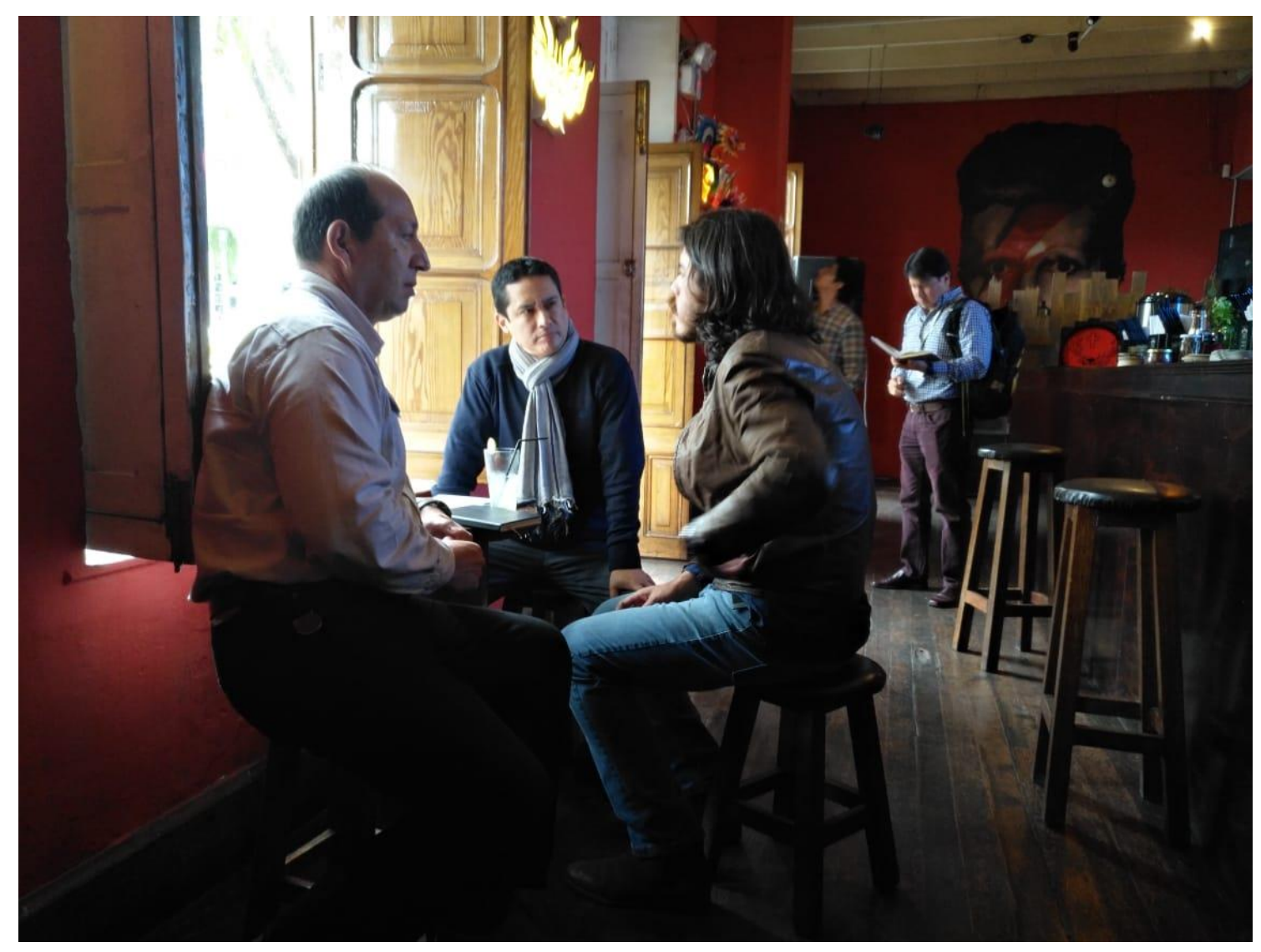

E1: Tú eres socio del bar victoria

Dueño: $\mathrm{Si}$ somos 3 socios

E1: Participaste de la implementación, de la idea, antes del lanzamiento? .

Dueño: Yo estuve desde la idea original pero estaba viviendo fuera, cuando vine a Lima me hice socio accionista, había pasado un año desde que había abierto el bar, vine a tomar el área de comunicación y comercial.

E1: Que fue lo que les motivo para formar este negocio de manera específica?.

Dueño: en este caso en particular uno de mis socios y yo, tuvimos por 7 años esta misma casa, al interior de la casa funcionaba un centro de arte contemporáneo, alquiler de talleres para artistas, funcionaba 15 talleres, mi socio por ejemplo es artista plástico. En ese tiempo había un bar que se llamaba mochileros, que estuvo cerca de 5 años, conocíamos el movimiento de la casa, estábamos familiarizados, regresamos y vimos si estaba disponible, hubo un tiempo de negociación para tomar este espacio. Estuvimos buscando varios lugares en Barranco y Miraflores un buen tiempo.

E2: El segmento al cual te diriges, es abierto? .

Dueño: Publico entre 25 a 40 años básicamente, luego lo tenemos como segmentado entre público entre semana y fines de semana que son más corporativos (viernes y 
sábado). Entre semana es más bohemio, gente que vive entre Miraflores y barranco que le gusta escuchar música y un público más particular, gente relacionada al arte y música. Los viernes y sábado público más corporativo, gente que trabaja sale más los fines de semana.

E2: Todo negocio tiene una propuesta de valor, al segmento que te diriges, cual es el concepto que ofreces?

Dueño: el concepto es estilo clásico y trasgresor. Hay una figura de la reina victoria y con lentes oscuros, con colores contemporáneos, clasicismo intervenido, trasgredido, elegante pero también cool, es un poco lo que proponemos. El contexto de la casa, la casa es el marco total de lo que tenemos.

E1: Estas dirigido a gente que le gusta el arte?

Dueño: La mayoría sí, no es el público discotequero, hay show en vivo, hay teatro, standard comedy, arriba hay un dj, funciona como un centro cultural.

E2: Que porcentaje son turistas?

Dueño: Bueno es un buen público de turistas, yo diría un 15 a 20\%, por ejemplo en Tripadvisor estamos bien posicionados, entre los 10 primeros, entonces vienen bastantes turistas.

E2: El aforo de cuanto es?

Dueño: Gente sentada entran como 80, pero como los espacios son abiertos, en aniversarios hemos tenido 400-500 personas

E1: Para la segmentación no usas nivel socioeconómico?

Dueño: Es más intuitivo, no hicimos estudio de mercado, conocemos el lugar, evaluamos al público según su consumo no su nivel socioeconómico, según sus gustos.

E2: Se comunican con ellos con los clientes?

Dueño: Lo principal es que tenemos fanpage con 50 mil personas y el instagram y ahí se publican todos los días cosas, al menos 3 publicaciones diarias, hay una agenda sobre lo que hay cada día, sobre conciertos y dj que hay, promociones.

\section{E2: ¿Tienes un Community?}

Dueño: No tenemos, es una chica que trabaja aquí y yo la asesoro.

E1: Para fidelizar, que es lo que usas?

Dueño: Hemos creado una base de datos clientes, hemos hecho unas tarjetas para descuentos, se emitieron 150 tarjetas victorias para el ultimo aniversario del 20\%, se les dio a gente familiares amigos que siempre vienen, gente que jala más gente sobre todo, 
tenemos un equipo de relaciones públicos, pasar la voz e invitar a eventos de Facebook. Es un lugar abierto, no se cobra entradas, pero abajo si las mismas bandas cobran su entrada lo que me conviene para que la gente venga.

E1: Pero entonces a ti te conviene crear tráfico para que la gente venga.

Dueño: Claro que sí, y por supuesto que consuman

E2: Entonces ustedes alquilan el espacio de los conciertos

Dueño: No debido a que nosotros nos beneficia la convocatoria de gente, todos van a beber.

E2: ¿Quiénes crees que sean tus principales competidores?

Dueño: Bueno antes no teníamos, igual yo creo que aún no tenemos, pero creo que las casonas grandes hechas bares son lo más cercano esta Ayahuasca. Que son casas antiguas donde se vende cocteleria y hay una propuesta musical, pero igual están bien diferenciadas. Barranco es el distrito más pequeño de lima, los fines de semana quintuplica su circulación.

E2: ¿Tienen al frente Barbarian?

Dueño: Si, pero no es una competencia, somos amigos de ellos, son conceptos diferentes, pero ellos son los de cerveza candelaria y hemos hecho convenios, tenemos propuestas artesanales, oferta variada.

E1: Cómo es tener a Barbarian al frente?

Dueño: El público es distinto, chelero básicamente, y acá vienen por el gintonic y estar al aire libre. La propuesta de consumo es en cuanto a producto y espacio. Allá vas a beber cerveza y acá tienen una experiencia, el espacio, encontrarte con gente, es grande y a tomar cocteles, piqueos.

E1: Cual es el porcentaje de piqueos y cocteles

Dueño: Los piqueos nos representa $15 \%$ solamente, lo fuerte es el trago.

E1: Tener los productos de la candelaria es una ampliación de carta?

Dueño: Como bar que se respete, si necesitábamos una oferta de artesanales, y habíamos estado trabajando con varias marcas aisladas eventualmente, pero nos enfocamos por una que quería apostar en serio con el bar. Tenemos convenios con 9 marcas, firmamos contratos anuales, el contrato es básicamente yo te compro un producto y tú me ayudas hacer activaciones, por ejemplo se invitan dj, bandas y se hace una promoción con un producto, lo hacemos con candelaria y otras como pisco, gin.

E2: Algunas dificultades que hayan encontrado en la creación o la gestión misma? 
Dueño: Bueno los costos, los costos son bien altos, nosotros tenemos que estar siempre bien, o perdemos plata, no te puedes dormir, echar a la cama, tenemos que pasar nuestro mínimo pronto, por eso debemos promoviendo, hacer actividades, activaciones permanentemente.

E1: La inversión inicial ya fue recuperada, 5 años de operación?

Dueño: Si fue recuperado pero hemos firmado hace menos de un año, la ampliación del alquiler local hasta fines del 2021. Vamos a seguir adelante.

E2: Con el tema legal de la municipalidad, ¿cómo hacen?

Dueño: Tenemos un gestor para los trámites, tenemos un estudio de abogado que nos asesora, un estudio contable, ambos externos y muy buenos.

E1: Quienes consideras clave dentro de tu cadena de valor, todos los participantes de tu cadena de valor?

Dueño: Nuestros proveedores, en tantos socios, es decir el proveedor que se compromete conmigo, que se asocia durante un año para hacer cosas, eso creo es lo que nos hace todo el cambio del flujo mensual. Luego por otro lado nuestros amigos, porque todavía sigue siendo un bar que se hizo para amigos, la gente sabe quiénes somos los socios, estamos ligados a las artes, hay un socio músico, antropólogo, artista plástico, eso le da una característica especial al bar.

E1: Y el personal, ¿cómo los consideras?

Dueño: Bien, es variable porque durante la semana cambia, un martes no es igual que un jueves, un jueves no es para nada un sábado, tenemos un gerente que ha gerenciado locales incluso más grandes que este y lo maneja el bien solo con un denominador comú: el servicio

E1: Pero me refería que al ser un negocio de servicio, entiendo que el personal es clave tienen alta rotación?

Dueño: Diría que mediana, hay gente que tratamos que nunca se vaya, que estén contentos aquí y los otros como cualquier negocio van rotando, sobretodo camareros, los administrativos son fijos.

E1: Nosotros, el plan de negocios que te comentamos, la propuesta que estamos planteando es la creación de un bar para gente de repente deportista, que esta medicada, que en algún momento no pueda consumir alcohol o abstemios totales.

Dueño: Conoces el bar medicinal que está en Pierola?

E1: Pero esos son infusiones pero el concepto es parecido, esa es la propuesta que estamos planteando y queríamos tu opinión como experto en bares? 
Dueño: En Perú básicamente en lima le gusta experimentar cosas nuevas, consumir cosas arriesgadas, no sé si eso se vaya a mantener mucho tiempo, yo creo que es un momento adecuado, es decir si hay que probarlo hay que probarlo ahora. El momento es clave no esperaría más de dos años, por ejemplo a las tiendas relacionadas a la salud le está yendo bien.

E1: ¿Tienes en tu carta opciones sin alcohol?

Dueño: $\mathrm{Si}$, tenemos limonadas, tragos vírgenes, siempre tenemos pero por supuesto que no es nuestro fuerte.

E1: ¿En general, alguna recomendación para alguien que está por lanzar un bar?

Dueño: Que cuide los costos, nosotros somos conscientes que tenemos un alquiler súper alto, si el alquiler fuera $30 \%$ menos hubiéramos abierto otro local. Hay una regla, en teoría que el alquiler no tendría que ser más del 10 o $15 \%$ de lo que facturas, pero es difícil, eso cuidar los costos

E: Un agradecimiento. 
Apéndice 7: Calificación de los Factores de éxito

Calificación de los Factores de Éxitos más importantes (según expertos)

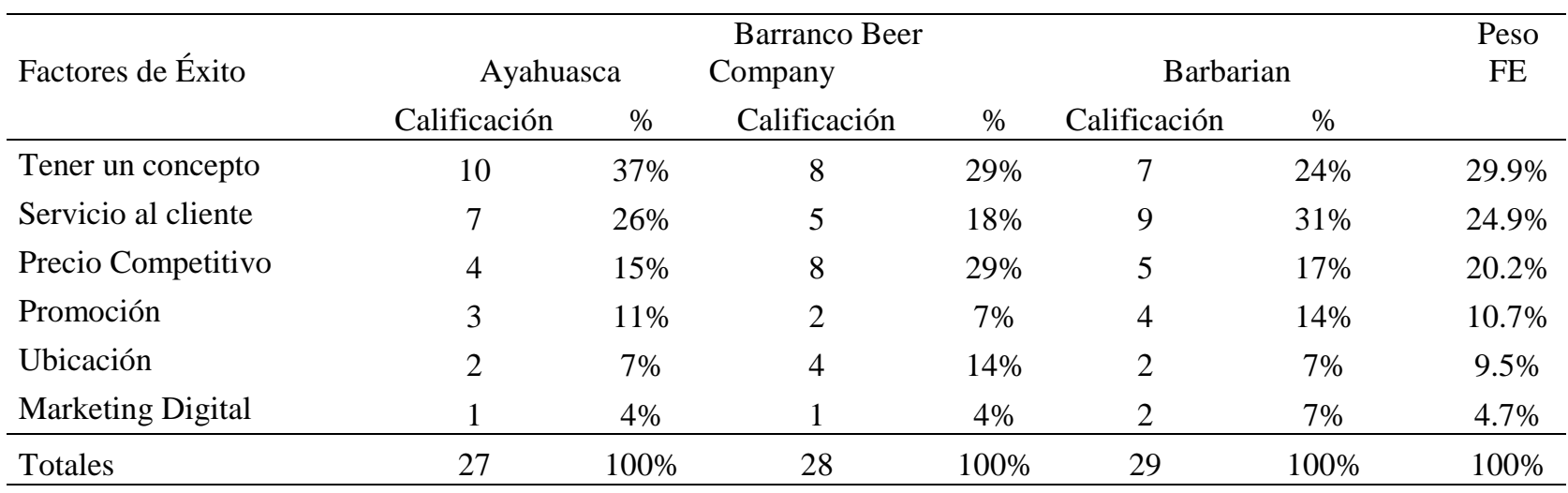

Nota: La calificación brindada se encuentra en un rango de 1 a 10 puntos (de menor a mayor consideración)

\section{Apéndice 8: Calificación cruzada de expertos}

Calificación cruzada entre los competidores

\section{Factores de Éxito}

\begin{tabular}{|c|c|c|c|c|c|}
\hline $\begin{array}{l}\text { Tener un } \\
\text { concepto }\end{array}$ & $\begin{array}{l}\text { Servicio al } \\
\text { cliente }\end{array}$ & $\begin{array}{c}\text { Precio } \\
\text { competitivo }\end{array}$ & Promoción & Ubicación & $\begin{array}{c}\text { Marketing } \\
\text { digital }\end{array}$ \\
\hline
\end{tabular}

\begin{tabular}{lllllll} 
De Ayahuasca para Barbarian & 4 & 2 & 4 & 4 & 3 & 4 \\
De Barbarian para Barranco Beer & 3 & 1 & 4 & 1 & 2 & 1 \\
De Barranco Beer para Ayahuasca & 4 & 2 & 1 & 3 & 4 & 3 \\
\hline
\end{tabular}

Nota: La calificación es de 1 a 4 puntos. 4 = fortaleza principal, 3 = fortaleza menor, $2=$ debilidad menor y $1=$ debilidad 